\title{
Substrate metabolism in skeletal muscle measured by magnetic resonance spectroscopy
}

Citation for published version (APA):

Zehnder, M. G. (2005). Substrate metabolism in skeletal muscle measured by magnetic resonance spectroscopy. [Doctoral Thesis, Maastricht University]. Universiteit Maastricht. https://doi.org/10.26481/dis.20050428mz

Document status and date:

Published: 01/01/2005

DOI:

10.26481/dis.20050428mz

Document Version:

Publisher's PDF, also known as Version of record

\section{Please check the document version of this publication:}

- A submitted manuscript is the version of the article upon submission and before peer-review. There can be important differences between the submitted version and the official published version of record.

People interested in the research are advised to contact the author for the final version of the publication, or visit the DOI to the publisher's website.

- The final author version and the galley proof are versions of the publication after peer review.

- The final published version features the final layout of the paper including the volume, issue and page numbers.

Link to publication

\footnotetext{
General rights rights.

- You may freely distribute the URL identifying the publication in the public portal. please follow below link for the End User Agreement:

www.umlib.nl/taverne-license

Take down policy

If you believe that this document breaches copyright please contact us at:

repository@maastrichtuniversity.nl

providing details and we will investigate your claim.
}

Copyright and moral rights for the publications made accessible in the public portal are retained by the authors and/or other copyright owners and it is a condition of accessing publications that users recognise and abide by the legal requirements associated with these

- Users may download and print one copy of any publication from the public portal for the purpose of private study or research.

- You may not further distribute the material or use it for any profit-making activity or commercial gain

If the publication is distributed under the terms of Article $25 \mathrm{fa}$ of the Dutch Copyright Act, indicated by the "Taverne" license above, 


\section{Substrate metabolism in skeletal muscle measured by magnetic resonance spectroscopy}

Monica G. Zehnder 


\section{nlutín}

\section{uni | eth | zürich}

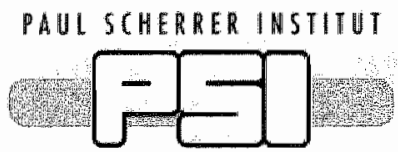

The studies presented in this thesis were performed at the Paul Scherrer Institute in Villigen, Switzerland, and the Inselspital in Berne, Switzerland.

The research described in this thesis was mainly supported by the ETH Zurich, Switzerlland and partly by the Swiss Society of Nutrition Research, the Swiss National Science Foundation and the Nestlé Research Center, Lausanne, Switzerland.

Cover design: Heike Wagner

Lay-out: Monica G. Zehnder

Printed by: $\quad$ Stiftung Zentralstelle, Studentendruckerei, Zürich

(C) Monica G. Zehnder, Berne, 2005

ISBN 3-033-00415-6 


\title{
Substrate metabolism in skeletal muscle measured by magnetic resonance spectroscopy
}

\author{
PROEFSCHRIFT
}

ter verkrijging van de graad van doctor aan de Universiteit Maastricht, op gezag van de Rector Magnificus

Prof. mr. G.P.M.F. Mols, volgens het beshuit van het College van Decanen, in het openbaar te verdedigen op donderdag 28 april 2005 om 12.00 uur

door

Monica Gita Zehnder

geboren te Kathmandu (Nepal) op 20 Juli 1968 


\section{Promotors:}

Prof Dr. Ir. W.M.M. Saris

Prof. Dr med. U. Boutellier (ETH Zurich, Switzerland)

\section{Beoordelimgscommisie:}

Prof. Dr. H. Kuipers (voorzitter)

Prof. Dr. P. Boesiger (ETH Zurich, Switzerland)

Dr. A. Jeukendrup (University of Birmingham, United Kingdom)

Dr. E. Kooy

Prof. Dr. E. Mariman 
Im Andenken an meine Eltern 



\section{CONTENTS}

Chapter 1 General Introduction

Chapter 2 Measurements of muscle phosphates and glycogen concentrations in elite soccer players by ${ }^{31} \mathrm{P}$ and ${ }^{13} \mathrm{C}$-magnetic resonance spectroscopy

Chapter 3 Muscle glycogen degradation during simulation of a fatiguing soccer match in elite soccer players examined by ${ }^{13} \mathrm{C}$-magnetic resonance spectroscopy

Chapter 4 Resynthesis of muscle glycogen after soccer specific performance examined by ${ }^{13} \mathrm{C}$-magnetic resonance spectroscopy in elite players

Chapter 5 Further glycogen decrease during early recovery after eccentric exercise despite a high carbohydrate intake

Chapter 6 High utilization of intramyocellular lipids by endurance trained males and females during prolonged cycling exercise

Chapter 7 Effect of two different intramyocellular lipid contents on substrate utilization during endurance exercise and subsequent performance

Chapter 8 General Discussion

Summary

Zusammenfassung

Publications

Curriculum vitae 


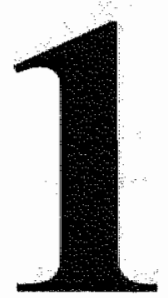

General Introduction 


\subsection{MUSCLE METABOLISM DURING EXERCISE}

Energy for all processes in our body, including muscle contraction is derived from the hydrolysis of adenosine triphosphate (ATP). The ATP stores in muscle cells are very small and would suffice only for a few seconds of maximal contraction and therefore ATP must be continuously resynthesized. There are three different mechanisms involved in the resynthesis of ATP for muscle force generation: (1) phosphocreatine (PCr) hydrolysis, (2) glycolysis, which involves metabolism of glucose-6-phosphate, derived from muscle glycogen or blood-borne glucose, and produces ATP by substrate-level phosphorylation reactions, and (3) the products of carbohydrate (CHO), fat, protein and alcohol metabolism that can enter the tricarboxylic acid (TCA) cycle in the mitochondria and be oxidized to carbon dioxide and water. This process is known as oxidative phosphorylation and yields energy for the synthesis of ATP. The purpose of these mechanisms is to regenerate ATP at sufficient rates to prevent a stgnificant fall in the intramuscular ATP concentration.

\subsubsection{The role of $\mathrm{ATP}$ and $\mathrm{PCr}$ - the phosphagen system}

$\mathrm{ATP}$ and $\mathrm{PCr}$, the high-energy phosphates are stored within muscle fibers (more in type II than type I) to provide energy for maximal bouts of exercise (speed, strength) lasting up to about 10 seconds. As ATP and $\mathrm{PCr}$ are stored at the contractile site of the muscle (between the myosine and actine filaments) it allows providing the energy anaerobically and most readily. The disadvantage of this energy-rich system is that only about 80-100 grams of ATP are stored within the muscles of trained athletes (40). This is also the reason why it lasts only for very short periods of high intensity exercises. Therefore, after only a few seconds of exhaustive work, the energy delivered by the phosphagen system fails and it is not possible to maintain the high intensity. The advantage of this system is its fast recovery as ATP and $\mathrm{PCr}$ are part of equilibrium system where there is a continuous synthesis and degradation (Figure 1).

Figure 1. The regulation and formation of ATP by the phosphagen system

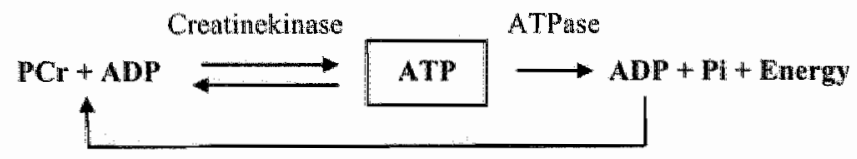

$\mathrm{PCr}=$ phosphocreatine, $\mathrm{ADP}=$ adenosine diphosphate, $\mathrm{ATP}=$ adenosine triphosphate, $\mathrm{Pi}=$ inorganic phosphate 


\subsubsection{The role of muscle glycogen - the glycolytic system}

Under normal conditions, muscle does not fatigue after only a few seconds of effort, so other sources of energy other than ATP and PCr must be available. An important source is glycolysis, which involves the breakdown of glucose (or glycogen) in a series of chemical reactions that yield pyruvate. This process does not require oxygen but does result in ATP being avallable to the muscle from reactions involving substrate-level phosphorylation. However, the pyruvate must be removed for the reactions to proceed. In low-intensity exercise, when adequate oxygen is available to the musele, pyruvate is converted to carbon dioxide and water by oxidative metabolism in the mitochondria. In some situations when oxygen availability is limited (e.g. isometric exercise) or the rate of formation of pyruvate is very high (e.g. sprinting) the pyruvate can also be removed by conversion to lactate, a reaction that does not involve oxygen. The anaerobic contribution from muscle glycogen to the total energy requirement during an exercise bout depends on the duration but it decreases from about $80 \%$ (exercise duration about 30 seconds) to $33 \%$ (exercise duration about 2 minutes) (6).

When lactate is produced by the working muscles it will be discharged to the circulation. Through the circulation, lactate can be transported to the liver where lactate will be converted and stored as glycogen or it serves as a substrate for oxidative metabolism in contracting skeletal and/or cardiac muscle. Not only glycogen present in the muscle but also glucose and lactate taken up from the circulation delivers energy via glycolysis. A specific transporter protein, GLUT 4, carries glucose molecules across the cell membrane. Once inside the muscle cell, an irreversible phosphorylation (addition of a phosphate group), catalyzed by the enzyme hexokinase, occurs to prevent the loss of glucose from the cell. The glucose is converted to glucose-6-phosphate (G6P). This hexokinase reaction is inhibited by an accumulation of $\mathrm{G} 6 \mathrm{P}$, and during high-intensity exercise, the increasing concentration of G6P limits the contribution of blood glucose to $\mathrm{CHO}$ metabolism in the active muscles.

While the anaerobic energy systems are able to generate ATP at high rates they only have a relatively small capacity. The aerobic system (oxidative phosphorylation) generates ATP at lower rates but has an almost infinite capacity. 
Figure 2. Average ATP-production rate from PCr, glycogen (anaerobic and aerobic) and lipids (adapted from McGilvery (4l))

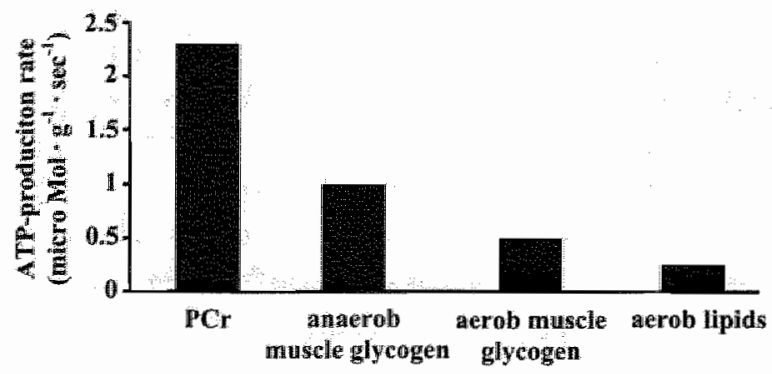

ATP = adenosine triphosphate, $\mathrm{PCr}=$ phosphocreatine

\subsubsection{The role of muscle glycogen and fat - the aerobic system}

The energy during intense exercises lasting longer than 2 minutes comes predominately from oxidative phosphorylation, a process that uses oxygen. Pyruvate may also undergo oxidative metabolism to carbon dioxide $\left(\mathrm{CO}_{2}\right)$ and water. This process occurs within the mitochondria, and pyruvate that is produced in the sarcoplasm is transported across the mitochondrial membrane by a specific carrier protein (monocarboxylic acid transporter). The 3-carbon pyruvate is converted by oxidative decarboxylation imto a 2-carbon acetate group, which is linked by a thio-ester bond to coenzyme A (CoA) to form acetyl-CoA. The pyruvate dehydrogenase enzyme complex catalyzes this reaction, in which $\mathrm{NAD}+$ is converted to NADH. Acetyl-CoA is also formed from the metabolism of fatty acids (FA) within the mitochondria, in a metabolic process called $\beta$ oxidation. The 2-carbon acetate units of acetyl-COA are combined with the 4carbon oxaloacetate to form 6-carbon citrate. The latter undergoes 2 successive decarboxylations to yield 4-carbon succinate, which, in subsequent reactions, is converted to oxaloacetate, completing the TCA cycle. Molecular oxygen $\left(\mathrm{O}_{2}\right)$ does not participate directly in these reactions. The most important function of the TCA cycle is to generate hydrogen atoms for subsequent passage to the electron transport chain by means of reducing equivalents (NADH and $\mathrm{FADH}_{2}$ ). Oxidation of these coenzymes in the electron transport chain releases energy that is used for the resynthesis of ATP. This process is called oxidative phosphorylation.

A highly trained athlete can run for about one and half hour with a relatively high intensity before depleting full glycogen stores. Generally it means the longer the exercise, the lower the intensity and speed, and therefore a higher contribution of fat to total energy use. Compared to $\mathrm{CHO}$, which are stored as glycogen in the muscles and liver in atal amount of about 500 grams, fat can be stored in vast 
quantities. The percentage fat of total body weight (bw) in a healthy, sedentary individual is about 10-20\% in males and $15-25 \%$ in females, which corresponds to 7-15 kilograms of fat. Additionally, it is possible to store up to about 400 grams of lipids within fibers of those muscles that are active in training (see paragraph 1.4.). During prolonged exercise the percentage of fat as energy source relative to $\mathrm{CHO}$ is dependent from several factors such as training status, intensity and duration of exercise as well as the diet before and during the event: $\mathrm{CHO}$ and fat, the fuel sources for the oxidative ATP synthesis, differ in the amount of stored energy. Fat yields $37 \mathrm{~kJ}$ and $\mathrm{CHO} 17 \mathrm{~kJ}$ per gram. However, each gram of $\mathrm{CHO}$ must be stored with 2 grams of water, which makes this fuel store bulkier and even less energy dense. The advantage of CHO as an energy source is that more ATP can be generated per unit of time compared to the oxidation of fat ((41); Figure 2).

The relative contribution of each of these energy sources during a certain type of exercise depends on the intensity and duration of the exercise load. Specific training and dietary interventions can also modify the percentage energy contribution of energy sources.

Figure 3. Major storage sites of carbohydrate and fat before converted into adenosine triphosphate (ATP) (26)

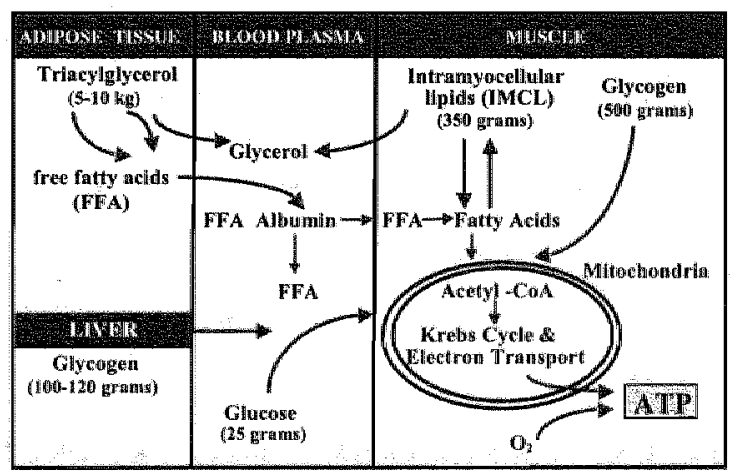

\subsection{SUBSTRATE UTILIZATION DURING EXERCISE - EFFECT OF INTENSITY, DURATION, DIET AND TRAINING}

During low intensity exercise, the energy demand is increased several fold compared to resting conditions and $\mathrm{CHO}$ as well as fat oxidation is enhanced. When the exercise intensity increases, $\mathrm{CHO}$ metabolism increases as a function of the aerobic work rate. This is in contrast to FA oxidation (mainly derived from 
adipose tissue), which increases further until exercise intensity reaches about $65 \% \mathrm{VO}_{2 \max }$. During higher performance a decline in the rate of fat oxidation is observed (e.g. 1, 32, 33). Muscle glycogen becomes the most important substrate when the exercise intensity increases above approximately $50 \% \mathrm{VO}_{2 \max }$ (e.g. 47 , 58). Plasma glucose typically contributes up to a maximum of about $1 \mathrm{~g} \cdot \mathrm{min}^{-1}$.

The duration of exercise also affects substrate oxidation. Fat oxidation increases and $\mathrm{CHO}$ oxidation decreases with increasing exercise duration. This increased fat oxidation is likely to be caused by a reduction in muscle glycogen stores towards the later stages of prolonged exercise.

A reduced respiratory exchange ratio (RER) after a high fat, low CHO diet was reported already in 1920 by Krogh and Lindhardt (38). In the late sixties, when the muscle biopsy technique was redeveloped it was shown that diets high in $\mathrm{CHO}$ increased muscle glycogen concentrations and reduced fat oxidation during a following exercise (7). The diminished fat oxidation is partly attributed to reduced intramyocellular lipids ([MCL') stores, which demonstrates that dietary fat may have an important role in helping to restore IMCL stores after exercise. Chronic high-fat diets ( $>3-7$ days) have been shown to result in a shift towards fat metabolism. This adaptation takes longer than the almost inmediate adaptation to an increase in CHO intake. It has been demonstrated that adaptation to a high-fat diet will lead to measurable changes in the capacity to store, mobilize, transport and oxidize fat. Such changes are similar to those observed after endurance training and result in a "sparing" of glycogen during exercise and a reduction in plasma glucose oxidation (e.g. 15). In other words there is an increased capacity to utilize fat as a substrate and reduced reliance on endogenous CFO oxidation during exercise if fat intake is increased (e.g. 29, 36). The enhanced contribution of fat as a fuel source after endurance training can be observed at the same absolute and relative workload (e.g. 29).

\subsection{GLYCOGEN DEPLETION AND REPLENISHMENT AFTER DIFFERENT TYPES OF EXERCISES}

\subsubsection{Glycogen utilization during intermittent exercise}

The majority of studies have focused on continuous endurance exercise while most popular modern sports like soccer are highly intermittent. Such sports are characterized by intermittent bursts of high intensity exercise followed by a

\footnotetext{
'Other acronyms in use include nTG or mTAG (muscle triacylglycerol), MCTG (myo-cellular TG), IMTG and imcTG. In this thesis, IMCL is used consistently for walues determined by 'H-MRS, biopsy and tracer studies.
} 
period of relatively rest. The literature shows that soccer is a glycogen depleting activity and that work volume and rate are influenced by level of muscle glycogen (e.g. 5, 44). It is generally accepted that CHO intake before and/or during this kind of exercise spares muscle glycogen (e.g. 5, 42) and that this has the potential to improve running performance in a soccer game. However, low concentrations of muscle glycogen have been reported in soccer players before a game and daily $\mathrm{CHO}$ intakes are often insufficient to replenish muscle glycogen stores. Therefore the effect of CHO supplementation during a soccer match is important and can result in greater second-half running distances or more goals being scored, when compared to consumption of water only (e.g. 25).

\subsubsection{Replenishment of glycogen after intermittent exercise}

During the course of a soccer game there is a partial to near complete depletion of glycogen reserves. In addition, during the season, "inter-game" interval for competitive soccer players is short (e.g. 52). Therefore it is of advantage to replenish glycogen rapid. Among soccer players, the average daily total quantity of $\mathrm{CHO}$ consumed is most of the time less than the proposed amount of $7-10 \mathrm{~g}$ $\mathrm{CHO} \cdot \mathrm{kg}^{-1}$ bw day ${ }^{-1}$ (e.g. $\left.10,13,14\right)$, resulting in the inability of maintaining even normal resting glycogen stores (e.g. 63).

\subsubsection{Glycogen depletion during and replenishment after eccentric exercise}

There are only a few studies investigating glycogen metabolism in connection with eccentric exercise. Most of the studies found no additional glycogen depletion during eccentric exercises following concentric exercise $(e . g .60,64)$ but delayed muscle glycogen repletion following damaging exercises (e.g. 3, 22). It seems that inflammatory processes, structural and cellular damage, and metabolic perturbations can disturb the replenishment of muscle glycogen.

\subsection{GENDER DIFFERENCES AND INTRAMYOCELLULAR LIPIDS}

It has been suggested that substrate use and the relative contribution of substrates are gender dependent. Although some studies have shown no gender difference in substrate utillization (e.g. 46, 48), the majority of studies (e.g. 11,27, 55) have reported that women rely more on fat oxidation than men during prolonged exercise. In a recent meta-analysis Tarnopolsky (56) used all studies between 1997 and 2002 that applied indirect calorimetry to study the influence of gender on substrate utilization during prolonged exercise. From these studies the author concluded that women have significantly lower RER than men during moderate 
to high intensity exercise $(0.87 \pm 0.04$ vs $0.90 \pm 0.04)$. Futhermore, men have been whwn to acquire a greater proportion of the energy from muscle glycogen oxidation than women (e.g. 11,55$)$. On the other side, it is less clear whether gender differences in the contribution of MCL exist MMCL have been shown to be an important energy source during exercise (e, g, $8,21,39)$ although this was not contrmed in all studies $(24,36)$. Several studies have shown that increased fat oxidation observed after endurance training is accounted for an noreased use of MCL stores (e.g. 29, 30, 37), and that endurance training by itself enhances MCL storage (e.g. 28). Recent studies have additionally shown how important it is to control the diet since it can strongly influence MMCL concentrations. It has been shown that $72 \mathrm{~h}$ fasting can increase IMCL levels (53), and has also been shown that IMCL concentration increased after a high-fat diet $(\mathrm{e}, \mathrm{g} .19,54)$ or infusion of lipids. (4). Furthermore, MCL content was inversely related to dietary $\mathrm{CHO}$ intake $(18,34)$.

\subsection{TECHNIQUES TO STUDY MUSCLE METABOLISM}

Diring the last decennia significant progress has been made in the study of muscle metabolism. Originally invasive muscle biopsy procedures were the only way to study substrate utilization in skeletal muscle. An indirect tracer approach was also used, which involved the infusion of a radioactive or stable isotopic tracer. More recently, non-invasive techniques to study muscle metabolism have emerged and are now used regularly to study muscle CHO and fat metabolism during exercise. The advantages and disadvantages of different methodologies will be discussed below and are summarized in Table 1 .

\subsubsection{Muscle biopsy}

The most common and direct approach to determine the utilization of muscle glycogen and IMCL is the biopsy technique in combination with biochemical analysis to measure the concentrations in the obtained muscle tissue. The reintroduction of this technique was done in the 1960 s by Bergstrom and Hulman (7). A guillotine system will cut of $20-200 \mathrm{mg}$ of muscle tissue. This technique allows the investigators not only to investigate the glycogen and IMCL concentration but also to study the activity or concentration of specific enzymes and the expression of various proteins. One of the methodological concerns with this technique is whether the small nuscle sample obtained is representative for the entire muscle. There is also substantial variation in the concentrations of muscle glycogen and IMCL obtained using this method with coefficients of variation around 10 and $26 \%$ (59). An advantage of the muscle biopsy 
technique, however, is that it is possible to quantify muscle substrate concentrations as well as enzyme concentrations and/or activities and protein expression.

\subsubsection{Tracer techniques}

Another method to measure muscle metabolism involves the use of tracers. An ideal tracer is chemically identical to the compound of interest (the tracee), but distinct in some characteristics that enables its precise detection. These tracers can be either radioactive or stable (not radioactive). The use of stable isotopes as metabolic tracers in vivo actually predates the use of radioisotopes by almost 20 years. In early studies Schoenheimer and Rittenberg (50) used stable isotopes of hydrogen (deuterium) to investigate fat metabolism in mice and ${ }^{15} \mathrm{~N}$ labeled leucine to study protein metabolism (51). Experiments were also performed in the 1930 using ${ }^{13} \mathrm{C}$ and ${ }^{18} \mathrm{O}$ as tracers. With the development of scintillation. counting and the increasing availability of radioactive tracers, most kinetic studies in the 50s and 60s used radioactive isotopes. Stable isotopes were first used to quantify glucose kinetics (i.e. rate of appearance (Ra), rate of disappearance (Rd) in human subjects in the late 1970s (e.g. 35)). In the early 1980 s, stable isotopes were applied to determine FA and glycerol kinetics (e.g. 61). The most obvious advantage of stable isotopes is that they are nonradioactive and present little or no risk to human subjects.

The determination of substrate fluxes with stable isotopes is usually based on dilution principles. Often a tracer of the compound of interest is infused at a constant and known rate and the dilution of the tracer/tracee ratio (enrichment) allows the calculation of the appearance rate of the "unlabeled" compound. At least in steady-state conditions, it is also possible to calculate the rate of disappearance of the compound. With the use of isotopic tracers, it is possible to measure whole body turnover rates of a substrate, as well as turnover across an organ if blood is sampled across the organ of interest. It has been demonstrated that the vast majority (95-99\%) of glucose disappearing from plasma is oxidized (31). By measuring Rd glucose, an estimate of plasma glucose oxidation can be obtained. When these measurements are combined with indirect calorimetry and plasma glucose oxidation is subtracted from total carbohydrate oxidation, whole body glycogen oxidation can be calculated. Similar principles can be applied to fatty acid metabolism. A detailed description of stable isotope methods, the assumptions and limitations is beyond the scope of this introductory chapter but for a more detailed explanation of the use of radioactive and stable isotopes in biomedical research the reader is referred to a comprehensive book by Wolfe (62) 


\subsubsection{Historic development of nuclear magnetic resonance}

More recently, magnetic resonance spectroscopy (MRS) has been introduced to measure intramuscular energy stores and their utilization during exercise. As it is the method, which has been applied in all the experiments presented in this thesis, it will be discussed in the following section in more detail.

The experiment of Gerlach and Stern in the 1920s, when they passed a beam of silver atoms through an inhomogeneous magnetic freld and obtained two distinct beams instead of one (23), can be seen as one of the first signs of a method mowadays called nuclear magnetic resonance (NMR) (9). In the 1950 s, the first spectra from chemical solutions were obtained (2) and in 1952, Bloch and Purcell won the Nobel Prize for the discovery of the magnetic moments of some nuclei, i.e. certain nuclei could absorb energy in a strong magnetic field in the radiofrequency range when irradiated by use of a coil. In the following 20 years NMR was used as a method for chemists to investigate concentrations of nuclei in solutions. But this method; the so-called Continues Wave NMR for the analysis of molecules was quite slow and not without problems. Richard Enst who also won the Nobel Price in chemistry in 1991 developed the modern, fast and robust Fourier Transform NMR in the 1960s (20). The big breakthrough for NMR came, when Lauterbur and Mansfield"s discoweries in the early $1970^{\circ} \mathrm{s}$ led to the development of modern magnetic resonance imaging (MRI), a method yielding three-dimensional images of organs inside the human body (Nobel price in physiology or medicine in 2003). In 1980s and 1990s, MRI became an essential tool in radiology using whole body magnets (Figure 4). Since then, it is predominantly applied in medicine to e.g. diagnose possible pathologies mainly in soft tissue. In the late 90 s a further developing of MRI, functional MRI ( $f$ MRI), became important and even revolutionary in brain research.

Figure 4. A medical whole-body magnet for climical MR at i.5 T (9)

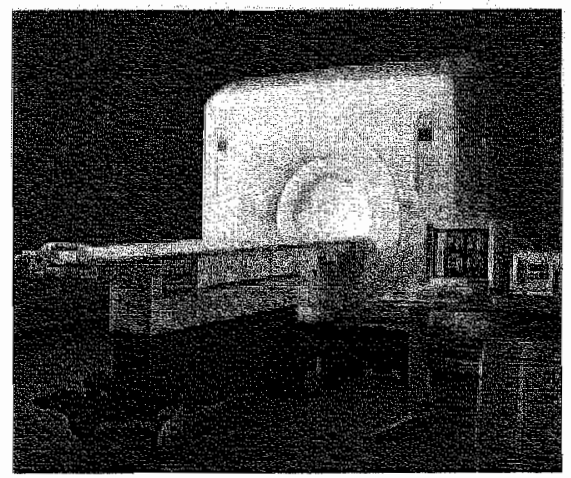


On the other hand, MRS also progressed. In witro MRS was used from the 1970 s on to investigate the structure of proteins and thus to resolve one of the main problems of biology, the functioning of the human proteom. Waithrich and coworkers discovered structures like Alpha helices and Beta-shits (Nobel Price 2002). In Medicine, the in wivo application of MRS serves mainly to the clarification of physiological or biochemical questions in findamental research. Unfortunately, in vivo MRS is significantly less successful for medical routine diagnosis than e.g. in wiwo MRI and f-MRI. Non-invasively examinations of skeletal muscles and their metabolism have been among the first applications of in wrvo MRS in the human body. In this connection, measuring the short-term energy metabolism ( $\mathrm{PCr}$, ATP and $\mathrm{Pi}$ ) at the beginning mainly in the lower leg muscles, is a major, successful in wivo application of ${ }^{31} \mathrm{P}$-MRS using classical surface coils in small-bore or later in whole body magnets (e.g. 16). Additionally, in vivo ${ }^{13} \mathrm{C}$-MRS made it possible to investigate muscle glycogen stores before and after exercise measuring natural abundance of ${ }^{13} \mathrm{C}$ (e.g. 43). Glycogen as an energy source for human skeletal muscle has been measured successfully by various research groups for several years using ${ }^{13} \mathrm{C}-\mathrm{MRS}$ (e.g. 12, 45, 57). The main advantage of using ${ }^{13} \mathrm{C}$-MRS compared with the traditional teclmique of the muscle biopsy is that MRS is non-invasive and multiple measurements are possible (Table 1). These reasons have made ${ }^{13} \mathrm{C}$-MRS a popular technique to study muscle glycogen metabolism and muscle metabolism in general. Besides glycogen, IMCL are an important energy source in skeletal muscle. IMCL have also been measured in vivo using ${ }^{1}$ H-MRS $(8,49)$. 'H-MRS was first used to investigate brain biochemistry but has been used successfully to measure muscle metabolism in more recent years. In all in wivo MRS and MRI applications, the main advantages of the NMR technique are that it is safe and non-invasive. Using NMR as a diagnostic tool it does, unlike $x$-ray based modalities (e.g. computed tomography), not employ ionizing radiation and, thus, not increase the probability for cancer. Investigating intramuscular energy metabolism MRS cannot completely replace the direct biochemical measurements obtained from muscle biopsy samples but it still offers distinct advantages (Table 1). For example, NMR enables the direct measurements of muscle energy metabolite concentrations in relative or absolute values with better time resolution and repeatability (e.g. $17,43,57$ ). 
Table 1. Advantages and disadvantages of different methods which enable to investigate musele metabolism

\begin{tabular}{|c|c|c|}
\hline Biopsy & Stable isotopes & MRS \\
\hline local, small samplle & $\begin{array}{l}\text { investigation of wholle } \\
\text { body metabolism }\end{array}$ & local, rellatively small volume \\
\hline $\begin{array}{l}\text { concentrations can be } \\
\text { determined }\end{array}$ & $\begin{array}{l}\text { no concentrations can be } \\
\text { deternined, only } \\
\text { estimated rates of } \\
\text { breakdown }\end{array}$ & $\begin{array}{l}\text { relative values, concentration } \\
\text { can be deternined from } \\
\text { silgnal }\end{array}$ \\
\hline invasive & less invasive & non-invasive \\
\hline once at the same location & $\begin{array}{l}\text { placemeni of the venous } \\
\text { catheter }\end{array}$ & $\begin{array}{l}\text { multiple measurements on the } \\
\text { same sample at the same } \\
\text { location }\end{array}$ \\
\hline $\begin{array}{l}\text { allows enzymatic and } \\
\text { mollecular biology } \\
\text { investigation }\end{array}$ & $\begin{array}{l}\text { allows to use multiple- } \\
\text { labeled compounds } \\
\text { simultaneously }\end{array}$ & $\begin{array}{l}\text { measurement of multiple } \\
\text { metabolite simultaneously }\end{array}$ \\
\hline less expensive & $\begin{array}{l}\text { costs dependent on kind } \\
\text { of isotopes; expensive } \\
\text { equipment for analysis }\end{array}$ & expensive equipment \\
\hline $\begin{array}{l}\text { distinction between muscle } \\
\text { fiber types, deep tissue } \\
\text { penetration }\end{array}$ & $\begin{array}{l}\text { no single muscle } \\
\text { investigation }\end{array}$ & $\begin{array}{l}\text { inability to distinguish muscle } \\
\text { fiber types, relatively shallow } \\
\text { tissue penetration }\end{array}$ \\
\hline $\begin{array}{l}\text { low concentrations of } \\
\text { metabolites measurable, } \\
\text { determination after the } \\
\text { experiment, high variability in } \\
\text { measuring muscle lipids }\end{array}$ & $\begin{array}{l}\text { flux-measurements of } \\
\text { energy metabolites } \\
\text { during experiment, } \\
\text { results calculated }\end{array}$ & $\begin{array}{l}\text { partly low sensitivity, } \\
\text { consequently long } \\
\text { measurement-times but direct } \\
\text { results }\end{array}$ \\
\hline $\begin{array}{l}\text { large number of netabolites, } \\
\text { enzymes etc. can be measured }\end{array}$ & $\begin{array}{l}\text { small number of } \\
\text { metabolites can be } \\
\text { measured }\end{array}$ & $\begin{array}{l}\text { middle number of metabolites } \\
\text { can be measured }\end{array}$ \\
\hline
\end{tabular}

\subsubsection{How does nuclear magnetic resonance work?}

The effect of NMR occurs in principle when two magnets interfere. It is well known that two magnets attract or repulse each other. The repulsion position leads to an instable, high-energy situation, the attraction to a stable, low-energy situation. The big and cylindrical magnets, which characterize MRI scanners, deliver a strong and very homogenous magnetic field (Figure 4). The other magnet is the nucleus of certain atom isotopes. An atom is an ensemble of electrons, protons and neutrons. Protons and neutrons form the nucleus, while the electrons move in orbits around the nucleus, like planets around the sun. Additionally, electrons, protons and neutrons turn around their axes like a 
spinning top. As everybody knows, a spinning top has a tendency to change its rotation axis in such a way, that the rotation axis describes a circle. This phenomenon can be explained by Newtonian mechanics and is called the "precession of a top".

Most nuclei do not have any magnetic dipole, i.e: are no magnets and do not react to the strong exterior magnetic field of the MRI Scanner but for instance hydrogen $\left({ }^{1} \mathrm{H}\right)$, phosphorus $\left({ }^{31} \mathrm{P}\right)$ and carbon- $13\left({ }^{13} \mathrm{C}\right)$ nuclei have a magnetic moment. Normally, the magnetic moments cancel out, because they are randomly directed. However, there is a way to rearrange them. If nuclei with a magnetic dipole are placed in a strong magnetic field, they will arrange parallel or antiparallel to the magnetic field, the latter having a lower state of energy than the former. It is essential to know, that nature prefers lower than higher energy levels, because they are more stable. Therefore in NMR more little nucleusmagnets will orient in an antiparallel (low energy) direction to the exterior field, than in the parallel direction (high energy). This leads to a total macroscopic magnetic dipole that can be measured. This small magnetic moment can be measured by disturbing the arrangement of magnetic moments and waiting until they return to their favorite (lowest energy) position. During this return, the nucleus-magnets transmit energy, which can be picked up. For the purposes of disturbing and measuring, an aerial is used as a transmitter and receiver. For measurements on muscle, so-called surface coils are used as aerial. A surface coil is placed over the muscle to be studied and the subject is moved into the MRI scanner, which realizes the static magnetic field. The received energy from the returning nucleus-magnet is an electromagnetic signal with a certain frequency. E.g. the frequency of phosphorus in a magnetic field of 1.5 Tesla is around $25.7 \mathrm{MHz}$, a value that can be compared with the medium wave on the radio. A plot of the received energy as a function of frequency along an axis is called a spectrum (Figure 5). In muscle tissue, e.g. phosphorus is found in different molecules, like PCr, ATP and Pi. The question, which remains to be answered, is how it can be distinguished between a magnetic nucleus in one molecule (e.g. ${ }^{31} \mathrm{P}$ in $\mathrm{PCr}$ ) and another nucleus of the same type in another molecule (e.g. ${ }^{3} \mathrm{P}$ in ATP or $\mathrm{Pi}$ ). The answer is simple as both magnetic nuclei will precess with different speeds and, hence, will emit signals of different radio frequencies. As a result the precession speeds are different. This is because the precession speed increases with the strength of the exterior magnetic field, seen by the nucleus. This exterior magnetic field is mainly that of the MRI scanner, but not completely, because the neighboring atoms of the molecule are able to shield and thus to diminish the field of the MRI scanner. Thus, the radio frequency signal emitted by a magnetic nucleus depends on its chemical environment, which decreases the magnetic field of the MRI scanner. Therefore, e.g. the signals in a ${ }^{31} \mathrm{P}$-spectrum from different metabolites (PCr, ATP, Pi) are ordered and distributed in a plot along the so- 
called chenical shift axis as the strength of the main magnetic field and the (small) magnetic influence of the surrounding molecules determine the exact resonance frequency of certain, e.g. phosphorus, nuclei (Figure 5). On the other hand, the same nuclei of one molecule are always at the same location on the axis therefore a ${ }^{31} \mathrm{P}$-spectrum of a muscle looks always the same. This allows MRS to represent and distinguish different metabolites in the tissue as the signals of ${ }^{13} \mathrm{C}$, ${ }^{31} \mathrm{P}$ and ${ }^{1} \mathrm{H}$ are completely separated on the chemical shift axis.

Figure 5. A typical in vivo ${ }^{3 !} \mathrm{P}$-spectrum of a human muscle (9)

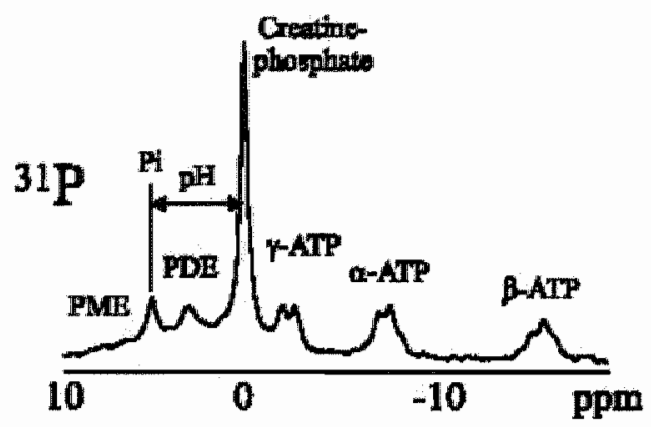

PME $=$ phosphomonoester, $\mathrm{Pi}=$ inorganic phosphate, $\mathrm{PDE}=$ phosphodiester, $\mathrm{ATP}=$ adenosine triphosphuate

MRS is a safe, non-invasive, versatile and diagnostic tool for in vivo metabolic studies. Concentrations of metabolites in different regions of the human body can be determined and the time course of the changes of these concentrations can be monitored.

\subsection{PURPOSE OF THE THESIS}

The aim of this thesis is to focus on muscle metabolism (see paragraph 1.2.-1.4.) using MRS. The major research questions addressed in this thesis using the MRS technology are; (a) determine the degradation rate of the major intramuscular energy supplies like the different phosphate metabolites, glycogen and IMCL during exercise, (b) monitor the effectiveness of dietary manipulations such as CHO and fat loading protocols, and (c) study metabolic recovery, with or without special diet, from exercise sessions in connection with readiness to participate in a following event. 


\subsection{THE OUTLINE OF THIS THESIS}

This thesis describes a variety of studies, in which we applied the non-invasive versatile measurement method MRS to investigate changes in intramuscular energy storage before and after various exercise protocols and/or different diet interventions. Chapter 2, a methodological chapter, serves to show possibilities of in-vivo ${ }^{31} \mathrm{P}-\mathrm{MRS}$, which means in our study measuring the phosphate parameters $\mathrm{PCr}, \mathrm{ATP}$ and $\mathrm{Pi}$ in elite soccer players in resting conditions. Additionally we were interested in the potential of ${ }^{13} \mathrm{C}$-MRS determining of glycogen concentration in the calf muscle after a 2-day individual, western-type diet, in the same athletes. Chapter 3 describes a study in which muscle glycogen degradation by ${ }^{13} \mathrm{C}-\mathrm{MRS}$ during an exercise test was observed intending to predict individual fatigue in intense soccer matches. Additionally, measurements of blood parameters, involved in energy metabolism, were performed in order to predict the MRS results. Chapter 4, is a follow up of chapter 3, investigating the resynthesis of glycogen over $24 \mathrm{~h}$ after a simulation of a fatiguing soccer match and repeated sprints. The results of chapter 3 and 4 helped to gain a better understanding of the role of glycogen storage in relation to performance. Chapter 5 focuses also on glycogen resynthesis. Using the ${ }^{13} \mathrm{C}$-MRS technology, we investigated if a diet, very rich in CHOs, could compensate the delayed replenishment of glycogen resynthesis in damaged muscle cells. Additionally, ${ }^{31}$ P-MRS was applied to show changes in phosphate metabolism as a consequence of delayed onset muscle soreness. Chapter 6 and Chapter 7 describe studies in which we made use of the proton $\left({ }^{1} \mathrm{H}\right)$-MRS to measure IMCL. Chapter 6 was designed to look for gender differences in the storage and usage of IMCL. In chapter 7, the main goal was to investigate the influence of stored glycogen and IMCL on high performance exercise as well as to measure the contribution of the single energy substrates during an endurance exercise. In Chapter 8, the general discussion, we provide an overview of the abovedescribed studies and summarize the main conclusions as well as the impact of our work in the light of the existing literature in this field. Also recommendations for possible research projects in the future are formulated. 


\subsection{REFERENCES}

1. ACHTEN $J$, and JEUKENDRUP AE. Maximal fat oxidation during exercise in trained men. Int J Spowts Med 24: 603-608, 2003.

2. ARNOLD JT, DHARMATTI SS, PACKARD ME. Chemical effects on nuclear induction signals from orgatnic compounds. J Chem Phys 19:507-507, 1951.

3. ASP S, DAUGAARD JR, RICHTER EA. Eccentric exercise decreases glucose trangporter GLUT4 protein in human skeletal muscle. If Physiol (Lond) 482: 705-712, 1995 .

4. BACHMANN OP, DAHL DB, BRECHTEL K, MACHANN J, HAAP M, MAIER T, LOVISCACH M, STUMVOLL M, CLAUSSEN CD, SCHICK F, HARING HU, JACOB S. Effects of intravenous and dietary lipid challenge on intramyocellular lipid content and the relation with insullin sensitivity in humans. Diaberes 50: 2579-2584, 2001.

5. BALSOM PD, WOOD K, OLSSON P, EKBLOM B. Carbohydrate intake and multiple sprint sports: with special reference to football (soccer). Int J Sports Med 20: 48-52, 1999.

6. BANGSBO $J$, GOLLNICK PD, GRAHAM TE, JUEL $C$, KIENS B, MIZUNO $M$, SALTIN B. Anaerobic energy production and $\mathrm{O} 2$ dieficit-debt relationship during exhaustive exercise in humans. I Physiol (Lond) 422: 539-559, 1990.

7. BERGSTROM J, and HULTMAN E. A study of the glycogen metabolism during exercise in man. Scand J Clin Lab Iwvest 19:218-228, 1967.

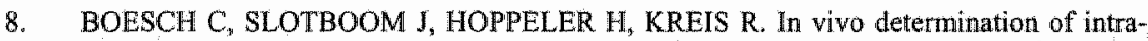
myocellular lipids in human muscle by means of localized 1H-MR-spectroscopy. Magn Reson Med 37: 484-493, 1997.

9. BOESCH C. Molecular aspects of magnetic resonance imaging and spectroscopy. Mol Aspects Med 20: 185-318, 1999.

10. BURKE LM, COX GR, CULMMINGS NK, DESBROW B. Guidelines for daily carbolnydrate intake: do athletes achieve them? Sports Med 31:267-299, 2001.

11. CARTER SL, RENNIE C, TARNOPOLSKY MA. Substrate utilization during endurance exercise in men and women after endurance training. Am $J$ Physiol Endocrinol Metab 280: E898-E907, 2001.

12. CASEY A, MANN R, BANISTER $\mathbb{K}$, FOX $\pi$, MORRIS PG, MACDONALD IA, QREENHAFF PL. Effect of carbohydrate ingestion on glycogen resynthesis in human liver and skeletal muscle, measured by (13)C MRS. Am J Physiol Endocrimol Metab 278: E65-E75, 2000.

13. CLARK K. Nutritional guidance to soccer players for training and competition. J Sports Sci Summer 12: \$43-S50, 1994.

14. CLARK M, REED DB, CROUSE SE, ARMSTRONG RB. Pre- and post-season dietary intake, body composition, and performance indices of NCAA division I female soccer players. Int J Sport Nutr Exerc Metab 13: 303-319, 2003.

15. COGGAN AR. Plasma glucose metabolism during exercise: effect of endurance training in humans. Med Sct Sports Exerc 29: 620-627, 1997.

16. CONLEY KE, CRESS ME, JUBRIAS SA, ESSELMAN PC, ODDERSON IR. From muscle properties to human performance, using magnetic resonance. $J$ Gerontol A Biol Sci Med Sci 50: 35-40, 1995.

17. DAWSON MJ. Quantitative analysis of metabolite levels in normal human subjects by 31P topical magnetic resonance. Biasci Rep 2: 727-733, 1982. 
18. DECOMBAZ J, FLEITH M, HOPPELER H, KREIS R, BOESCH C. Effect of diet on the replenishment of intramyocellular lipids after exercise. Eur $I$ Nutr 39: 244-247, 2000 .

19. DECOMBAZ J, SCHMITT B, ITH M, DECARLI B, DIEM P, KREIS R, HOPPELER H, BOESCH C. Post-exercise fat intake repletes intramyocellular lipids, but no faster in trained than in sedentary subjects. Am I Physiol Regul Integr Comp Physiol 281: R760R769, 2001 .

20. ERNST RR, and ANDERSON WA. Application of fourier transform spectroscopy to magnetic resonance. Rev Sci Instrum 37: 93-102, 1966.

21. ESSEN B. Intramuscular substrate utilization during prolonged exercise. Ann NY Acad Sci 301: 30-44, 1977 .

22. EVANS WJ. Muscle damage: nutritional considerations. Int J Sport Nurr 1: 214-224, 1991.

23. GERLACH W, and STERN O. Der experimentelle Nachweis des magnetischen Moments des Silberatoms. Z Phys 8: 110-111, 1921.

24. GOLLNICK PD, IANUZZO CD, WILLIAMS C, AND HILL TR. Effect of prolonged, severe exercise on the ultrastructure of human skeletal muscle. Int $Z$ Angew Physiol 27 : $257-265,1969$.

25. HAWLEY JA, DENNIS SC, NOAKES TD. Carbohydrate, fluid, and electrolyte requirements of the soccer player: a review. Int J Sport Nurt 4: 221-236, 1994.

26. HAWLEY J. The fuels for exercise. Austo J Nutr Dieter 58: $\$ 19,2001$.

27. HORTON TJ, PAGLLASSOTTI MJ, HOBBS K, HILL JO. Fuel metabolism in men and women during and after long-duration exercise. J Appl Physiol 85: 1823-1832, 1998.

28. HOPPELER H, HOWALD H, CONLEY K, LINDSTEDT SL, CLAASSEN H, VOCK P, WEIBEL ER. Endurance training in humans: aerobic capacity and structure of skeletall muscle. J Appl Physiol 59: 320-327, 1985

29. HURLEY BF, NEMETH PM, MARTIN WH 3RD, HAGBERG JM, DALSKY GP, HOLLOSZY JO. Muscle triglyceride utilization during exercise: effect of training. $J$ App $/$ Physiol 60: 562-567, 1986 .

30. JANSSON E, and KAIJSER L. Substrate utilization and enzymes in skeletal muscle of extremely endurance-trained men. $J$ Appl Physiol 62: 999-1005, 1987.

31. JEUKENDRUP AE; RABEN A, GIISEN A, STEGEN JH, BROUNS F, SARIS WH, WAGENMAKERS AJ. Glucose kinetics during prolonged exercise in highly trained human subjects: effect of glucose ingestion. I Physiol (Lond) 515: 579-589, 1999.

32. JEUKENDRUP AE, and ACHTEN J. Fatmax: A new concept to optimize fat oxidation during exercise? Eur J Spont Sci 1: 1-5, 2001.

33. JEUKENDRUP AE. Regulation of fat metabolism in skeletal muscle. Anm NY Acad Sol 967:217-235, 2002.

34. JOHNSON NA, STANNARD SR, MEHALSKI K, "TRENELL MI, SACHINWALLA T, THOMPSON CH, THOMPSON MW. Intramyocellulat triacylglycerol in prolonged cycling with high- and low-carbohydrate availability. I Appl Physiol 94: 1365-1372, 2003.

35. KALHAN SC, SAVIN SM, ADAM PA. Estimation of glucose turnover with stable tracer glucose-1 - 13C.J Lab Clin Med 89: 285-294, 1977.

36. KIENS B, ESSEN-GUSTAVSSON B, CHRISTENSEN NJ, SALTIN B. Skeletal muscle substrate utilization during submaximal exercise in man: effect of endurance training. $J$ Physiol (Lond) 469:459-478, 1993. 
37. KLEIN S, COYLE EF, WOLFE RR. Fat metabolism during low-intensity exercise in endurance-trained and untrained men. Am I Physiol Endocrimol Metab 267: E934-E940, 1994.

38. KROGH A, and LINDFARD J. The relative value of fat and carbohydrate as sources of muscular energy Biochem J 14:290-363, 1920.

39. LITHELL H, ORLANDER $J$, SCHELE $R$, SJODIN B, KARLSSON $J$. Changes in lipoprotein-lipase activity and lipid stores in humain skeletal muscle with prolonged heavy exercise. Acta Physiol Scand 107: 257-261, 1979.

40. MCARDLE WD, KATCH FI, KATCH VL. Sports \& Exercise Nutrition. Section II: Nutrient bioenergetics in exercise and training, p. 122. Lippincott Williams \& Wilkins, 1999.

41. MoGILVERY RW. The use of fuels for muscular work. In: Metabolic adaption to prolonged physical exercise. Proceedings of the second international symposium on biochemistry of exercise Maggligen 1973, H Howald \& JR. Poortmans (eds) Birkhäuser Verlag, Basel, Switzerland, 1975, pp 12-30.

42. NICHOLAS CW, TSINTZAS K, BOOBIS L, WILLIAMS C. Carbohydrate-electrolyte: ingestion during intermittent high-intensity running. Med Sci Sports Exere 31: 12801286, 1999 .

43. PRICE TB, ROTHMAN DL, SHULMAN RG. NMR of gllycogen in exercise. Proc Nutr Soc 58: $851.859,1999$

44. RICO-SANZ J, ZEHNDER M, BUCHLI R, DAMBACH M, BOUTELLIER U. MUscle glycogen degradation during simulation of a fatiguing soccer match in elite soccer players examined noninvasively by 13C-MRS. Med Sei Sports Exerc 31: 1587-1593, 1999.

45. RODEN M, and SHULMAN GI. Applications of NMR spectroscopy to study muscle glycogen metabolism in man. Ammu Rev Med 50: 277-290, 1999.

46. ROEPSTORFF C, STEFFENSEN CH, MADSEN M, STALLKNECHT B, KANSTRUP $\mathbb{I L}$, RICHTER EA, KIENS $\mathbb{B}$. Gender differences in substrate utilization during submaximal exercise in endurance-trained subjects. Am J Physiol Endocrinol Metab 282: E435-E447, 2002.

47. ROMINN JA, COYLE EF, SIDOSSIS LS, GASTALDELLI A, HOROWITZ JF, ENDERT E, WOLFE RR. Regulation of endogenous fat and carbohydrate metabolism in relation to exercise intensity and duration. Am J Physiol Endocrinol Metab 265: E380L339\, 1993.

48. ROMLN JA, COYLE EF, SIDOSSIS LS, ROSENBLATT $J$, WOLFE RR. Substrate metabolism during different exercise intensities in endurance-trained women. $J$ Appl Plosiol 88: 1707-17142000.

49. SCHICK F, EISMANN B, JUNG WI, BONGERS H, BUNSE M, LUTZ O. Comparison of localized proton NMR signals of skeletal muscle and fat tissue in vivo: two lipid compartments in muscle tissue. Magn Reson Med 29: 158-167, 1993.

50. SCHOENHEIMER $R$, and RITTENBERG $D$. Deuterium as indicator in study of intermediary metabolism. Science $82: 156,1935$.

51. SCHOENHEIMER R, RUTER S, RITTENBERG D. Studies in protein metabolism: Metabolic activity of body proteins investigated with $1(-)$-leucine containing 2 isotopes. $J$ Biol Chem 130; 730-732, 1939.

52. SHEPHARD RJ, and LEATT P. Carbohydrate and fluid needs of the soccer player. Sports Med 4: 164-176, 1987.

53. STANNARD SR, THOMPSON MW, FAIRBAIRN K, HUARD B, SACHINWALLA T, THOMPSON $\mathrm{CH}$. Fasting for $72 \mathrm{~h}$ increases intramyocellular lipid content in 
nondiabetic, physically fit men. Am I Physiol Endocrinol Metab 283. E1185-E1191, 2002.

54. STARLING RD, TRAPPE TA, PARCELL AC, KERR CG, FINK WJ, COSTILL DL. Effects of diet on muscle triglyceride and endurance performance. $I$ Appl Physiol 82 : $1185-1189,1997$.

55. TARNOPOLSKY LJ, MACDOUGALL JD, ATKINSON SA, TARNOPOLSKY MA. Sutton IR. Gender differences in substrate for endurance exercise. $J$ Appl Physibl 68:302$308,1990$.

56. TARNOPOLSKY MA. Females and males: should nutritional recommendations be gender specific? Schweiz Z Sportsmed Sporttraumat 51 : $39-46,2003$.

57. TAYLOR R, PRICE TB, ROTHMAN DL, SHULMAN RG, SHULMAN GI. Validation of $13 \mathrm{C}$ NMR measurement of human skeletal muscle glycogen by direct biochemical assay of needle biopsy samples. Magn Reson Med 27: 13-20, 1992.

58. VAN LOON LJ, GREENHAFF PL, CONSTANTIN-TEODOSIU D, SARIS WH, WAGENMAKERS AJ. The effects of increasing exercise intensity on muscle fuel utilisation in humans. J Physiol (Lond) 536: 295-304, 2001.

59. WENDLING PS, PETERS SJ, HEIGENHAUSER GIF, SPRIET LL. Wariability of triacylglycerol content in human skeletal muscle biopsy samples. $J$ Appl Phpsiol 81: $1150-1155,1996$.

60. WIDRICK JJ, COSTILL DL, MCCONELL GK, ANDERSON DE, PEARSON DR. ZACHWIEJA JJ. Time course of glycogen accumulation after eccentric exercise. $J$. Appl Physiol 72; 1999-2004, 1992.

61. WOLFE RR, EVANS JE, MULLANY CJ, BURKE JF. Measurement of plasma free fatty acid turnover and oxidation using [1-13C] palmitic acid. Biomed Mass Spectrom 7: 168171,1980 .

62. WOLFE RR. Radioactive and stable isotope tracers in biomedicine. New York: WileyLiss, 1992.

63. ZEHNDER M, RICO-SANZ J, KUHNE G, BOUTELLIER U. Resynthesis of muscle glycogen after soccer specific performance examined by $13 \mathrm{C}$-magnetic resonence spectroscopy in elite players. Eur J Appl Physiol 84: 443-447, 2001 .

64. ZEHNDER M, MUELLI M, BUCHLI R, KUEHNE G, BOUTELLIER U. Further glycogen decrease during early recovery after eccentric exercise despite a high carbohydrate intake. Eur $J$ Nutr 43: 148-159, 2004. 


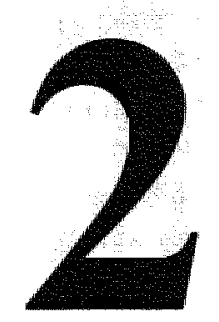

\section{Measurements of muscle phosphates and glyco- gen concentrations in elite soccer players by ${ }^{31} \mathrm{P}$ - and ${ }^{13} \mathrm{C}$-magnetic resonance spectroscopy}

${ }^{1}$ Rico-Sanz J, ${ }^{2}$ Zehnder M, ${ }^{3}$ Buchli R, ${ }^{3}$ Kühne G, ${ }^{2}$ Boutellier U.

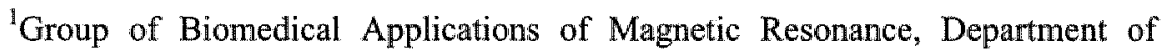
Biochemistry and Molecular Biology, University Autonoma of Barcelona, Spain; ${ }^{2}$ Exercise Physiology, Institute for Human Movement Sciences, Swiss Federal Institute of Technology Zurich and Institute of Physiology, University of Zurich, CH-8057 Zurich, Switzerland; ${ }^{3}$ Paul Scherrer Institute, CH-5232 Villigen-PSI, Switzerland.

adapted from: Medicine \& Science in Sports \& Exercise 31: 1580-1586, 1999. 


\section{ABSTRACT}

Purpose The purpose of this study was to measure non-invasively the absolute concentrations of muscle adenosine triphosphate (ATP), phosphocreatine ( $\mathrm{PCr}$ ), inorganic phosphate $(\mathrm{Pi})$, and glycogen of ellite soccer players. Methods Magnetic resonance spectroscopy $\left({ }^{3 !} \mathrm{P}\right.$ - and ${ }^{13} \mathrm{C}$-MRS) was used to measure the concentrations of metabolites in the calf muscles of 18 young male players (age $=17.5 \pm 1.0$ (SD) yrs). Results Average muscle PCr and ATP concentrations were $17.8 \pm 3.3$ and $6.0 \pm 1.2 \mathrm{mmol} \cdot \mathrm{kg}^{-1}$ wet weight (ww), respectively. The ratios of $\mathrm{Pi} / \mathrm{PCr}$ and $\mathrm{PCr} / \mathrm{ATP}$ were $0.15 \pm 0.05$ and $3.00 \pm 0.26$, respectively: Muscle glycogen concentration was $144 \pm 54 \mathrm{mmol} \cdot \mathrm{kg}^{-1}$ ww. There was a high correlation $(r=0.93, p<0.0001)$ between muscle ATP and PCr concentrations, but there was no correlation between glycogen and PCr or ATP concentrations. The concentrations of the different metabolites determined in the present study with noninvasive MRS methods were within the ranges of values reported in human muscle from biochemical analysis of muscle biopsies. Conclusion MRS methods can be utilized to assess non-invasively the muscle energetic status of elite soccer players during a soccer season. The high correlation between ATP and PCr might be indicative of fiber type differences in the content of these two metabolites.

Key words adenosine triphosphate, magnetic resonance spectroscopy, phosphocreatine, skeletal muscle 


\section{INTRODUCTION}

Despite the worldwide popularity of soccer, relatively few physiological studies have aimed to measure muscle energy stores in soccer players. Only muscle glycogen levels in soccer players have been obtained by biochemical analysis of muscle biopsies $(9,18,28,32)$, which might present problems with healing when performed repetitively $(5,35)$. Also, it is difficult to interpret any measurement of alterations in metabolite content associated with exercise or longitudinal training and nutritional modifications as a true change, since the repeated determinations have to be performed in different muscle portions. Recently, magnetic resonance spectroscopy (MRS) methods have been applied to noninvasively evaluate muscle metabolite concentrations in humans with the advantage that subsequent determinations can be obtained from the same muscle volume of interest. In one experiment, individual resting concentrations of total creatine, intramyocellular- and extramyocellular lipids in calf muscles of trained male volunteers, including soccer players, were obtained with ${ }^{\mathrm{H}} \mathrm{H}$-MRS (25). Also, ${ }^{13} \mathrm{C}$-MRS technique can be used to measure absolute muscle glycogen (1, 36 , 37), and ${ }^{31}$ P-MRS can be used to determine phosphate metabolite concentrations in human muscle $(3,4,6,7,39)$. To our knowledge, glycogen in muscles of soccer players has not been determined by noninvasive methods. Furthermore, phosphate metabolite concentrations in muscles of soccer players have not been determined by invasive nor noninvasive methods. In the present study, we used ${ }^{31} \mathrm{P}$-MRS and ${ }^{13} \mathrm{C}-\mathrm{MRS}$ to determine individual concentrations of muscle phosphates and glycogen, respectively, of 18 elite soccer players.

\section{METHODS}

\section{Subjects}

The volunteers for this experiment were 18 elite soccer players, members of teams of the 1st and 2 nd division of the Swiss National League. Six of these players competed internationally with the U-19 National Team. The study was approved by the Human Subjects Committee of the University Autonoma of Barcelona. Subjects were informed of the experimental procedures and written informed consent was obtained. They were asked to keep a dietary record of the foods consumed during the two days prior to the measurements and to avoid exercising intensively the day before. Only subjects who did not take creatine (Cr) supplements were accepted to participate in the study as $\mathrm{Cr}$ supplementation can affect the values for phosphocreatine (PCr) concentrations (17). 


\section{Magnetic Resonance}

Subjects" dominant leg was positioned inside a 4.7 Tesla $30 \mathrm{~cm}$ bore spectrometer (Varian, Palo Alto, CA, USA) after taping the lower part of the leg at three locations to a nonmagnetic support system, containing the magnetic resonance (MR) radiofrequency (RF) surface coils, to prevent leg movement during spectra acquisition. The home-made surface coils were one-loop, the ${ }^{31} \mathrm{P}$ coil ( $6 \mathrm{~cm}$ of diameter) being placed inside the ${ }^{13} \mathrm{C}$-coil $(10 \mathrm{~cm}$ of diameter), to achieve sampling from similar areas of muscle tissue. Both concentrical coils were placed under the center of the belly of the calf muscle, and they were tuned to ${ }^{31} \mathrm{P}(80.98 \mathrm{MHz})$ and ${ }^{13} \mathrm{C}(50.31 \mathrm{MHz})$. Small external references of phenyl phosphoric acid for ${ }^{31} \mathrm{P}$ and of formic acid for ${ }^{13} \mathrm{C}$ ( $99 \%$ enriched) were placed in the center of the two send-and-receive coils in order to check the sensitivity of the MR experiment and to check its stability during the whole time-span of the study. The homogeneity of the static magnetic field was adjusted before each ${ }^{31} \mathrm{P}$ and ${ }^{13} \mathrm{C}$ - experiment with an automatic shimming procedure using the proton signal from water. Also before each experiment, the surface coils were frequency-tuned and impedance-matched with mechanically variable capacitors.

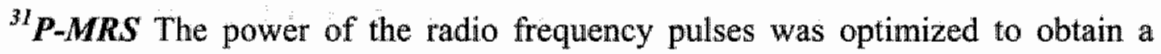
maximum of signal intensity. The interpulse delay of $4 \mathrm{~s}$ chosen for this study allows for only small corrections of the signal areas, which were reduced due to spin lattice relaxation time $\left(T_{1}\right)$ saturation effects. The $T_{1}$ of the muscle metabolites were obtained in four subjects in order to correct for the saturation effects. For signal-to-noise $(\mathrm{S} / \mathrm{N})$ improvement, 100 free induction decays were sampled before Fourier transformation. The spectrum was phased and baseline corrected and was then fitted iteratively to Lorentzian shape curves in order to determine the peak areas of the resonance lines of the metabolites investigated. Quantification was achieved with a calibration phantom used as a concentration standard. The in wivo muscle and the in vitro calibration measurements were identical with respect to all measurement parameters and to the load of the radio frequency coil. The only difference concerned the interpulse delay of the calibration measurements, which was $20 \mathrm{~s}$ in order to avoid $T_{1}$ effects. A cylindrical bottle containing $2 \mathrm{~L}$ of $50 \mathrm{mmol} \cdot \mathrm{L}^{-1} \mathrm{KH}_{2} \mathrm{PO}_{4}$ solution was used as a phantom. The electrical conductivity of the solution $\left(\sigma=0.58\right.$ Siemens $\left.\cdot \mathrm{m}^{-1}\right)$ was matched to the average conductivity of calf muscle tissue by adding salt $(\mathrm{NaCl})$ into the calibration solution and comparing the obtained coil load with that of several volunteers. In order to correct for interindividual coil-load differences a coil-load correction factor was introduced. 
${ }^{13} C-M R S$ The glycogen concentrations were determined by natural abundance ${ }^{13} \mathrm{C}-\mathrm{MRS}$. The interpulse delay was $0.150 \mathrm{~s}$. Saturation of the glycogen signal was corrected by determining the $T_{1}$ time in the muscle at 4.7 Tesla. After the acquisition of 6000 scans, the spectra were processed as mentioned above for ${ }^{31}$ P-MRS. Metabolite concentrations were also obtained with the simulation phantom method. The cylindrical $2-L$ bottle was filled with $100 \mathrm{mmol} \cdot \mathbb{L}^{-1}$ of oyster glycogen buffered to a $\mathrm{pH}$ of 7.2 . The electrical conductivity of the solution $\left(\sigma=0.58\right.$ Siemens $\left.\mathrm{m}^{-1}\right)$ was also adjusted to match that of human muscle tissue at the RF of the ${ }^{13} \mathrm{C}$ nuclei. As the signal intensity of glycogen depends on the temperature of the solution, the phantom was warmed-up to $37^{\circ} \mathrm{C}$. A coil-load correction factor was also used to correct for interindividual coil load differences.

Calculations To compare with published results in other studies, muscle metabolite concentrations in $\mathrm{mmol} \cdot \mathrm{L}^{-1}$ were converted to mmol $\cdot \mathrm{kg}^{-1}$ wet weight (ww) using the constant of $1.1 \mathrm{~kg} \cdot \mathrm{L}^{-1}$ of muscle (22). Also, for comparison, those values in the literature reported in $\mathrm{mmol} \cdot \mathrm{kg}^{-1} \mathrm{dry}$ weigh were converted to $\mathrm{mmol} \cdot \mathrm{kg}^{-1}$ ww assuming that $77 \%$ of muscle mass is water (2).

Reproducibility The reproducibility of muscle metabolite measurements by the MRS techniques was obtained in four subjects ranging in activity levels from healthy active to highly trained. The measurements were obtained two times separated by about $1.5 \mathrm{~h}$.

\section{Diet analysis}

Subjects were asked to record the foods and drinks they consumed for $2 \mathrm{~d}$ before the MRS measurements. Whenever they could not measure the weight of the food consumed, subjects were asked to estimate the size (small, medium, lange) with the aid of pictures showing portions of known weights. They also noted which ingredients were used in the preparation of the meals and how the food was prepared (e.g. steamed, fried). Any commercially prepared items were recorded as the weight or volume specified by the manufacturers' labels. The food records were analyzed by EBIS 2.0 (E+D Partner, Stuttgart, Germany).

\section{Statistical analysis}

The values are expressed as means $\pm \mathrm{SD}$ throughout this paper. The Pearson product-moment correlation coefficients were determined and Fisher $\$$ $r$ to $z$ pvalues were used to test the correlation coefficients for significance. Statistical significance was chosen at the level of $p<0.05$. 


\section{RESULTS}

\section{Subjects}

Subjects" average age, body weight (bw) and height were $17.5 \pm 1.0 \mathrm{yr}$, $69.4 \pm 6.4 \mathrm{~kg}$ and $177.3 \pm 5.3 \mathrm{~cm}$, respectively.

\section{Magnetile resonance}

The ${ }^{31}$ P-MRS measurements of inorganic phosphate (Pi), $\mathrm{PCr}$, and adenosine triphosphate (ATP) obtained in four subjects had a coefficient of variability of 12,5 , and $5 \%$, respectively. The ${ }^{13} \mathrm{C}$-MRS measurements of muscle glycogen had a coefficient of variability of $16 \%$.

Figure 1. Typical ${ }^{31}$ P-MRS spectrum in calf muscle of an elite soccer player

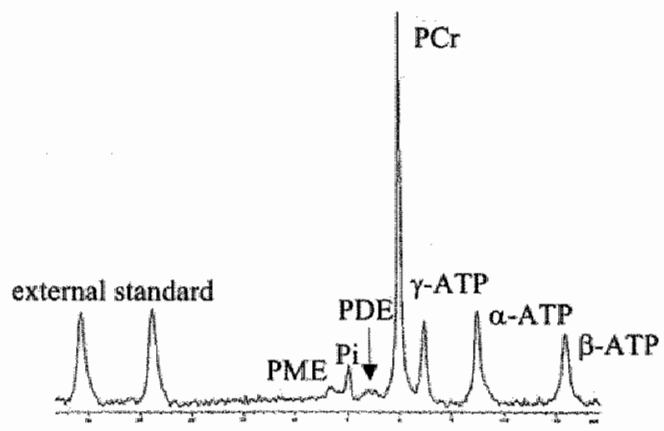

$\mathrm{PME}=$ phosphomonoester $(6.5 \mathrm{ppm}), \mathrm{Pi}=$ inorganic phosphate $(5 \mathrm{ppm}), \mathrm{PDE}=$ phosphodiesters $(3 \mathrm{ppm}), \mathrm{PCr}=$ phosphocreatine $(0 \mathrm{ppm}), \mathrm{ATP}=$ adenosine triphosphate $\gamma$-ATP $(-2.5$ ppm), $\alpha-\operatorname{ATP}(-7.5 \mathrm{ppm}), \beta-\operatorname{ATP}(-16 \mathrm{ppm})$

Figure 2. The area of glycogen in the ${ }^{13} \mathrm{C}-\mathrm{MRS}$ spectrum in calf muscle of an elite soccer player

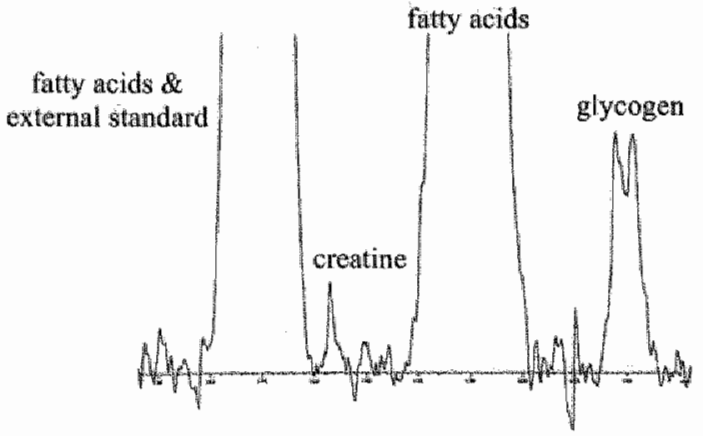

Mainly carboxylgroups from fatty acids (180-160 ppm), creatine (157 ppm), mainly carbons from polyunsaturated and unsaturated fatty acids $(140-120 \mathrm{ppm}), \mathrm{Cl}$ of glycogen (104-98 ppm) 
Table 1. Individual concentrations (mmol $\mathrm{kg}^{-1}$ wei weight for muscle phosphomonoester (PME); inorganic phosphate $\left(\mathrm{Pi}^{\mathrm{i}}\right.$, phospliodiesters (PDE), phosphocreatine (PCD), B-ndenosine triphosphate ( $\beta-\mathrm{ATP})_{\mathrm{s}}$ and glycogen (Gly), and the ratios of $\mathrm{P} / \mathrm{PCr}$ and $\mathrm{PCr} / \mathrm{ATP}$ in elite soecer players noninvasively determined by magnetic resonance spectroscopy

\begin{tabular}{lcccccccc}
\hline Player & PME & Pi & PDE & PCr & B-ATP & Gly & PIPCr & PCr/ATP \\
\hline 1 & 0.0 & 2.1 & 0.8 & 18.2 & 5.7 & 1.14 & 0.11 & 3.17 \\
2 & 0.8 & 1.9 & 0.7 & 13.4 & 3.9 & 117 & 0.14 & $\mathbf{3 . 3 9}$ \\
3 & 0.8 & 3.0 & 0.3 & 18.6 & 5.8 & 88 & 0.16 & 3.20 \\
4 & 0.0 & 2.0 & 0.4 & 18.7 & 5.4 & 138 & 0.11 & 3.47 \\
5 & 5.2 & 5.8 & 0.2 & 20.5 & 7.0 & 89 & 0.28 & 2.93 \\
6 & 2.0 & 2.7 & 0.5 & 16.6 & 5.6 & 156 & 0.16 & 2.94 \\
7 & 2.3 & 1.8 & 0.2 & 12.2 & 4.3 & 60 & 0.15 & 2.86 \\
8 & 0.5 & 3.6 & 0.5 & 15.6 & 4.6 & 1.95 & 0.23 & 3.41 \\
9 & 1.7 & 2.4 & 0.2 & 13.8 & 5.0 & & 0.17 & 2.74 \\
10 & 1.8 & 2.2 & 1.0 & 18.0 & 6.0 & 265 & 0.12 & 3.02 \\
11 & 2.0 & 3.3 & 0.3 & 21.3 & 7.4 & 242 & 0.15 & 2.88 \\
12 & 1.9 & 2.6 & 0.6 & 13.8 & 5.5 & 184 & 0.19 & 2.52 \\
13 & 0.5 & 3.1 & 0.2 & 23.2 & 8.2 & 169 & 0.13 & 2.84 \\
14 & 2.7 & 1.8 & 0.4 & 15.1 & 5.2 & 110 & 0.12 & 2.91 \\
15 & 1.0 & 2.8 & 0.0 & 22.8 & 7.9 & 109 & 0.12 & 2.87 \\
16 & 1.1 & 2.6 & 0.1 & 20.3 & 6.8 & 136 & 0.13 & 2.98 \\
17 & 0.2 & 1.6 & 0.3 & 17.7 & 5.6 & 96 & 0.09 & 3.18 \\
18 & 0.6 & 2.1 & 0.6 & 20.6 & 7.6 & 155 & 0.10 & 2.73 \\
Mean & $\mathbf{1 . 4}$ & $\mathbf{2 . 6}$ & $\mathbf{0 . 4}$ & $\mathbf{1 1 7 . 8}$ & $\mathbf{6 . 0}$ & $1 \mathbf{4 4}$ & $\mathbf{0 . 1 1}$ & $\mathbf{3 . 0 0}$ \\
\pm SD & $\mathbf{1 . 3}$ & $\mathbf{1 . 0}$ & $\mathbf{0 . 3}$ & $\mathbf{3 . 3}$ & $\mathbf{1 . 2}$ & $\mathbf{5 4}$ & $\mathbf{0 . 0 5}$ & $\mathbf{0 . 2 6}$ \\
\hline
\end{tabular}

* Unable to determine due to technical problems

Correlations between muscle adenosine triphosphate (ATP) and phosphocreatine $(\mathrm{PCr})$ concentrations (Figure 3, $y=2.5 x+3.0, r=0.93$ ) and between ATP and glycogen concentrations (Figure 4, $y=10.6 x+80.1, r=0.25$ ) in calf muscle of 18 elite soccer players

Filgure 3.

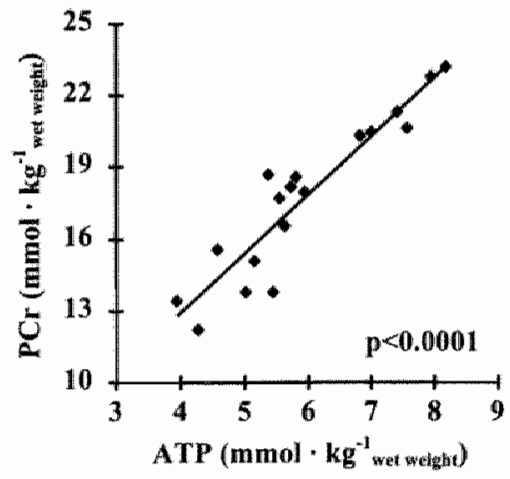

Figure 4.

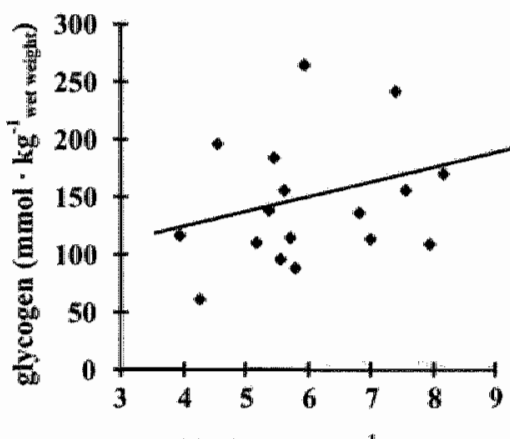

$\operatorname{ATP}\left(\mathbf{m m o l} \cdot \mathrm{kg}^{-1}\right.$ wet weight $)$ 
Figure 5. Correlation between muscle phosphocreatine $(\mathrm{PCr})$ and glycogen concentrations in calf muscle of 18 elite soccer players, $(y=3.5 x+81.7, \mathrm{r}=0.21)$

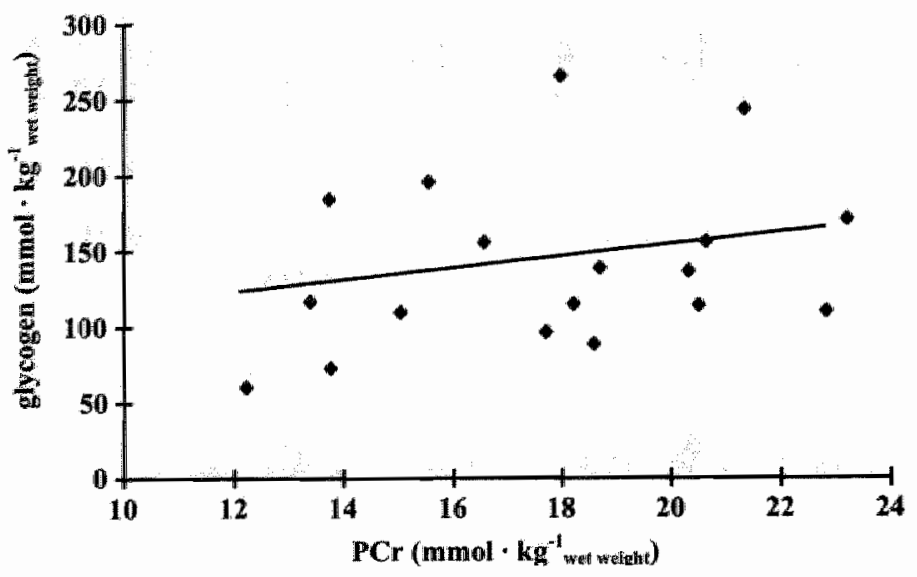

\section{Diet analyses}

One player did not conform to the guidelines set for dietary reports and his data was excluded from the analysis. Analysis of the diet of the remaining 17 players showed that players ingested $2536 \pm 613 \mathrm{kcal} \cdot \mathrm{day}^{-1}$. The amounts of carbohydrate (CHO), fat, and protein in the diet were $316 \pm 97,95 \pm 38$, and $85 \pm 28 \mathrm{~g} \cdot$ day $^{-1}$, respectively, which corresponded to $50 \pm 5,32 \pm 6$, and $13 \pm 3 \%$ of the total energy intake. The daily absolute amounts corrected for $\mathrm{kg}$ bw were $4.58 \pm 1.05,1.33 \pm 0.44$, and $1.20 \pm 0.24 \mathrm{~g}$ for CHO, fat, and protein, respectively. There was evidence of correlation $(p=0.05)$ between the levels of CHO intake and the resting muscle glycogen (Figure 6).

Figure 6. Correlation between the carbohydrate (CHO) content in the habitual diet of elite soceer players and muscle glycogen in their calf muscle, $(\mathrm{N}=16, y=47.0 \mathrm{x}-43.8, \mathrm{r}=0.49)$

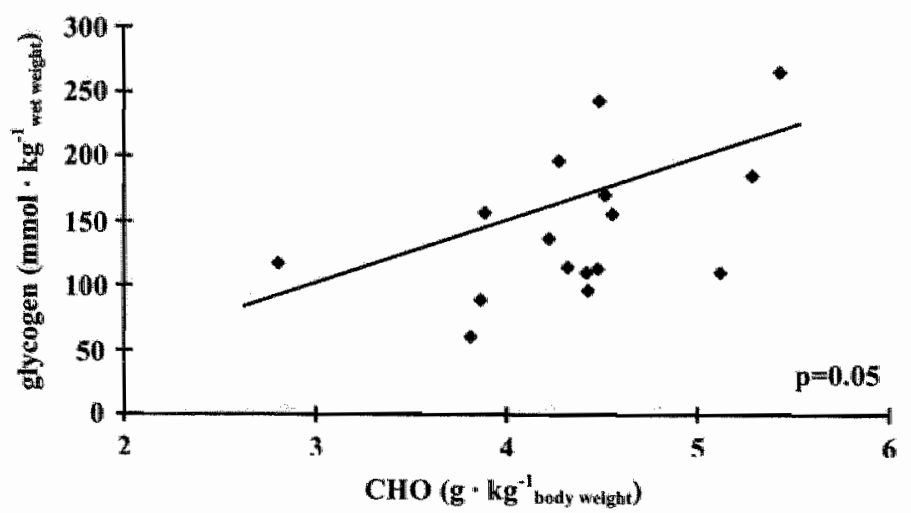




\section{DISCUSSION}

The purpose of this study was to determine non-invasively muscle glycogen and muscle phosphates of soccer players with MRS methods and to compare them with values reported in the literature. The individual values observed for ATP, $\mathrm{PCr}$ and glycogen concentrations in the present study fell within the ranges reported in human muscle from biochemical analysis of muscle biopsies and MRS techniques. We observed a high correlation between ATP and PCr concentrations, but no correlation was found between glycogen and ATP or PCr concentrations.

To our knowledge, this is the first study that has measured muscle glycogen concentrations in soccer players by noninvasive methods. Previously, levels of muscle glycogen in soccer players had been obtained only by biochemical analysis of muscle biopsies $(9,18,28,32)$. The average muscle glycogen concentration of the players in the present study $\left(144 \mathrm{mmol} \cdot \mathrm{kg}^{-1}\right.$ ww $)$ was higher than those vallues previously reported for Swedish and Fimnish elite soccer players, which averaged between 58 and $96 \mathrm{mmol} \cdot \mathrm{kg}^{-1}{ }_{\mathrm{ww}}(9,18,28,32)$. It is important to note, however, that they were determined by biochemical analysis of biopsies of vastus lateralis, and the experiments were performed in the 1970s and early 1980 s. In the early 1980 s, Jansson (19) showed that supra-normal levels of glycogen could not be detected by histochemical methods. And, after treating the biopsy specimens with perchloric acid, as was commonly done during those years, lower glycogen values were obtained. Harris et al. (16) found muscle glycogen values to range between 46 and $161 \mathrm{mmol} \cdot \mathrm{kg}^{-1}$ ww in 33 human biopsy samples. Other studies have found that the average muscle glycogen levels for mixed fibers can range between about 60 to $210 \mathrm{mmol} \cdot \mathrm{kg}^{-1}$ ww when analyzed by biochemical analysis $(10,11,12,13,26,30,31,40)$. The average glycogen value obtained in calf muscles by MRS $(36,37)$ also falls within these ranges, although, on average, it is lower than the average muscle glycogen obtained in our study.

Besides methodological differences, the level of activity and the diet of the subjects might considerably influence the results $(12,13,23,26,30,40)$. Whereas the subjects of other MRS experiments were untrained $(36,37)$, our subjects were elite competitors. Indeed, an average muscle glycogen concentration of about $160 \mathrm{mmol}$ " $\mathrm{kg}^{-1}$ ww has been observed in trained runners and bodybuilders $(12,30)$, which is about $15 \%$ higher than the average value observed in the present study. The training and diet during the previous days might provoke that average values range from 100 to $210 \mathrm{mmol} \cdot \mathrm{kg}^{-1}{ }_{\text {ww }}(23,26$, $30,40)$. We minimized these effects by asking our subjects to abstain from 
intensive training the day before and they recorded their diet during the 2 days prior to the measurements. Furthermore, as the data from Taylor et al. (37) showed that muscle glycogen was raised about $3 \mathrm{~h}$ after the ingestion of a meal, the subjects of the present study were asked to ingest their last meal $3 \mathrm{~h}$ before their seheduled time to be at the laboratory. None of our subjects were taking glucose supplements. The diet data showed that, on average, subjects ingested about $4.6 \mathrm{~g}$ of $\mathrm{CHO}$ per $\mathrm{kg}$ of bw. Pascoe et al. (23) showed that ingesting $5.0 \mathrm{~g}$ of $\mathrm{CHO}$ per $\mathrm{kg}$ bw subjects' average muscle glycogen concentration was 120 mmol $\mathrm{kg}^{\mathrm{l}}{ }_{\text {ww }}$, which is very similar to our average glycogen value.

The large range in muscle glycogen observed in our study can be also partly influenced by the capacity for glycogen deposition in the different fiber types. In one study (15), single fiber analysis of muscle glycogen showed higher values in FT fibers compared to ST (120 vs $91 \mathrm{mmol} \cdot \mathrm{kg}^{-1}$ ww): However, in another study, the values were similar (131 and $128 \mathrm{mmol} \cdot \mathrm{kg}^{-1}$ in ST and FT fibers, respectively) (10). Essen and Henriksson (10) observed a range of glycogen content of ST fibers in quadriceps femoris from $36-230 \mathrm{mmol} \cdot \mathrm{kg}^{-1}$ ww and that of FT fibers was $32-234 \mathrm{mmol} \cdot \mathrm{kg}^{-1}$ m. Furthermore, the trained runners and bodybuilders $(12,30)$ with relatively more ST and FT, respectively, showed almost identical average muscle glycogen $\left(159\right.$ vs $160 \mathrm{mmol} \cdot \mathrm{kg}^{-1}$ ww respectively). All the data from the different studies presented do not show a consistent difference in muscle glycogen in different fibers.

To our knowledge, the present investigation is the first that reports concentrations of muscle phosphates in soccer players. The mean concentrations for ATP and PCr obtained in the present study were in good agreement with the average values of $5.5 \mathrm{mmol} \cdot \mathrm{kg}^{-1}{ }_{\text {ww }}$ for ATP and $17.4 \mathrm{mmol} \cdot \mathrm{kg}^{-1}$ ww for $\mathrm{PCr}$ reported by Harris et al. (16) in 81 human subjects using biochemical analysis of biopsies. Our ${ }^{31}$ P-MRS data are also in good agreement with data for ATP, PCr, and $\mathrm{Pi}$ concentrations in human calf muscle from other MRS studies, which average values ranged from 4.8 to $7.5,16$ to 26 , and 1.7 to $4.3 \mathrm{mmol} \cdot \mathrm{kg}^{-1}$ wan, respectively $(3,4,6,7,39)$. As discussed for muscle glycogen, several studies have suggested that part of the individual differences in phosphate metabolites can be explained by the inherent diversity of fiber type composition in mammalian muscle $(20,21)$. Indeed, although similar $\mathrm{PCr}$ or ATP values in ST and FT fibers have been reported in some studies in humans (15, 24, 33), higher ATP $(29,34)$ and PCr contents in FT compared with ST fibers have been shown in other human studies $(14,27,29,33,34,38)$. Edström et al. (8) measured higher $\mathrm{PCr}$ and ATP concentrations in the vastus lateralis (41\% ST) compared to the soleus muscle (65\% ST). We found a significant correlation between ATP and $\mathrm{PCr}$ concentrations, which might be due to fiber type differences in 
accumulation of these metabolites in muscle. After an exhaustive review of the literature, we are not aware of any human study that has attempted to correlate the ATP and $\mathrm{PCr}$ levels. Therefore, the relation between $\mathrm{PCr}$ and ATP concentrations might indicate that those soccer players with higher values of $\mathrm{PCr}$ and ATP might have a greater percent of FT fibers. Contrary to the relation of ATP and $\mathrm{PCr}$ concentrations, there was no correlation between the muscle glycogen and ATP or PCr concentrations. This might be due to overlap between the levels of glycogen in ST and FT fibers, which might be an adaptation in soccer players who require primarily of this intramuscular energy source in both $\mathrm{ST}$ and FT fibers during the intense running.

When comparing all our results and those measured with MRS with the results obtained by biochemical analysis in other studies, it is evident that the MRS methods can be used with a high degree of accuracy to determine muscle phosphates and glycogen in soccer players. The advantage with the MRS methods is that the sample site is larger and the measurement can be made noninvasively and repetitively in the same muscle volume of interest. Thereby, a good estimate of the concentration of mixed muscle metabolites can be obtained without disrupting the muscle. The advantage of the biopsy technique over the MRS methods, at present, is that it can differentiate metabolite contents between single fibers in human muscle. However, in addition to potential problems with healing and the methods of analysis and preservation with the biopsy technique $(5,19,31,35)$, there is a problem with repeated measures or longitudinal studies, as subsequent determinations have to be performed in other muscle samples. Furthermore, even when the muscle piece is the same, there are variations in the metabolite content depending on the section of the fiber used. For instance, Rehunen and Härkönen (24) observed a wide range in ATP concentrations in three sections of human ST $\left(3.85-6.7 \mathrm{mmol} \cdot \mathrm{kg}^{-1}\right.$ ww $)$ and FT fibers $(5.4-$ $7.6 \mathrm{mmol} \cdot \mathrm{kg}^{-1}{ }_{\mathrm{ww}}$ ), and the ranges for $\mathrm{PCr}$ concentrations were 11.5 . $19.3 \mathrm{mmol} \cdot \mathrm{kg}^{-1}{ }_{\mathrm{ww}}$ (ST) and $12.0-19.6 \mathrm{mmol} \cdot \mathrm{kg}^{-1}$ ww $(\mathrm{FT})$. These problems are overcome by the MRS methods when determining mixed muscle energy compounds as they are less susceptible to tissue inhomogeneities. The MRS methods, on the other hand, have to resolve imprecisions due to shimming, tuning, and positioning during the MRS experiment, and those due to processing and peak measurement and quantification (absolute ws relative), which might vary among laboratories. 


\section{CONCLUSION}

We determined non-invasively concentrations of muscle phosphates and glycogen in elite soccer players with MRS methods. The results showed that the muscle ATP, PCr, and glycogen concentrations of the players were within the ranges of concentrations reported in human muscle using biochemical analyses of muscle biopsies and MRS methods.

\section{ACKNOWLEDGEMENT}

This study was partly supported by CICYT project SAF96-0147 and Farma Aid, Barcelona, Spain. The authors would like to thank the experimental assisstance of Micha Dambach and the collaboration of the coaches and players of FC Aarau and $F C$ Baden during the course of the study. 


\section{REFERENCES}

1. AVISON MJ, ROTHMAN DL, NADEL E, SHULMAN RG. Detection of human muscle glycogen by natural abudance ${ }^{13} \mathrm{C}-\mathrm{NMR}$. Proc Natl Acad Sci USA 85: 1634-1636, 1988.

2. BERGSTRÖM J, GUARNIERI G, HULTMAN E. Carbohydrate metabolism and electrolyte changes in human muscle tissue during heavy work. $J A$ Appl Physio, 30: 122$125,1971$.

3. BUCHLI $\mathbb{R}_{3}$ and BOESIGER P. Comparison of methods for the deternination of absolute metabolite concentrations in human muscles by ${ }^{31}$ P-MRS. Mag Res Med 30: 552-558, 1993.

4. BUCHLI R, MEIER D, MARTIN E, BOESIGER P. Assessment of absolute metabolite concentrations in human tissue by "P-MRS in vivo. Part $\mathbb{M}$ : Muscle, liver, kidney. Mog Res Med 32: 453-458, 1994.

5. CONSTANTIN-TEODOSIU D, CASEY A, SHORT AH, HULTMAN E, GREENHAFF PL. The effect of repeated muscle biopsy sampling on ATP and glycogen resynthesis following exercise in man. Eur J Appl Physiol 73: 186-190, 1996.

6. DOYLE VL, PAYNE GS, COLLINS DJ, VERRILL MW, LEACH MO. Quantification of phosphorus metabolites in human calf muscle and soft-tissue tumors from localized MR spectra acquired using surface coils. Phys Med Biol 42: 691-706, 1997.

7. DUNN JF, KEMP GJ, RADDA GK. Depth selective quantification of phosphorus metabolites in human calf muscle. NMR Biomed 5: 154-160, 1992.

8. EDSTRÖM L, HULTMAN E, SAHLIN K, SJÖHOLM H. The contents of high-energy phosphates in different fibre types in skeletal muscles from rat, guinea-pig and man. $J$ Physiol (Lond) 332: 47-58, 1982.

9. EKBLOM B. Applied physiology of soccer. Sports Med 3: 50-60, 1986.

10. ESSEN B, and HENRIKSSON J. Glycogen content of individual muscle fibres in man. Acta Physial Scand 90: 645-647, 1974.

11. ESSEN B, JANSSON E, HENRIKSSON J, TAYLOR AW, SALTIN B. Metabolic characteristics of fibre types in human skeletal muscle. Acta Physiol Scand 95: 153-165, 1975.

12. ESSEN-GUSTAVSSON B, and TESCH PA. Glycogen and triglyceride utilization in relation to muscle metabolic characteristics in men performing heavy-resistance exercise. Eur J Appl Physiol 61: 5-10, 1990.

13. GREEN HI, BALL-BURNETT M, SYMON S, GRANT S, JAMIESON G. Short-term training, muscle glycogen, and cycle endurance. Can J Appl Physiol 20: 315-324, 1995.

14. GREENHAFF PL, NEVILL ME, SÖDERLUND K, BOOBIS L; WILLIAMS $C$, HULTMAN E. Energy metabolism in single muscle fibres during maximal sprint exercise in man. J Physiol (Lond) 446: 528P, 1991.

15. GREENHAFF PL, SÖDERLUND K, REN JM, HULTMAN E. Energy metabolism in single human muscle fibres during intermittent contraction with occluded circulation. $f$ Physiol (Lond) 460: 443-453, 1993.

16. HARRIS RC, HULTMAN E, NORDESJÖ LO. Glycogen, glycolytic intermediates and high-energy phosphates determined in biopsy samples of musculus quadriceps femoris of man at rest. Methods and variance of values. Scand J Clin Lab Imest 33: 109-120, 1974.

17. HARRIS RC, SODDELUND K, HULTMAN E. Elevation of creatine in resting and exercising muscles of normal subjects by creatine supplementation. Clin Sci 83: 367-374, 1992. 
18. JACOBS 1, WESTLW W, KALLSSON J, RASMUSSON M, HOUGHTON B. MUSCle glycogen and det in elle soccer players. Eur J Appl Phystol 48:297-320, 1982.

19. JANSSON E. Acid soluble and insoluble gycogen in human skeletal muscle. Acia Physiol soand $113 \cdot 337-340$, 1981 .

20. KUSWMERTK MJ MOERLAND TS, WISEMAN RW. Mammalin skelleta muscle fibers distinguished by contents af phosphocreatine, $\mathrm{ATP}$, and Pl. Proc $\mathrm{Nat} / \mathrm{Acad} \mathrm{Scl}$ US, $89: 7521-7525,1992$.

21. WADAPALLMATHAM AO, CROSS A, NISHIO ML, JEELEEBHOY KN. Stability of high-energy wubstrates in fast-and slow-twitch muscle: conparison of enzymatic assay of biopsy with in viwo "P Nuclear Magnetic Resonance Spectroscopy. And Blochem 217 : $103-109,1994$

22. MENDEZ 3, and KEYS A. Density and composition of mamalian muscle Metabolism 9: 184-188, 1960 .

23. PASCOE DD, COSTLL DL, ROBERGS RA, DAVIS JA, FINK WJ, PEARSON DR. Lffects of exercise mode on muscle glycogen restorage diring repeated days of exercise. Med Sci Sports Exerc 22:593-598, 1990.

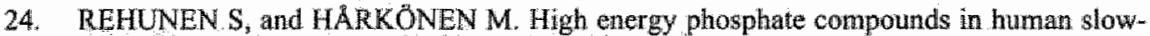
twitch and fast-twitch muscle fibres. Scand J Clin Lab Invest 40:45-54, 1980.

25. RICO-SANZ J, HAINAL JV, THOMAS EL, MIERISOVA S, ALA-KORPRLA M, BELL JD. Intracellular and extracellular triglyceride metabolism during alternating intensity exercise in humans. I Phystiof (Lond) 510:615-622, 1998.

26. ROEDDE S, MACDOUGALL JD, SUTTON JR, GREEN HJ. Supercompensation of muscle glycogen in trained and untrained subjects. Can J Appl Sport Sci 11: 42-46, 1986 .

27. SAHLN K, SODERLUND K, TONKONOGI M, HIRAKOBA K Phosphocreatine content in single fibers of human muscle after sustained submaximal exercise. Am $d$ Physiol 273: C172-C178, 1997.

28. SALTIN B. Metabolic fundamentals in exercise. Med Sci Sports 5: 137-146, 1973.

29. SANT"ANA PEREIRA JA, SARGEANT AJ, RADEMAKER AC, DE HAAN A, VAN MECHELEN W. Myosin heawy chain isoform expression and high energy phosphate content in human muscle fibres at rest and post-exercise. I Physiol 496: 583-588, 1996.

30. SHERMAN WM, COSTILL DL, FINK WI, MILLER JM. Effect of exercise-diet manipulaton on muscle glycogen and its subsequent utilization during performance. Int $J$ Sports Med 2: 114-118, 1981.

31. SHERMAN WM, DOYLE JA, LAMB DR, STRAUSS RH, Dietary carbohydrate, muscle glycogen, and exercise performance during 7 a of training. Am I Chn Nutr 57: 27-31, 1993.

32. SMAROS G. Energy usage thing football match. In: Proceedings Ist Intemational Congress on Sports Medicine Applied to Football. Vecchiet L (ed), Guanillo D, Rome: $1980, \mathrm{pp} .795-801$.

33. SODERLUND K, AND HULTMAN E. ATP and phosphocreatine changes in single human muscle fibers after intense electrical stimulation. Am $\int$ Physiol 261: E737-E741, 1991.

34. SODERLUND K, GREENHAFF PL, HULTMAN E. Energy metabolism in type I and type II human muscle fibres during short term electrical stimulation at different frequencies. Acta Physiol Sicond 144:15-22, 1992. 
35. STARON RS, HIKIDA RS, MURRAY TF, NELSON MN, JOHNSON P, HAGERMAN F. Assessment of skeletal muscle damage in succesive biopsies from strength-trained and untrained men and women. Eur J Appl Physiol 65: 258-264, 1992.

36. TAYLOR R, PRICE TB, ROTHMAN DL, SHULMAN RG, SHULMAN GI. Validation of ${ }^{13} \mathrm{C}$ NMR measurement of human skeletal muscle glycogen by direct biochenical assay of needle biopsy samples. Magn Reson Med 27: 13-20, 1992.

37. TAYLOR R, PRICE TB, KATZ LD, SHULMAN RG, SHULMAN GI. Dired measurement of change in muscle glycogen concentration after a mixed meal in normal subjects. Am J Physiol 265: E224-E229, 1993.

38. TESCH PA, THORSSON A, FUJTSUKA N. Creatine phosphate in fiber types of skeletal muscle before and after exhaustive exercise. IApl Plysiol 66: 1756-1759, 1989.

39. VENKATASUBRAMANIAN PN, MAFEE MF, BARANY M. Quantitation of phosphate metabolites in human leg in vivo. Magn Reson Med 6: 359-363, 1988.

40. WIDRICK JJ, COSTILL DL, FINK WJ, HICKEY MS, MCCONELL GK, TANAKA H. Carbohydrate feedings and exercise performance: effect of initial muscle glycogen concentration. I Appl Physiol 74: 2998-3005, 1993. 



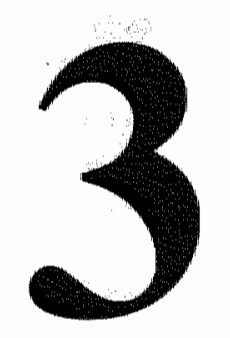

\section{Muscle glycogen degradation during simulation of a fatiguing soccer match in elite players exa- mined by ${ }^{13} \mathrm{C}$-magnetic resonance spectroscopy}

${ }^{1}$ Rico-Sanz J, ${ }^{2}$ Zehinder M, ${ }^{3}$ Buchli R, ${ }^{2}$ Dambach $M,{ }^{2}$ Boutellier U.

${ }^{\text {I} G r o u p ~ o f ~ B i o m e d i c a l ~ A p p l i c a t i o n s ~ o f ~ M a g n e t i c ~ R e s o n a n c e, ~ D e p a r t m e n t ~ o f ~}$ Biochemistry and Molecular Biology, University Autonoma of Barcelona, Spain; ${ }^{2}$ Exercise Physiology, Institute for Human Movement Sciences, Swiss Federal Institute of Technology Zurich and Institute of Physiology, University of Zurich, CH-8057 Zurich, Switzerland; ${ }^{3}$ Paul Scherrer Institute, CH-5232 Villigen-PSI, Switzerland.

adapted from: Medicine \& Science in Sports \& Exercise 31: 1587-1593, 1999. 


\section{ABSTRACT}

Purpose The purpose of this research project was to non-invasively determine individual muscle glycogen degradation during a test intended to predict individual fatigue in intense soccer matches. Methods The glycogen of the calf muscles of 17 elite soccer players (age $=17.4 \pm 0.8$ (SD)) were measured with ${ }^{13} \mathrm{C}$-magnetic resonance spectroscopy before and after an alternating velocity test to exhaustion. Blood samples were taken before and three minutes after the test for determination of blood metabolites. Results Average muscle glycogen was $135 \pm 53 \mathrm{mmol} \cdot \mathrm{kg}^{-1}$ wet weight (ww) before and $87 \pm 27 \mathrm{mmol} \cdot \mathrm{kg}^{-1}{ }_{\text {ww }}(\mathrm{p}<0.001)$ after exhaustion $(42 \pm 25 \mathrm{~min})$. There was a high correlation $(\mathrm{r}=0.87$, $\mathrm{p}<0.0001$ ) between muscle glycogen at rest and net muscle glycogen utilized. There was also a more moderate correlation $(\mathrm{r}=0.62, \mathrm{p}<0.01)$ between net muscle glycogen used and time to exhaustion during the soccer-specific test. There was some evidence of correlation $(r=0.42, p=0.09)$ between resting glycogen and time to exhaustion. Plasma lactate increased $(p<0.001)$ from $0.8 \pm 0.4$ before the test to $2.5 \pm 1.0 \mathrm{mmol} \cdot \mathrm{L}^{-1}$ at exhaustion, whereas ammonia was raised $(p<0.0001)$ from $44.1 \pm 10.3$ to $89.7 \pm 14.9 \mu \mathrm{mol} \cdot \mathrm{L}^{-1}$. Similarly, plasma free fatty acids were elevated $(\mathrm{p}<0.0001)$ from $148 \pm 106$ to $797 \pm 401 \mu \mathrm{mol} \cdot \mathrm{L}^{-1}$, and glycerol was increased $(p<0.0001)$ from $48.3 \pm 17.7$ to $182.2 \pm 61.8 \mu \mathrm{mol} \cdot \mathrm{L}^{-1}$. Insulin levels $\left(11.9 \pm 3.7 \mathrm{vs} 11.7 \pm 4.8 \mu \mathrm{mol} \cdot \mathrm{L}^{-1}\right)$ remained the same. Creatine kinase levels increased $(p<0.0001)$ from $486 \pm 501$ to $640 \pm 548 \mu \mathrm{mol} \cdot \mathrm{L}^{-1}$ after the test. Conclusion We conclude that exhaustion during soccer specific performance is related to the capacity to utilize muscle glycogen. The results underline the importance of dietary counseling (glycogen loading and resynthesis strategies) and proper training to enhance the glycogen levels and glycogenolitic capacity of the players.

Key words alternating intensity exercise, creatine kinase, glycogenolysis, magnetic resonance spectroscopy, skeletal muscle 


\section{INTRODUCTION}

Soccer is an alternating-intensity endurance sport that has been shown to require utilization of muscle glycogen stores during a match $(6,13,18,26,29)$, the extent of which might be governed by the duration and intensity of the exercise (28). Although these original studies in soccer players illustrated a possible role for muscle glycogen in soccer performance, since then, no systematic controlled study has been performed to show the relationship between muscle glycogen or its utilization and exhaustion during soccer-specific running performance. The running intensity of the players during a match can vary according to its importance, the score during the match, the caliber and position $(6,23)$ of the players, and fatigue as time progresses (24). And, the reduction in work rate might be due to low muscle glycogen $(6,26)$.

The detection of the time when fatigue occurs for each individual player during a real soccer match is a rather complicated task and almost impossible to determine as the runs for each player vary at random in exercise intensity and duration and are alternated with diverse rest pauses, which also vary in intensity and duration. Two tests have been developed to test the endurance capacity of soccer players $(2,7)$. But, the duration of the tests, approximately $10(7)$ and $16.5 \mathrm{~min}(2)$ make these tests too short for the actual duration of a real match (i.e. $90 \mathrm{~min}$ ). Therefore, it is very difficult with these procedures to detect differences in players' capacities to endure an intense 90 min soccer match. In the present study, we utilized a soccer-specific test, which alternated 3 different shuttle running velocities, representative of the actual running velocities during soccer match play. This permitted the detection of individual times to fatigue in elite soccer players. The results of the test were compared with the glycogen in gastrocnemius muscle and its utilization during the test measured by magnetic resonance spectroscopy $\left({ }^{13} \mathrm{C}\right.$-MRS), which had been validated against biochemical analysis of muscle biopsies (32).

\section{METHODS}

\section{Subjects}

The volunteers for this experiment were 17 elite soccer players, members of two teams of the 1 st and 2 nd division of the Swiss National League. Six of these players were members of the U-19 Swiss National Team and they competed at international level. The study was approved by the Human Subjects Committee 
of the University Autonoma of Barcelona. Subjects were informed of the experimental procedures and written informed consent was obtained.

\section{Magnetic Resonance}

Subjects" dominant leg was positioned inside a 4.7 Tesla $30 \mathrm{~cm}$ bore spectrometer (Varian, Palo Alto, CA, USA) after taping the lower part of the leg at three locations to a nonmagnetic support system, containing the ${ }^{13} \mathrm{C}-\mathrm{MR}$ radiofrequency (RF) surface coll, to prevent leg movement during spectra acquisition. The home-made surface coil of $10 \mathrm{~cm}$ of diameter was placed under the center of the belly of the calf muscle, and was tuned to $50.31 \mathrm{MHz}$. A small external reference of formic acid for ${ }^{13} \mathrm{C}(99 \%$ enriched) was placed in the center of the send-and-receive coll in order to check the sensitivity of the MRS experiment. The homogeneity of the static magnetic field was adjusted before each experiment with an automatic shimming procedure using the proton signall from water. Also before each experiment, the surface coil was frequency-tuned and impedance-matched with mechanically variable capacitors.

${ }^{13}$ C-MRS Muscle glycogen concentrations were determined by natural abundance ${ }^{13} \mathrm{C}$-MRS. The interpulse delay was $0.150 \mathrm{~s}$. Saturation of the glycogen signal was corrected by determining the spin lattice relaxation time $\left(T_{1}\right)$ in the muscle at 4.7 Tesla. For signal-to-noise (S/N) improvement, 6000 free induction decays were sampled before Fourier transformation. The spectrum was phased and baseline corrected and was then fitted iteratively to Lorentzian shape curves in order to determine the peak areas of the resonance lines of muscle glycogen. Quantification was achieved with a calibration phantom used as a concentration standard. The in vivo muscle and the in vitro calibration measurements were identical with respect to all measurement parameters and to the load of the radio frequency coil. A cylindrical $2 \mathrm{~L}$-bottle was filled with $100 \mathrm{mmol} \cdot \mathrm{L}^{-1}$ of oyster glycogen buffered at a pH of 7.2. The electrical conductivity of the solution $\left(o=0.58\right.$ Siemens $\left.\cdot \mathrm{m}^{\circ}\right)$ was also adjusted to match that of human muscle tissue at the RF of the ${ }^{13} \mathrm{C}$ nuclei. As the signal intensity of glycogen depends on the temperature of the solution, the phantom was warmed-up to $37^{\circ} \mathrm{C}$. In order to correct for interindividual coil-load differences a coil-load correction factor was introduced. The individual formic acid reference signal was divided by the average of all the subjects tested.

Calculations In order to compare with published results in other soccer players, muscle glycogen in mmol $\mathrm{L}^{-1}$ was converted to $\mathrm{mmol} \cdot \mathrm{kg}^{-1}$ wer weight (ww) using the constant of $1.1 \mathrm{~kg} \cdot \mathrm{L}^{-1}$ of muscle (19). Also, for comparison, those values in the 
literature reported in mmol $\mathrm{kg}^{-1}$ dry weigh were converted to mol $\mathrm{kg}^{\mathrm{m}}$ ww assuming that $77 \%$ of muscle mass is water (4).

\section{Fatigue Test}

An exhaustive shuttle ruming test protocol (JRS Fatigue Test), simulating the conditions of a highly intense soccer match, was performed immediately after the resting ${ }^{13} \mathrm{C}-\mathrm{MRS}$ measurement and pre-exercise blood sampling. The test was performed in a room adjacent to the magnet room. Prior to starting the protocol, subjects warmed-up for $5 \mathrm{~min}$, which consisted of 3 min of ruming and 2 min of stretching exercises. The shuttle locomotion velocities during the warm-up and the experimental protocol consisted of $36 \mathrm{~s}$ at $2.5 \mathrm{~m} \cdot \mathrm{s}^{-1}$ (running) followed by $18 \mathrm{~s}$ at $1.7 \mathrm{~m} \cdot \mathrm{s}^{-1}$ (jogging) and $6 \mathrm{~s}$ at $5 \mathrm{~m} \cdot \mathrm{s}^{-1}$ (sprinting) between two lines $15 \mathrm{~m}$ apart. The sprinting velocity was the maximal velocity, which all players could sustain. Players covered 3 shuttle-laps of $30 \mathrm{~m}$ running, 1 lap of $30 \mathrm{mo}$ jogging, and sprinting, summing up to a total distance of $150 \mathrm{~m}$ every min. This was repeated 3 times ( $3 \mathrm{~min}$ ) during the warm-up before stretching. Immediately thereafter, subjects ran every min alternating the 3 different velocities of runing, jogging and sprinting. Time was controlled by two stop watches. The first watch was used to test for compliance during the running and jogging while the second watch was used to monitor the sprinting time. Subjects received feedback every $15 \mathrm{~m}$ and the time was recorded every $30 \mathrm{~m}$ to assess velocity compliance. The test termination criterion was the time when subjects voluntarily reported they were exhausted or when the time in the $30 \mathrm{~m}$ sprints exceeded $7 \mathrm{~s}$. If subjects were able to complete $45 \mathrm{~min}$, a rest pause of $15 \mathrm{~min}$ sitting was taken and the subjects were allowed to ingest $500 \mathrm{ml}$ of plain water. Immediately after the end of the test, subjects were repositioned in the magnet for the post-test ${ }^{13} \mathrm{C}-\mathrm{MRS}$ measurement. During the running test, players wore a monitor (Polar Electro, Kempele, Finland) to assess the heart rate. The data was later downloaded into a personal computer using an interface (Polar Electro, Kempele, Finland).

\section{Blood analysis}

Before the test and at 3 min post-test and with the subject lying supine, a blood sample was obtained from an antecubital vein for detemination of plasma lactate, ammonia, free fatty acids (FFA), glycerol, and creatine kinase (CK). Following centrifugation ( $4800 \mathrm{rpm}$ at $4{ }^{\circ} \mathrm{C}$ for $15 \mathrm{~min}$ ), the serum was removed from the aliquot and stored at $-80^{\circ} \mathrm{C}$ until the analyses were performed. The blood, other than that for lactate analysis, was collected in a $7.5 \mathrm{~mL}$ EDTA-K tube. Ammonia (Manmheim, Germany), gllycerol (Sigma,Deisenhofen, Germany), FFA (Wako, Neus, Germany), and CK (Hoffmanm-La Roche, Basel, Switzerland) were measured enzymatically. The blood for the analysis of lactate 
was collected in a $2.7 \mathrm{~mL}$ Glucose-FE tube and measured by the enzymatic method of Hohorst (10). Insulin was determined with a radioimmuno assay method (CIS biointemational, Sur-Yvette, France).

\section{Statistical analysis}

The values are expressed as means \pm SD throughout this paper. Repeated measures analysis of variance was used to test for statistical differences between pre- and post-test walues. The Pearson product-moment correlation coefficients were determined and Fisher's $\mathrm{r}$ to $\mathrm{z}$ p-values were used to test the correlation coefficients for significance. The significance level was chosen at $p<0.05$.

\section{RESULTS}

\section{Magnetic resonance}

Figure 1 shows typical ${ }^{13} \mathrm{C}-\mathrm{MR}$ spectra of muscle glycogen before (A) and after (B) the test. The average muscle glycogen before the test was $135 \pm 53 \mathrm{mmol} \cdot \mathrm{kg}^{-1}$ wa and decreased to $87 \pm 27 \mathrm{mmol} \cdot \mathrm{kg}^{-1}$ ww $(\mathrm{p}<0.001)$ after the test. Time to exhaustion during the soccer specific test was $42 \pm 25 \mathrm{~min}$.

Figure 1. Typical ${ }^{13} \mathrm{C}-\mathrm{MR}$ spectra of muscle glycogen of an elite soccer player before (A) and after (B) the JRS Fatigue Test

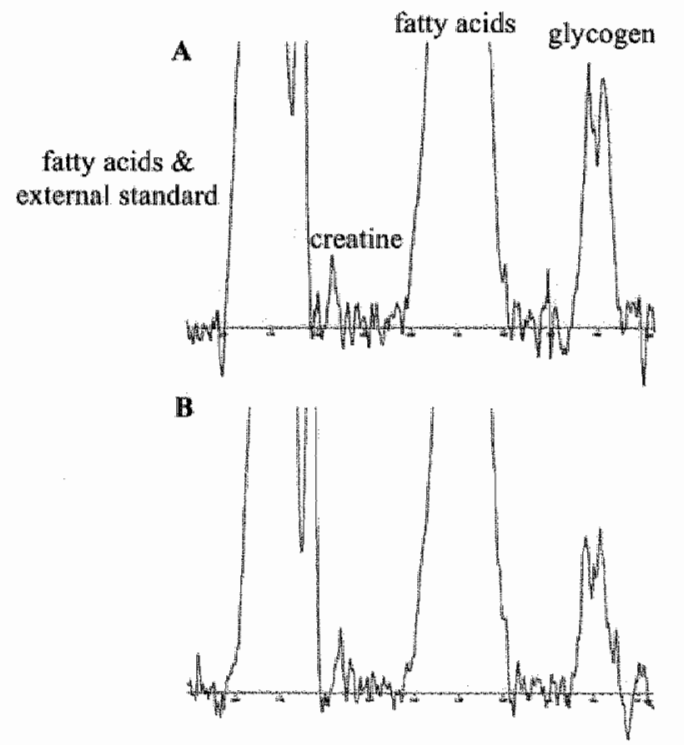

Mainly carboxylgroups from fatty acids (180-160 ppm), creatine (157 ppm), mainly carbons from polyunsaturated and unsaturated fatty acids (140-120 ppm), Cl of glycogen (104-98 ppm) 
The individual results showed a high correlation $(r=0.87, p<0.0001)$ between muscle glycogen at rest and net muscle glycogen utilized (Figure 2 ). There was a weaker correlation $(\mathrm{r}=0.62, \mathrm{p}<0.01)$ between net muscle glycogen used and time to exhaustion during the soccer specific test (Figure 3). There was some evidence $(p=0.09)$ of correlation $(r=0.42)$ between resting muscle glycogen and time to exhaustion (Figure 4).

Figure 2. Signifrcant correlation $(y=0.62 x-36.03, r=0.87$ ) between muscle glycogen at nest and net muscle glycogen utilized during the JRS Fatigue Test in 17 elite socer players

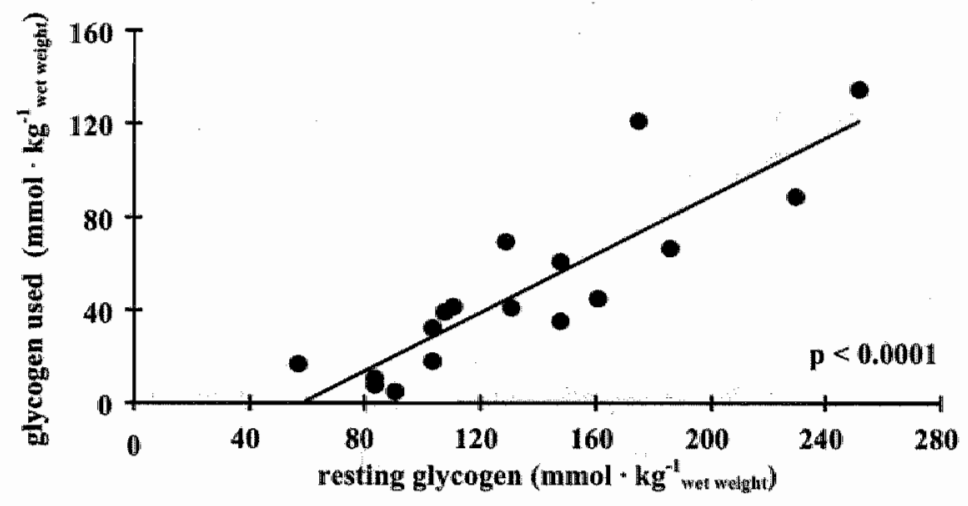

Figure 3. Significant correlation $(y=0.41 x+21.83, \mathrm{r}=0.62)$ between muscle glycogen utilized and time to exhaustion during the JRS Fatigue Test in 17 elite soccer players

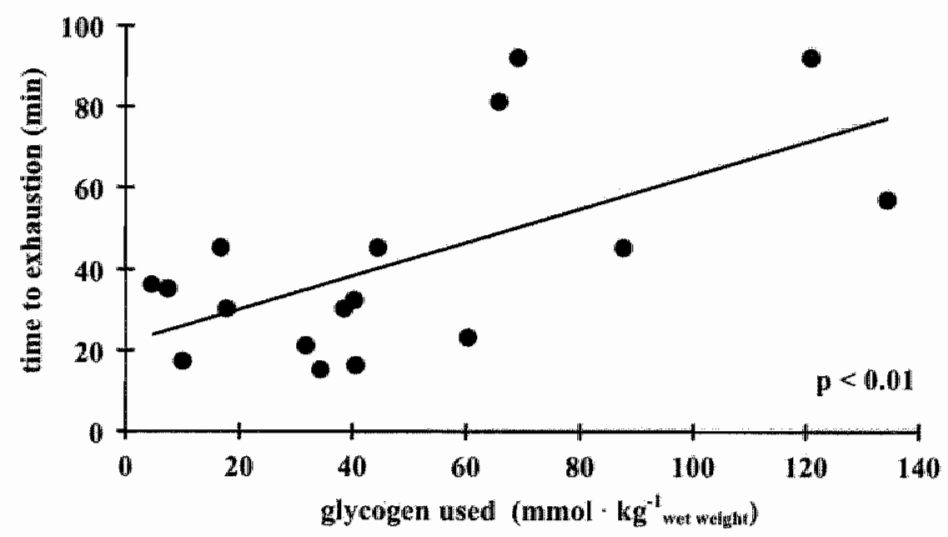


Figure 4. Nonsignificant comelation $(y=0.20 x+14.80, r=0.42$ ) between muscle glycogen at rest and time to exhaustion during the JRS Fatigue Test in 17 elite soccer players

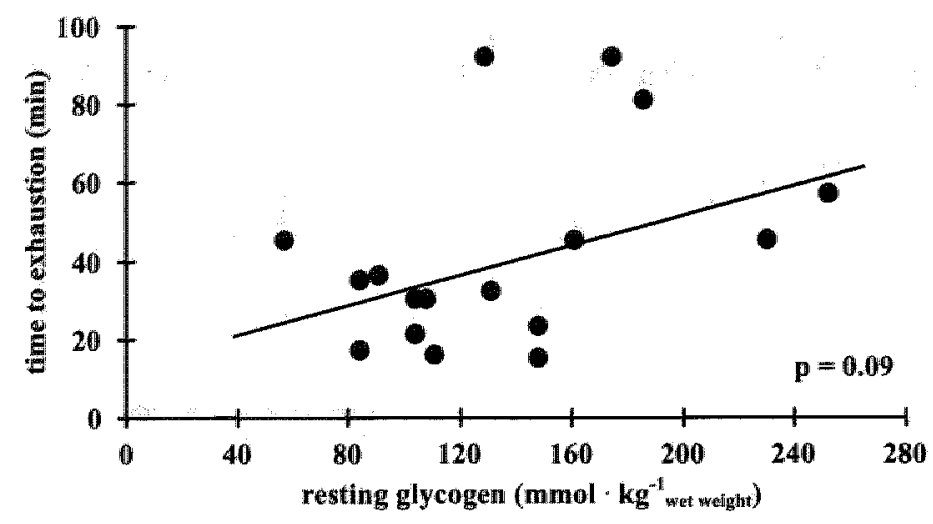

\section{Bllood analyses}

Table 1 shows the concentrations of plasma lactate, ammonia, FFA, glycerol, insulin, and $\mathrm{CK}$ before and after the soccer specific performance. All parameters examined, except for insulin, showed a highly significant accumulation $(\mathrm{p}<0.0001)$ after the test.

Table 1 . Changes in plasma lactate, ammonia, free fatty acids (FFA), glycerol, insulin, and creatine kinase (CK) concentrations of elite soccer players before (Pre) and after (Post) a fatiguing soccer specific test

\begin{tabular}{|c|c|c|}
\hline & Pre & Post \\
\hline Lactate (mmol $\left.\mathrm{L}^{-1}\right)$ & $0.84 \pm 0.37$ & $2.52 \pm 1.04 * * *$ \\
\hline Ammonia $\left(\mu \mathrm{mol} \cdot \mathrm{L}^{-1}\right)$ & $44.1 \pm 10.3$ & $89.7 \pm 14.9 *$ \\
\hline FA $\left(\mu\right.$ Hnol L $\left.L^{-1}\right)$ & $148 \pm 106$ & $797 \pm 401$ * \\
\hline Glycerol $\left(\mu m \mathrm{LL}^{-1}\right)$ & $483 \pm 177$ & $1822+618 * * *$ \\
\hline$C K\left(\mu m o l \cdot L^{-1}\right)$ & $486 \pm 501$ & $640 \pm 548 * * *$ \\
\hline Insulin (uU min $\left.{ }^{-1}\right)$ & $11.9+3.7$ & $11.7+4.8$ \\
\hline
\end{tabular}

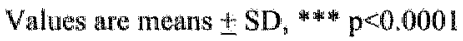

\section{DISCUSSION}

The main purpose of this study was to evaluate the individual muscle glycogen degradation and time to exhaustion during a soccer-specific running test. The results of the study showed a net muscle glycogen degradation of $36 \%$ of the resting value at exhaustion, a high correlation between resting muscle glycogen 
and muscle glycogen degraded during the test, and a less significant correlation between muscle glycogen used and time to exhaustion during the test. This indicates a possible role for players" muscle glycogenolytic capacity in fatigue during soccer-specific performance.

The results of the JRS Fatigue Test used in the present study can be utilized to compare soccer-specific endurance capacity among different players, which in real soccer matches is almost impossible to assess. The running activities for each player vary at random in exercise intensity and duration and are alternated with diverse rest pauses. For instance, Reilly and Thomas (23) found that about 843 random changes of locomotion activities can occur during a soccer match. The JRS Fatigue Test consists of shuttle running at three different velocities, which are representative of the running activities during real soccer matches and detects an exhaustion time point. Other tests, developed to evaluate soccerspecific performance, have consisted of all-out running 4 laps with a total distance of $2160 \mathrm{~m}$ including forward, backward, and sideways running, turns, running around markers, and jumping activities (7), or alternating high- and lowintensity exercise for 15 and $10 \mathrm{~s}$, respectively, during $16.5 \mathrm{~min}$ (2). It is very difficult with these two tests to detect individual differences in players' capacities to endure a $90 \mathrm{~min}$ soccer match. The JRS Fatigue Test protocol required a sprint of $5 \mathrm{~m} \cdot \mathrm{s}^{-1}$ for $30 \mathrm{~m}$ in a shuttle run every $54 \mathrm{~s}$ what is more demanding than an average soccer match in which soccer players are required to sprint about $16 \mathrm{~m}$ with a frequency of one every $90 \mathrm{~s}$ for $90 \mathrm{~min}$ (23). While during soccer matches players might walk or stand still, during the JRS Fatigue Test, only running, jogging, and sprinting were allowed, requiring a high intensity throughout the test. The high intensity level can be shown by the high heart rates. After the initiation of the test, the heart rate was fluctuating between 160 and

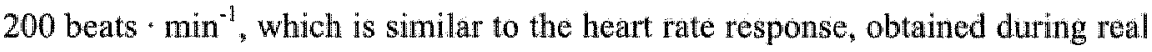
soccer matches $(1,6,17,23,25)$. Our players ran on average for $42 \mathrm{~min}$, at which time fatigue occurred. If our players had been allowed to continue running at lower velocities to the end of the $90 \mathrm{~min}$ of a real match, all players who did not cover $90 \min (15$ out of 17 ) would have run over $10 \mathrm{~km}$, which is the average total distance covered by Danish, Swedish, Japanese, English, and Australian elite players in reall matches $(3,6,21,23,35)$. The results of the present study showed that players cannot complete an intense soccer match maintaining the same velocity of locomotion, particularly the sprinting velocity, and that fatigue might be already occurring by the end of the first half $(42 \mathrm{~min})$. A decrement in velocity at the end of a soccer match had been previously reported in elite players (24). In the present study we showed that with the JRS Fatigue Test it is possible to discern that the ability to perform repeated sprints varies among players and can last as little as $15 \mathrm{~min}$ in some players. The results of this test can be used by 
coaches to select those players who can maintain a higher velocity for a longer time.

The JRS Fatigue Test can be used in conjunction with physiological measurements to evaluate differential responses among the players. We used ${ }^{13} \mathrm{C}$ MRS to measure muscle glycogen. The decrement in muscle glycogen in the present study was within the ranges of average muscle glycogen degradation by the end of the match measured by biochemical analysis of muscle biopsies (50 (6), 26 (18), 87 (high muscle glycogen players) and 45 (low muscle glycogen

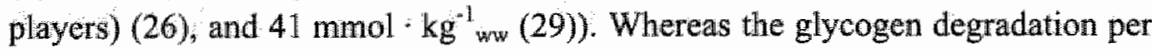
unit time reported by those investigators was $0.56(6), 0.29(18), 0.97$ and 0.50 (26), and $0.46 \mathrm{mmol} \cdot \mathrm{kg}^{-1}$ win ${ }^{-1}(29)$, the muscle glycogen degradation in the present study was $1.31 \mathrm{mmol} \cdot \mathrm{kg}^{-1} \mathrm{ww}^{\cdot} \mathrm{min}^{-1}$. Muscle glycogen might be an important factor in soccer performance. Ekblom (6) had reported that players with the lowest muscle glycogen content at half time had a slower average velocity and covered less ground in the second half of the match. Similarly, Saltin (26) found that players with the lowest muscle glycogen levels covered $25 \%$ less distance, walked $50 \%$, and sprinted $15 \%$ of the distance, whereas the high muscle glycogen players walked $27 \%$ and sprinted $24 \%$ of the distance. However, it is difficult to conclude that muscle glycogen was the only factor for this decrement in performance in those experiments, as it is possible that the players with low muscle glycogen levels occupied a different position in the team, which required less running. For instance, from match analysis it has been found that midfield players cover more distance than the other field players (23). There was some evidence of correlation between muscle glycogen and time to exhaustion in the present study. However, we observed a moderate correlation between muscle glycogen utilization and time to exhaustion during socer specific performance indicating that the capacity for muscle glycogenolysis is more important than resting muscle glycogen during soccer-specific performance. Some reports have shown that resting muscle glycogen concentration might influence glycogen degradation during exercise $(17,22)$, while other reports measured no effect of augmented glycogen levels on glycogen breakdown $(9,27,33)$. The results of the present study demonstrated that glycogen breakdown correlated highly with resting muscle glycogen. In contrast to Saltin et al. (27) who showed no correlation between glycolytic rate and initial muscle glycogen, in the present study, we evaluated 17 soccer players and showed that there is a relationship between resting glycogen and glycogen degradation.

The correlation between glycogen utilization and nunning time was weaker than between resting glycogen and glycogen utilized. Therefore, performance time 
could possibly be influenced by the capacity to utilize other intramuscular and circulating energy sources in addition to glycogen. In the present study, there was a very significant accumulation of plasma FFA after the fatigue test, which was similar to that reported by Bangsbo (1) in Danish soccer players. Whereas Bangsbo (1) reported a minor increase in glycerol, the rise in glycerol in the present study was allso significant (Table 1 ). The large accumulation of plasma FFA and glycerol is probably due to enhanced lipolysis in adipose tissue, as intramyocellular (IMCL) and extramyocellular (EMCL) lipids appear not to be utilized in soccer players under similar protocols (25). Although some researchers have reported decrements of IMCL of 20 to $50 \%$ of the resting value $(5,8,12,15)$, others have reported no changes after 25 to $120 \mathrm{~min}$ of cycling between 50 to $65 \%$ of $\mathrm{VO}_{2 \max }$ or $120 \mathrm{~min}$ of dynamic knee extension exercise $(14,16,30,31,34)$ in agreement with Rico-Sanz et al. (25). The lower plasma lactate of the present study compared to other studies (1) might have been due to lactate being used as an additional energy source during the lower intensity periods (20). Protein degradation must have also contributed to the energy turnover during the soccer-specific running as indicated by the rise in plasma ammonia levels. The eccentric component of decelerations during the soccer specific running while performing the JRS Fatigue Test might have caused some muscle damage as demonstrated by the increased levels of CK. Elevated CK has been shown after concentric and eccentric exercise for instance by Hubinger et al. (11).

\section{CONCLUSION}

We have demonstrated that ${ }^{13} \mathrm{C}$-MRS can be used to non-invasively assess the individual muscle glycogen degradation of elite soccer players during a soccerspecific fatigue test. The results showed a high correlation between muscle glycogen utilization and resting muscle glycogen and a moderate correlation between the net muscle glycogen utilized and time to exhaustion, thereby indicating a role for muscle glycogenolytic capacity in the onset of fatigue in soccer. The elevated values of glycerol, FFA and ammonia after the exercise demonstrate the activation of other metabolic pathways for energy delivery, and the higher plasma CK may indicate some muscle damage during soccer specific performance. These results emphasize the importance of dietary counseling (glycogen loading and resynthesis strategies) and proper training to enhance the glycogen levels and glycogenolitic capacity of the players. 


\section{ACKNOWLEDGEMENT}

This study was partly supported by CICYT project SAF96-0147 and Farma Aid, Barcelona, Spain. Guido Kühne is greatly acknowledged for excellent technical assistance. The authors would like to thank the collaboration of the coaches and players from FC Aarau and FC Baden during the course of the study. 


\section{REFERENCES}

1. BANGSBO J. The physiology of soccer - with special reference to intense intermittent exercise. Doctoral Thesis, University of Copenhagen, 1994.

2. BANGSBO J, and LINDQUIST F. Comparison of various exencise tests with endurance performance during soccer in professional players. Im J Sports Med 13: 125 132, 1992.

3. BANGSBO J, NORREGAARD L, THORSOE F. Activity profile of competition soceer. Can J Spart Sci 16: $110-116,1991$.

4. BERGSTRÖM J, GUARNIERI G, HULTMAN E. Carbohydrate metabolism and electrolyte changes in human muscle tissue during heavy work. I Appl Physiol 30: 122125,1971 .

5. CLEROUX J, VAN NGUYEN P, TAYLOR AW, LEENEN FHH. Effects of $\beta_{1}$ - vs. $\beta_{1}+$ $\beta_{2}$ blockade on exercise endurance and muscle metabolism in humans. J Appl Physiol 66: $548-554,1989$.

6. EKBLOM B. Applied physiology of soccer. Sports Med 3: 50-60, 1986.

7. EKBLOM B. A field test for soccer players. Sci Football 1: 13-15, 1989.

8. ESSEN B, HAGENFELDT L, KAIJSER L. Utilization of blood-borne and intramuscular substrates during continuous and intermittent exercise in man. J Physiol (Lond) 265: 489. $506,1977$.

9. HAWLEY JA, PALMER GS, NOAKES TD. Effects of 3 days of carbohydrate supplementation on muscle glycogen content and utilisation during a $1 \mathrm{~h}$ cycling performance. Eur J Appl Physiol 75: 407-4 12,1997 .

10. HOHORST HJ. Method of an enzymatic analysis. In: Method of enzymatic analysis, Bergmeyer HU (ed), New York, USA, Academic Press, 1963, p268.

11. HUBINGER L, MACKINNON LT, BARBER L, MCCOSKER J, HOWARD A, LEPRE F. Acute effects of treadmill running on lipoprotein(a) levels in males and females. Med Sci Sports Exerc 29: 436-442, 1997.

12. HURLEY JF, NEMETH PM, MARTIN III WH, HAGBERG JM, DALSKY GP, HOLLOSZY JO. Muscle triglyceride utilization during exercise: effect of training. $J$ Appl Physiol 60: 562-567, 1986.

13. JACOBS I, WESTLIN N KARLSSON J, RASMUSSON M, HOUGHTON B. MUSCle glycogen and diet in elite soccer players. Eur J Appl Physiol 48: 297-320, 1982.

14. JANSSON E, and KAIISER L. Effect of diet on the utilization of blood-borne and intramuscular substrates during exercise in man. Acta Physiol Scand 115: 19-30, 1982.

15. JANSSON E, and KAJSER L. Substrate utilization and enzymes in skelletal muscle of extremely endurance-trained men. $J$ Appl Physiol 62: 999-1005, 1987.

16. KIENS B, ESSEN-GUSTAVSON B, CHRISTENSEN NJ, SALTIN B, Skeleta】 muscle substrate utilization during submaximal exercise in man; effect of endurance training. of Physiol (Lond) 469: 459-478, 1993.

17. KLAUSEN $K_{\text {, }}$ and SJÖGAARD G. Glycogen stores and lactate accumulation in skeletall muscle of man during intense bicycle exercise. Scand J Sports Sei 2: 7-12,1980.

18. LEATT PB, and JACOBS I. Effects of glucose polymer ingestion on glycogen depletion during a soccer match. Can J Sport Sci 14: 112-116, 1989.

19. MENDEZ J, and KEYS A. Density and composition of mamalian muscle. Metabolism 9: $184-188,1960$. 
20. NORDHEIM K, and VOLLESTAD NK. Glyoogen and lactate metabolism during lowintensity exercise in man. Acta Physio. Scand 139: 475-484, 1990.

21. OHASHI J, TOGARI H, ISOKAWA M, SUZUKI S. Measuring mowement speeds and distances covered during soccer match-play. In: Science and Football. Reilly $T$, Lees A, Dawids K, Murphy WJ (eds) E \& FN Spon, London: 1988, pp. 434-440.

22. RAUCH LH, RODGER I, WILSON GR, BELONIE JD, DENNIS SC, NOAKES TD, HAWLEY JA. The effects of carbohydrate loading on muscle glycogen content and cycling performance. Int ISport Nurr 5: 25-36, 1995.

23. REILLY T, and THOMAS V. A motion analysis of work-rate in different positional roles in professional football match-play. J Human Mov Stud 2: 87-97, 1976.

24. RICO-SANZ J, FRONTERA WR, RIVERA MA, RIVERA-BROWN A, MOLE PA, MEREDITH CN. Effects of hyperbydration on total body water, temperature regulation and performance of elite young soccer players in a warm climate. Int I Sports Med 17 $85-91,1996$.

25. RICO-SANZ J, HAJNAL JV, THOMAS EL MIERISOVA S, ALA-KORPELA M, BELL JD. Intracellular and extracellular triglyceride metabolism during alternating intensity exercise in humansis of Physiol (Lond) 510:615-622, 1998.

26. SALTIN B. Metabolic fundamentals in exercise. Med Sci Sports 5: 137-146, 1973.

27. SALTIN B, BANGSBO J, GRAHAM TE, JOHANSEN L. Metabolism and performance in exhawstive intense exercise, different effects of muscle glycogen availabillity, previous exercise and muscle acidity. Med Sport Sci 34: 87-114, 1992.

28. SALTIN B, and KARLSON J. Muscle glycogen utilization during work of different intensities. In: Muscle metabolism during exercise, Pernow and Saltin B (eds), Plenum Press, New York, 1971, pp. 289-299.

29. SMAROS G. Energy usage during football match. In: Proceedings Ist International Congres on Sponts Medicine Applied to Football. L. Vecchiet (ed), Guanillo D, Rome, $1980, \mathrm{pp} .795-801$.

30. STANDL E, LOTZ N, DEXEL TH, JANKA HU, KOLB HJ. Muscle triglycerides in diabetic subjects. Diabetologia 18: 463-469, 1980.

31. STARLING RD, TRAPPE TA, PARCELL AC, KERR CG, FINK WJ, COSTILL DL. Effects of diet on muscle triglyceride and endurance performance. $J$ Appl Physiol 82: $1185-1189,1997$.

32. TAYLOR R, PRICE TB, ROTHMAN DL, SHULMAN RG, SHULMAN GI. Validation of ${ }^{17} \mathrm{C}$ NMR measurement of human skeletal muscle glycogen by direct biochemical assay of needle biopsy samples. Mag Res Med 27: 13-20, 1992.

33. VANDERBERGHE $K$, HESPEL P, VANDEN EYNDE B, LYSENS R, RICHTER EA No effect of glycogen level on glycogen metabolism during high intensity exercise. Med Scl Sports Exerc 27: 1278-1283, 1995.

34. WENDLING PS, PETERS SJ, HEIGENHAUSER GJF, SPRIET L, Variability of triacylglycerol content in human skeletal muscle biopsy samples. I Appl Physiol 81: $1150-1155,1996$.

35. WITHERS RT, MARICIC Z, WASILEWSKI S, KELLY L. Mateh analysis of Australian professional soccer players. J Human Mow Stud 8: 159-176, 1982. 


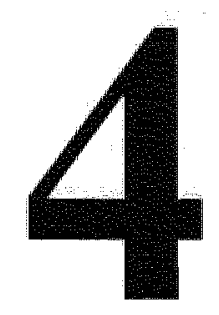

\section{Resynthesis of muscle glycogen after soccer specific performance examined by ${ }^{13} \mathrm{C}$-magnetic resonance spectroscopy in elite players}

${ }^{1}$ Zehnder M, ${ }^{2}$ Rico-Sanz R, ${ }^{3}$ Kühne G, ${ }^{1}$ Boutellier U.

${ }^{\text {E}}$ Exercise Physiology, Institute for Human Movement Sciences, Swiss Federal Institute of Technology Zurich and Institute of Physiology, University of Zurich, CH-8057 Zurich, Switzerland; ${ }^{2}$ Group of Biomedical Applications of Magnetic Resonance, Department of Biochemistry and Molecular Biology, University Autonoma of Barcelona, Spain; ${ }^{3}$ Paul Scherrer Institute, CH-5232 Villigen-PSI, Switzerland.

adapted from: European Journal of Applied Physiology 84: 443-447, 2001. 


\section{ABSTRACT}

Purpose The purpose of this study was to examine with ${ }^{13} \mathrm{C}$-magnetic resonance spectroscopy (MRS) whether muscle glycogen utilized during a simulation of a fatiguing soccer match followed by repeated sprints would be resynthesized during the next $24 \mathrm{~h}$ while players consumed their habitual diet. Methods 12 elite young players (age $=17.5 \pm 0.8$ (SD) years, body weight $(\mathrm{bw})=68.9 \pm 6.6 \mathrm{~kg}$, height $=177.0 \pm 5.4 \mathrm{~cm})$ participated in the study. The glycogen of the calf muscles was measured with ${ }^{13} \mathrm{C}-\mathrm{MRS}$ before and after an alternating velocity test to exhaustion as well as $24 \mathrm{~h}$ later. Subjects recorded their food intake during the experimental time. Results Average muscle glycogen before the soccer match simulation was $134 \pm 16 \mathrm{mmol} \cdot \mathrm{kg}^{-1}$ wet weight (ww) and decreased during the exercise $(\mathrm{p}<0.001)$ to $80 \pm 29 \mathrm{mmol} \cdot \mathrm{kg}^{-1}$ ww. The value increased $(p<0.01)$ to $122 \pm 33 \mathrm{mmol} \cdot \mathrm{kg}^{-1}{ }_{\text {ww }} 24 \mathrm{~h}$ later but this was not significantly different from the value obtained before the soccer specific test. Dietary analysis of the food intake during the $24 \mathrm{~h}$ after the exercise revealed that players consumed $2681 \pm 970 \mathrm{kcal} \cdot$ day $^{-4}$. Daily protein, fat, and carbohydrate (CHO) intake was $85 \pm 29,99 \pm 44$, and $327 \pm 116 \mathrm{~g}$, respectively. The amount of CHO intake corrected for $\mathrm{kg}$ bw was $4.8 \pm 1.8 \mathrm{~g}$. Conclusion The results of this study showed that despite a CHO intake of less than $5 \mathrm{~g} \cdot \mathrm{kg}^{-1}$ bw the habitual diet of soccer players might be sufficient to replenish in $24 \mathrm{~h}$ the muscle glycogen utilized during soccer specific performance. However, cumulative deficits of about $10 \%$ in glycogen replenishment as found in the present study might provoke decrements in performance. Thus, players should pay attention to their habitual diets and add more $\mathrm{CHO}$ to replenish their daily deficits and perhaps increase their basal levels of intake.

Key words carbohydrate, recovery, skeletal muscle 


\section{INTRODUCTION}

Soccer is an endurance sport of varying intensity, which places high metabolic demands on the energy delivery pathways. A few studies using biochemical analysis of muscle biopsies have shown that muscle glycogen utilization during soccer matches is, on average, about $50 \mathrm{mmol} \cdot \mathrm{kg}^{-1}$ wet weigh (ww) $(8,11,22,24)$. The intense daily training and competition of elite players requires that muscle glycogen of the players is replaced from day to day in order to keep a high rate of work during both training and competition. An analysis of the average diet of 88 international senior and junior soccer players revealed that players consumed about $53 \%$ of the energy intake in the form of carbohydrates (CHO) (20), a value which is below the recommendation for soccer players in training and competition (4). Despite the importance of this mutritional issue in soccer nutrition and performance, only two studies have evaluated the diet of players and muscle glycogen resynthesis after a soccer match (11, 13). However, neither of these studies reported measurements of muscle glycogen prior to the match to determine whether the muscle glycogen utilized during the match was resynthesized the day after. In the present study; we examined with ${ }^{13} \mathrm{C}$-magnetic resonance spectroscopy (MRS) whether the habitual CHO intake of elite soccer players was sufficient to restore muscle glycogen utilized during a fatiguing simulation of a soccer match to the levels existing before the test during the following $24 \mathrm{~h}$.

\section{METHODS}

\section{Subjects}

The volunteers for this experiment were 12 elite soccer players (age $=17.5 \pm 0.8$ (SD) years, body weight (bw) $=68.9 \pm 6.6 \mathrm{~kg}$, height $=177.0 \pm 5.4 \mathrm{~cm}$ ) members of teams of the 1st and 2nd division of the Swiss National League. Six of these players were members of the under- 19 Swiss National Team and they competed at international level. The study was approved by the Human Subjects Committee of the University Autonoma of Barcelona. Subjects were informed of the experimental procedures before written informed consent was obtained. The experiments complied with the laws of Switzerland where the study was performed.

\section{Experimental design}

An exhaustive shuttle running test protocol simulating the conditions of a highly intense soccer match, which has been described elsewhere (21), was performed 
immediately after the resting ${ }^{13} \mathrm{C}-\mathrm{MRS}$ measurement. Pre-exercise blood sampling had been taken in a room adjacent to the magnet room. Briefly, subjects warmed-up for 5 min by ruming for 3 min and stretching for 2 min. The shuttle runing velocities during this wamip and the experimental protocoll consisted of $36 \mathrm{~s}$ at $2.5 \mathrm{~m} \cdot \mathrm{s}$ (running) followed by $18 \mathrm{~s}$ at $1.7 \mathrm{~m} \cdot \mathrm{s}^{-1}$ (jogging) and $6 \mathrm{~s}$ at $5 \mathrm{~m} \cdot \mathrm{s}^{-1}$ (sprinting) between two lines $15 \mathrm{~m}$ apart. The sprinting velocity was the maximal velocity, which all players could sustain. Players covered 3 shuttle-laps of $30 \mathrm{~m}$ running, 1 lap of $30 \mathrm{~m}$ jogging, and 1 lap of $30 \mathrm{~m}$ sprinting, summarizing at total distance of $150 \mathrm{~m}$ every min. This was repeated 3 times ( 3 min) during the warm-up before stretching. Immediately thereafter, subjects ran every min altemating the 3 different velocities of running, jogging, and sprinting. Time was monitored by two stop watches. The first watch was used to ascertain that the running and jogging schedule was adhered to, while the second watch was used to monitor the sprinting time. Subjects received feedback every $15 \mathrm{~m}$ and the time was recorded every $30 \mathrm{~m}$ to assess velocity compliance. The test termination criterion was the time when subjects voluntarily reported their exhaustion or when the time in the $30 \mathrm{~m}$ sprints exceeded $7 \mathrm{~s}$. If subjects were able to complete $45 \mathrm{~min}$, a rest pause of $15 \mathrm{~min}$ sitting was taken and the subjects were allowed to drink $500 \mathrm{ml}$ of plain water. Immediately after the end of the test, subjects were repositioned in the magnet for the post-exercise ${ }^{13} \mathrm{C}$-MRS measurement. $24 \mathrm{~h}$ later, subjects came to the laboratory to have their muscle glycogen determined again. Records of their habitual diet were collected by the subjects during this $24 \mathrm{~h}$ period.

\section{${ }^{13}$ C-Magnetic Resonance Spectroscopy}

Subjects" dominant leg was positioned inside a 4.7 Tesla $30 \mathrm{~cm}$ bore spectrometer (Varian, Palo Alto, CA, USA) after taping the lower part of the leg at three Jocations to a nonmagnetic support system, containing the ${ }^{13} \mathrm{C}-\mathrm{MR}$ radiofrequency (RF) surface coil, to prevent leg movement during spectra acquisition. The home-made sturface coil of $10 \mathrm{~cm}$ of diameter was placed under the center of the belly of the call muscle, and it was tuned to $50.31 \mathrm{MHz}$. A small external reference of formic acid for ${ }^{13} \mathrm{C}$ (99\% enriched) was placed in the center of the send-and-receive coil in order to check the sensitivity of the MR experiment. The homogeneity of the static magnetic field was adjusted before each experiment with an automatic shimming procedure using the proton signal from water. Also before each experiment, the surface coil was frequency-tuned and impedancematched with mechanically variable capacitors. Muscle glycogen was determined by natural abundance ${ }^{13} \mathrm{C}$-MRS. The interpulse delay was $150 \mathrm{~ms}$. Saturation of the glyoogen signal was corrected by determining the spin lattice relaxation time (T, ) value in the muscle at 4.7 Tesla. For signal-to-noise improvement, 6000 free 
induction decays were sampled before Fourier transformation. The spectrum was phase and baseline corrected and was then fitted iteratively to Lorentzian shape curves in order to determine the peak areas of the resonance lines of glycogen. Quantification was achieved with a calibration phantom used as a concentration standard. The muscle and the calibration measurements were identical with respect to all measurement parameters and to the load of the RF coil A cylindrical $2 \mathrm{~L}$-bottle was filled with $100 \mathrm{mmol} \cdot \mathrm{L}^{-1}$ of oyster glycogen buffered at a $\mathrm{pH}$ of 7.2 . The solutions' electrical conductivity $\left(\sigma=0.58\right.$ Siemens $\left.\cdot \mathrm{m}^{-1}\right)$ was also adjusted to match that of human muscle tissue at the RF of the ${ }^{13} \mathrm{C}$. As the signal intensity of glycogen depends on the temperature of the solution, the phantom was warmed-up to $37^{\circ} \mathrm{C}$. In order to correct for interindividual coilload differences, a coil-load correction factor was used.

\section{Blood sampling and analysis}

A blood sample from an antecubital vein was taken before and after the exercise to examine levels of plasma insulin. Insulin was determined with a radioimmuno assay method (CIS biointernational, Sur-Yvette, France).

\section{Diet analysis}

Subjects were asked to record the food and drink they consumed during the first $2 \mathrm{~h}$ after the end of the running protocol as well as during the following $22 \mathrm{~h}$ until the MRS measurement $24 \mathrm{~h}$ after the test. Whenever they could not measure the weight of the food consumed, subjects were requested to describe the size (small, medium, large) of items consumed with the aid of pictures of known weight. They also noted which ingredients were used in the preparation of the meals and how the food was prepared (i.e. steamed, fried). Any commercially prepared items were recorded as the weight or volume specified by the manufacturers' llabels. The food records were analyzed by EBIS 2.0 (E+D Partner, Stuttgart, Germany).

\section{Calculations}

In order to compare with published results of other human studies, muscle metabolite concentrations in mmol $\cdot \mathrm{L}^{-1}$ were converted to $\mathrm{mmol} \cdot \mathrm{kg}^{-1}$ ww $\mathrm{using}$ the constant of $1.1 \mathrm{~kg} \cdot \mathrm{L}^{-1}$ of muscle (18).

\section{Statistical analysis}

The values are expressed as means $\pm \mathrm{SD}$ throughout this paper. Repeated measures ANOVA was used to compare the values before, after, and $24 \mathrm{~h}$ after the fatiguing test. A post-hoc Scheffé F-test was used to further analyze any significant difference detected using the ANOVA. The Pearson product-moment 
correlation coefficients were determined and Fisher"s $\mathrm{r}$ to $\mathrm{z} \mathrm{p}$-values were used to test the correlation coefficients for significance. Significance level was chosen at $\mathrm{p}<0.05$.

\section{RESULTS}

\section{Exercise protocol}

The exhaustive shuttle-run test lasted $39 \pm 26 \mathrm{~min}$.

\section{Magnetic resonance}

Average muscle glycogen after the soccer match simulation was $80 \pm 29 \mathrm{mmol} \cdot \mathrm{kg}^{-1}$ ww. Muscle glycogen increased $(\mathrm{p}<0.001)$ to $122 \pm 33$ $\mathrm{mmol} \cdot \mathrm{kg}^{-1}$ w $24 \mathrm{~h}$ later, which was not significantly different from the values before the soccer match simulation $\left(134 \pm 16 \mathrm{mmol} \cdot \mathrm{kg}^{-1}\right.$ ww). Figure 1 shows the muscle glycogen in a typical ${ }^{13} \mathrm{C}$-MRS spectrum before, immediately after the fatigue test, and 24 h later.

Figure 1. Typical resting glycogen region of the ${ }^{13} \mathrm{C}-\mathrm{MR}$ spectrum of an elite soccer player before (A), after a saccer specific performance (B), and $24 \mathrm{~h}$ after the exercise (C)

A

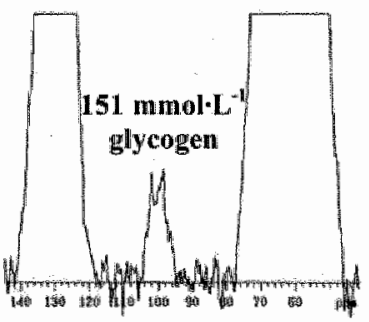

B

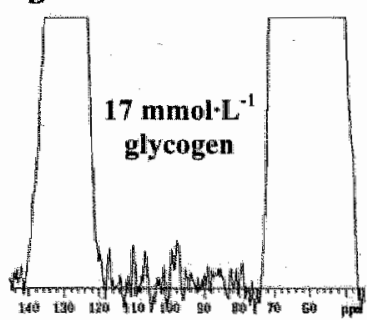

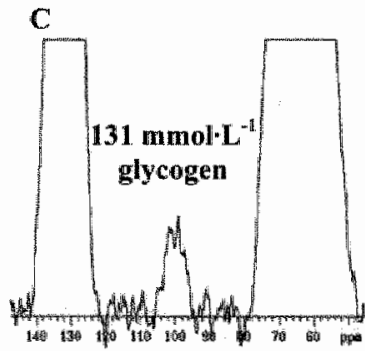

Mainly carbons from polyunsaturated and unsaturated fatty acids $(140-120 \mathrm{ppm}), \mathrm{Cl}$ of glycogen (104-98 ppm), mainly carbons of glycerol and C2 - C6 of glycogen (78-50 ppm)

Muscle glycogen resynthesized was related to the post-exercise muscle glycogen $(y=-0.57 x+86.77, r=0.57, p=0.05)$ and the muscle glycogen utilized during the exercise (Figure 2, $p<0.01$ ). From the linear regression equation of Figure 2 , the fractional glycogen resynthesis can be calculated by dividing both sides by $x$. A glycogen resynthesis of $100 \%(y / x=1)$ was theoretically obtained after $28.35 \mathrm{mmol} \cdot \mathrm{kg}^{4}$ anw glycogen had been used $(\mathrm{x}=13.89 / 0.49)$. 
Figure 2. Significant correlation $(y=0.51 \mathrm{x}+13.89, \mathrm{r}=0.75)$ between the anount of glyeogen utilized in $m$. gastrocnemius of 12 elite soccer players during the penfomance of the soced specific exercise and the amount of glycogen resynthesized 24 h after the test

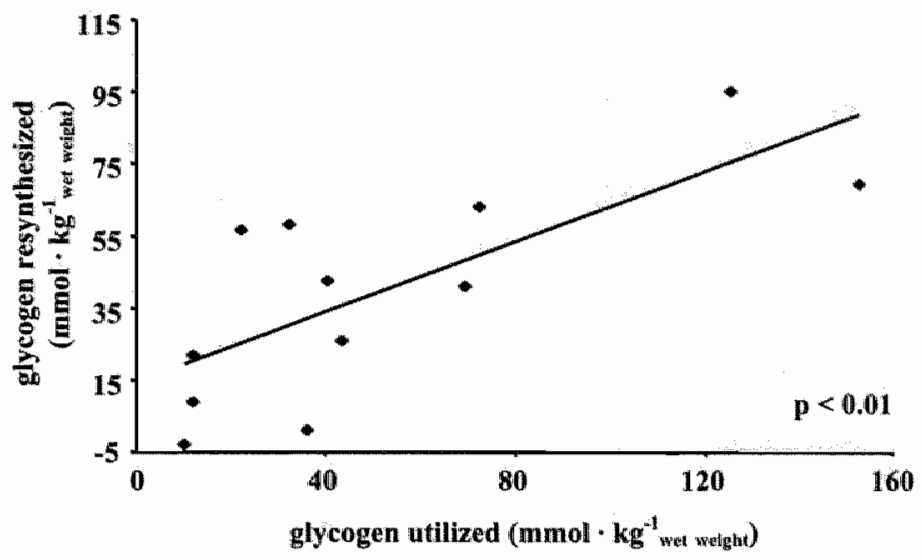

\section{Blood analysis}

Plasma insulin concentration was $12.2 \pm 3.9 \mu$ units $\mathrm{mL}^{-1}$ before the exercise protocol and $11.8 \pm 5.5 \mu$ units $\cdot \mathrm{mL}^{-1}$ after the running.

\section{Diet analyses}

Dietary analysis of the food intake of the individual players during the first $2 \mathrm{~h}$ of recovery showed that players consumed $811 \pm 269 \mathrm{kcal}$. Mean protein, fat, and CHO intake was $27 \pm 23,32 \pm 19$, and $104 \pm 19 \mathrm{~g}$, respectively. For the entire $24 \mathrm{~h}$ recovery period, the players consumed a mean of $2681 \pm 970 \mathrm{kcal} \cdot \mathrm{day}^{-1}$. Average daily protein, fat, and $\mathrm{CHO}$ intake was $85 \pm 29,99 \pm 44$, and $327 \pm 116 \mathrm{~g}$, respectively, or $12.7,32.2$, and $49.8 \%$ of the energy intake, respectively. The remaining $5.3 \%$ were dietary fibers. The amount of protein, fat, and $\mathrm{CHO}$ intake expressed in terms of $\mathrm{kg} \mathrm{bw}$ was $1.2 \pm 0.5,1.5 \pm 0.7$, and $4.8 \pm 1.8 \mathrm{~g}$, respectively. There was no relationship between muscle glycogen resynthesized and the amount of $\mathrm{CHO}$ ingested during the $24 \mathrm{~h}$ post-exercise $(y=3.50 x+24.17 ; r=0.20)$.

\section{DISCUSSION}

The purpose of this study was to evaluate whether with a habitual diet muscle glycogen of soccer players could recover within $24 \mathrm{~h}$ after a soccer specific performance. The results showed that muscle glycogen $24 \mathrm{~h}$ after the fatiguing 
exercise was not significantly different from pretest values. However, cumulative daily deficts of about $10 \%$ in glycogen replenishment might provoke decrements in performance after some days of intensive training or competition (5).

Previous to this study, two other studies had evaluated the resynthesis of muscle glycogen in elite soccer players using biochemical analysis of muscle biopsies (11, 13). As Taylor et al. (25) have shown the results from assessing glycogen obtained by MRS are in the same range as the results from using biopsies. In the first report, the small amount of muscle glycogen resynthesized was attributed to the low CHO content of the habitual diet of the players (11). However, analysis of the diet revealed that players consumed $596 \mathrm{~g}$ of $\mathrm{CHO}_{4}$, which is the largest amount of $\mathrm{CHO}$ intake reported in soccer players. Furthermore, we computed the average intake expressed in terms of bw for the Swedish players of the study of Jacobs et al. (11). We calculated that they ingested, on average, $8.1 \mathrm{~g} \mathrm{CHO} \cdot \mathrm{kg}^{-1}$ bw, which is within the ranges given $\left(8-10 \mathrm{~g} \cdot \mathrm{kg}^{-1}\right.$ bw) to achieve optimal muscle glycogen storage (3). On the other hand, despite our players having a significantly lower CHO intake $\left(327 \mathrm{~g}\right.$ or $\left.4.8 \mathrm{~g} \cdot \mathrm{kg}^{-1} \mathrm{bw}\right)$, they resynthesized almost twice the amount of muscle glycogen resynthesized by the Swedish players. The CHO intake of the players in the present study was sufficient to replenish most of the glycogen utilized during the fatiguing exercise, which simulated the physical demands of an intense soccer match.

Thus, it appears that the amount of $\mathrm{CHO}$ in the diet might not be the only factor in muscle glycogen resynthesis in soccer players. In agreement with this argument are the results of Leatt and Jacobs (13) who showed that the muscle glycogen resynthesized in soccer players during $19 \mathrm{~h}$ after a match was similar whether players ingested 536 or $397 \mathrm{~g}$ of $\mathrm{CHO}$. Costill and Miller (5) demonstrated that muscle glycogen can be still below resting levels, even when subjects ingest up to $70 \% \mathrm{CHO}$ in their diet during $22 \mathrm{~h}$ after $2 \mathrm{~h}$ of training, which reduced muscle glycogen levels by about $50 \%$. Thus, the results of Leatt and Jacobs (13), Costill and Miller (5), and those of the present study indicate that, in addition to a high CHO intake, other factors must influence glyeogen resynthesis.

One possible factor affecting the glycogen resynthesis is the timing of the $\mathrm{CHO}$ ingestion. It is known that glycogen resynthesis is highest during the first $2 \mathrm{~h}$ after exencise (23). Therefore, it is recommended to ingest $100 \mathrm{~g}$ of CHO during the first $2 \mathrm{~h}$ after exercise (6). The analyses of the uniestricted food intake showed that the subjects in this study consumed an average of $104 \mathrm{~g}$ of CHO in the first $2 \mathrm{~h}$. Another important factor for the resynthesis of glycogen is the 
glycemic index. Glucose polymers and starch, historically described as complex $\mathrm{CHO}$, can be absorbed by the gut very quickly if they have a high glycemic index. As our subjects ingested predominantly food such as sugared beverages, cookies, and other $\mathrm{CHO}$ with high glycemic indexes during the first $2 \mathrm{~h}$, most of the $104 \mathrm{~g} \mathrm{CHO}$ ingested in the first $2 \mathrm{~h}$ might have been absorbed quickly. In addition, CHO with a high glycemic index leads to higher muscle glycogen content after $24 \mathrm{~h}$ compared to the same CHO intake but with a lower glycemic index (2). Thus, despite the rather low $24 \mathrm{~h} \mathrm{CHO}$ intake in the present study, part of the high glycogen resynthesis can be explained by an optimal timing and composition of the $\mathrm{CHO}$ intake.

Another critical factor in the amount of glycogen resynthesized after exercise appears to be the concentration of glycogen itself. Muscle glycogen synthesis is regulated by glycogen synthetase (GS) (14). The percentage of active GS increases when glycogen content is low (19). Zachwieja et al. (26) showed a greater GS activity and glycogen resynthesis after large glycogen depletion compared to small glycogen depletion. In the present study, when we subtracted the glycogen $24 \mathrm{~h}$ after the soccer specific running session from the values immediately after the exercise, the resulting value correlated $(p=0.05)$ with the glycogen after the fatigue test. The variance of the correlation was about 0.3 . This means that $30 \%$ of the variance can be explained by this correlation. Also, the amount of muscle glycogen resynthesized correlated $(\mathrm{p}<0.01)$ with the muscle glycogen utilized during the soccer specific fatigue test, in agreement with the data from Zachwieja et al. (26). Thus, it is possible that those soccer players experiencing larger glycogen resynthesis had larger activity of GS. An additional aspect of our study was the fact that 4 players could refill their glycogen stores within $24 \mathrm{~h}$ because they used less than $28.35 \mathrm{mmol} \cdot \mathrm{kg}^{-1}$ wor glycogen. As muscle glycogen usage exceeded $28.35 \mathrm{mmol} \cdot \mathrm{kg}^{-1}{ }_{\mathrm{ww}}$ in 8 players, a complete muscle glycogen resynthesis would have required more than $24 \mathrm{~h}$ with these players habitual diet. Another possibility would be to add $\mathrm{CHO}$ to the players" habitual diet to reduce the time needed for a complete muscle glycogen resynthesis.

Jacobs et al. (11) and Leatt and Jacobs (13) also observed a correlation between muscle glycogen post-exercise and muscle glycogen resynthesis but they concluded that the resynthesis seemed slow. The authors attributed the slow resynthesis to the relatively high muscle glycogen content post-exercise and to the effect that muscle glycogen has on insulin sensitivity which is affected by the intensity and duration of the exercise. In the present study, the insulin concentrations immediately after the soccer match simulation were the same as before the exercise. The time to exhaustion was, on average, less than $45 \mathrm{~min}$, 
which is half time of a soccer match. In agreement with our findings, Bangsbo (1) found no change in insulin concentration during the first half of a soccer match. The glycogen resynthesis stimulation of glucose transport by insulin is related to the expression of the glucose transporter (GLUT-4) in humans $(7,12$, 17) whose content is also increased by just $7-10$ days of training $(9,10)$ and has been correlated with oxidative capacity $(15,16)$. The training regimen of the players of the present study consisted of 3 to 5 sessions of about 90 min duration every week with a competitive match on the weekend for the previous 2 months. In addition, they were involved in training and competition for 10 months for at least 2 years. Therefore, it is likely that they all had a considerable aerobic capacity. However, individual differences, which probably exist in the aerobic capacity of soccer players, are primarily determined by genetic factors. Since they followed similar training regimens, it is possible that the soccer players with higher oxidative capacities had also larger glycogen resynthesis capacities. In support of this are the facts that we found that those players who run longer during the soccer match simulation had higher glycogen utilization during the exercise (21) and higher glycogen resynthesis after the test. It is possible then that small differences in oxidative capacity might have determined the expression of GLUT -4 and the glycogen resynthesis in the subjects of the present study.

\section{CONCLUSION}

The results of this study showed that although the CHO intake was less than $5 \mathrm{~g} \cdot \mathrm{kg}^{-1}$ bw the habitual diet of soccer players might be sufficient to replenish the muscle glycogen utilized during soccer specific performance in $24 \mathrm{~h}$. However, cumulative deficits of about $10 \%$ in glycogen replenishment as found in the present study might provoke decrements in performance. Thus, players should pay attention to their habitual diet and add more CHO to replenish any daily deficits and perhaps increase their basal levels of intake.

\section{ACKNOWLEDGEMENT}

This study was partly supported by CICYT project SAF96-0147 and Laboratorios Rubió, Barcelona, Spain, as well as by Wander, Berne, Switzerland. The authors would like to thank Micha Dambach and Mirjam Mülli for their experimental assistance, Reto Buchli for technical assistance, and the coaches and players from FC Aarau and FC Baden for their collaboration during the course of the study. 


\section{REFERENCES}

1. BANGSBO J. The physiology of soccer - with special reference to intense intermittent exercise. Acta Physiol Scand Suppl 619, 1994.

2. BURKE LM, COLLIER GR, BEASKEY SK, DAVIS PG, FRICKER PA, HEELEY P, WALDER $K$, HARGREAVES $M$. Effect of coingestion of fat and protein with carbohydrate feedings on muscle glycogen storage. J Appl Plywiol 78:2187-2192, 1995 .

3. BURKE LM, COLLIER GR, HARGREAVES M. Muscle glycogen storage after prolonged exercise: effect of the glycenic index of carbohydrate feedings. IAspl Physiol 75: 1019-1023, 1993.

4. CLARK K. Nutritional guidance to soccer players for training and competition. J Sports Sci 12: S43-S50, 1994.

5. COSTILL DL, AND MILLER JM. Nutrition for endurance sport: carbohydrate and fluid balance. Int I Sports Med 1: 2-14, 1980.

6. COYLE EF. Timing and method of increased carbohydrate intake to cope with heavy training, competition and recovery. In: Williams $\mathrm{C}$, Devlin JT (eds) Food, nutrition and sports performance. E \& FN Spon, London, pp 35-63, 1992.

7. EBELING P, BOUREY R, KORANYI L, TOUMINEN IA, GROOP LC, HENRIKSSON J, MUECKLER M, SOVIJARVI A, KOIVITSO VA. Mechanism of enhanced insulin sensitivity in athletes. Increased blood flow, muscle glucose transport protein (GLUT-4) concentration and gly cogen synthase activity. $J$ Clin Invest 92: 1623-1631, 1993.

8. EKBLOM B. Applied physiology of soccer. Sports Med 3: 50-60, 1986.

9. GULVE EA, SPINA RI. Effect of 7-10 days of cycle ergometer exercise on skeletal muscle GLUT-4 protein content. $J$ App/ Physial 79: 1562-1566, 1995.

10. HOUMARD JA, HICKEY MS, TYNDALL GL, GAVIGAN KE, DOHM GL. Seven days of exercise increase GLUT-4 protein content in human skeletal muscle. $J$ Appl Physiol 79: 1936-1938, 1995.

11. JACOBS 』, WESTLIN $\mathbb{N}$, KARLSSON J, RASMUSSON M, HOUGHTON B. MUIScle glycogen and diet in elite soccer players. Eur J Appl Physiol 48: 297-302, 1.982.

12. KORANYI LI, BOUREY RE, VOURINEN-MARKKOLA $H$, KOIVITSO VA, MUECKLER M, P'ERMUTT MA, YKI-JARVINEN H. Level of skeletal muscle glucose transporter protein correlates with whole bodly glucose disposal in man. Diabetologia 34: $763-765,1991$.

13. LEATT PB, AND JACOBS 1. Effects of glucose polymer ingestion on muscle glyeogen utilization during a soccer match. In: Reilly T, Lees A, Dawids K, Murphy WJ (eds) Science and Footballl. E\& FN Spon, London, pp 42-47, 1988.

14. LELOIR LF, OLAVARRIA JM, GODEMBERG SH, CARMINATTI H. Biosynthesis of glycogen from uridine diphosphate glucose. Arch Blochem Biophys 81: 508-520, 1959.

15. MCCONNELL G, MCCOY M, PROIETTO J, HARGREAVES M Skeletal muscle GLUT-4 and glucose uptake during exercise in humans. I Appl Physiof 77: 1565-1568, 1994.

16. MCCOY M, PROIETTO J, HARGREAVES M. Effect of detraining on GLUT-4 protein in human skeletal muscle. $J$ Appl Physiol 77; 1532-1536, 1994.

17. McCOY M, PROIETTO J, HARGREAVES M. Skeletal muscle GLUT-4 and postexercise muscle glycogen storage. J Appl Physiol 80: 411-415, 1996. 
18. MENDEZ $J_{9}$ AND KEYS A. Density and composition of mamalian muscle Metabolism 9: 184-188, 1960 .

19. PIEHL $K$, ADOLFSSON $\$$, NAZAR $K$. Glycogen storage and glycogen synthetase activity in trained and untrained muscle of man. Acta Physiol Scand 90: 779-788, 1974.

20. RICO-SANZ J. Body composition and mutritional assessments in soccer. Int I Sport Nutr 8: $113-123,1998$.

21. RICOSSANZ J ZEHNDER M, DAMBACH M, BUCHLI R, KÜHNE G, BOUTELLIER U. Muscle glycogen degradation during sirmulation of a fatiguing soccer match in elite soccer players examined by ${ }^{13}$ C-MRS. Med Sci Sports Exerc 31: 1587-1593, 1999.

22. SALTIN B. Metabolic fundamentals in exercise. Med Sci Sports 5: 137-146, 1973.

23. SHERMAN WM. Recowery from endurance exercise. Med Sci Sports Exerc 24 (Suppl): \$336-\$339, 1992 .

24. SMAROS $\mathrm{G}$. Energy usage during football match. In: Vecchiet $\mathrm{L}$ (ed) Proceedings Ist International Congres on Sports Medicine Applied to Football. Guanello D, Rome, pp $795-801,1980$.

25. TAYLOR R, PRICE TB, KATZ LD, SHULMAN RG, SHULMAN GI. Validation of ${ }^{13} \mathrm{C}$ NMR measurement of human skeletal musele glycogen by direct biochemical assay of needle biopsy samples. Magn Reson Med 27: 13-20, 1992.

26. ZACHWIEJA JJ, COSTILL DL, PASCOE DD, ROBERGS RA, FINK WJ. Influence of muscle glycogen depletion on the rate of resynthesis. Med Sci Sports Exerc 23: 44-48, 1991. 


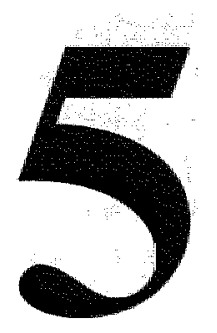

\section{Further glycogen decrease during early recovery after eccentric exercise despite a high carbo- hydrate intake}

${ }^{1}$ Zehnder M, ${ }^{1}$ Muelli M, ${ }^{1}$ Buchli R, ${ }^{2}$ Kuehne G, ${ }^{1}$ Boutellier U.

${ }^{1}$ Exercise Physiology, Institute for Human Movement Sciences, Swiss Federall Institute of Technology Zurich, and Institute of Physiology, University of Zurich, CH-8057 Zurich, Switzerland; 2Paul Scherrer Institute, CH-5232 Villigen-PSI, Switzerland.

adapted from: European Journal of Nutrition 43: 148-159, 2004. 


\section{ABSTRACT}

Delayed onset muscle soreness (DOMS) is a well-known phenomena of athletes. It has been reported from muscle biopsies that the rate of muscle glycogen resynthesis is reduced after eccentric compared to concentric exercise. Purpose Try to compensate by a carbohydrate (CHO)-rich diet the decelerated glycogen resynthesis after eccentric exercise, measured by magnetic resonance spectroscopy. Methods Glycogen, phosphocreatine ( $\mathrm{PCr}$ ), adenosine triphosphate, and inorganic phosphate ( $\mathrm{Pi}$ ) were measured in the human calf muscle. 20 athletes divided into two groups (DOMS and CONTROL), reduced glycogen in $m$. gastrocnemius during two different running protocols. Additionally, 12 DOMS subjects performed an eccentric exercise while the CONTROL group rested. Subsequently, subjects consumed a $\mathrm{CHO}$-rich diet $\left(>10 \mathrm{~g} \cdot \mathrm{kg}^{-1}\right.$ body weight $\left.\cdot 24 \mathrm{~h}^{-1}\right)$. Results In both groups, glycogen has been reduced by about $50 \%$. The first $2 \mathrm{~h}$ after exercise, glycogen concentration dropped further $\left(-15.6 \pm 15.7 \mathrm{mmol} \cdot \mathrm{kg}^{-1}\right.$ wet weight (ww) $)$ in the DOMS but rose by $\left(+18.4 \pm 20.8 \mathrm{mmol} \cdot \mathrm{kg}^{-1}\right.$ ww $)$ in the CONTROL group $(\mathrm{p}<0.001)$. CONTROL subjects reached resting glycogen within $24 \mathrm{~h}\left(137 \pm 47 \mathrm{mmol} \cdot \mathrm{kg}^{-1}\right.$ ww $)$, while DOMS subjects needed more than one day $\left(91 \pm 23 \mathrm{mmol} \cdot \mathrm{kg}^{-1}\right.$ ww; $\left.;<0.001\right)$. Pi and $\mathrm{Pi} / \mathrm{PCr}$, indicators of muscle injury, rose significantly in the DOMS but not in the CONTROL group. Conclusion The diet rich in CHO's was not able to refill glycogen stores after eccentric exercise. Glycogen decreased even further during the beginning of recovery. This loss, which to our knowledge has not been measured before is probably the consequence of muscle cell damage and their reparation.

Key words magnetic resonance spectroscopy, muscle injury, inorganic phosphate, delayed onset of muscle soreness 


\section{INTRODUCTION}

Delayed onset muscle soreness (DOMS) is caused by exercise of unaccustomed vigor or intensity, especially by exercise involving eccentric contractions (28). Manifestations of DOMS are muscle damage including inflammation, loss in muscle strength and range of motion, swelling release of muscle proteins in the blood, and decrement in motor control (10). In addition, it has been reported from muscle biopsies that the rate of muscle glycogen resynthesis is reduced after eccentric compared to concentric exercise (26).

In our study, we were interested in finding out, if a carbohydrate (CHO) rich diet is able to compensate for the delayed glycogen resynthesis after eccentric exercise. So far, subjects were only investigated through muscle biopsies and received less than $8.5 \mathrm{~g} \mathrm{CHO} \cdot \mathrm{kg}^{-1}$ body weight (bw) $24 \mathrm{~h}^{-1}$ during recovery in studies showing a delayed glycogen resynthesis after eccentric muscle contractions $(3,15,17,35,36,50)$. This lack of sufficient $\mathrm{CHO}$ in the diet could explain a part of the delayed glycogen resynthesis after eccentric exercise because it was shown that $10 \mathrm{~g} \mathrm{CHO} \cdot \mathrm{kg}^{-1} \mathrm{bw} \cdot 24 \mathrm{~h}^{-1}$ are necessary for a complete replenishment of glycogen stores within $24 \mathrm{~h}$ after glycogen-depleting concentric exercise $(7,25,40,44,46)$.

As mentioned before, glycogen resynthesis studies have mainly been conducted by the method of muscle biopsies, which have a damaging effect on muscles. Therefore, the number of measurements is limited and it is not possible to closely follow the time course of the glycogen resynthesis with this method. Furthermore, it is impossible to investigate the same muscle specimen several times because muscle biopsy sampling induces focal damage (trauma) which is not completely repaired after two weeks, and also retards the rate of glycogen resynthesis $(13,14,49)$, i.e. it would interfere with the aim of our study. Finally, the major muscle damage from eccentric exercise occurs in the deepest extensor muscles and may only affect a small percentage of the fibers. It would be relatively easy to miss these sites of injury in biopsy samples from human muscles (2). The non-invasive method of ${ }^{13} \mathrm{C}$-magnetic resonance spectroscopy (MRS), which we have applied in our study can use an adequate diameter of the surface coil for complete measurements of fibers, which are located in some distance from the body surface and part of the analysis. This method also allows as many measurements from the same muscle specimen as it is necessary to follow the time course of glycogen resynthesis after glycogen reducing exercise.

Eccentric exercise followed by DOMS does not only delay glycogen resynthesis but it also affects phosphate variables. Phosphocreatine ( $\mathrm{PCr}$ ), adenosine 
triphosphate (ATP), and inorganic phosphate (Pi) are destabilized after muscle fiber injuries which occur after eccentric exercise (43). The increase in the resting $\mathrm{P} / \mathrm{PCr}$ ratio in muscles, indicating a structurall and cellular damage, reaches its peak 1 to 2 days after an exercise induced injury as analysis with ${ }^{34} \mathrm{P}$ MRS have shown $(31,32,41,42)$. The $\mathrm{P} / \mathrm{PCr}$ ratio inversely reflects the oxidative capacity of the mitochondria, which is decreased after muscle damage. In addition, a decreased metabolic efficiency of ATP may occur after eccentric contractions in human muscle (43).

The aim of our study was 1) to induce muscle soreness by eccentric exercise, 2) to investigate with ${ }^{13} \mathrm{C}$-MRS if a $\mathrm{CHO}$-rich diet can reduce a delayed glycogen resynthesis during DOMS, and 3) to measure with ${ }^{3 /} \mathrm{P}$-MRS phosphate variables, which possibly emerge as disturbing factors for glycogen resynthesis.

\section{METHODS}

\section{Subjects}

20 well-trained, non-smoking men volunteered to participate in the study. The risks and benefits were explained, and written informed consent was obtained from each subject. All subjects were instructed to refrain from exercise and to follow the nutritional guidelines during the course of the study starting $48 \mathrm{~h}$ before the glycogen reducing protocol (see below) and lasting until the last MRS measurement $48 \mathrm{~h}$ after exercise. The University of Zurich Ethic's Committee of Physiology and Pharmacology approved the experimental protocol. The subjects were randomly assigned to one of the two groups. (DOMS 1.2 subjects, CONTROL 8 subjects). The awerage ( \pm SD) age, height, and bw in the DOMS group were $34( \pm 9)$ years, $179.4( \pm 5.4) \mathrm{cm}$, and $71.0( \pm 6.2) \mathrm{kg}$ and in the

CONTROL group $37( \pm 11)$ years, $178.9( \pm 5.0) \mathrm{cm}$ and $73.4( \pm 3.8) \mathrm{kg}$, respectively. None of the parameters showed any difference between the two groups.

\section{Experimental design}

At least one week before the experiment, each subject performed a Conconi test (12) on a treadmill (H-P-Cosmos, Nussdorf-Traustein, Germany). Depending on the training status, the subject started running with a velocity of 9 or $10 \mathrm{~km} \cdot \mathrm{h}^{-1}$. Every $200 \mathrm{~m}$, the velocity increased by $0.5 \mathrm{~km} \cdot \mathrm{h}^{-1}$ untill the subject was exhausted. To supervise the cardiac frequency, each subject was equipped with a heart rate monitor (Polar Electro, Kempele, Finland). From the individual maximal velocity, we calculated the $65 \%$ velocity. 
On the test day, the subjects ingested a $\mathrm{CHO}$-rich breakfast and consumed their lunch $\left(7 \mathrm{~g} \mathrm{CHO} \cdot \mathrm{kg} \mathrm{bw}^{-1}\right)$, including $0.5 \mathrm{~L}$ of an isotonic drink, at least $1.5 \mathrm{~h}$ before their arrival in the laboratory at $1.30 \mathrm{p} . \mathrm{m}$. "To reduce glycogen stores in the fast twitch fibers, each subject performed several bouts of sprints. Each bout corresponded to 6 sprints of $15 \mathrm{~m}$ length. As soon as a subject was more than $10 \%$ below his maximal sprint velocity, the sprints were stopped. The $65 \%$ velocity of the Conconi test was then used for a $\mathbb{1}$ h tread-mill run, in order to reduce the glycogen stores in the slow twitch fibers of the calf muscles. After these glycogen-reducing protocols, 12 subjects (DOMS group) performed a single-leg toe-raise exercise to induce muscle soreness. Standing in an erect position with fully extended knees and with the forefoot on a board $7 \mathrm{~cm}$ thick, the subject lifted and lowered his body by plantar and dorsi flexion of the ankle joint. Each subject completed 10 bouts of $20 \mathrm{~s}$ toe-raise exercise $\left(1 \cdot \mathrm{s}^{4}\right)$ followed by $40 \mathrm{~s}$ of rest. To increase the intensity of this exercise, each subject had to lift $+25 \%$ of his body mass in form of dumb-bells around the hips. Instead of the eccentric exercise, the CONTROL group rested for the same amount of time.

\section{Magnetic resonance spectroscopy}

A 4.7 Tesla $30 \mathrm{~cm}$-bore spectrometer (Varian, Palo Alto, CA, USA) and a standard Varian spectral processing software were used for the in vivo MRS measurements. Two concentrical, radiofrequency (RF) surface coils in $6 \mathrm{~cm}$ of diameter for ${ }^{3.1} \mathrm{P}$ and of $10 \mathrm{~cm}$ in diameter for ${ }^{13} \mathrm{C}$ were used to transmit and receive the signals. Both coils were placed under the center of the right calf muscle ( $m$. gastrocnemius and $m$. soleus) of each subject and were frequencytuned to $80.98 \mathrm{MHz}$ for the ${ }^{31} \mathrm{P}$ - and to $50.31 \mathrm{MHz}$ for the ${ }^{13} \mathrm{C}-\mathrm{MRS}$ measurements. To assure the same coil position in the subjects for each measurement, a fit for the right calf and heel was constructed. Additionally, waterproof marks on the skin provided an exact repositioning until the end of the experiment. A sticky tape tagged each subject's leg to the fit to inhibit any movement.

Small external reference samples of phenylphosphoric acid for " $P$ and of formic acid for ${ }^{13} \mathrm{C}$ were placed in the center of the two concentrical coils. First, they had to control the stability of the RF signal and of its amplification during the whole experiment. Second, they optimized the RF pulse power in order to achieve a precise $180^{\circ}$ flip angle in the center of the RF coil. This $180^{\circ}$ pulse guaranteed that the main signal was collected from the deeper part of $\mathrm{m}$. gastrocnemius and not the one adjacent to the coil. Before each measurement, the homogeneity of the static magnetic field was adjusted with an automatic 
shimining procedure $\left(x, y, z, x^{2}, y^{2}, z^{2}\right.$, and $\left.x^{2}-y^{2}\right)$ using proton signals from water.

${ }^{13}$ C-spectra acquisition Glycogen concentration was measured in the calf muscle before (Pre exercise) and 0 (Post exercise for the DOMS, Post resting for the CONTROL group), $2,15,24$, and $48 \mathrm{~h}$ after exercise by ${ }^{13} \mathrm{C}$-MRS (Figure 1 ). The interpulse delay (repetition time $=\mathrm{Tr}$ ) was $0.15 \mathrm{~s}$ and the partial saturation of the glycogen signal was corrected by determining its relaxation time (T1) in the calf muscle at 4.7 Tesla. For a better signal-to-noise ratio (S/N), 6000 free induction decays were sampled before Fourier transformation. The spectra were collected using a simple pulse-acquire sequence.

Figure 1. Natural abundance, undecoupled ${ }^{13} \mathrm{C}$-MR spectrum of the $m$. gastrocnemius and $m$. soleus of a subject before exercise

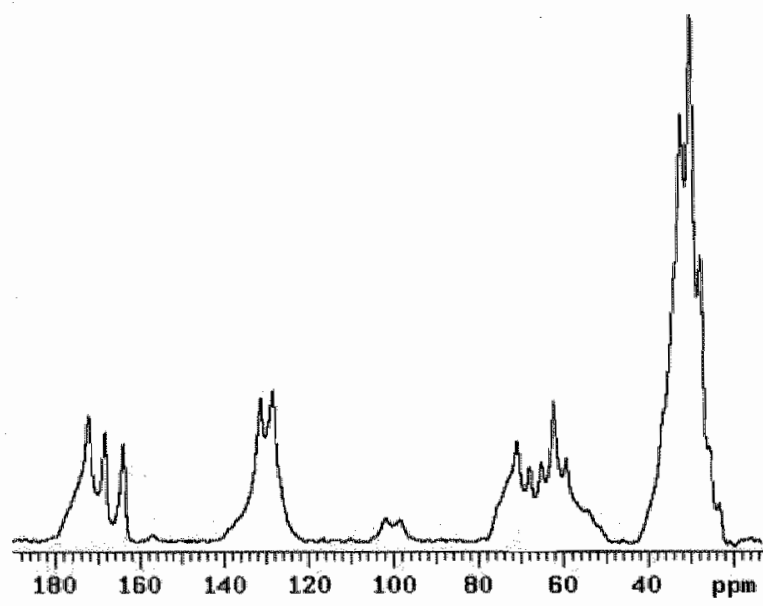

Carboxylgroups from fatty acids \& extemal standard (180-160 ppm), creatine (157 ppm); carbons from polyunsaturated \& saturated free fatty acids (140-1120 ppm), $\mathrm{Cl}$ of glycogen (10498 pprn), carbons of glycerol \& $\mathrm{C} 2-\mathrm{C} 6$ of glycogen ( $50-78 \mathrm{ppm})$, carbons of saturated free fatty acids $(40-20 \mathrm{ppm})$

"P-spectra acquisition $\mathrm{PCr}, \mathrm{ATP}$, and Pi concentrations were determined after the glycogen measurements by ${ }^{31}$ P-MRS (Figure 2). The interpulse delay Tr was $4 \mathrm{~s}$. The T1 values of the muscle metabolites were obtained in four subjects to correct the partial saturation effect. In order to increase $\mathrm{S} / \mathrm{N}, 100$ free induction decays were sampled, phased, and baseline corrected. 
Figure 2. Typical resting ${ }^{31}$ P-MR spectrum of the m. gastrochemas and $m$ solkess of a subject

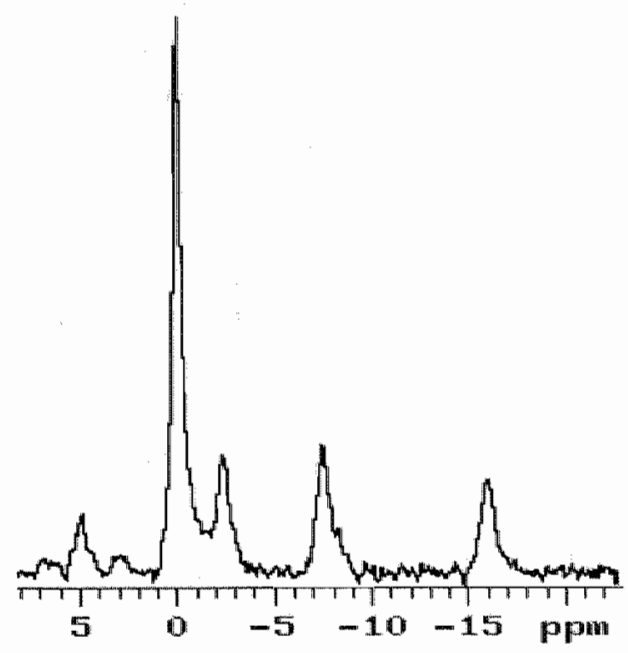

Phosphomonoester (PME, 6.5 ppm), inorganic phosphate (Pi, $5 \mathrm{ppm}$ ), phosphodiesters (PDE, $3 \mathrm{ppm})$, phosphocreatine $(\mathrm{PCr}, 0 \mathrm{ppm})$ and the three different adenosine triphosphates $(\alpha-, \beta-, \gamma-$ ATP, -2.5 to $-16 \mathrm{ppm}$ )

Processing of the ${ }^{13} \mathrm{C}$ - and ${ }^{31} \mathrm{P}$ - spectra and fitting of the peaks At the end of each measurement, the spectra were phased, baseline corrected and finally fitted in order to determine the peak areas of the resonance lines of the investigated metabolites. In order to avoid severe systematic errors due to baseline distortion and peak overlapping, integration is not valid. Therefore we fitted our data in the time as well as in the frequency domain. The time domain fitting was performed with an iterative least-squares method. Exponentially decreasing model signals were fitted to the experimental signals. These model signals were converted into Lorentzian lines by Fourier transformation. Iteration was started with a list of model signals, one signal for each in-vivo resonance. The first two milliseconds of the experimental signal were omitted for fitting in order to avoid the strong but fast dephasing signal of the almost immobile membrane molecules.

Quantification of the glycogen and phosphate peaks ${ }^{13} \mathrm{C}$-quantification was achieved with a calibration phantom used as a concentration standard. A cylindrical $2 \mathrm{~L}$ bottle was filled with a solution of $100 \mathrm{mmol} \cdot \mathrm{L}^{-1}$ of oyster glycogen buffered to.a $\mathrm{pH}$ of 7.2 and supplemented with sodium acid to impair bacterial influence. The natural abundance of ${ }^{13} \mathrm{C}$ was identical in the oyster 
glycogen and the in-vivo muscle glycogen. As the signal intensity of partially relaxed glycogen depends on the temperature of the solution, the glycogen phantom was warmed up to $37^{\circ} \mathrm{C}$. The in-vivo (muscle glycogen) and in-vitro (phantom oyster glycogen) measurements were identical with respect to all measurement parameters, to the area investigated in the tissue respectively phantom, and to the load of the RF-coil. The coil load for the calibration measurement was adjusted to match the one of the muscle examination in the following way: After the in-vivo measurement, the matching capacity of the RFcoil was left unchanged. In contrast, the coil load of the calibration measurement was successively increased with a small saline bottle, which was gradually brought closer to the phantom-loaded RF-coil until identical matching was achieved. The electrical conductivity of the phantom solution was improved by adding $\mathrm{NaCl}\left(\sigma=0.65\right.$ Siemens $\left.{ }^{*} \mathrm{~m}^{-1}\right)$ and was slightly kept below the one of human tissue $\left(\sigma=0.69\right.$ Siemens $\left.\cdot \mathrm{m}^{-1}\right)$ in order to allow the described fine adjustment of the coil load with the small saline bottle.

In a pilot study, the accuracy and reproducibility of the glycogen quantification with and without proton decoupling was examined. The calibration strategy using an external phantom was significantly more accurate if proton decoupling was not applied. The reason therefore is probably the heat deposition pattern, which develops during decoupling and differs quite a lot between a phantom and human tissue. As a high field 4.7 Tesla spectrometer has been used, an excellent $\mathrm{S} / \mathrm{N}(>10)$ was obtained for glycogen and a decrease in peak height by a factor of two could have been afford. Thus, peak fitting was not a problem. It was rather more accurate as a lifelike ${ }^{13} \mathrm{C}$-spectrum shows two peaks of glycogen instead of one after decoupling.

The quantification of the ${ }^{31} \mathrm{P}$-spectra, using a replacement phantom, was done by the same procedure as described above. Immediately after the in-vivo session, an identical in-vitro measurement was performed with a $2 \mathrm{~L}$ calibration phantom containing a solution of $50 \mathrm{mmol} \cdot \mathrm{L}^{-1}$ of $\mathrm{KH}_{2} \mathrm{PO}_{4}$.

In order to compare quantified glycogen, $\mathrm{PCr}, \mathrm{ATP}$, and $\mathrm{Pi}$ with results from other human studies, muscle metabolite concentrations were converted from mmol $\cdot \mathrm{L}^{-1}$ to mmol $\cdot \mathrm{kg}^{-1}$ wet weight (ww), using the constant value of $1.04 \mathrm{~kg} \cdot \mathrm{L}^{-1}$ for the specific gravity of muscle tissue (48).

\section{Blood sampling and analyses}

Blood samples for the examination of glucose, insulin, free fatty acid (FFA), Bhydroxybutyrate $(\mathrm{B}-\mathrm{Hb})$, creatine kinase $(\mathrm{CK})$, myoglobin $(\mathrm{Mb})$, and lactate were 
drawn from an antecubital vein of the left arm. The first blood sample was drawn before exercise (after resting $30 \mathrm{~min}$ in a supine position), the following samples $0,2,15,24$, and $48 \mathrm{~h}$ after exercise. The blood for the analyses of insulin. FFA, $\mathrm{CK}$, and $\mathrm{Mb}$ was filled in a $7.5 \mathrm{ml}$ EDTA tube containing $\mathrm{NH}_{4}$-heparin (Sarstedt, Nümbrecht, Germany). The blood for the analyses of glucose, $\mathbb{B}$-Hb, and lactate was collected in a $2.7 \mathrm{ml} \mathrm{NaF}$ tube. Following centrifugation (4800 revolutions $\cdot \min ^{-1}$ at $4{ }^{\circ} \mathrm{C}$ for $15 \mathrm{~min}$ ) the plasma was separated from the erythrocytes and stored until analysis at $-80^{\circ} \mathrm{C}$. Lactate and glucose were analyzed with an enzymatic calorimetrical method, $\mathrm{B}-\mathrm{Hb}, \mathrm{CK}$, and FFA by a photometric-enzymatic method. Lactate was measured with a test kit of Bergmeyer (New York, USA), glucose, B-Hb, and CK with the Cobas Mira (Roche, Basel, Switzerland), and FFA by a kit of WAKO (Neuss, Germany). Insulin and $\mathrm{Mb}$ were determined by radioimmunoassay. Insulin with a test kit of INSI-PR Cis bio international (Sur-Yvette Cedex, France) and Mb by a test kit of immuno diagnostic center (Dallas, USA).

\section{Diet analyses}

Starting two days before the experiment, subjects were told to eat foods selected from a list of CHO-rich meals and to additionally ingest $1 \mathrm{~L}$ of an isotonic drink. every evening, made of maltodextrine powder, to ensure full muscle glycogen stores. If the subjects were not able to eat all of the suggested food, they had to record it. The subjects were not allowed to ingest any drink containing caffeine from $24 \mathrm{~h}$ before the start until the end of the experiment. At least $1.5 \mathrm{~h}$ before their arrival in the laboratory on the experimental day, the subjects consumed a CHO-rich lunch, including again $0.5 \mathrm{~L}$ of the isotonic drink. From the moment the subjects were in the laboratory and started the experiment, they were allowed to eat and drink only the food prepared by us to ensure that every subject ingested at least $10 \mathrm{~g} \mathrm{CHO} \cdot \mathrm{kg}^{-1} \mathrm{bw} \cdot 24 \mathrm{~h}^{-1}$ during recovery. To optimize glycogen resynthesis after the reducing exercise, the meals were composed of dried fruits, gingerbread, rice pudding, pasta, rice, etc., and an isotonic drink. The snack given immediately after exercise (Table 1) and the dinner on the testing day were consumed in the laboratory. On the next day, the subjects consumed the delivered breakfast at home, $1.5 \mathrm{~h}$ before the $15 \mathrm{~h}$ post exercise MRS measurements. From 15 until $24 \mathrm{~h}$ after exercise, the subjects stayed in the laboratory again and consumed the morning snack, lunch, and afternoon snack under our supervision (Table 1). The subjects took the dinner, which they consumed after the $24 \mathrm{~h}$ MRS measurements, and all the other prepared foods for the second day with them. If anything was left over, they brought it back to the laboratory before the last MRS measurements (48 h after exercise). The food 
records were analyzed using a standard nutrition analysis software package (EBIS 2.0; E+D Partner, Stuttgart, Germany).

Table 1. Food ingested after the exercise until the end of the experiment $48 \mathrm{~h}$ later

\begin{tabular}{|c|c|c|}
\hline When & Food & $\begin{array}{l}\text { Carbohydrates } \\
\text { (g/Portion) }\end{array}$ \\
\hline Snack after exercise & $0.5 \mathrm{~L}$ isotomic drínk, $150 \mathrm{~g}$ apple puree & 112 \\
\hline Dinmer after exercise & $\begin{array}{l}75 \mathrm{~g} \text { apricot pie, } 280 \mathrm{~g} \text { rice, } 160 \mathrm{~g} \text { mixed vegetables, } \\
2 \mathrm{dl} \text { mushroom sauce, water ad libitum }\end{array}$ & 461 \\
\hline$\frac{\text { Day } 1 \text { and } 2 \text { after excreise }}{\text { Breakfast }}$ & $\begin{array}{l}132 \mathrm{~g} \text { toast ( } 6 \text { slices), } 40 \mathrm{~g} \text { honey, } \\
150 \mathrm{~g} \text { banana chups yogurt, } 3 \mathrm{dl} \text { orange juice }\end{array}$ & 171 \\
\hline Morming snack & $\begin{array}{l}100 \text { dried fruit, } 75 \text { g gingerbread suffed } \\
\text { with almond paste, } 3 \text { dl apple juice }\end{array}$ & 135 \\
\hline Lunch & $\begin{array}{l}5 \mathrm{dl} \text { ice tea, } 132 \mathrm{~g} \text { toast ( } 6 \text { slices), } \\
75 \mathrm{~g} \text { pear bread, } 200 \mathrm{~g} \text { rice pudding }\end{array}$ & 199 \\
\hline Afternoon snack & $\begin{array}{l}1.00 \mathrm{~g} \text { dried fruit, } 42 \mathrm{~g} \text { crunchy chocolate bar, } \\
3 \text { dll orange juice }\end{array}$ & 110 \\
\hline Dinner & $180 \mathrm{~g}$ pasta, $75 \mathrm{~g}$ pear bread, $0.5 \mathrm{~L}$ isotonic drink & 246 \\
\hline
\end{tabular}

\section{Perceived muscle soreness}

Muscle soreness in the calf muscle was rated according to a modified Borg scale ranging from 0 (not at all sore) to 10 (maximally sore) and was determined by asking the subject while walking slowly. Always the same investigator performed the soreness recording before each withdrawal of blood.

\section{Statistical analyses}

The results are presented as mean value \pm standard deviation (SD). Differences over time between the two groups (DOMS and CONTROL, respectively) were analyzed by multiple analysis of variance (MANOVA) and, if significant, indicated with an asterisk (*). Differences within each group were tested by oneway analysis of variance (ANOVA-factorial) folllowed by Fisher's testing for significance. Within a group, a plus $(+)$ shows significant differences from the base vallue before exercise. Linear regression analysis was performed with standard procedures. 


\section{RESULTS}

\section{Exercise protocols}

During the glycogen reducing exercise, the DOMS group sprinted for $6.1 \pm 3.3 \mathrm{~min}$ with an average heart rate of $155.4 \pm 11.0$ beats $\mathrm{min}^{-1}$, the CONTROL group for $7.9 \pm 5.2 \mathrm{~min}$ with a mean lheart rate of $158.5 \pm 11.4$ beats " min $^{-1}$. Afterwards, all subjects finished the 1 h running protocol at $65 \%$ maximal performance (DOMS: $12.0 \pm 1.1 \mathrm{~km} \cdot \mathrm{h}^{-1}$; CONTROL: $11.1 \pm 1.6$ $\mathrm{km} \cdot \mathrm{h}^{-1}$ ), determined by the Conconi test before. The average heart rate amounted to $151.7 \pm 14.0$ beats $\cdot \mathrm{min}^{-1}$ in the DOMS and $154.4 \pm 11.5$ beats $\cdot \min ^{-1}$ in the CONTROL group. None of the comparisons between the two groups showed a significant difference.

\section{Diet analyses}

Table 2 presents the average results of the daily-ingested macronutrients and energy in both groups, which were similar. The intake of more than $10 \mathrm{~g}$ $\mathrm{CHO} \cdot \mathrm{kg}^{-1}$ bw $\cdot 24 \mathrm{~h}^{-1}$ was achieved during recovery as intended.

Table 2. Average $24 \mathrm{~h}$-intake of macronutrients and energy during $48 \mathrm{~h}$ before and after glycogen-reducing exercise with additional eccentric contractions (DOMS) or without eccentric exercise (CONTROL)

\begin{tabular}{llllll}
\hline Nutrients & Group & $-48 \mathrm{~h}$ & $-24 \mathrm{~h}$ & $+24 \mathrm{~h}$ & $+48 \mathrm{~h}$ \\
\hline Carbohydrates & DOMS & $9.1 \pm 2.4$ & $10.0 \pm 2.7$ & $12.4 \pm 0.8$ & $11.8 \pm 1$ \\
$\left(\mathrm{~g} \cdot \mathrm{kg}^{-1} \mathrm{bw} \cdot 24 \mathrm{~h}^{-1}\right)$ & CONTROL & $7.4 \pm 3.3$ & $8.2 \pm 2.2$ & $11.9 \pm 0.7$ & $11.0 \pm 1$ \\
Fat & DOMS & $1.1 \pm 0.5$ & $0.9 \pm 0.3$ & $1.0 \pm 0.1$ & $0.9 \pm 0.2$ \\
$\left(\mathrm{~g} \cdot \mathrm{kg}^{-1} \mathrm{bw} \cdot 24 \mathrm{~h}^{-1}\right)$ & CONTROL & $0.9 \pm 0.5$ & $0.8 \pm 0.2$ & $1.1 \pm 0.2$ & $0.8 \pm 0.1$ \\
Protein & DOMS & $1.4 \pm 0.6$ & $1.5 \pm 0.5$ & $1.2 \pm 0.2$ & $1.1 \pm 0.2$ \\
$\left(\mathrm{~g} \cdot \mathrm{kg}^{-1} \mathrm{bw} \cdot 24 \mathrm{~h}^{-1}\right)$ & CONTROL & $1.1 \pm 0.6$ & $1.2 \pm 0.2$ & $1.2 \pm 0.2$ & $1.1 \pm 0.2$ \\
Energy & DOMS & $15.9 \pm 4.3$ & $16.7 \pm 3.8$ & $19.4 \pm 1.43$ & $18.5 \pm 1.4$ \\
$\left(\mathrm{MJ} \cdot 24 \mathrm{~h}^{-1}\right)$ & CONTROL & $13.9 \pm 6.1$ & $14.4 \pm 2.8$ & $20.1 \pm 1.2$ & $17.7 \pm 1.3$ \\
\hline
\end{tabular}

Values are means $\pm \mathrm{SD}, \mathrm{N}=12$ (DOMS) and 8 (CONTROL)

\section{Magnetic resonance}

Figure 3 shows the different ${ }^{13}$ C-MRS measurements of muscle glycogen. Sprinting and running in both groups, and the additional eccentric exercise performed by the DOMS group, significantly reduced the glycogen concentrations identically by about $50 \%(\mathrm{p}<0.001)$. The concentration dropped 
further by $7.8 \pm 7.9 \mathrm{mmol} \cdot \mathrm{kg}^{-1} \cdot \mathrm{h}^{-1}$ in the first $2 \mathrm{~h}$ of recovery in the DOMS group and increased by $9.2 \pm 1.0 .4 \mathrm{mmol} \cdot \mathrm{kg}^{-1}$ ww $\mathrm{h}^{-1}$ during the same time period in the CONTROL group $(p<0.001)$. In the following hours, there was a trend for lower glycogen concentrations in the DOMS compared to the CONTROL group ( $15 \mathrm{~h}: \mathrm{p}=0.07 ; 24 \mathrm{~h}: \mathrm{p}<0.01 ; 48 \mathrm{~h}: \mathrm{p}=0.08$ ). The glycogen concentration of the DOMS group was still significantly $(p<0.001)$ below the resting concentration $24 \mathrm{~h}$ after exercise. Only after $48 \mathrm{~h}$ the glycogen concentration was no different from the resting level, whereas the CONTROL group achieved this already after $15 \mathrm{~h}$.

Figure 3. Muscle glycogen concentrations in the calf muscles of the DOMS $(\mathrm{N}=\mathbb{2})$ and CONTROL $(\mathrm{N}=8)$ group

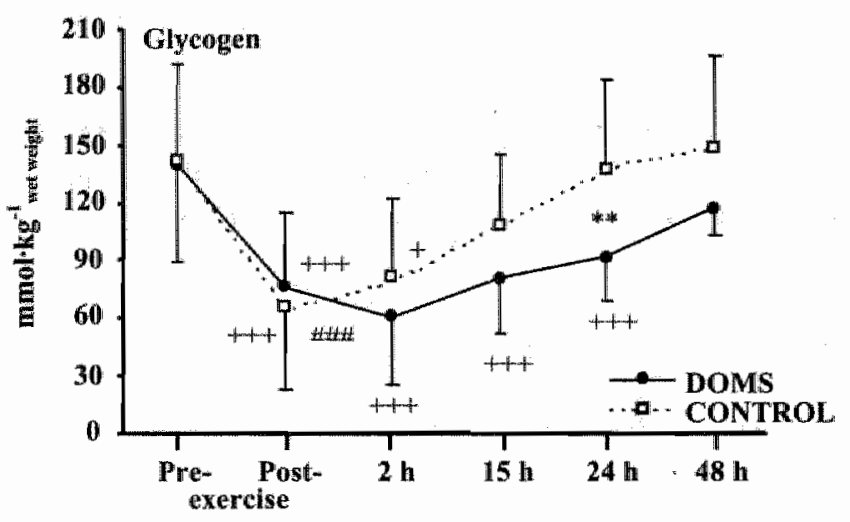

Significant differences between the two groups are indicated with an asterisk (*), within a group, a plus $(+)$ shows significant differences between Pre and any Post exercise concentration, in addition, a pound sign (\#) shows significant differences between the glycogen resynthesis rates of the two groups: $+: p<0.05 ; * ; p<0.01 ; 4+4$, $p<0.001$, walues are means $\pm \mathrm{SD}$

Whereas the PCr, ATP, and Pi concentrations (Figure 4) of the DOMS group diftered significantly from the base value, was this not the case in the CONTROL group (one exception: PCr at $24 \mathrm{~h} ; \mathrm{p}<0.05$ ). In the DOMS group, the $\mathrm{PCr}$ concentration was significantly higher $(\mathrm{p}<0.01)$ compared to the resting level up to $15 \mathrm{~h}$ after exercise, which resulted in a significant difference between the wo groups $(p<0.01)$. The ATP concentration declined immediately after exereise and remained significantly below the resting concentration until the end of the study $(p<0.001)$. Therefore, the DOMS group significantly differed from the CONTROL group during most of the recovery period $(\mathrm{p}<0.001)$. The Pi drop during exercise in the DOMS group and the following rise over $48 \mathrm{~h}$ were 
significant $(p<0.01)$ and showed a significant difference to the CONTROL group during the first $24 \mathrm{~h}(\mathrm{p}<0.01)$.

Figure 4. Inorganic phosphate (Pi), adenosine triphosphate (ATP), and phosphocreane (PCr) concentrations in the alf muscles of the DOMS $(\mathrm{N}=12)$ and CONTROL $(\mathrm{N}=8)$ group
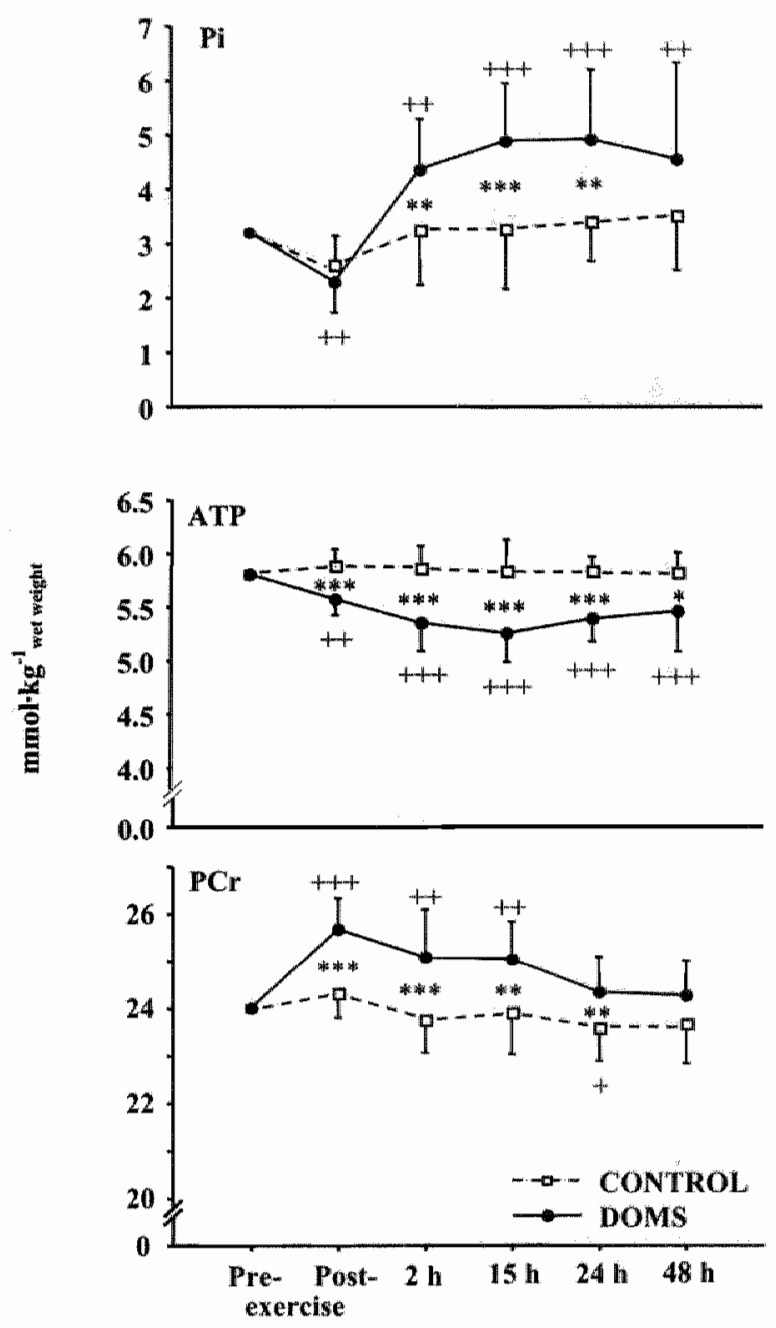

Significant differences between the two groups are indicated with an asterisk ("), within a group, a plus $(+)$ shows significant differences between Pre and any Post exercise

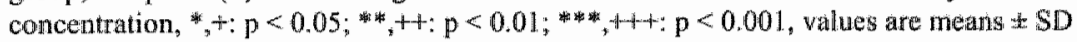




\section{Blood analyses}

Figure 5. Concentrations of creatine kinase (CK), nyoglobin (Mb), glucose, insulin, free fatty actids (FFA), beta hydroxy butyrate ( $(\mathrm{Hb})$, and lactate, of the DOMS $(\mathrm{N}=12)$ and CONTROL $(\mathrm{N}=8)$ group
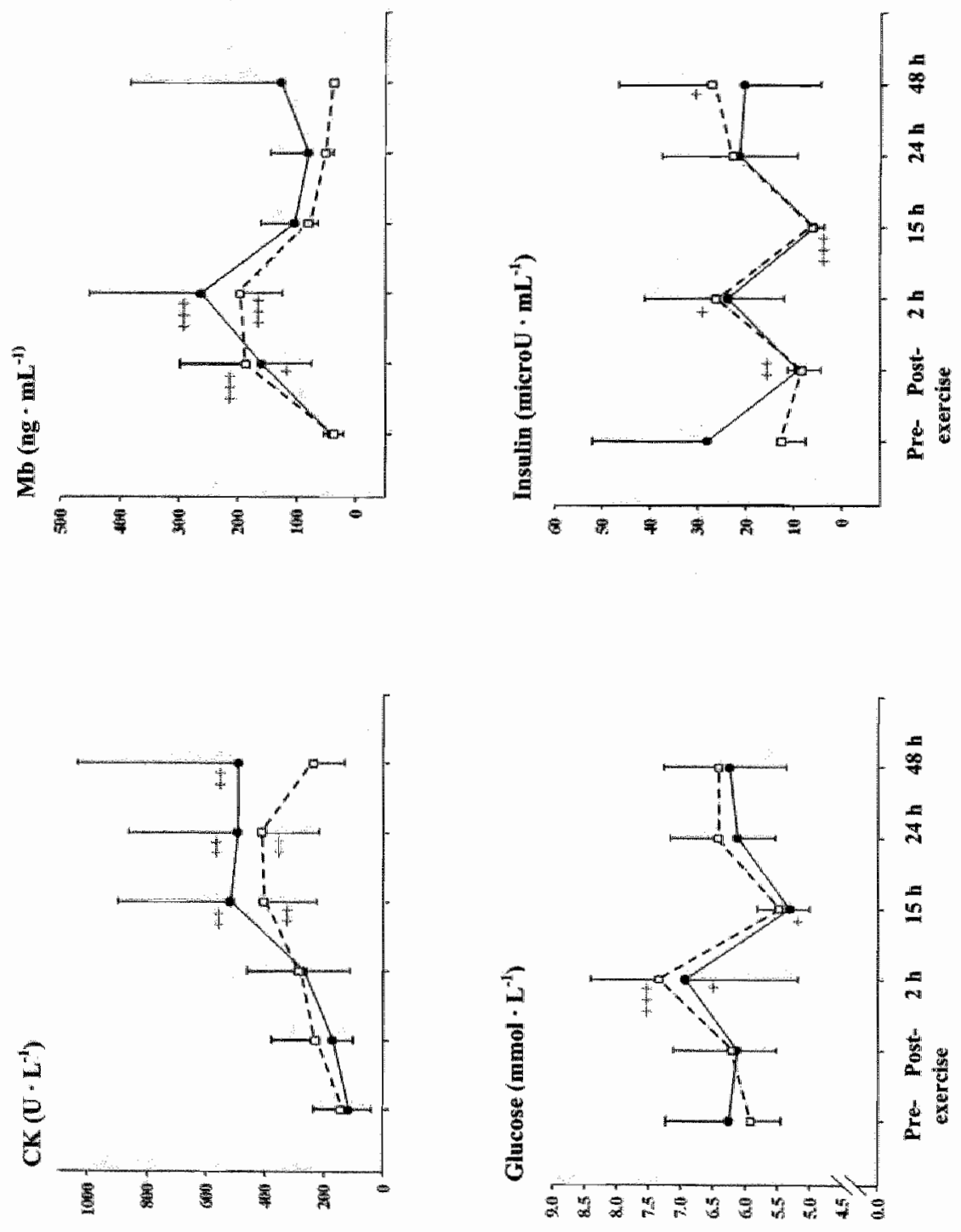

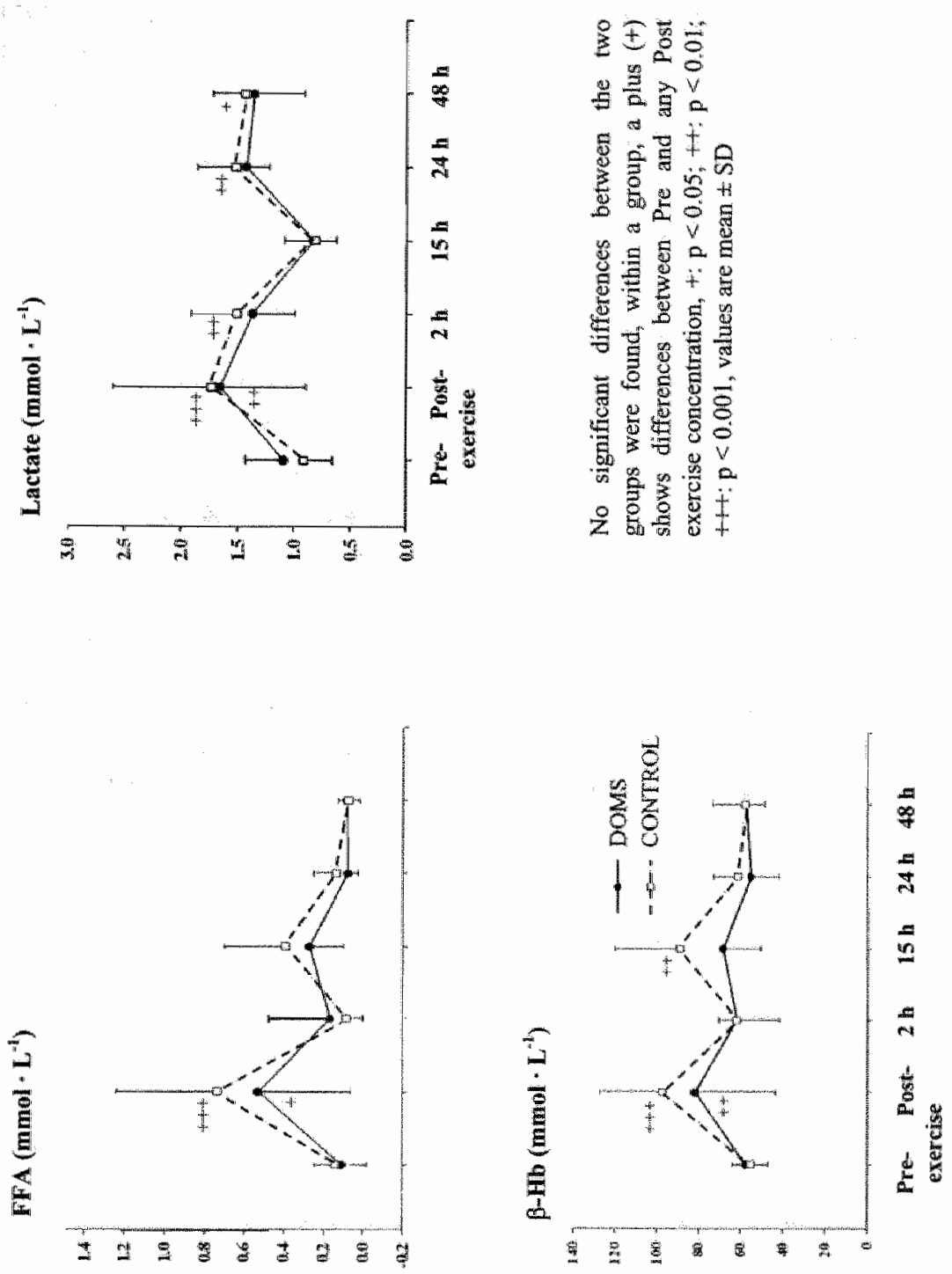

None of the blood concentrations of $\mathrm{CK}, \mathrm{Mb}$, glucose, insulin, FFA, B-Hb, and lactate showed a difference between the two groups over time (Figure 5). Subsequently, only $\mathrm{CK}$ and $\mathrm{Mb}$, which are consistently mentioned in connection with DOMS, will be described in more detail. CK rose until it was significantly above the base value after $15 \mathrm{~h}(\mathrm{p}<0.01)$ in both groups. It remained ellevated 
(p<0.01) until the end of the study in the DOMS group and up to $24 \mathrm{~h}$ in the CONTROL group $(p<0.01)$. Contrary to $C K$, Mb was already significantly increased after exercise in both groups, remained increased up to $2 \mathrm{~h}(\mathrm{p}<0.001)$, and fell back to normal values thereafter. Mb started to increase again after $24 \mathrm{~h}$ in the DOMS group. However, this slight increase did not reach a significant level. Additionally; a few correlations were observed between $\mathrm{Mb}$ and perceived soreness (after $24 \mathrm{~h}: \mathrm{r}=0.52 ; \mathrm{p}<0.08$ ) as well as $\mathrm{Mb} / \mathrm{CK}$ and $\mathrm{PI} / \mathrm{PCr}$ ratio (after $15 \mathrm{~h}: \mathrm{r}=0.63 ; \mathrm{p}<0.05 \% \mathrm{r}=0.71 ; \mathrm{p}<0.01$ ) in the DOMS but not in the CONTROL group.

\section{Perceived muscle soreness}

Both groups showed a significant increase of the perceived soreness immediately after exercises ( $p<0.001$; Figure 6). Testing of the differences between the two groups revealed a significantly higher perceived soreness rating in the DOMS group after $48 \mathrm{~h}(\mathrm{p}<0.05)$, which started with a trend after $24 \mathrm{~h}(\mathrm{p}=0.07)$. The toe-raise exercise additionally significantly increased the $\mathrm{Pi} / \mathrm{PCr}$ ratio after $15 \mathrm{~h}$ ( $<<0.001$; Figure 6) in the DOMS group. This ratio remained higher than the resting ratio until the end of the study, whereas in the CONTROL group it always showed resting values. Comparing the two groups, the DOMS group had a significantly higher $\mathrm{Pi} / \mathrm{PCr}$ ratio after 15 and $24 \mathrm{~h}(\mathrm{p}<0.01)$. After 2 and $48 \mathrm{~h}$, but not after 15 and $24 \mathrm{~h}$, there was a significant correlation between perceived soreness and $\mathrm{Pi} / \mathrm{PCr}$ ratio in the DOMS (Figure 7) but not in the CONTROL $(r=0.17 ; p=0.67$ and $r=0.17 p=0.68$, respectively) group.

Figure 6. $\mathrm{Pi} / \mathrm{PCr}$ ratio and perceived muscle soreness of the DOMS $(\mathrm{N}=12)$ and $\mathrm{CONTROL}$ $(\mathbb{N}=8)$ group
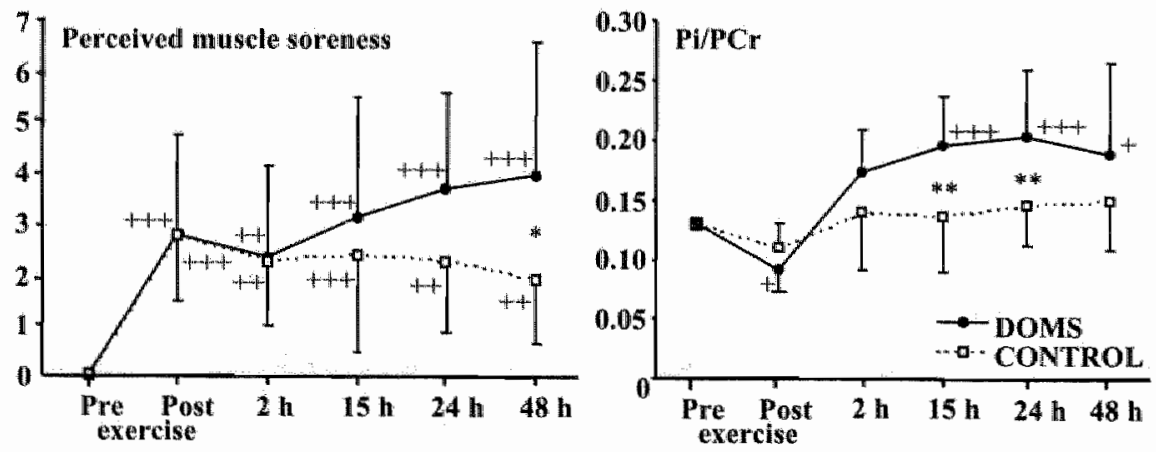

Significant differences between the two groups are indicated with an asterisk $(*)$, within a group, a plus $(+)$ shows significant differences between Pre and any Post exercise value $*,+$ : $\mathrm{p}<0.05 ; *,+t \mathrm{p}<0.01 ;+t+\mathrm{p}<0.00 \|_{\text {, values are means } \pm S D,} \mathrm{Pi}=$ inorganic phosphate, $\mathrm{PCr}=$ phosphocreatine 
Figure 7. Correlation between perceived muscle soreness and PIPCr ratio in the DOMS group at $2 \mathrm{~h}$ (plot $\mathrm{A}, \mathrm{y}=43.4 \mathrm{x}-5.1, \mathrm{r}=0.89$ ) and at $48 \mathrm{~h}$ (plot B, $\mathrm{y}=24.85 \mathrm{x}-0.72, \mathrm{r}=0.74$ ) after eccentric exercise, $\mathrm{Pi}=$ inorganic phosphate, $\mathrm{PCr}=$ phosphocreatine

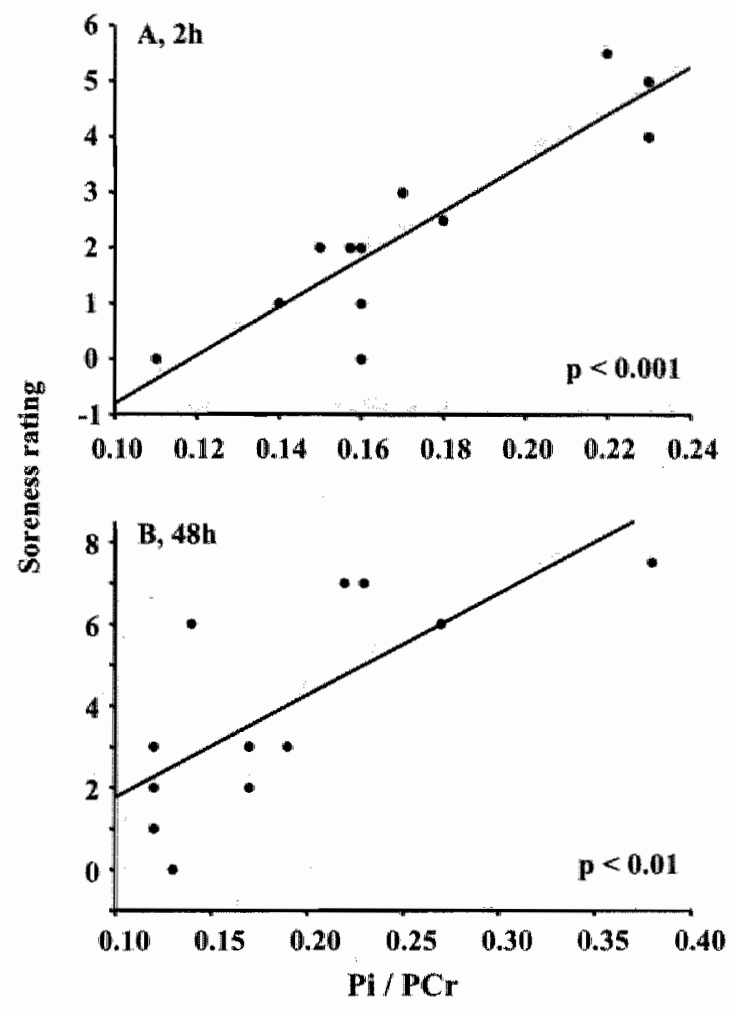

\section{DISCUSSION}

Muscle glycogen concentration was equally lowered after runining and sprinting irrespective to whether subjects rested or performed an additional eccentric exercise. Eccentric exercise of the DOMS group successfully induced muscle soreness. The CHO-rich diet immediately consumed after exercise not only failed to prevent delayed glycogen resynthesis. Glycogen concentration even further decreased during the first $2 \mathrm{~h}$ of recovery in the group of the DOMS subjects $\left(-15.6 \pm 1.5 .7 \mathrm{mmol}^{\prime} \mathrm{kg}^{-1}{ }_{\text {ww }}\right)$ in contrast to the CONTROL group, where glycogen started to refill $\left(+18.4 \pm 20.8 \mathrm{mmol} \cdot \mathrm{kg}^{-1}{ }_{\mathrm{ww}}\right)$. This decrease in glycogen concentration after eccentric exercise is reported here for the first time and has not been seen in previous studies, which measured glycogen after 4 to $6 \mathrm{~h}$ of exercise (e.g. $17,40,50$ ). The further glycogen loss during early recovery is 
especially disadvantageous because the first 2 h of exercise recovery are nomally characterized by a rapid, insulin independent, glycogen resynthesis phase (38). The mean glycogen resynthesis rate of $9.2 \pm 10.4 \mathrm{mmol} \cdot \mathrm{kg}^{-1}{ }_{\mathrm{ww}} \cdot \mathrm{h}^{-1}$ found in the CONTROL group corresponded to what is described in other studies $(35,38)$.

Several factors may account alone or in combination for the further decrease in glycogen concentration found during the first $2 \mathrm{~h}$ after vigorous eccentric exercise followed by muscle soreness. A significant rise of $\mathrm{Pi}(\mathrm{p}<0.001)$ was measured during the first $2 \mathrm{~h}$ (Figure 4 ). This elevated $P$ i concentration persisted during at least $24 \mathrm{~h}$ and was also responsible for an increased $\mathrm{Pi} / \mathrm{PCr}$ ratio in the DOMS group during recovery (Figure 6). Increased $\mathrm{Pi}$ and $\mathrm{Pi} / \mathrm{PCr}$ are indicators of muscle cell damage (31,32). McCully et al. (31) suggested that the steepness of the slope of the $\mathrm{Pi} / \mathrm{PCr}$ ratio could indicate the severity of the exercise induced muscle injury. In addition, a shallower $\mathrm{Pi} / \mathrm{PCr}$ ratio curve points to a preservation of PCr as it also happened in ou CONTROL group. In the present study, the slope of the $\mathrm{PI} / \mathrm{PCr}$ ratio was highest during the first $2 \mathrm{~h}$ after eccentric exercise (DOMS group: $40.09 \pm 0.05$; CONTROL group: $+0.03 \pm 0.06 ; p<0.05$; Figure 6). This result of the DOMS group is in close relation with the result of MeCully et al. (32), where 24 h after repeated lengthening contraction exercise resulting in muscle injury, the subjects showed a maximum $\mathrm{Pi} / \mathrm{PCr}$ ratio increase $(+0.1)$. Also, Lund et al. (29) described the elevated Pi/PCr as a reliable indicator for muscle injury after eccentric exercise. Therefore, we assume that in the present study the eccentric exercise, followed by DOMS, caused muscle fiber injury observable already early during recovery. This assumption is realistic because $O^{\prime}$ Reilly and colleagues (34) showed numerous ultra-structural abnormalities in muscle cells immediately after eccentric exercise as e.g. focal myofibrillarlysis or damage to the sarcoplasmic reticulum.

During eccentric toe-raise exercise with fully extended knees, m. gastrocnemius is predominately strained. $M$. gastrocnemius contains mainly fast-twitch fibers. These fibers are characterized by an increased intramuscullar Pi concentration after muscle injury (8). $\mathrm{P}_{\mathrm{i}}$ is one of the substrates for phosphorylation and activated by glycogenolysis, especially in fast-twitch muscles (8). Moreover, phosphorylase $a$ is also activated by elevations in intracellular $\mathrm{Ca}^{2+}$ levels, which occur after fiber injury and result in glycogenolysis (18).

Furthermore, Hultman and Greenhaff (22) described that eccentric exercise causes metabolic perturbations in muscle fibers. Type II fibers were unable to maintain a high rate of ATP resynthesis for energy provision, as it is necessary e.g. for glycogen resynthesis. This happened most likely also in the present study because the DOMS group had a significantly lower ATP concentration 
$(p<0.001)$ than the CONTROL group after exercise (Figure 4). The diminished ATP concentration and its negative consequences for glycogen resynthesis in the DOMS group may be also explained by the evoked micro ruptures. The result is an uptake of $\mathrm{Ca}^{2+}$ into the sarcoplasma, followed by a disturbance of the oxidative phosphorylation, which reduces ATP resynthesis (20).

Ryschon et al. (43) estimated the efficiency of ATP utilization for concentric, eccentric, and isometric muscle action. A higher metabolic efficiency during an eccentric compared to a concentric action followed a lower ATP resynthesis rate after eccentric action. An explanation for this is the recruitment of more efficient fibers during eccentric compared to concentric exercise (43). Therefore, we could assume that the ingested CHO in the DOMS group was rather used to provide energy for e.g. the regeneration of the hydrolyzed ATP than being used to restore muscle glycogen during the initial $2 \mathrm{~h}$ of recovery.

The influence of eccentric exercise on phosphate metabolism and glycogen resynthesis was not only seen after $2 \mathrm{~h}$. The trend for different glycogen concentrations between the two groups after $15 \mathrm{~h}(\mathrm{p}<0.07)$ and the significant difference after $24 \mathrm{~h}(\mathrm{p}<0.01$, Figure 3$)$ was paralleled by a significant difference in the Pi/PCr ratio ( $p<0.01$, Figure 6). The higher $\mathrm{Pi} / \mathrm{PCr}$ ratios in the DOMS group can still reflect the disrupted muscle fibers. Damaged muscle fibers lead in turn to a defect in oxidative metabolism, i.e. in our study to a perturbation of the phosphate equilibrium, which enables an influx of plasma $\mathrm{Pi}$ (1). Additionally, it can be also a sign of an increased oxidative capacity of mitochondria (31), which evokes increased energy demand. This increased energy demand might be a result of the healing process of the injured fibers. Therefore, also after $2 \mathrm{~b}$ glucose could provide energy for the ATP resynthesis used for the healing process rather than for the glycogen resynthesis. This is in accordance with a reduced glycogen resynthesis between post exercise and $15 \mathrm{~h}$ of only $4 \pm 28 \mathrm{mmol} \cdot \mathrm{kg}^{-1}$ ww in the DOMS compared to $43 \pm 26 \mathrm{mmol} \cdot \mathrm{kg}^{-1}$ ww in the CONTROL group (Figure 3).

Additionally, different studies $(3,4,5,23)$ investigated the influence of glucose transport proteins (GLUT 4) in connection with eccentric exercise and impaired glycogen resynthesis. They found on the one hand a reduced amount of GLUT 4 in damaged muscle cells (3), on the other hand a diminished function, caused by a relatively short-term insulin resistance after eccentric exercise $(4,23)$. In a newer study, Asp et al. (5) measured a delay of muscle glycogen resynthesis after a muscle damage inducing marathon run although GLUT 4 concentration was unaltered. Therefore, they concluded that other factors than GLUT 4 concentration must be involved in the slow glycogen resyrithesis. Compared to our study, the subjects consumed less CHO (only $7 \mathrm{~g} \mathrm{CHO} \cdot \mathrm{kg}^{-1}$ bw $\cdot 24 \mathrm{~h}^{-1}$ ) 
during the recovery from the marathon and it is not clear whether the subjects received $\mathrm{CHO}$ immediately after exereise. Therefore, one could argue if "immediately administered" or more CHO would have reduced or prevented the delayed glycogen resynthesis. However, from the previous insights of our study: this option has to be abaindoned.

From Kapui et al. (24) and Schmidt and Walter (45) a further potential explanation arises for the diminished glycogen resynthesis of the DOMS compared to the CONTROL group. It concerns the cytokine inducible enzyme, one of the three different nitric oxide synthase isozymes, which is most evident in fast-type extensor muscles (39). On the one hand the enzyme is enhanced during inflammation and on the other hand its activity causes impaired insulinstimulated glucose uptake. The impaired insulin activity would reduce muscle glucose uptake and therefore glycogen resynthesis.

Besides $\mathrm{Pi}, \mathrm{Pi} / \mathrm{PCr}$ ratio, and probably the cytokine inducible enzyme, muscle soreness is another reliable indicator for muscle damage. The Pi/PCr ratio of the DOMS group correlated significantly with the perceived muscle soreness $2 \mathrm{~h}$ post exercise $(\mathrm{p}<0.001$; Figure $7 \mathrm{~A})$. Soreness follows muscle injury, which is mostly caused by eccentric exercise (e.g. 3). McCully et al. (32) reported a ratio of $\mathrm{Pi} / \mathrm{PCr}$ peaking one or two days after exercise, which is similar to the results found in our study (Figure 6). Additionally, the $\mathrm{Pi} / \mathrm{PCr}$ ratio correlated significantly with the perception of muscle soreness $(p<0.01$, Figure $7 \mathrm{~B})$. After $48 \mathrm{~h}$, the perception of muscle soreness achieved its maximum value (as reported. by others, e.g. 19) and differed significantly from the CONTROL group $(\mathrm{p}<0.05$, Figure 6). This correlation makes perceived soreness rating a supplementary possible candidate for the judgment of the severity of the muscle fibers injury after eccentric exercise.

Often, $\mathrm{CK}(\mathrm{e} . \mathrm{g} .37,47)$ and $\mathrm{Mb}(\mathrm{e} . \mathrm{g} .47)$ are used to detect injured muscle fibers after eccentric exercise and to judge the severity of the damage. In our study, CK and $\mathrm{Mb}$ were both elevated in the course of recovery, but not significantly different in the two groups. (Figure 5). From the shown results and other studies $(26,27,30,35)$ one can question the suitability of $\mathrm{CK}$ and $\mathrm{Mb}$ as indicators or predictors of muscle injury. Additionally, there is also a large inter-subject variability in the rise of $\mathrm{CK}$ (e.g. 9, 33). However, $48 \mathrm{~h}$ after exercise, $\mathrm{CK}$ concentration was still elevated in the DOMS but not in the CONTROL group (Figure 5). At the same time, the amount of glycogen in the DOMS group reached approximately resting concentration, which is a sign that CK does not negatively influence glycogen resynthesis (Figure 3).

As a critique of the MRS method, one might argue that after eccentric exercise, swelling and storage of water in the contracted muscle can occur and could lead 
to a diminished glycogen signal in the ${ }^{19} \mathrm{C}$-spectra. However, substantial swelling and edema occurs only $24 \mathrm{~h}$ after eccentric exercise $(11,16,18,41)$. The extent of swelling and edema after eccentric exercise was about 3 to $9 \%(21)$. This low fluid expansion is within the accuracy of MRS-measurements (6) and would therefore hardly disturb such measurements.

\section{CONCLUSION}

Despite a high $\mathrm{CHO}$ supply during recovery $\left(10 \mathrm{~g} \mathrm{CHO} \cdot \mathrm{kg}^{-1}\right.$ bw $\left.\cdot 24 \mathrm{~h}^{-1}\right)$, the delay of muscle glycogen resynthesis after eccentric exercise could not be prevented. An important new finding was a further reduction of the glycogen concentration during the initial $2 \mathrm{~h}$ of recovery after eccentric exercise instead of a high resynthesis rate. $24 \mathrm{~h}$ after eccentric exercise, muscle glycogen concentration in the DOMS group was still $35 \%$ below the resting concentration. The initial, further glycogen reduction and the delayed glycogen resynthesis were most likely an effect of muscle cell damage as indicated by increased $\mathrm{Pi}$ concentration and $\mathrm{Pi} / \mathrm{PCr}$ ratio. In consideration of this fact, it is probably impossible to eliminate the negative effect of muscle injury on the glycogen resynthesis after eccentric exercise even with a large supply of CHO during recovery.

\section{ACKNOWLEDGMENT}

The authors thank Mirtha Arnold and Toni Moses for the analyses of the blood parameters and Wander (Neuenegg, Switzerland) as provider of the isotonic drink ISOSTAR LONG ENERGY. We would also like to thank Fred Brouns for the interesting exchanges of ideas about DOMS, Wim Saris for the revision of the manuscript, Markus Lamprecht for the help with the statistical analyses and Stephanie Frey for the corrections in English. 


\section{REFERENCES}

1. ALDRIDGE $R$, CADY EB, JONES DA, OBLETTER G. Muscle pain after exercise is linked with an inorganic phospthate increase as shown by 31P NMR. Biosci Rep 6: 663$667,1986$.

2. ARMSTRONG RB. Muscle damage and endurance events. Sports Med 3: 370-381, 1986.

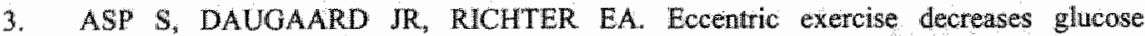
transporter Glut4 protein in human skeletal muscle. J Physiol (Lond) 482: 705-712, 1995.

4. ASP $\$$, DAUGAARD JR, KRISTIANSEN S, KIENS B, RICHTER EA. Eccentric exercise decreases maximal insulin action in humans - muscle and systemic effects. $J$ Physiol (Lond) 494: 891-898, 1996.

5. ASP $S, R O H D E ~ T, R I C H T E R$ EA. Impaired muscle glycogen resynthesis after a marathon is not caused by decreased muscle GLUT-4 content. $J$ Appl Physiol 83 : 1482$1485,1997$.

6. BUCHLI R, AND BOESIGER P. Comparison of methods for the determination of absolute metabolite concentrations in human muscles by 31P MRS. Magn Reson Med 30: 552-558, 1993.

7. BURKE LM. Nutrition for post-exercise recovery. Aust I Sci Med Sport 29: 3-10, 1997.

8. CHASIOTIS D, SAHLIN $\mathbb{K}$, HULTMAN E. Regulation of glycogenolysis in human muscle at rest and during, exercise. $J$ Appl Physiol $53: 708-715,1982$.

9. CLARKSON PM, AND EBBELING C. Investigation of serum creatine kinase variability after muscle-dlamaging exercise. Ciin Sci 75:257-261, 1988.

10. CLARKSON PM. Eccentric exercise and muscle damage. Int $J$ Sports Med 18: 5314 S317, 1997.

11. CLEAK MJ, AND ESTON RG. Muscle soreness, swelling, stiffness and strength loss after intense eccentric exercise. Br J Sports Med 26: 267-272, 1992

12. CONCONI F, FERRARI M, ZIGLIO PG, DROGHETTI P, CODECA L. Determination of the anaerobic threshold by a noninvasive field test in runners. $J$ Appl Physiol 52: 869873,1982

13. CONSTANTIN-TEODOSIU D, CASEY A, SHORT AH, HULTMAN E, GREENHAFF PL. The effect of repeated muscle biopsy sampling on ATP and glycogen resynthesis following exercise in man. Eur J Appl Physiof 73: 186-190, 1996.

14. COSTIL DL, PEARSON DR, FINK WJ. Impaired muscle glycogen storage after muscle biopsy. I Appl Physiol 64: 2245-2248, 1988.

15. COSTILL DL, PASCOE DD, FTNK WJ, ROBERGS RA, BARR SI, PEARSON D. Impaired muscle glycogen resynthesis after eccentric exercise. $J$ Appl Physiol 69: 46-50, 1990.

16. CRENSHAW AG, THORNELL LE, FRIDEN J. Intramuscular pressure, torque and swelling for the exercise-induced sore vastus lateralis muscle. Acta Physiol Scand 152: $265-277,1994$.

17. DOYLE JA, SHERMAN WM, STRAUSS RL. Effects of eccentric and concentric exercise on muscle glycogen replenishment. J Appl Physiol 74: 1848-1855, 1.993.

18. ENTMAN ML, KESLENSKY SS, CHU A, VAN WINKLE WB. The sarcoplasmic reticulura-glycogenolytic complex in mammalian fast twitch skeletal muscle. Proposed in vitro counterpart of the contraction-activated glycogenolytic pool. I Biol Chem 255: $6245-6252,1980$. 
19. FRIDEN I, SFAKIANOS PN, HARGENS AR, AKESON WH. Residual muscular swelling after repetitive eccentric contractions. JOrthop Res $6: 493-498,1988$.

20. GREEN HI. Mechanisms of muscle fatigue in intense exencise. I Sports So 15:247-256, 1997 .

21. HOWELL JN, CHLEBOUN G, CONATSER $\mathbb{R}$. Musele stiflness, strength loss, swellimg and soreness following exercise-induced injury in humans. J Physiol (Lond) 464 : 183 $196,1993$.

22. HULTMAN E, AND GREENHAFF PL. Skeletal muscle energy metabolism and fatigue during intense exetcise in man. Sci Prog 75:361-370, 1991

23. IDE K, HGAKI $Y$, NISHIZUMI M, KIYONAGA A, SHINDO M, TANAKA H: Impaired non-insulin mediated glucose uptalse after downhll rumning in rats. Life $5 \mathrm{c}$ i 3 : $1601-1605,1996$.

24. KAPUR S, BEDARD $S$, MARCOTTE B, COTE CH, MARETTHE A. Expression of nitwic oxide synthase in skeletal muscle: a novel role for mitric oxide as a modulator of insulin action. Diabetes $46: 1691-1700,1997$

25. KIRWAN JP, COSTILL DL, MITCHELL JB, HOUMARD JA, FLYNN MG, FIN WJ, BELTZ JD. Carbohydrate balance in competitive munners during successive dxys of intense training. J Appl Physiol 65: 2601-2606, 1988.

26. KOMI PV, AND VIITASALO JT. Changes in motor tuit activity and metabolism in humar skeletal muscle during and after repeated eccentric and concentric contractions. Acta Physiol Scand 100: 246-254, 1977.

27. KUIPERS H. Exercise-1nduced muscle damage. Im J Sports Med 15: 132 135, 1994.

28. LINDSTEDT SL, LASTAYO PC, REICH TE. When active muscles lengthen: properties and consequences of eccentric contractions. News Physiol Sci 1.6. 256-261, 2001.

29. LUND H, VESTERGAARD-POULSEN P, KANSTRUP IL, SEJRSEN $\mathbb{P}$. The effect of passive stretching on delayed onset muscle soreness, and other detrimental effects following eccentric exercise. Scand J Med Sci Sporis 8: 216-221, 1998.

30. MANFREDI TG, FIELDING RA, O'REILEY KP, MEREDITH CN, LEF HY, EVANS WJ. Plasma creatine kinase activity and exereise-induced muscle damage in older men. Med Sci Sports Exerc 23: 1028-1034, 1991.

31. MCCULLY KK, KENT JA, CHANCE B. Application of 31P magnetic resonance: spectroscopy to the study of athetic performatice. Sports Med $5: 312-321,1988$

32. MOCULY KK, ARGOV Z, BODEN BP, BROWN RL, BANK WJ, CHANCE B Detection of puscle injury in humans with $31 / \mathrm{P}$ magnetic resonance spectroscopy. Mascle Never 11:212-216, 1988.

33. NEWHAM DI, JONES DA, EDWARDS RH. Large delayed plasma creatine kinase changes after stepping exercise. Muscle Nerve 6:380-385, 1983 .

34. ORELLY KP, WARHOL MI, FELDRG RA, FRONTERA WR, MEREDITH CN. EVANS WJ. Eccentric exercise-induced muscle damage inapairs muscle glycogen repletion. I Appl Physial 63: 252-256, 1987.

35. PASCOE DD, COSTILL DL, ROBERGS RA, DAVIS JA, FINK WJ, PEARSON DR. Effects of exercise mode on muscle gllycogen restorage during repeated days of exercilse. Med Sci Sports Exerc 22: 593-598, 1990.

36. PASCOE DD, AND GLADDEN LB. Muscle glycogen resynthesis after shont term, high intensity exercise and resistance exercise. Sports Med 21:98-118, 1996.

37. PEDERSEN BK, OSTROWSKI K, ROHDE T, BRUUNSGAARD H. The cytokine response to strenuous exercise. Can J Phywiol Pharnacol 76:505-5』1, 1998 . 
38. PRICI TB, LAUREWT D, PETERSEN KT, ROTHMAN DL, SHULMAN GI. GIYCogen lodding allers mulsele glyogen resynthesis after exercise. $J$ Appl Physiol 88: 698-704, 2000 .

39. REID MB Role of nitric oxide in skeletal muscle: synthesis, distribution and functional importance. Acra Physiol Scand 162: 401-409, 1998.

40. ROBERGS RA. Nutrition and exercise determinants of postexemeise glycogen synthesis. Int $J$ Spont Nutr 1: $307-337,1991$.

41. RODENBURG JB, DEBOER RW, SCHERECK P, VANECHTELD CJA, BAR PR. Changes if phosphorus compounds and water content in skeletal muscle due to eccentric exercise. Eur I Appl Physiol 68: 205-213, 1994.

42. RODENBURG JB, DEGROOT MCH, VANECHTELD CJA, JONGSMA HJ, BAR PR. Phosphate metabolism of prior eccentrically loaded vastus medialis muscle during exercise in humans. Acka Physiol Scand 153:97-108, 1995.

43. RYSCHOW TW, FOWLER MD, WYSONG RE, ANTHONY A, BALABAN RS. Efliciency of human skeletal muscle in wivo: comparison of isometric, concentric, and eccentric muscle action. I Appl Physiof 83: 867-874, 1997.

44. SARIS WH, VAM ERP-BAART MA, BROUNS F, WLSTERTERP KR, TEN HOOR F. Study on food intake and energy expenditure during extreme sustained exercise the Tour de France. Int J Sports Med 10: 526-\$31, 1989.

45. SCHMIDT HH, AND WALTER U. NO at work. Cell 78: 919-925, 1994:

46. SIMONSEN JC, SHERMAN WM, LAMB DR, DERNBACH AR, DOKLE JA, STRAUSS R. Dietary carbohydrate, muscle glycogen, and power output during rowing training. I App/ Physiol 70: 1500-1505, 1991.

47. SORICHTER S, MAIR , KOLLER A, PELSERS MM, PUSCHENDORF B, GLATZ JF. Early assessment of exercise induced skeletal muscle injury nsing plasma fatty acid binding protein. Bir J Sports Med 32: 121-124, 1998 .

48. SPENCER RP. CRC Mandbook Series. In: Clinical Laboratory Science, Section A: Nuclear Medicine Volume I, Cleveland, CRC Press, p 165, 1977.

49. STARON RS, HIKIDA RS, MURRAY TF, NELSON MM, JOHNSON P, HAGERMAN F. Assessment of skeletal muscle damage in successiwe biopsies from strength-trained and tuntrained men and women. Eur $J$ Appl Physiol 65: 258-264, 1992.

50. WIDRICK IJ, COSTILL DL, MCCONELL GK, ANDERSON DE, PEARSON DR, ZACHWIDJA JJ. Thme course of glycogen accumulation after eccentric exercise. of Appl Physiol 72: 1999.2004, 1992. 


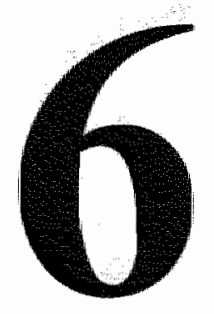

\section{High utilization of intramyocellular lipids by endurance trained males and females during prolonged cycling exercise}

${ }^{1,2,3}$ Zehnder M, ${ }^{2}$ Ith M, ${ }^{2}$ Kreis R, ${ }^{3}$ Saris W, ${ }^{~}$ Boutellier U, ${ }^{2}$ Boesch C.

${ }^{1}$ Exercise Physiology, Institute for Human Movement Sciences, Swiss Fedleral Institute of Technology Zurich and Institute of Physiology, University of Zurich, CH-8057 Zurich, Switzerland; ${ }^{2}$ Department of Clinical Research, MR Spectroscopy and Methodology, University of Berne, CH-3010 Berne, Switzerland; ${ }^{3}$ Nutrition and Toxicology Research Institute Maastricht, Department of Human Biology, Maastricht University, the Netherlands.

adapted version submitted in: Medicine \& Science in Sports \& Exercise. 


\section{ABSTRACT}

Purpose Gender differences in substrate utilization during exercise have been reported with women relying more on fat than men. It is not clear what the source is of the fatty acids oxidized. Therefore we wanted to investigate if gender differences exist in the utilization of intramyocellular lipids (IMCL). Methods IMCL concentrations and total fat oxidation were measured in 9 males $(\mathrm{M})$ and 9 females (F) before and after an endurance exercise. The trained volunteers exercised on a bicycle ergometer at $50 \%$ maximal workload for 3 hours. IMCL concentrations were determined in $m$. wastus intermedius by proton magnetic resonance spectroscopy at 1.5 Tesla. Oxygen uptake $\left(\mathrm{VO}_{2}\right)$ and carbon dioxide production were determined by open circuit spirometry and used to calculate total fat oxidation. Results The average total fat oxidation and its relative contribution to total energy used were not significantly different between $\mathrm{M}$ and F. M and F depleted IMCL significantly $(p<0.001)$ during the 3 -h exercise, but IMCL levels at rest (M:7.2 $\pm 2.9 \mathrm{mmol} \cdot \mathrm{kg}^{-1}$ wet weight (ww) and $\mathrm{F}: 4.7 \pm 1.7$ mmol $\cdot \mathrm{kg}^{-1}$ ww; $\left.\mathrm{p}<0.05\right)$ and its depletion during exercise $(\mathrm{M}: 4.2 \pm 1.6$ $\mathrm{mmol} \cdot \mathrm{kg}^{-1}{ }_{\mathrm{ww}}, \mathrm{F}: 1.8 \pm 0.6 \mathrm{mmol} \cdot \mathrm{kg}^{-1}$ ww; $\left.\mathrm{p}<0.001\right)$ showed significant differences between genders despite the fact that relative power output, $\%$ of maximum heart rate, $\% \mathrm{VO}_{2 \text { peak, }}$, and respiratory exchange ratio were the same. Conclusion We conclude that during the 3 -h exercise total fat oxidation was similar in both genders and males as well as females reduced their IMCL stores significantly. The larger contribution of IMCL during exercise in males compared to females could either be a result of gender-specific substrate selection, or different long-term training habit.

Key words $\mathrm{H}$-magnetic resonance spectroscopy, fat metabolism, endurance training 


\section{INTRODUCTION}

The main fuels oxidized by the muscle for energy production during exercise are fatty acids (FFA) and carbohydrates (CHO) and to a lesser extend possibly blood triglycerides and intramyocellular lipids (IMCL). The relative contribution of these substrates to energy expenditure depends on the exercise intensity and duration, diet, and training status of the subject. It has also been suggested that substrate use and the relative contribution of substrates are gender dependent. Although several studies have shown no gender differences in substrate utilization (e.g. $(39,41,42))$ the majority of studies $(6,13,19,33,51-53)$ have reported that women rely more on fat oxidation than men during prolonged exercise. Furthermore, men have been shown to acquire a greater proportion of their energy from muscle glycogen oxidation than women $(6,42,51)$.

Especially newer studies accumulate evidence that $\mathrm{IMCL}$ are an important energy source during exercise $(24,32,40,55,59)$ although this has not been shown in all studies $(15,25)$. It also has been shown by one study that IMCL is further reduced after exercise (26) and that it can be replenished by a diet containing moderate to high amounts of fat $(9,29,56,63)$. But it is still controversial and a matter of debate how the utilization of IMCL is regulated, and how much IMCL contribute to the total fat oxidation and total energy consumption during endurance exercise $(4,30,32,40)$. It is also less clear whether gender differences in the IMCL contribution to energy needs and in the storage of IMCL exist. One study found decreased IMCL levels in females after exercise, while in males IMCL levels was unaffected by exercise (50), another study found no difference in IMCL reduction between males and females (62). With regard to the storage of IMCL, Thamer et al. (54) measured significantly higher IMCL in soleus in males compared to females, and slightly but not significantly higher IMCL in tibialis in female than in male subjects.

These controversial results may be, in part, due to the methodology used, which Watt et al. pointed out in his review (60). Muscle biopsies and, on the other hand, indirect stable isotopic tracer methods $(40,41)$ have been used for many years. It has been shown that IMCL concentrations measured in repeated biopsy samples is variable, with a $\mathrm{CV}$ of $20-26 \%$ (61). Morphometrical analysis on the other hand is observer dependent (20). Assumptions that have to be made for the application of stable isotopes $(40,41)$ do not always hold true since (a) the contribution from circulating plasma triglycerides is neglected, and (b) if extramyocellular lipids (EMCL) would contribute locally to the energy demands of a muscle, this would lead to an overestimation of the IMCL oxidation. 
Localized 'H-magnetic resonance spectroscopy was recently introduced to measure IMCL concentrations non-invasiwely and safely $(4,44)$. Based on the observation that two methylene resonances from different fat compartments can be distinguished in skeletal muscle (44), the signals from IMCL (lipid droplets within a muscle cell) and EMCL (fat layers outside the muscle eell) have been characterized (4). In contrast to indirect methods, ${ }^{1} \mathrm{H}$-MRS of muscle tissue yield a resonance signal that is directly proportional to the concentration of $\mathrm{IMCL}$, thus allowing a determination of absolute $\mathbb{M M C L}$ concentrations (3) based on the signal from muscle water. Repeated 'H-MRS measurements allow for a follow up of depletion and replenishment of a major intramuscular component. Since repeated MR spectra can be obtained from exactly the same location in a muscle this method is less susceptible to regional variations of $\operatorname{IMCL}(4,20,21,38)$ than repeated biopsies.

The aims of this study were to investigate

whether it is possible with an adequate/appropriate endurance exercise protocol to highlly reduce IMCL in the m. vastus intermedius in both males and females, and

whether there is a gender difference in the utilization of IMCL during exercise at the same relative intensity in a group of trained males and females:

\section{METHODS}

\section{Subjects}

9 male and 9 female cyclists or triathletes participated in the study. All were well trained, involved in endurance exercise training programs for at least 3 times a week $(\geq 2 \mathrm{~h} /$ training session), and with a training history of at least 3 years. The recruited females were all eumenorrheic and the 3 -h exercise was performed during the follicular phase between the third and eighth day. The mean \pm SD age and weight were $M: 34 \pm 4 y$ vs. F: $30 \pm 4 y$, and $M: 73.9 \pm 8.4 \mathrm{~kg}$ vs. E: $58.9 \pm 5.6 \mathrm{~kg}$, respectively. There was no difference in the percentage of measured body fat between genders (M: $9.2 \pm 5.5 \%$ vs. F: $8.8 \pm 3.1 \%$ ). All subjects signed an informed consent form, including nutritional and activity guidelines, before admission into the study. The institutional Ethic's Committee approved the experimental protocol. 


\section{Preliminary testing}

In order to evaluate training status and maximal workload, the subjects performed a maximal workload ( $W_{\max }$ )-test on a cycle ergometer (Ergometrics 800 S, Ergoline, Bitz, Germany) at least one week before the experiment. The test took place after an overnight fast that followed a day without exercise and with consumption of carbohydrate rich meals. After $2 \mathrm{~min}$ of rest, male subjects started exercising at a work rate of $100 \mathrm{~W}$ for $2 \mathrm{~min}$; females at a work rate of $60 \mathrm{~W}$ for $2 \mathrm{~min}$ whereas the pedal rate had to been kept above 80 revolutions per min (rpm) throughout the whole test. Resistance was increased for maies in $30 \mathrm{~W}$ steps, for females in $20 \mathrm{~W}$ steps every 2 min until exhaustion. Oxygen uptake $\left(\mathrm{VO}_{2}\right)$, carbon dioxide production $\left(\mathrm{VCO}_{2}\right)$, and heart rate were continuously monitored. $\mathrm{VO}_{2}$ and $\mathrm{VCO}_{2}$ were determined by an open-circuit system (Oxycon B, Jäger, Höchberg, Germany), while the cardiac frequency was measured by a heart rate monitor (Polar Vantage NV, Electro, Kempele, Finland). The highest intensity that the subjects could maintain for at least $1 \mathrm{~min}$ by a pedal rate above $80 \mathrm{rpm}$ defined as the subjects' voluntary $\mathrm{W}_{\text {max }}$ and was scored as $100 \%$. VO $\mathrm{V}_{2 \text { penk }}$ was defined as the highest value reached in a $30-5$ period.

\section{Diet monitoring}

Since IMCL concentrations can be influenced by diet (e.g.(9)), short-term nutritional intake was standardized and monitored. During the 2 days prior to the trials, diet was controlled and volunteers received a nutrition protocol for each meal (breakfast, lunch, dinner and snacks) and were instructed to choose from a selection of food and beverages. Detailed food exchange lists with serving sizes (e.g., dried fruits, gingerbread, rice pudding, pasta, rice, soft drinks, dairy products, beef, tuna, tofu) were used for nutrient recommendations. Any change of the diet recommendation had to be documented by the volunteers. The day before the test, an additional amount of at least $0.75 \mathrm{~g} \mathrm{fat} \cdot \mathrm{kg}^{-1}$ body weight (bw) was provided by $3-4$ fat-rich snacks in order to replenish IMCL stores. Subjects were also asked to renounce caffeine-containing beverages $24 \mathrm{~h}$ before exercise. The food records (Table 1 ) for carbohydrate, fat, and protein contents as well as for the total amount of energy were analyzed by a computer based nutrient analysis program (EBIS 2.0; E+D Partner, Stuttgart, Germany).

\section{Experimental protocol}

For the exercise endurance test, subjects reported after a day without any exercise and an overnight fast to the MR-Center of the Inselspital in Berne (Switzerland) at $7 \mathrm{am}$ and were positioned in the magnet for the magnetic resonance measurements. The pre-exercise measurements of IMCL were obtained between $7.30 \mathrm{am}$ and $8.15 \mathrm{am}$. The exercise on a bicycle ergometer started at $08: 30 \mathrm{am}$ 
and continued for 3 hours (h) with constant revolutions $(70-75 \mathrm{rpm}$ ) at an intensity of $50 \% \mathrm{~W}_{\text {max }}$ corresponding to $60-65 \%$ VO2peat This exercise intensity was chosen since it should optimize fat oxidation (1). The number of rpm were carefully supervised since higher frequencies seem to prefer the activation of type II muscle fibers $(31,43)$, which, in turn, contain less IMCL than type I fibers (12). A preliminary test of one individual at our own institution supported this hypothesis since much less IMCL was used at rpm's between 80 and 90 . During the endurance test; the heart rate was recorded continuously (Polar Electo, Kempele, Finland). To determine total fat oxidation by indirect calorimetry, subjects were connected by a facemask with a gas analyzer for $\mathrm{VO}_{2}$, $\mathrm{VCO}_{2}$ and volume (Oxycon $B$, Jäger, Höchberg, Germany). Following calibration of the gas analyzers before each experiment, expired gases were measured intermittently (every $18 \mathrm{~min}$ for at least $6 \mathrm{~min}$ ) for $\mathrm{O}_{2}$ (paramagnetic) and $\mathrm{CO}_{2}$ (infrared). During cycling, the subjects were allowed to drink water ad libitum. limmediately after exercise, subjects were repositioned in the magnet and the identical MR measurements as before the 3-h cycling test were done.

\section{Magnetic resonance (MR)}

MR imaging and spectroscopy examinations were done on a clinical 1.5 Tesla MR system (SIGNA, General Eleetric, Milwaukee WI, USA), using a flexible, dual tuned surface coil (Medical Advance, Milwaukee, WI, USA) placed over the m. quadriceps femoris. A cast fixed the right leg such that the shape of the thigh muscles was the same before and after exercise and that the coil could be placed identically. Careful and reproducible placement of the 'H-MRS voxel, i.e., a sensitive volume where the IMCL signal is coming from, is crucial. Following localizer series (gradient echo, $30^{\circ}$ flip angle, a repetition time (TR) $100 \mathrm{~ms}$, echo time (TE) $6.8 \mathrm{~ms}$ ), a volume $11 \mathrm{~mm} \times 12 \mathrm{~mm} \times 18 \mathrm{~mm}$ without any sign of fatty infiltration was defined (Fig. 1).

Figure 1. Transwersal MR image of a thigh with voxell placed in m. vastus intermedius. The woxel positioning avoids any sign of adipose tissue (extramyocelluar lipids) in fasciae or subeutancous fat

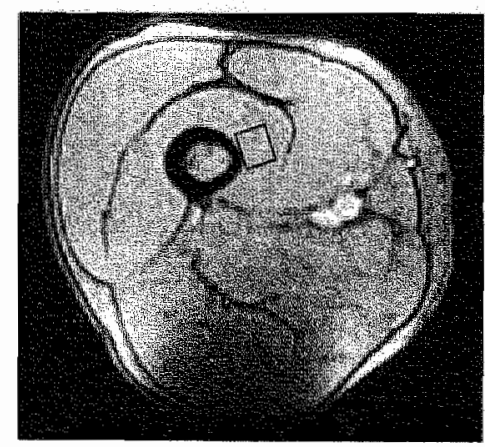


The voxel was positioned in the $m$. vastus intermedius close to the femoral bone. $M$ vastus intermedius was chosen because of its similarity to $m$ vasfus lateralis (57). Measuring IMCL by 'H-MRS, m. vastus intermedius shows a higher reproducibility and less contamination of extramyocellular lipids (EMCL) compared to $m$ : vastus lateralis (3). Additionally, both muscles reduce IMCL equally during endurance cycling (unpublished own data), and are composed of predominantly red skeletal muscle (58), thus showing larger IMCL concentrations than a muscle with primarily white muscle fibers $(11,30)$.

${ }^{\mathrm{I}} \mathrm{H}-\mathrm{MR}$ spectra were recorded by an optimized PRESS sequence with a TE of $20 \mathrm{~ms}$, a TR of $3000 \mathrm{~ms}, 128$ acquisitions, and 16 phase rotation steps. Fitting of IMCL and EMCL in water suppressed spectra by four Voigt lines each $(3,4)$ was followed by absolute quantification of IMCL (in mmol $\cdot \mathrm{kg}^{-1}$ wer weight), based on the signal of water in a TE series of free induction decays obtained without water suppression (3). Figure 2 shows representative spectra of one volunteer before and after the exercise, including the difference spectrum that shows almost exclusively the IMCL resonances that are used to quantify this metabolite.

Figure 2. "H-MR spectra before (lower trace) and after a 3-h exercise (middle trace) of a male subject, the difference spectrum between pre- and post-exercise (top trace) shows the resonance lines of intramyocellular lipids (IMCL)

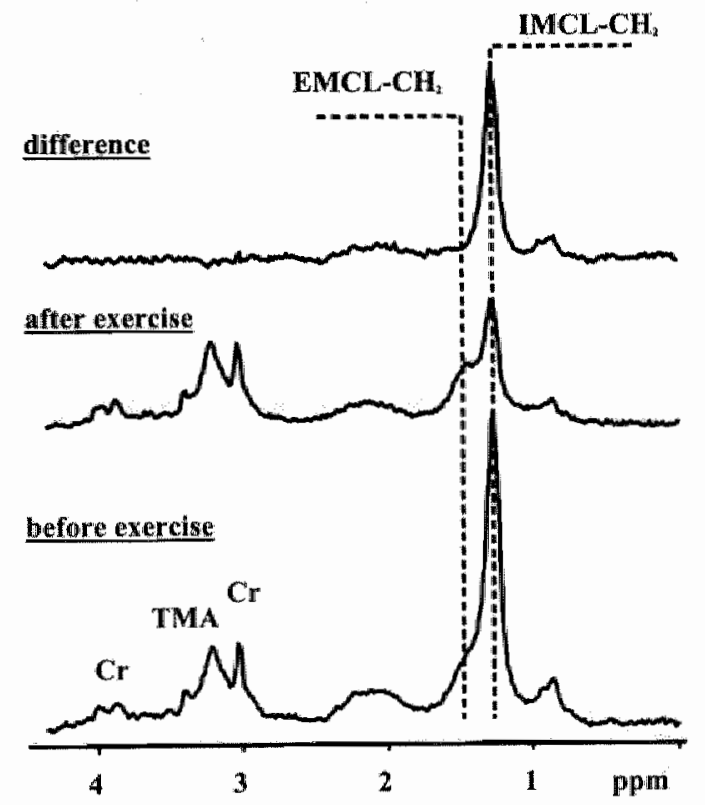

The peak of IMCL-methylene groups (IMCL-CH2) is used for a determination of IMCL concentrations, $\mathrm{EMCL}=$ extramyocellular lipids 


\section{Borg scale}

During the 3-h exercise, each subject rated its perceived exertion according to the Borg scale (5). After the standardized question of "how do you score the exertion?" the subject read from a visible scale a number between 6 ( $<$ very, very light) and 20 ( $>$ very, very hard). The recording was performed always by the same investigator.

\section{Determination of body fat free mass, total fat oxidation, and total energy used}

Skin-fold was measured with a caliper (GPM Siber Hegner, Zurich, Switzerland) at ten different locations of the body (cheek below temple, throat, chest, midaxillary, suprailiac, abdomen, triceps, subscapular, calf, and thigh above patella) before each 3 -h exercise. The same person always performed the measurements with a subject, and the average of 3 determinations of each measuring site was taken as a valid result for the calculation of the fat free mass following a formula given by (45).

Whole body fat oxidation rate was estimated from expired $\mathrm{VO}_{2}$ and $\mathrm{VCO}_{2}$, assuming the non-protein respiratory quotient (36):

Fat oxidation $\left(\mathrm{g} \cdot \mathrm{min}^{-1}\right)=\left(1.695 \cdot \mathrm{VO}_{2} \mathrm{ml} \cdot \mathrm{min}^{-1}-1.701 \cdot \mathrm{VCO}_{2} \mathrm{ml} \cdot \mathrm{min}^{-1}\right) \cdot 1000^{-1}$

CHO oxidation $\left(\mathrm{g} \cdot \mathrm{min}^{-1}\right)=\left(4.585 \cdot \mathrm{VCO}_{2} \mathrm{ml} \cdot \mathrm{min}^{-1}-3.226 \cdot \mathrm{VO}_{2} \mathrm{ml} \cdot \mathrm{min}^{-1}\right) \cdot 1000^{-1}$

Total energy was calculated by adding total energy expenditure from fat and CHO oxidations.

\section{Statistical analysis}

Differences within each group were tested by two-way analysis of variance (MANOVA) for repeated measures, followed by Bonferroni adjustment for multiple comparisons (SPSS 11.0). Differences between females and males were analyzed by a two-sided unpaired $t$-test. Linear regression analysis was performed with standard procedures, using Excel XP (Microsoft). Statistical significance was set at $\mathrm{p}<0.05$.

\section{RESULTS}

\section{Preliminary testing}

The maximum power $\mathrm{W}_{\max }$ that has been produced by at least 1 min during the $\mathrm{VO}_{2 \text { nax }}$-test was significantly $(\mathrm{p}<0.001)$ higher in males $(368 \pm 22 \mathrm{~W})$ than in females $(240 \pm 20 \mathrm{~W})$. Maximal oxygen uptake $\mathrm{VO}_{2 \text { Peak }}$ was also significantly 
$(\mathrm{p}<0.002)$ higher in males $\left(4363 \pm 488 \mathrm{ml} / \mathrm{min}=60 \pm 8 \mathrm{ml} \cdot \mathrm{min}^{-1} \cdot \mathrm{kg}^{-1} \mathrm{bw}=\right.$ $65 \pm 7 \mathrm{ml} \cdot \mathrm{min}^{-1} \cdot \mathrm{kg}^{-1}$ lean bw) than in females $(2853 \pm 325 \mathrm{ml} / \mathrm{min}=48 \pm 4$ $\mathrm{ml} \cdot \min ^{-1} \cdot \mathrm{kg}^{-1}$ bw $=53 \pm 4 \mathrm{ml} \cdot \mathrm{min}^{-1} \cdot \mathrm{kg}^{-1}$ lean bw).

Relative parameters, however, did not differ between genders, such as $\mathrm{VO}_{2 \text { pealk }}$ standardized by $W_{\max } \quad \mathrm{M}: 11.9 \pm 1.1 \quad \mathrm{ml} \mathrm{VO}_{2} \cdot \min ^{-1} \cdot \mathrm{W}^{-1}, \quad \mathrm{~F}: 11.9 \pm 0.7$ $\mathrm{ml} \mathrm{VO} \mathrm{O}_{2} \cdot \min ^{-1} \cdot \mathrm{W}^{-1}$ ), and also maximal heart rate per min (M: $182 \pm 11$ beats $\cdot \min ^{-1}, F: 183 \pm 10$ beats $\cdot \min ^{-1}$ ).

\section{Diet analyses}

Table 1 shows that there was no difference between genders in the average intake of $\mathrm{CHO}$, fat, protein $\left(\mathrm{g} \cdot \mathrm{d}^{-1} \cdot \mathrm{kg}^{-1}\right.$ lean bw) and energy $\left(\mathrm{kJ} \cdot \mathrm{kg}^{-1}\right.$ lean bw) before the trial. In relation to the total energy uptake, the percentage intake of fat, CHO, and protein was also not significantly different between genders.

Table 1. Daily average intake of macronutrients and energy by male and female subjects during the 2 days prior to the exercise

\begin{tabular}{llll}
\hline & & males $(\mathrm{N}=9)$ & fermales $(\mathrm{N}=9)$ \\
\hline \% energy & CHO & $48 \pm 9$ & $55 \pm 9$ \\
& Fat & $41 \pm 8$ & $35 \pm 8$ \\
$\mathrm{~g}$ & Protein & $14 \pm 3$ & $13 \pm 2$ \\
& CHO & $529 \pm 129^{*}$ & $500 \pm 112$ \\
& Fat & $215 \pm 100^{* *}$ & $112 \pm 21$ \\
energy & protein & $157 \pm 53 * *$ & $93 \pm 22$ \\
$\mathrm{~g} \cdot \mathrm{kg}^{-11}$ lean bw & kJ & $19772 \pm 5757^{* *}$ & $12672 \pm 1961$ \\
& CHO & $8.0 \pm 2.5$ & $7.6 \pm 2.3$ \\
& Fat & $3.3 \pm 1.8$ & $2.1 \pm 0.4$ \\
$\mathrm{~kJ} \cdot \mathrm{kg}^{-1}$ lean bw & protein & $2.4 \pm 0.9$ & $1.8 \pm 0.4$ \\
\hline
\end{tabular}

Values are means $\pm \mathrm{SD}^{*}=\mathrm{p}<0.05_{*} *=\mathrm{p}<0.01$ significantly different from females, $\mathrm{CHO}=$ carbohydrate, bw $=$ body weight

\section{Experimental protocol}

As the absolute power output $W_{\max }$ on the bicycle ergometer showed a significant difference between males and females, the workload of $50 \% \mathrm{~W}_{\max }$ during the endurance exercise, corresponding to $184 \pm 11 \mathrm{~W}$ for males and $120 \pm 10 \mathrm{~W}$ for females, respectively, was also different $(p<0.001)$. In contrast, the percentage

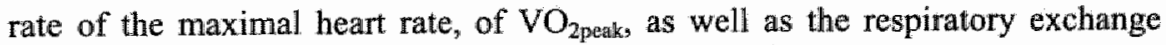
ratio ( $R E R$ ) were the same in males and females (Table 2). 


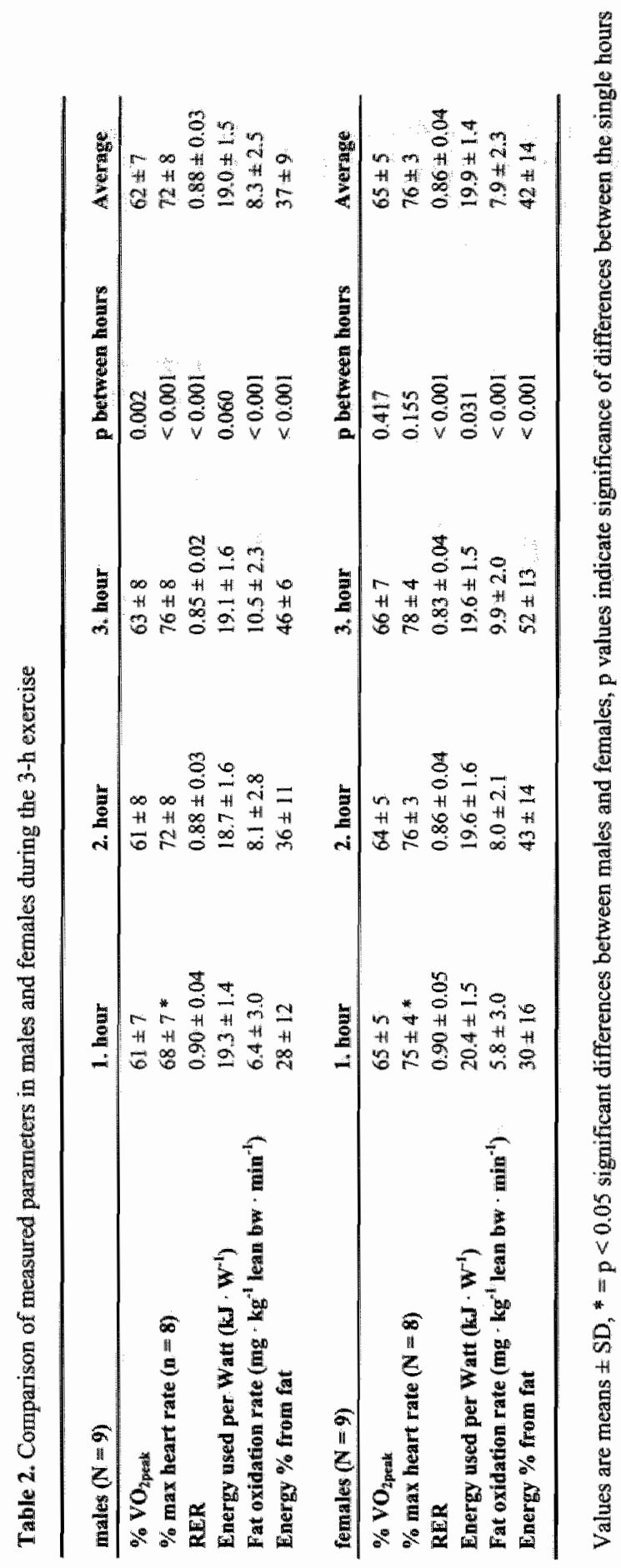


The RER changed significantly only within the group over time. Both gender scored the perceived exertion during exercise similarly, which was between " 12 " - "fairly light" and "14" - "somewhat hard". Average oxygen uptake per workload (M: $14.54 \pm 1.19 \mathrm{ml} \mathrm{O}_{2} \mathrm{~min}^{-1} \cdot \mathrm{W}^{-1}, \mathrm{~F}: 15.36 \pm 0.08 \mathrm{ml} \mathrm{O}_{2} \mathrm{~min}^{-4} \cdot \mathrm{W}^{-1}$ ) was the same in both genders.

\section{Magnetic resonance}

Figure 3 shows a higher IMCL concentration in males $\left(7.2 \pm 2.9 \mathrm{mmol} \mathrm{kg}^{-1}\right.$ ww $)$ compared to females $\left(4.7 \pm 1.7 \mathrm{mmol} \mathrm{kg}^{-1}{ }_{\mathrm{ww}}\right)$ before exercise $(\mathrm{p}<0.05)$, and indistinguishable values after exercise $\left(\mathrm{M}: 3.0 \pm 1.5 \mathrm{mmol} \cdot \mathrm{kg}^{-1}{ }_{\text {ww; }}\right.$; F: $2.9 \pm 1.7 \mathrm{mmol} \cdot \mathrm{kg}^{-1}{ }_{w w}$ ). The reduction of IMCL during the 3-h trial was highly significant in both males and females $(p<0.001)$, but was larger in males compared with females in absolute (M: $4.2 \pm 1.6 \mathrm{mmol} \cdot \mathrm{kg}^{-1}{ }_{\mathrm{ww}}$; $\left.\mathrm{F}: 1.8 \pm 0.6 \mathrm{mmol} \cdot \mathrm{kg}^{-1}{ }_{\mathrm{ww}}, \mathrm{p}<0.001\right)$ as well as in relative terms (M: $59 \pm 11 \%$; F: $42 \pm 14 \%, p=0.01$ ).

Figure 3. Intramyocellular lipids (IMCL) concentrations of 9 males and 9 females before and after a 3 -h exercise (dotted lines), the group averages are shown in fat lines

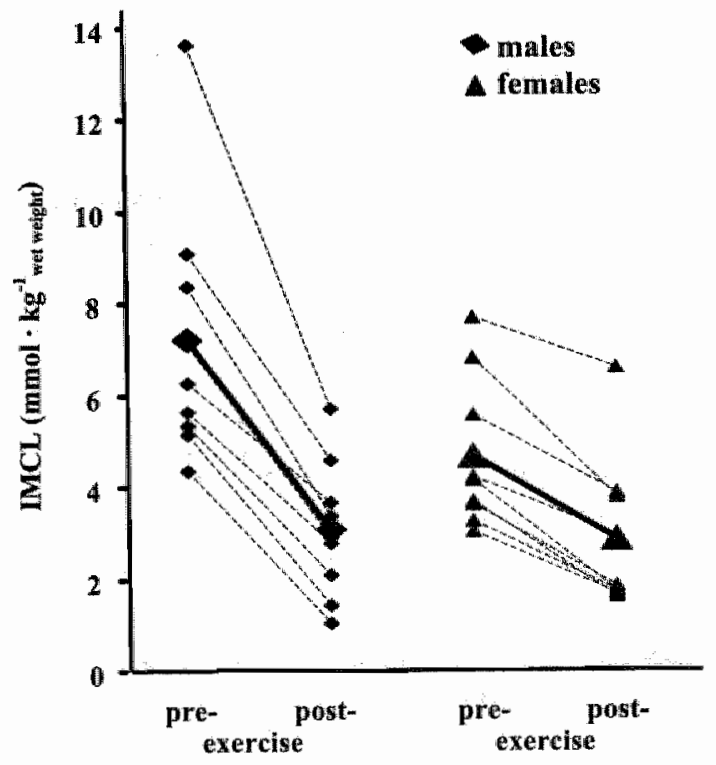

Figure 4 shows a strong correlation $(r=0.83)$ between $\mathrm{MCL}$ levels prior to exercise and the reduction of IMCL during the $3 \mathrm{~h}$ trial if both genders are pooled. The correlation remains for males $(y=0.37+1.64 x, p<0.001, r=0.93)$ 
however, it vanishes if females are analyzed separately $y=3.86+0.39 x$, $p=0.71, x=0.14)$.

Ngare 4 Correlation of intramyocellular lipids (MMCL) concentrations before exercise and the reduction during exercise for males and females combined, $(y=211+1.28 x, r=0.83)$

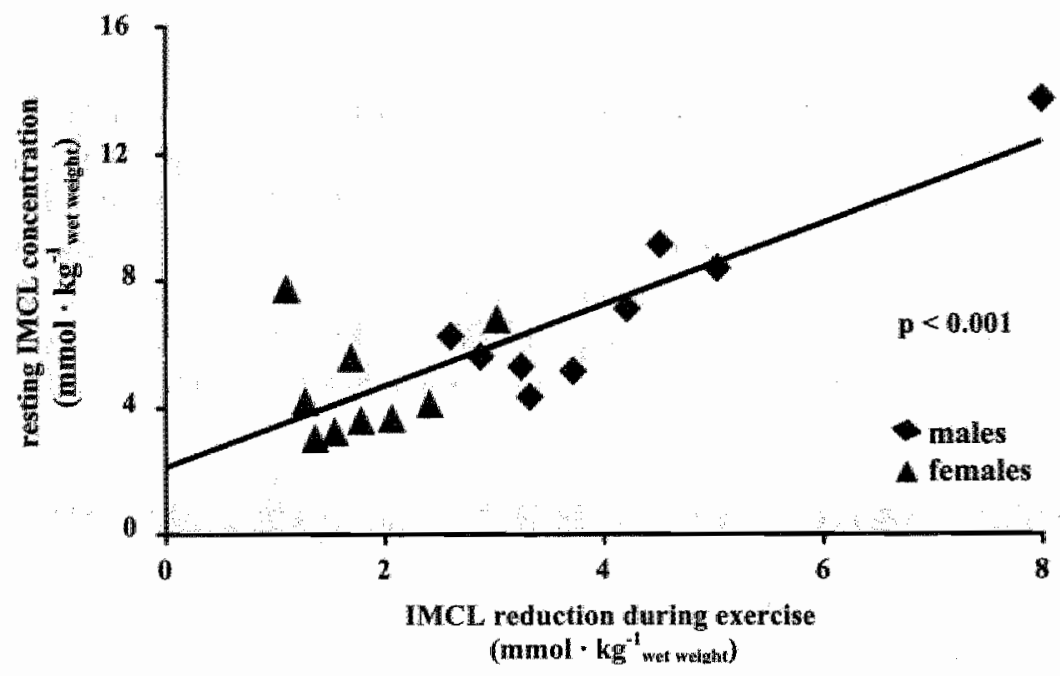

In males and in females, there was no correlation between the total fat oxidation and the $\mathrm{MCL}$ concentration at rest $(\mathrm{M}: \mathrm{r}=0.08, \mathrm{p}=0.82 ; \mathrm{F}: \mathrm{r}=0.05, \mathrm{p}=0.89$ ) nor the IMCL depletion $(\mathrm{M}: r=0.01, p=0.97 ; \mathrm{F}: \mathrm{r}=0.33, \mathrm{p}=0.38$ ). Pooling both genders, a weak correlation between relative $\mathrm{DMCL}$ depletion and total fat oxidation $(r=0.48, p<0.05)$ was found. Furthermore, there was no correlation between the amount of IMCL stores at rest, i.e., after the additional fat rich snacks, and the fat intake during the 2 days before the exercise in $m$. vastus internedius, neither in males nor in females (M: $r=0.35, p=0.36 ; F: r=0.17$, $p=0.67$ ). Figure 5 shows that subjects with higher lean bw have generally higher concentrations of IMCL at rest (5A) and are reducing larger amounts of IMCL during exercise $(5 \mathrm{~B})$. There was no correlation between $\mathrm{VO}_{2 \text { peak }}$ and resting IMCL in males $(r=0.04, p=0.91)$, yet a trend could be identified in females $(\mathrm{r}=0.52, \mathrm{p}=0.15)$. 
Figure 5. Relationship between intranyocellular lipids (IMCL) concentration before exercise $($ A, $y=5.61+0.192 x, r=0.581)$, the reduction during exercise $(B, y=5.49+0.141 x$, $\mathrm{r}=0.659$ ) (in mmol $\cdot \mathrm{kg}^{-1}$ wer weight) and the lean body weight of males and females

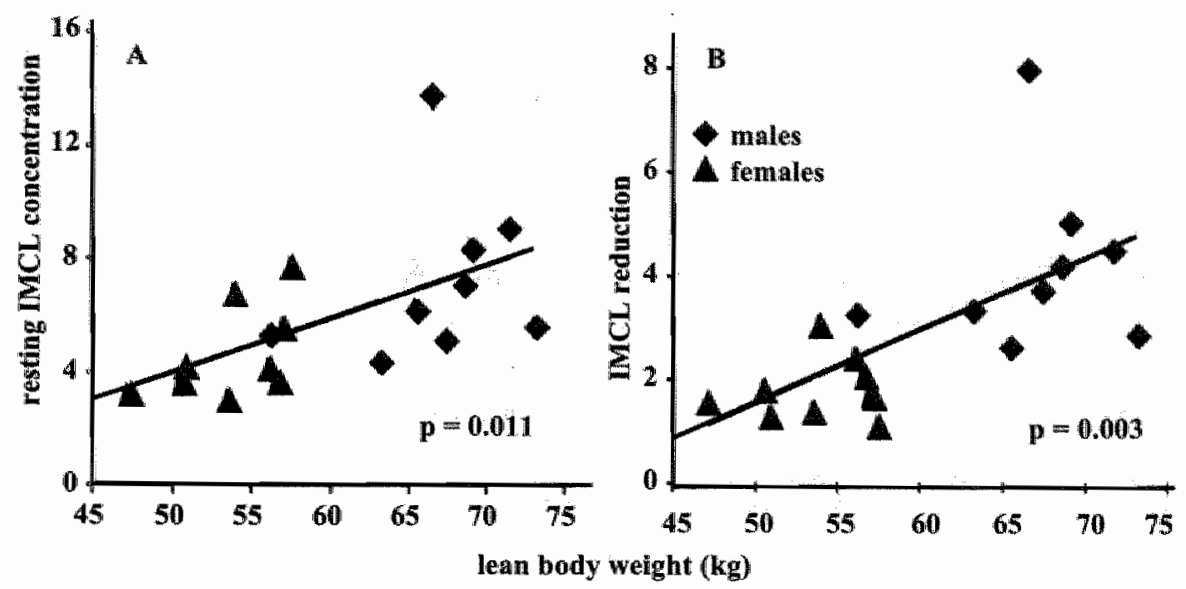

\section{Fat oxidation}

Figure 6 shows the fat oxidation rates in $\mathrm{g}$ per $\mathrm{kg}$ lean bw per min during the single hours and the average over the $3-\mathrm{h}$ exercise for males and females. Average total fat oxidation in $g$ per min during the endurance exercise was $0.56 \pm 0.17 \mathrm{~g} \cdot \mathrm{min}^{-1}$ in males and $0.43 \pm 0.14 \mathrm{~g} \cdot \mathrm{min}^{-1}$ in females, which did also not significantly differ from each other.

Figure 6. Average fat oxidation in $\mathrm{mg}$ per $\mathrm{kg}$ lean body weight per minute during hour $1-3$ of the endurance exercise in males and females and the average over the whole period

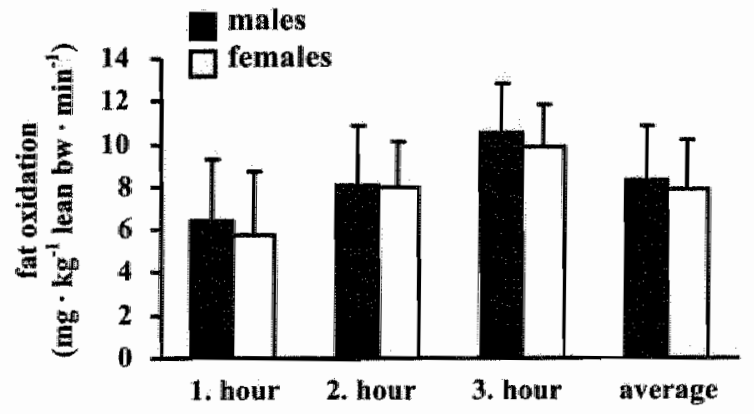

Values are means $\pm \mathrm{SD}$, the bourly increase in fat oxidation was highly significant in both genders (Table 2) 


\section{DISCUSSION}

The most remarkable result of this study is that females as well as males were able to highly reduce their IMCL concentrations during the 3 -h exercise test. Male athletes stored higher levels of IMCL than females and, subsequently. depleted more IMCL in absolute as well as in relative terms. In contrast, the average total fat oxidation measured during the 3 -h exercise did not differ between genders.

There are a series of potential explanations for the observed dissimilarity between the groups, which will be discussed, in the following paragraphs.

The short-term diet of the subjects before exercise has been closely monitored (Table 1) and showed a trend to slightly higher fat intake in males compared to females. Even if this trend did not reach statistical significance for fat uptake relative to bw, relative to lean bw, or rellative to total energy consumed, one has to consider that higher IMCL levels at rest in males could be partially due to this factor. It also has to be considered, that there was one male subject who had $113 \%$ more resting IMCL than the average of all the other male subjects. If we delete this value the difference between resting $I M C L$ concentrations in males and females barely persists $(p=0.048)$. On the other hand, there was no correlation found between the fat intake during the 2 days before the main exercise and the IMCL-stores in $m$. vastus intermedius at rest. Since Décombaz and coworkers (9) showed no difference in IMCL replenishment when they fed the subjects with 40 or $70 \%$ fat energy, one could speculate that the additional fat-rich snacks prior to the first MR-examination were sufficient to fill the IMCL stores such that any minor differences in the diet of the preceding 2 days would have been compensated. In addition, females showed a higher skeletal muscle triglyceride uptake compared to males after the same amount of fat intake (50). Literature reports several mechanisms to increase IMCL levels via increased free fatty acid levels in plasma. While it has been shown that $72 \mathrm{~h}$ fasting can increase IMCL levels (47), it has also been shown that IMCL concentration increased after a high-fat diet $(10,48)$ or infusion $(2)$ and that IMCL content was inversely related to dietary carbohydrate intake $(9,24)$.

Since endurance training over a longer period of time enhances the IMCL concentration at rest $(17,25)$, and the capacity to oxidize IMCL during an endurance exercise (32), long-term training habits were evaluated. In this study, females and males were both endurance-trained healthy athletes matched for age and training history. However, differences between the types of training and intensity cannot be excluded and have most likely led to the higher $\mathrm{VO}_{2 \text { peak }}$ in males compared to females. Since this parameter is often associated with a better 
training status, we cannot exclude that higher IMCL concentrations in males are partially due to this difference between the two groups:

It is also possible that the performed workloads during the training sessions were in a more optimal range to stimulate fat metabolism in males compared to females.

Given that some lean subjects ( 2 females, 1 male) were included in this study, one has also to consider that a determination of body fat by measuring skin-folds with a caliper can lead to an underestimation of body fat in very slim athletes.

In order to make results from the two groups comparable, it was necessary to require equal relative performance of both genders, standardized by $\mathrm{VO}_{2 p e a k}$ and average maximal heart rate. Both genders scored the perceived exertion as "somewhat hard", and physiological parameters averaged over the 3-h exercise, such as the average percentage of maximal heart rate and of $V_{2 \text { peak, }}, R E R$, energy used per workload, average fat oxidation rate, and average oxygen uptake per workload were the same in both genders (Table 2).

Since type I fibers contain three times more IMCL than type II fibers $(11,21)$ and are predominantly recruited during endurance exercise (22), a systematic dissimillarity between the types of muscle fibers could explain gender-specific differences in IMCL levels and depletion. However, literature on gender-specific fiber type distribution is controversial. While some studies showed less type $\mathbb{I}$ fibers in $m$. vastus lateralis in females compared to males (27), other groups did not detect significant differences in untrained females and males (49) or endurance trained subjects of both genders (50). Some publications even found more type I fibers in females, (e.g. (35)). It is also noteworthy that the crosssectional area of all three major fiber types was larger for males compared to the respective fiber types in females (49). Bachmann and coworkers (2) observed larger absolute changes of IMCL in soleus compared to tibialis anterior muscle and explain this observation by differences in the fiber type composition.

IMCL depletion is strongly correlated with IMCL levels at rest if male and female values are pooled (Fig.4). However, if both genders are looked at separately, the correlation remains in males, while it disappears for females even if specific points are omitted that seem to influence this result most prominently. Since the values for females are much closer together than in males this finding may partially result from the smaller dynamic range that could jeopardize the correlation of noisy data. Previous transversal studies confirm that higher IMCL concentrations lead to a greater degree of IMCL breakdown during exercise, e.g. in insulin dependent diabetic and healthy men (46) or in women and/or men $(50,62)$. Dietary intervention studies reached a similar conclusion from either indirect (8) or direct (24) determination. 
It is unclear how the hormonal status may influence the IMCL content specifically. Some evidence has been found that the adrenergic system may play an important role in the activation of lipolysis of IMCL. Cleroux and coworkers (7) showed that MMCL utilization during an endurance exercise was completely blocked by a nonselective beta-blockade and in the study of Froberg et al., (14) a 4-h infusion of noradrenalin resulted in a significant reduction of resting IMCL concentration in male subjects. In addition, the catecholamine response is greater in men compared to women during the same relative workload (19), resulting in a higher activity of the hormone-sensitive lipase, which is responsible for IMCL hydrolysis (28). Other groups (18) investigated the variations of the sex hormones during the menstrual cycle and their influence on energy metabolism. Perseghin et al: (37) presented various explanations for the differences between IMCL accumulation and utilization between genders. E.g. they suggest that nonobese men may maintain low IMCL content due to a greater ability to metabolize fatty acids in the oxidative pathways. Bachmann et al. (2) and White and coworkers (62) present different mechanisms, which help explain MMCL metabolism, even most of them are still speculative. E.g. the increase of $\mathrm{MMCL}$ may be induced by the activation of acetyl-CoA carboxylase and fatty acid synthase and a potential regulator of IMCL mobilization and use includes altered muscle hormone-sensitive lipase activity.

Since no venous blood samples were taken in this study, no plasma metabolites could be determined, e.g., hormones or free fatty acids.

Our study found higher IMCL levels and depletion in males compared to females. This is in disagreement with other studies, which found enhanced resting IMCL and utilization during exercise in females compared to males (50) or no change during exercise $(16,23)$. The reason for this discrepancy is not obvious: Considering the resting conditions, the discrepancy could be explained by the applied method ( 50 ), in the recruitment of a different type of subject (sedentary instead of well trained athletes), different diet regimes (2), or in the measurement of different muscle groups $(37,54)$. Nevertheless $m$. lateralis, which is mostly chosen for IMCL analysis in connection with endurance exercise, acts similarly as $m$. intermedius in female and male athletes (unpublished own data).

Another study also used "H-MRS to determine IMCL before and after exercise in females and males (62). If they calibrated IMCL by the water signal as it is done in our study, resting IMCL was $20 \%$ and its utilization $30 \%$ higher in males compared to females. The lack of significance in these results is probably due to the large between subject variability of IMCL decrements in both gender. 
Considering IMCL depletion, exercise studies are strongly dependent on the specific workload, duration, and intensity. A major difference between other investigations $(50,62)$ and this study is the duration of the workload, which was typically not longer than $90 \mathrm{~min}$ in the cited publications. As an additional factor, we found a remarkable influence of the pedal rate on the IMCL depletion in a pilot experiment. The subject working at higher crank speed during a preliminary test depleted less IMCL compared to when he was working at lower speed (70$75 \mathrm{rpm}$ ). This finding may be explained by increased recruitment of type II muscle fibers, which contain less IMCL than type I fibers, at higher crank speed from $50 \mathrm{rpm}$ up to $120 \mathrm{rpm}$ (31). According to this study, the mean optimal cadence was $70 \mathrm{rpm}$ for $200 \mathrm{~W}$ and $57 \mathrm{rpm}$ for $100 \mathrm{~W}$. This would mean that the cadence chosen for our female subjects $(70-75 \mathrm{rpm})$ was too high, as they cycled the 3-h exercise with an average of $120 \mathrm{~W}$. This in turn could be a reason for the lower IMCL degradation in females. We did not find any other endurance exercise study, which looked at IMCL degradation and at the same time strictly controlled crank speed.

The average total fat oxidation measured during the $3 \mathrm{~h}$ was similar in both genders. Since males used more IMCL than females, the latter had to use another fat source as energy supply, most probably free fatty acids (34). As indirect calorimetry gives estimates for whole body lipid oxidation, one has to consider that fat oxidation in the liver could contribute to the results.

\section{CONCLUSION}

This study, investigating well-trained athletes both genders, revealed a high decrease in IMCL concentrations in females as well as in males during a submaximal 3-h endurance exercise. Additionally, the reduction of IMCL during the 3-h trial was larger in males compared to females. Since the relative parameters, such as $\% \mathrm{VO}_{2 \text { peaks }}$, $\mathrm{RER}$, energy used per Watt, and fat oxidation rate were comparable between the two groups and the methodological variations were minimized, in these trained individuals, a sex-specific difference in IMCL. utilization may explain the results. However, $\mathrm{VO}_{2 \text { peak }}$ per $\mathrm{kg}$ lean bw was higher in males compared to females. This fact points to a better training state in males and may have partly contributed to the gender differences in IMCL utilization found in this study. 


\section{ACKNOWLEDGEMENT}

We are very grateful to $\mathrm{K}$. Zwygart-Briggger and $\mathrm{B}$. Jung for their assistance during the MR-measurements, to $\mathrm{H}$. Hoppeler for his help with initial experiments, to I.-P. Schmid and R. Steiner for the generous offer to use their lab space, and to J. Décombaz from the Nestlé Research Center in Lausanne for critical review of the manuscript. This study was supported by the Swiss Society of Nutrition Research (Project 290) and by the Swiss National Science Foundation (3100-065315.01). 


\section{REFERENCES}

1. ACHTEN J, GLEESON M, JEUKENDRUP AE. Determination of the exercise intensity that elicits maximal fat oxidation. Med Sci Sports Exerc 34: 92-97, 2002.

2. BACHMANN OP, DAHL DB, BRECHTEL $K$, MACHANN J, HAAP M, MAIER T, LOVISCACH M, STUMVOLL M, CLAUSSEN CD, SCHICK F, HARING HU, JACOB $S$. Effects of intravenous and dietary lipid challenge on intranyocellular lipid content and the relation with insulin sensitivity in humans. Diabetes 50: 2579-2584, 2001 .

3. BOESCH C, DECOMBAZ J, SLOTBOOM J, KREIS R. Observation of intramyocellular lipids by means of $1 \mathrm{H}$ magnetic resonance spectroscopy. Proc Nutr Soc 58: $841-850$, 1999.

4. BOESCH C, SLOTBOOM J, HOPPELER H, KREIS R. In viwo determination of intramyocellular lipids in human muscle by means of localized 1H-MR-spectroscopy. Magn Reson Med 37: 484-493, 1997.

5. BORG GA. Psychophysical bases of perceived exertion. Med Sei Sports Exerc 14: 377. $381,1982$.

6. CARTER SL, RENNIE C, TARNOPOLSKY MA. Substrate utilization during endurance exercise in men and women after endurance training. Am J Physiol Endocrinol Metab 280: E898-E907, 2001.

7. CLEROUX J, VAN NGUYEN P, TAYLOR AW, LEENEN FH. Effects of beta 1- vs. beta $1+$ beta 2-blockade on exercise endurance and muscle metabolism in humans. $J$ Appl Physiol 66: 548-554, 1989.

8. COYLE EF, JEUKENDRUP AE, OSETO MC, HODGKINSON BJ, ZDERIC TW. LOWfat diet alters intramuscular substrates and reduces lipolysis and fat oxidation during exercise. Am J Physiol Endocrinol Metab 280: E391-E398, 2001.

9. DECOMBAZ J, FLEITH $M_{;}$HOPPELER $H$, KREIS R, BOESCH C. Effect of diet on the replenishment of intramyocellular lipids after exercise. Eum J Nutr 39: 244-247, 2000.

10. DECOMBAZ J, SCHMITT B, ITH M, DECARLI B, DIEM P, KREIS R, HOPPELER H, BOESCH C. Post-exercise fat intake repletes intramyocellular lipids, but no faster in trained than in sedentary subjects. Am J Physiol 281: R760-R769, 2001.

11. ESSEN B. Intramuscular substrate utilization during prolonged exercise. Anm $N Y$ Acad Sci $301: 30-44,1977$.

12. ESSEN B, JANSSON E, HENRIKSSON J, TAYLOR AW" SALTIN B. Metabolic characteristics of fibre types in human skeletal muscle. Acta Physiol Scand 95: 153.165, 1975.

13. FRIEDLANDER AL, CASAZZA GA, HORNING MA, HUIE MJ, PLACENTINI MF, TRIMMER JK, BROOKS GA. Training-induced alterations of carbohydrate metabolism in women: women respond differently from men. $J$ Appl Physiol 85: 1175-1186, 1998.

14. FROBERG SO, HULTMAN E, NLLSSON LH. Effect of noradrenaline on triglyceride and glycogen concentrations in liver and muscle from man. Metabolism 24: 119-126, 1975.

15. GOLLNICK PD, IANUZZO CD, WILLIAMS C, HILL TR. Effect of prolonged, severe exercise on the ultrastructure of human skeletal muscle. Int $Z$ Angew Physiof 27:257.265, 1969.

16. GUO $Z$, BURGUERA $B$, JENSEN MD. Kinetics of intramuscular triglyceride fatty acids. in exercising humans. $J$ Appl Physiol 89: 2057-2064, 2000. 
17. HOPPELER H, HOWALD H, CONLEY K, LNDSTEDT SL, CLAASSEN H, VOCK P, WEIBEL ER. Endurance training in humans: aerobic capacity and structure of skeletal muscle. I Appl Physiol 59: 320-327, 1985.

18. HORTON TJ, MLLER EK, GLUECK D, TENCH K. No effect of menstrual cycle phase on glucose kinetics and fuel oxidation during moderate-intensity exercise. Am I Physiol Endocrinol Metab 282: E752-E762,2002.

19. HORTON TJ, PAGLIASSOTTI MJ, HOBBS K, HILL JO. Fuel metabolism in men and women during and after long-duration exercise. J Appl Phystol 85: 1823-1832, 1998.

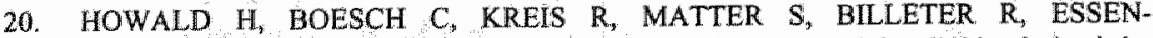
GUSTAVSSON B, HOPPELER H. Content of intramyocellular lipids derived by electron microscopy, biochemical assays, and (1)H-MR spectroscopy. I Appl Physiol 92: 2264-2272, 2002 .

21. HOWALD H., HOPPELER H, CLAASSEN $H$, MATHIEU $O$, STRAUB $\mathbb{R}$. Influences of endurance training on the ultrastructural composition of the different muscle fiber types in humans. Pfugers Arch 403: 369-376, 1985.

22. HULTMAN E. Fuel selection, muscle fibre. Prac Nutr Soc 54: 107.121, 1995.

23. JANSSON E, and KAIJSER $\mathrm{L}$. Effect of diet on the utilization of blood-borne and intramuscular substrates during exercise in man. Acta Physiol Scand 115: 19-30, 1982.

24. JOHNSON NA, STANNARD SR, MEHALSKI K, TRENELL MI, SACHINWALLA T, THOMPSON $\mathrm{CH}_{*}$ THOMPSON MW. Intramyocellular triacylglycerol in prolonged cycling with high- and low-carbohydrate availability. $J$ Appl Physiol 94: 1365-1372, 2003.

25. KIENS B, ESSEN-GUSTAVSSON B, CHRISTENSEN NJ, SALTIN B. Skeletal muscle substrate utilization during submaximal exercise in man: effect of endurance training. $J$ Physiol 469: 459-478, 1993.

26. KIENS $B$, and RICHTER EA. Utilization of skeletal muscle triacyllglycerol during postexercise recovery in humans. Am J Physiol 275: E332-E337, 1998.

27. KOMI PV, and KARLSSON J. Skeletal muscle fibre types, enzyme activities and physical performance in young males and females. Acta Physiol Scand 103: 210-218, 1978.

28. LANGFORT J, DONSMARK M, PLOUG T, HOLM C, GALBO H. Hormone-sensitive lipase in skeletal muscle: regulatory mechanisms. Acto Physiol Sicand 178: 397-403, 2003.

29. LARSON-MEYER DE, NEWCOMER BR, HUNTER GR. Influence of endurance rurming and recovery diet on intramyocellular lipid content in women: a IH NMR study. Am J Physiol Endocrinol Metab 282: E95-E106, 2002.

30. LITHELL $H$, ORLANDER J, SCHELE $R$, SJODIN $B$, KARLSSON $J$. Changes in lipoprotem-lipase activity and lipid stores in human skeletal muscle with prolonged heavy exercise. Acra Physiol Scand 107: 257-261, 1979.

31. MACINTOSH BR, NEPTUNE RR, HORTON JF, Cadence, power, and muscle activation in cycle ergometry. Med Sci Sports Exerc 32:128 $\rrbracket-1287,2000$.

32. MARTIN WH III, DALSKY GP, HURLEY BF, MATTHEWS DE, BIER DM, HAGBERG JM, ROGERS MA, KING DS, HOLLOSZY JO. Effect of endurance training on plasma free fatty acid turnover and oxidation during exercise. Am J Physiol 265: E708-E714, 1993 .

33. MCKENZIE S, PHILLIPS SM, CARTER SL, LOWTHER $S$, GIBALA MJ, TARNOPOLSKY MA. Endurance exercise training attenuates lencine oxidation and 
BCOAD activation during exercise in humans. Am I Physiol Endochinol Metab 278: E580-E587, 2000.

34. MTTENDORFER B, HOROWITZ JF, KLEIN S. Effect of gender on lipid kinetics during endurance exercise of moderate intensity in untrained subjects. Am $J$ Physiol Endocrinol Metab 283: E58-E65, 2002.

35. NYGAARD E. Skeletal muscle fibre characteristics in young women. Acta Physiol Scand 112: $299-304,1981$.

36. PERONNET F, and MASSICOTTE D. Table of nomprotein respiratory quotient: an update. Can J Sporr Sci 16:23-29, 1991.

37. PERSEGHIN G, SCIFO P, PAGLIATO E, BATTEZZATI A, BENEDINI S, SOLDINI L, TESTOLNN G, DEL MASCHIO A, LUZI L. Gender factors affect fatty acids-induced insulin resistance in nonobese humans: effects of oral steroidal contraception. $J$ Chin Endocrinol Metab 86: 3188-3196, 2001.

38. RICO-SANZ J, HAJNAL JV, THOMAS EL, MIERISOVA S, ALA-KORPELA M, BELL JD. Intracellular and extracellular skeletal muscle triglyceride metabolism during alternating intensity exercise in humans. J Physiol 510: 615-622, 1998.

39. ROEPSTORFF C, STEFFENSEN CH, MADSEN M, STALLKNECHT B, KANSTRUP IL, RICHTER EA, KIENS B. Gender differences in substrate utilization during submaximal exercise in endurance-trained subjects. Am J Physiol Endocrinol Metab 282: E435-E447, 2002.

40. ROMIN IA, COYLE EF, SIDOSSIS LS, GASTALDELLI A, HOROWITZ JF, ENDERT E, WOLFE RR. Regulation of endogenous fat and carbohydrate metabolism in relation to exercise intensity and duration. Am J Physiol 265: E380-E391, 1993.

41. ROMIJN JA, COYLE EF, SIDOSSIS LS, ROSENBLATT J, WOLFE RR. Substrate metabolism during different exercise intensities in endurance-trained women. $d$ Appt Physiol 88: 1707-1714, 2000.

42. RUBY BC , COGGAN AR, ZDERIC TW. Gender differences in glucose kinetics and substrate oxidation during exercise near the lactate threshold. I Appl Physfol 92: 1125$1132,2002$.

43. SARGEANT AJ. Human power output and muscle fatigne. Int J Sports Med 15:116-121, 1994.

44. SCHICK F, EISMANN B, JUNG WI, BONGERS H, BUNSE M, LUTZ O. Comparison of localized proton NMR signals of skeletal muscle and fat lissue in wivo: two lipid compartments in nuscle tissue. Magn Reson Med 29: 158-167, 1993.

45. SINNING WE, DOLNY DG, LITTLE KD, CUNNINGHAM LN, RACANIELLO A, SICONOLFI SF, SHOLES JL. Validity of "generalized" equations for body composition analysis in male athletes. Med Sci Sports Exerc 17:124-130,1985.

46. STANDL E, LOTZ N, DEXEL T, JANKA HU, KOLB HI. Muscle triglycerides in diabetic subjects. Effect of insulin deficiency and exercise. Diabetologia 18: 463-469, 1980.

47. STANNARD SR, THOMPSON MW, FAIRBAIRN K, HUARD B, SACHINWALLA T, THOMPSON CH. Fasting for $72 \mathrm{~h}$ increases intramyocelluilar lipid content in nondiabetic, physically fit men. Am $J$ Physiol Endocrinol Metab 283: E1185-E1191, 2002.

48. STARLING RD, TRAPPE TA, PARCELL AC, KERR CG, FINK WJ, COSTILL DL. Effects of diet on muscle triglyceride and endurance performance. $J$ Appl Physiol 82: $1185-1189,1997$. 
49. STARON RS, HAGERMAN FC, HIKLDA RS, MURRAY TF, HOSTLER DP, CRILL $M T$, RAGG KE, TOMA $K$. Fiber type composition of the vastus laterallis muscle of young men and woment. $J$ Histochem Cylochem 48: 623-629, 2000.

50. STEFFENSEN CH, ROEPSTORFF $C$, MADSEN M, KIENS B. Myocelliliar triacylglycerol breakdown in females but not in males during exercise. Am $J$ Physiol Endocrinol Metab 282: E634-E642, 2002.

51. TARNOPOLSKY LJ, MACDOUGALL ID, ATKINSON SA, TARNOPOLSKY MA, SUTTON JR. Gender differences in substrate for endurance exercise. $J$ Appl Physiol 68 : 302-308, 1990.

52. TARNOPOLSKY MA, ATKINSON SA, PHILLIPS SM, MACDOUGALL JD. Carboliydrate loading and metabolism during exercise in men and women. $J$ Appl Physiol 78: 1360-1368, 1995.

53. TARNOPOLSKY MA, BOSMAN M, MACDONALD JR, VANDEPUTTE D, MARTIN $J$, ROY BD. Postexercise protein-carbohydrate and carbohydrate supplements increase muscle glycogen in men and women. J Appl Physiol 83: 1877-1883, 1997.

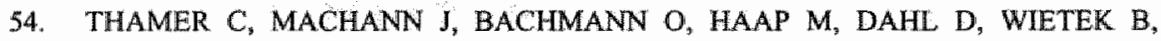
TSCHRITTER O, NIESS A, BRECHTEL K, FRITSCHE A, CLAUSSEN C, JACOB S, SCHICK F, HARING HU, STUMVOLL M. Intramyocellular lipids: anthropometric determinants and relationships with traximal aerobic capacity and insulin sensitivity. $J$ Clin Endocrinol Metab 88: 1785-1791, 2003.

55. VAN LOON LI, KOOPMAN R, STEGEN JH, WAGENMAKERS AJ, KEIZER HA, SARIS WH. Intramyocellular lipids form an important substrate source during moderate intensity exercise in endurance-trained males in a fasted state. $J$ Physiol 553: 61 1-625, 2003.

56. VAN LOON LJ, SCHRAUWEN-HINDERLING VB, KOOPMAN $R$, WAGENMAKERS AJ, HESSELINK MK, SCHAART G, KOOI ME, SARIS WH. Influence of prolonged endurance cycling and recovery diet on intramuscular triglyceride content in trained males. Am $J$ Physiol Endocrinol Metab 285: E804-E811, 2003.

57. VERMATHEN $P$, KREIS R, BOESCH C. Intra-myocellular Lipids (IMCL) in thigh muscles - determination of distribution and measurement of reproducibility by MRSI. 21 st ESMRMB Annual Meeting, \$17. 2004.

58. VIHKO V, SALMINEN A, RANTAMAKI J. Exhaustive exercise, endurance training, and acid hydrolase activity in skeletal muscle. $J$ Appl Physiol 47: 43-50, 1979.

59. WATT MJ, HEIGENHAUSER GJ, DYCK DJ, SPRIET LL. Intramuscular triacylglycerol, glycogen and acetyl group metabolism during $4 \mathrm{~b}$ of moderate exercise in man. I Physiol 541: 969-978, 2002.

60. WATT MJ, HEIGENHAUSER GJ, SPRIET LL. Intramuscular triacylglycerol utilization in human skeletal muscle during exercise: is there a controversy? $J$ Appl Physiol 93: $1185-1195,2002$.

61. WENDLING PS, PETERS SJ, HEIGENHAUSER GJ, SPRIET LL. Variability of triacylglycerol content in human skeletal muscle biopsy samples. $J$ Appl Physiol 81: $1150-11.55,1996$.

62. WHITE LJ, FERGUSON MA, MCCOY SC, KIM H. Intramyocellular lipid changes in men and women during aerobic exercise: a (1)H-magnetic resonance spectroscopy study. $J$ Clin Endocrinal Metab 88: 5638-5643, 2003.

63. ZDERIC TW, DAVIDSON CJ, SCHENK $S$, BYERLEY LO, COYLE EF. High-fat diet elevates resting intramuscular triglyceride concentration and whole body lipolysis during exercise. Am J Physiol Endocrinol Metab 286: E217-E225, 2004. 


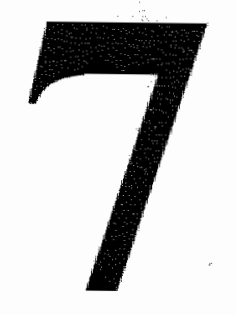

\section{Effect of two different intramyocellular lipid contents on substrate utilization during endurance exercise and subsequent performance}

${ }^{1}$ Zehnder M, ${ }^{2}$ Christ ER, ${ }^{1}$ Ith $M,{ }^{1}$ Kreis R, ${ }^{2}$ Trepp R, ${ }^{2}$ Diem P, 'Boesch C, ${ }^{3}$ Décombaz J.

${ }^{1}$ Department of Clinical Research, University and Inselspital Berne, Switzerland; ${ }^{2}$ Department of Endocrinology and Diabetes, Inselspital Berne, Switzerland; ${ }^{3}$ Nestlé Research Center, Lausanne, Switzerland.

adapted version submitted in: Journal of Applied Physiology. 


\section{ABSTRACT}

Purpose To investigate the effect of a dietary-induced high content of intramyocellular lipids (IMCL) before exercise (EX) on the availability of local fuels (MMCL and glycogen), and on a following performance, during which glycogen is theoretically the limiting factor. Methods 11 endurance-trained males were investigated twice in a randomized crossover design after either a high fat high carbohydrate $(H F)$, or a low fat high carbohydrate (LF) diet, $H F$ : fat $0.5 \mathrm{~g} \cdot \mathrm{kg}^{-1}$ during 1 day followed by fat $3.5 \mathrm{~g} \cdot \mathrm{kg}^{-1}$ during 1.5 days, and $L F$ : fat $0.5 \mathrm{~g} \cdot \mathrm{kg}^{-1}$ during 2.5 days. Carbohydrate (CHO) intake was identical on both occasions $\left(7 \mathrm{~g} \cdot \mathrm{kg}^{-1} \cdot \mathrm{d}^{-1}\right)$. Before and after a 3-h EX on a bicycle-ergometer ( $50 \%$ of $W_{\max }$ ) IMCL and glycogen were measured in the m. quadriceps femoris by ${ }^{1} \mathrm{H}$ (IMCL) and ${ }^{13} \mathrm{C}$ (glycogen) magnetic resonance spectroscopy (MRS). Oxygen uptake, carbon dioxide production, plasma glucose, insulin, free fatty acids and triacylglycerol (TAG) were determined at baseline and at regular intervals throughout $\mathbb{E X}$. The MRS-measurements after $\mathbb{E X}$ were followed by a $20 \mathrm{~km}$ time trial (TT) that subjects performed on a fixed racing bicycle. Results IMCL levels at rest were $55 \%$ higher $(\mathrm{p}<0.001)$ after $H F$ compared to $L F$ whereas glycogen levels were similar. $\mathrm{MCL}$ utilization during EX was correlated with aerobic capacity and was 3-fold larger after $H F$ compared to $L F$ $(\mathrm{p}<0.001$ ). In contrast, muscle glycogen utilization, whole body fat and CHO oxidation, as well as energy expenditure were similar, independent of the preceding diet. Post EX IMCL and glycogen concentrations were similar after either diet. Plasma TAG concentration was $\sim 30 \%$ lower after $H F(\mathrm{p}<0.02)$ than after $L F$ throughout $E X$. Subjects were on average $34 \mathrm{~s}$ faster in the TT after $H F$ compared to $L F$, but this was not significant. Correlations ( $H F: \mathrm{r}=-0.54$; $L F$ : $\mathrm{r}=-0.78$ ) between IMCL breakdown during the 3-h $\mathrm{EX}$ and time used for TT were found. Conclusion IMCL concentration can be increased (by a short-term fat supplement) and decreased (by exercise) independent of glycogen storage and use, respectively. These data also suggest that higher IMCL concentrations and a better training condition lead independently to an increased energy contribution of IMCL during submaximal exercise.

Key words high fat, low fat diet, muscle glycogen, ${ }^{1} \mathrm{H} /{ }^{13} \mathrm{C}$-magnetic resonance 


\section{INTRODUCTION}

Muscle glycogen is capital for intense physical performance. The higher the performed intensity, the higher is the rate of consumption. When exercising at $60-85 \%$ of the aerobic capacity, often muscle glycogen availability is the factor that limits performance. In spite of this, indirect calorimetry data demonstrate a contribution of about 25 to $50 \%$ lipid oxidation to energy expenditure during prolonged exercise, depending on exercise intensity and level of training. In addition, a substantial use of intramuscular lipids (IMCL) during exercise has been shown from various angles (biopsy: e.g. $(50,55)$, isotopic: e.g. $(38,41)$ as well as magnetic resonance methods: e.g. $(26,56))$, but quantitative and dynamic information is still scarce. Now that the essentials of glycogen loading are well understood (24), a great deal of scientific and empirical effort is being placed on devising ways to increase the contribution of lipid energy during exercise, with the aim to spare muscle glycogen for the later part of a performance exercise. Endurance training is the only recognized method that significantly increases the fat to carbohydrate ( $\mathrm{CHO}$ ) ratio during exercise and performance at the same time.

Strategies of feeding high fat diets ( $50 \%$ lipid energy or more) for periods of weeks have been tried in order to adapt metabolic pathways to a more efficient use of fatty acids (FFA). The effects of these metabolic adaptations on exercise capacity or performance during prolonged exercise are equivocal (17). Chronic exposure to high-fat diets has led to improvements in endurance performance in some $(27,31)$, but not the majority $(6,8,18,22,39)$ of studies. However, an observation common to nearly all studies is an increase in the contribution of total lipid fuel to exercise metabolism. These investigations focused on the possibility of chronic adaptations after one to several weeks of feeding high-fat (low carbohydrate) diets. Due to the lack of precise data on the response of IMCL to exercise and diet, they disregarded the notion of drawing lipid energy specifically from this local reservoir. Some have not accounted for the reduction in muscle glycogen induced by high-fat (low-CHO) diets (27). Low muscle glycogen, an impaired ability to use glycogen $(19,21)$ or to maintain training intensity, and decreased mood states are mechanisms that have been proposed to explain the lower or unchanged performance on high fat diets.

There are no data on the role of IMCL as a fuel during exercise at similar initial glycogen status. Therefore, the primary objective of this study is to investigate the use of local fuels (IMCL and muscle glycogen by magnetic resonance spectroscopy - MRS) and total fuels (fat and CHO by indirect calorimetry) during prolonged submaximal exercise when $\mathbb{I M C L}$ are modulated at constant glycogen. According to the evidence that post-exercise replenishment of IMCL 
levels can be achieved within a day $(4,11,12,28,48)$, a short lipid feeding protocol is chosen. It is made use of observations that glycogen is replenished faster in the early post exercise period (24), whereas IMCL accumulation takes: place with a certain delay $(2,3)$. Following an initial bout of exercise, both diet interventions provide a high intake of CHO throughout, in order to optimize preexercise glycogen stores. During the last 1.5 days of interwention a lipid supplement is added to one group"s diet.

It is hypothesized that the increased availability of local lipid fuel when IMCL levels are high will spare the use of muscle glycogen during submaximal exercise, such that more glycogen remains at the end (since the cost of exercise is the same). During a subsequent high intensity performance exercise, more glycogen will be available and performance should be improved. It is further hypothesized that higher IMCL levels will shift substrate usage during submaximal exercise towards the use of more totall lipids (specifically IMCL, not plasma lipids).

\section{METHODS}

\section{Subjects}

11 healthy, endurance trained male volunteers $\left(\mathrm{VO}_{2 \text { peak }} \geq 60 \mathrm{~mL} \cdot \mathrm{min}^{-1} \cdot \mathrm{kg}^{-1}\right)$ with cycling as one of their main sports (road or cross-country cyclists, duathletes, and triathletes) and with competitive practice participated in the study. All were involved in endurance exercise training programs for at least 3 times a week $\left(2-3 \mathrm{~h} \cdot\right.$ training $\left.^{-1}\right)$, and with a training history of at least 5 years. The mean ( $\mathbb{E} \mathrm{SE}$ ) age, height, and body weight (bw) of the subjects were $31.4 \pm 1.7$ years, $1.81 \pm 0.02 \mathrm{~m}$, and $74.5 \pm 2.5 \mathrm{~kg}$, respectively. Body-fat was $7.6 \pm 0.6 \%$ of bw and body mass index $22.6 \pm 0.5 \mathrm{~kg} \cdot \mathrm{m}^{-2}$. All subjects signed an informed consent form, including nutritional and activity guidelines, before admission into the study, which was approved by the institutional Ethic's Committee.

\section{General study design}

This was a reference-controlled crossover (two-treatment, two-period), balanced, single center outpatient metabolic trial. The experimental design is shown in Figure 1. After a 3-day baseline to normalize diet and physical activity, the subjects performed a 3 -h exercise (Exl) on a bicycle ergometer at $50 \%$ maximal voluntary workload (Wmax) intended to reduce $\mathrm{MCL}$ and glycogen stores. This was followed by $2.5 \mathrm{~d}$ of dietary intervention with a high $\mathrm{CHO}$ diet providing 
enther high fat (HF diet) or low fat ( $L F$ diet). At the end of the dietary treatment, a test exercise (Ex2) that was identical to the initial depleting exercise Ex1 was carried out, during which energy, lipid and CHO oxidation was investigated. After completion of $\mathbb{E x} 2$, the subjects ended by performing a $20-\mathrm{km}$ time trial (TT). IMCL and glycogen in thigh muscles were measured before starting on the diet (post-Ex1), after the dietary intervention (pre-Ex2) and at the end of the test exercise $\mathrm{Ex} 2$ (before the TT). During all exercise trials there were no differences in either room temperature $\left(23.0-24.2^{\circ} \mathrm{C}\right)$ or humidity $(30.4-31.2 \% \mathrm{rh})$.

Figure 1. Study protocol with the "run-in" period, the depleting exercise Exl, the dief intervention and the main trial including Ex2, and the $20-\mathrm{km}$ time trial (TT)

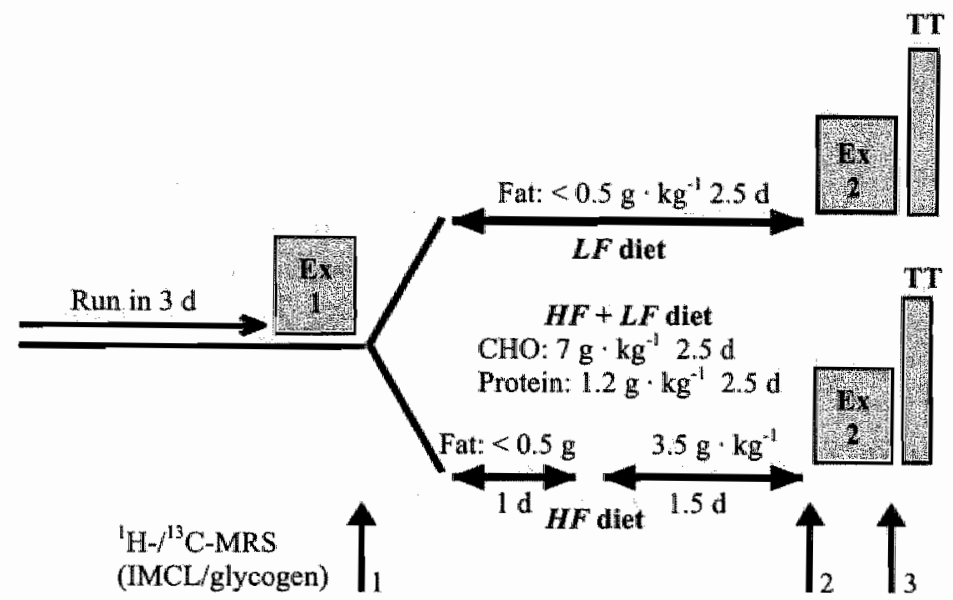

Ex1 $=$ Ex2 $=3$-h cycling at $50 \%$ of maximal power

\section{Preliminary testing}

At least one week prior to the main experiment, the subjects reported to the laboratory for anthropometric measurements and the assessment of training status. Body fat was evaluated from skin-fold measurements. Maximal workload and aerobic capacity were determined with a maximal workload ( $\left.\mathrm{W}_{\text {max }}\right)$-test on a cycle ergometer (Ergometrics 900, Ergoline, Bitz, Germany). The test took place after an overnight fast and followed a day without exercise. After 2 min of rest, subjects started exercising at a work rate of $100 \mathrm{~W}$ for 2 min. Resistance was increased in $30 \mathrm{~W}$ steps every $2 \mathrm{~min}$ until exhaustion. Oxygen uptake $\left(\mathrm{VO}_{2}\right)$, carbon dioxide production $\left(\mathrm{VCO}_{2}\right)$, and heart rate were continuously monitored. $\mathrm{VO}_{2}$ and $\mathrm{VCO}_{2}$ were determined by an open-circuit systerm (Oxycon $\mathrm{B}$, Jäger, 
Hochberg, Germany), while the cardiac frequency was measured by a heart rate monitor (Pollar vantage NV, Polar Electro, Kempele, Finland). The highest intensity that the subjects could maintain for at least 1 min by a pedal rate above 80 revolutions per min (rpm) defined the subjects ${ }^{*} \mathrm{~W}_{\text {max }} . \mathrm{VO}_{2 \text { peak }}$ was defined as the highest value reached in a 30 -s period.

\section{Run-in period}

A 3-day run-in period preceded the initial endurance exercise (Figure 1). Its purpose was to ensure a reproducible physiological status at the start of both treatments and to initiate a gradual lowering of IMCL. The following instructions were given on an individual basis to follow at home and to replicate before the treatment for the second period: (1) maintenance of physical activity over the 3 days according to the individual average, mostly prolonged submaximal cycling (target $>3 \mathrm{~h}$ total within 3 days); (2) adherence to a moderately low fat diet, based on avoidance of specified food items such as fried foods (French fries, fried meat or fish), bread spreads (butter, margarine), oil in salad dressing, mayonnaise, cream, fat-rich deserts, and full-fat milk, yoghurts or cheeses. During the run-in period subjects kept a nutritional diary (analyzed by GENESIS R\&D software, ESHA Research, Inc. Salem, OR) and activity records to facilitate reproducibility.

\section{Initial endurance exercise (Ex1)}

Exl. was performed on a cycle ergometer (Ergometrics 900, Ergoline, Bitz, Germany) in the afternoon, at least $2 \mathrm{~h}$ after a light lunch. Its aim was to reduce IMCL and glycogen stores in the thigh muscles and to provide a reproducible starting position of glycogen and IMCL stores for the follow-up treatments. After 10 min sitting quiet, the subjects started with a short warm-up followed by a 3-h exercise with constant $\mathrm{rpm}(70-75)$ at an intensity of $50 \% \mathrm{~W}_{\max }$. Total fat and $\mathrm{CHO}$ oxidation rates were determined by indirect calorimetry ( $\max 29 \mathrm{c}$, SensorMedics, Bilthoven, The Netherlands) assuming the non-protein respiratory quotient (37). For this, a mouthpiece connected subjects with the $\mathrm{VO}_{2}$ (paramagnetio) and $\mathrm{VCO}_{2}$ (infrared) gas analyzers. The analyzers were calibrated before each experiment and expired gases were measured intermittently for 10 min periods, first at rest and then at 20 -min intervals over the exercise. Subjective perception of fatigue was assessed every 20 min using the Borg scale (33). At the standard question "how do you score the exertion?", the subject read from a visible scale a number between $6(<$ very, very light) and 20 ( $>$ very, very hard). Always the same investigator performed the recording. Subjects were allowed to drink water ad libitum. Weight loss during exercise was determined by pre- and post-exercise weighing to $0.1 \mathrm{~kg}$ (Seca, Cosmos c/o B. Schild, Biel, 
Switzerland). After Exl the first MR measurements were performed to determine IMCL and glycogen concentrations in the thigh (vide infra). The subjects then started on the study diets.

\section{Dietary intervention}

Diet was strictly controlled and entirely provided. All food items were packed by meal and supplied on a subject and treatment basis for the 2.5 days between $\mathrm{Ex} 1$ and Ex2. Only calorie-free and caffeine-free beverages were allowed next to the prescribed foods. Diets were composed of regular food items, dishes and ingredients to lead to either high (HF diet) or low ( $L F$ diet) IMCL levels and to approximately equal muscle glycogen concentrations before Ex2. Diets provided equal amounts of protein $\left(1.0-1.2 \mathrm{~g} \cdot \mathrm{kg}^{-1} \mathrm{bw} \cdot \mathrm{d}^{-1}\right)$ and $\mathrm{CHO}\left(7 \mathrm{~g} \cdot \mathrm{kg}^{-1} \mathrm{bw} \cdot \mathrm{d}^{-1}\right)$. On the first day ( 3 meals, starting with the evening meal) they were isocaloric $\left(\sim 180 \mathrm{~kJ} \cdot \mathrm{kg}^{-1} \mathrm{bw} \cdot \mathrm{d}^{-1}\right)$, with only minimal fat content $\left(0.5 \mathrm{~g} \cdot \mathrm{kg}^{-1} \mathrm{bw} \cdot \mathrm{d}^{-1}\right)$. For the last 1.5 day (4 meals), HF diet provided more energy $\left(\sim 276 \mathrm{~kJ} \cdot \mathrm{kg}^{-1}\right.$ bw $\left.\cdot \mathrm{d}^{-1}\right)$ and all the additional calories were in the form of fat $\left(3.5 \mathrm{~g} \cdot \mathrm{kg}^{-1} \mathrm{bw} \cdot \mathrm{d}^{-1}\right)$. The energy partition between macromutrients over the 2.5 days was on average $11 / 52 / 37(H F), 14 / 73 / 12(L F) \%$, respectively as protein, $\mathrm{CHO}$ and fat, and it was 9/43/48 during the last 1.5 day of fat-enriched feeding on the $H F$ diet. The subjects were assigned to one of both diet sequences as shown in. Figure 1. Lipids in the $H F$ diet were relatively low in saturated FFA. They comprised $>50 \%$ $\mathrm{C} 18: 1,>20 \% \mathrm{C} 18: 2$ and other polyunsaturated FFA. An example of such a diet is shown in Table 1. Food items known to be naturally enriched in ${ }^{13} \mathrm{C}$ were excluded from the treatment diets (corn, pineapple, soft drinks), also during the lipid supplement phase (corn oil). A local investigator provided instructions for home feeding. Dietary treatments could not be made blind to the subjects, but their expectation about treatment effects was balanced as much as feasible. Namely, they were told that both times everybody received the individually calculated energy needed for endurance and optimal performance. Empty boxes, wrappers and possible leftovers were returned to the investigators on the second visit for records. Nutrient intake was calculated from manufacturers' information and standard food tables (Souci, Fachman \& Kraut). Additionally, physical activity was strictly limited to sedentary occupations during the 2.5 days of diet treatment. 


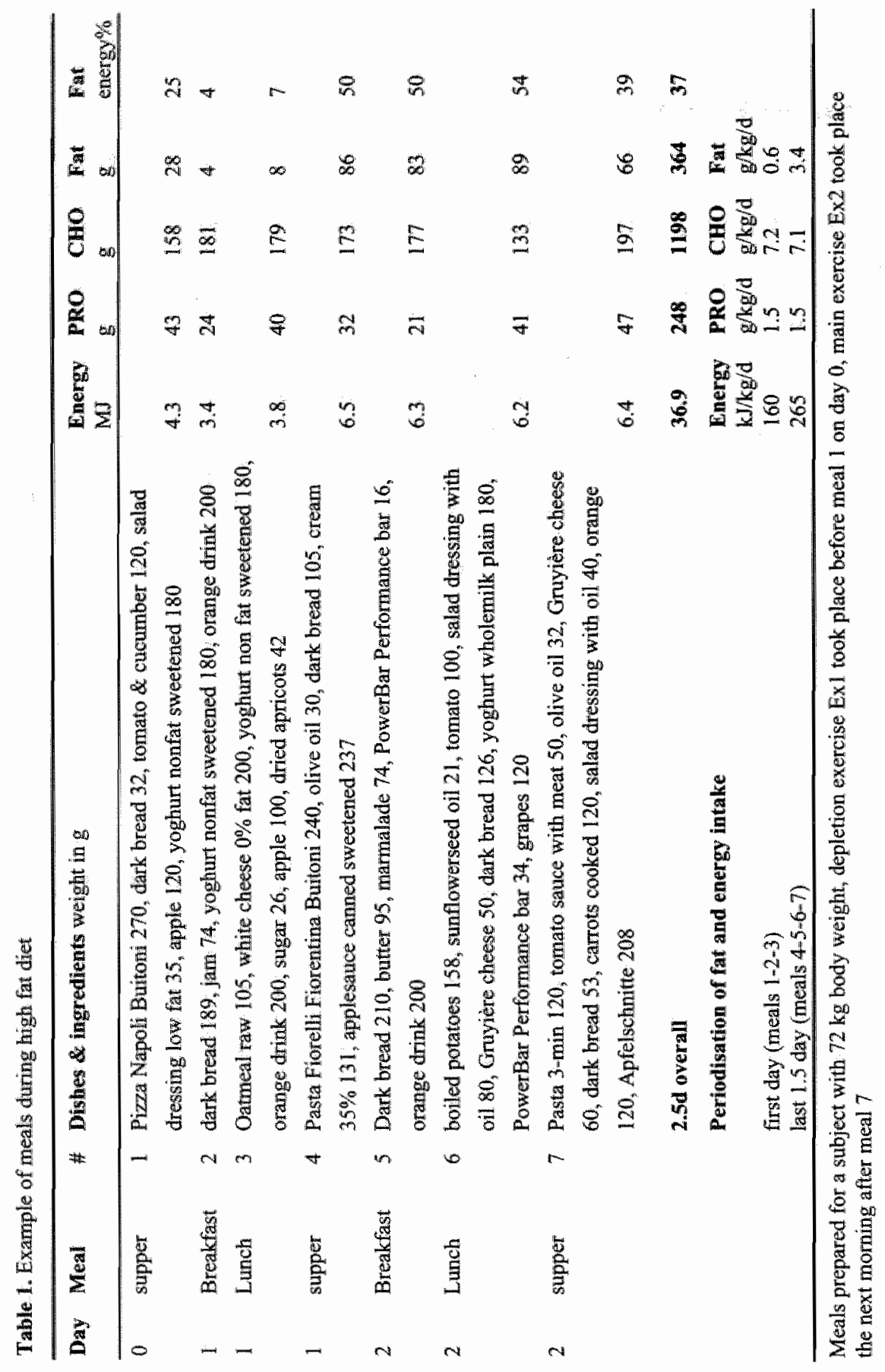




\section{Main test exercise (Ex2)}

After Ex 1 and the 2.5 days treatment diet, the overnight fasted subject reported to the laboratory for the second sequence of MR measurements. At $7.45 \mathrm{am}, 100 \mathrm{~g}$ of white bread were ingested before being positioned in the magnet. Muscle glycogen and IMCL stores were acquired as described later between 8.00 and $9.30 \mathrm{am}$. After this, the subject voided his bladder, was weighed and lay down for the insertion of a catheter (Venflon 18G) into an arterialized left forearm vein. The catheter was kept patent with saline infusion during the whole experiment. Resting blood samples were collected and resting metabolic rate was measured for $10 \mathrm{~min}$ (V $\max 29 \mathrm{C}$, SensorMedics) while the subject was sitting quietly on the ergometer. Ex2 then started $2.5-3 \mathrm{~h}$ after the morning snack. After the first $6 \mathrm{~min}$, steady state was reached and was continued for $3 \mathrm{~h}$ at the same power as in Ex1, with only water to drink. Additionally to the 10 -min indirect calorimetry measurements for fat and $\mathrm{CHO}$ oxidation and periodic reconds of subjects" perceived exertion, heart rate (15-s periods) was recorded, and blood was sampled at rest $30 \mathrm{~min}$ before exercise, and at $15,18,45,80,110,130,150$, and $180 \mathrm{~min}$ during exercise (total $90-100 \mathrm{~mL}$ per perfusion) for the determination of plasma metabolites (vide infra). Immediately after exercise, total urine was collected for nitrogen analysis ( $\mathrm{kjeldahl}$ method). Subjects were weighed again to evaluate their water balance, and then drank half a liter of an isotonic drink ( $25 \mathrm{~g} \mathrm{CHO})$ before being repositioned in the magnet for the final MR measurements.

\section{Cycling Time trial (TT)}

The TT followed Ex 2 by approximately $1.5 \mathrm{~h}$, immediately after the final MR measurements (Figure 1) and after complete rehydration. It was designed such that thigh muscle glycogen should be the major limiting factor for high-intensity performance. The TT was performed on a racing bicycle (Trek 1200 Alpha, Waterloo WI) with clipless pedals attached so that the subject could use their own shoes. Additionally, the professional road version of the SRM Training System (Schoberer Rad Messtechnik, Julich, Germany) was instrumented to the bicycle and was calibrated before each TT. The system consists of a powermeter, whereby power output is calculated from the average torque of one crank rpm multiplied by the angular velacity of one rpm. This is linked to a powercontrol unit (a small handlebar mounted computer) that records and stores power, speed, number of $\mathrm{rpm}$, distance, time, work, and heart rate data. The back wheel of the bicycle was fixed to a magnetic brake (Camielli, model Leader, Vittorio Veneto, 1), and a fan was positioned in front of the cyclist to allow circulation of air. The TTs were performed at the same time of day and supervised by the same investigator. The amount of water the subject consumed during the first TT had 
to be consumed during the cross-over trial. After an individual warm up of at least $5 \mathrm{~min}$ subject started the $20-\mathrm{km}$ TT out of a resting saddle position and was not allowed to stand up. Pedaling cadence could freely be selected. The covered distance was the only parameter the subject could look at. Subjects as well as the investigator were not aware of the elapsed time. Heart rate was monitored continuously (15-s periods). Time to completion was measured through the SRM system and checked with an additional stopwatch. Ambient temperature and relative humidity $(\% \mathrm{rh})$ were measured and no difference was found between the two trials $\left(H F: 22.9 \pm 0.3^{\circ} \mathrm{C}\right.$ and $32.0 \pm 1.5 \% \mathrm{rh} ; L F: 23.1 \pm 0.5^{\circ} \mathrm{C}$ and $30.8 \pm 2.1 \%$ th).

\section{Magnetic resonance}

Muscle glycogen and IMCL stores in the m. quadriceps femoris of the right leg were measured sequentially, glycogen first, within the same session. An entire session consisted of image acquisition, ${ }^{13} \mathrm{C}$ - and ${ }^{1} \mathrm{H}-\mathrm{MRS}$ and lasted about 90 minutes. MR measurements were performed on a $1.5 \mathrm{~T}$ whole body system (SIGNA, General Electrics, Milwaukee WI, USA), images and spectra were acquired with a ${ }^{13} \mathrm{C} /{ }^{1} \mathrm{H}$ double-tuned flexible coil (Medical Advance; ${ }^{13} \mathrm{C}$ : single turn $11.5 \cdot 11.5 \mathrm{~cm}^{2}$ quadratic coil; ${ }^{1} \mathrm{H}$ : Helmholtz design). The volunteers were placed on a specially designed mount to guarantee a reproducible positioning of the right leg for all MR-sessions (after Exl, and before and after Ex2). Repositioning of the volunteer and placement of the coil were controlled using the acquired images.

Determination of muscle glycogen stores Muscle glycogen was measured by ${ }^{13} \mathrm{C}$-MRS using a pulse-and-acquire sequence (repetition time $(\mathrm{TR})=165 \mathrm{~ms}$, adiabatic $90^{\circ}$ excitation, $5000 \mathrm{~Hz}, 512 \mathrm{pts}$ ) with decoupling during, and nuclear Overhauser enhancement (NOE) buildup in between the acquisitions. For each session $12^{*} 000$ averaged acquisitions added up to the measured ${ }^{13} \mathrm{C}$-spectrum. The sensitive volume of the ${ }^{13} \mathrm{C}$-coil included the $m$. rectus femoris, vastus lateralis and medialis. The spectra were evaluated using the jMRUI 1.3 software package (32). Preprocessing of the spectra included zero and first order corrections as well as filtering of the signals from $\mathrm{CH}=\mathrm{CH}$ double bonds, $\mathrm{CH}_{2}$ and $\mathrm{CH}_{3}$ of fatty acyl chains with HLSVD filtering (40). The spectra were fitted using AMARES (51). Frequency shifts as well as linewidth of the creatine and glycogen signals were fixed relative to the respective values of the $\mathrm{COOH}$-signal from fatty acyl chains at $172 \mathrm{ppm}$. These values were determined using a summed spectrum of all measurements. Signal areas of total creatine and glycogen were corrected for spin lattice relaxation time $\left(\mathrm{T}_{1}\right)$-saturation and NOE effects. Glycogen concentrations in units of millimol per kilogram wet weight 
( $\mathrm{mmol} \cdot \mathrm{kg}^{-1}$ ww) were finally calculated using total creatine as muscle specific internal standard. A creatine concentration of $32 \mathrm{mmol} \cdot \mathrm{kg}^{-1}$ ww was assumed for all volunteers (5).

Determination of IMCL stores IMCL content was determined with single voxel ${ }^{1} \mathrm{H}-\mathrm{MRS}$. The recorded spectra thereby came from a predefined volume (voxel) that measured $18 \cdot 11 \cdot 12 \mathrm{~mm}^{3}$ (IS $\cdot \mathrm{RL} \cdot \mathrm{AP}$ ). The voxel was positioned in the m. vastus intermedius close to the femoral bone. $M$. vastus intermedius was chosen because of its similarity to m. vastus lateralis (53). Measuring IMCL by ${ }^{1} \mathrm{H}-\mathrm{MRS}, m$. vastus intermedius shows a higher reproducibility and less contamination of extramyocellular lipids (EMCL) compared to $m$. vastus lateralis (4). Additionally, both muscles reduce IMCL equally during endurance cycling (unpublished own data), and are composed of predominantly red skeletal muscle (54), thus showing larger IMCL concentrations than a muscle with primarily white muscle fibers (29). Care was taken that inside the voxel no sign of fatty infiltration was visible that would be the source of contamination of the spectrum by large EMCL signal. Since optimal and reproducible placement of the ${ }^{1}$ H-MRS-voxel is crucial, positioning as well as repositioning of the voxel was achieved using the image series (fast spin echo sequence with a $\mathrm{TR}=1000 \mathrm{~ms}$ and an echo time of $\mathrm{TE}=17 \mathrm{~ms}$ ). ${ }^{1} \mathrm{H}-\mathrm{MR}$-spectra were recorded using an optimized PRESS-sequence (TR $=3 \mathrm{~s}, \mathrm{TE}=20 \mathrm{~ms}, 128$ acquisitions, 16 phase rotating steps, $2000 \mathrm{~Hz}, 1024 \mathrm{pts}$ ) with water and additional outer volume suppression. The spectra were quantified using the fully relaxed, unsuppressed water signal as internal concentration standard. IMCL concentrations in $\mathrm{mmol} \cdot \mathrm{kg}^{-1}{ }_{\mathrm{ww}}$ were evaluated as described earlier (4).

\section{Plasma analyses}

Blood was collected in two 5-mL EDTA tubes. After centrifugation ( $4000 \mathrm{rpm}$ at $4^{\circ} \mathrm{C}$ for $10 \mathrm{~min}$ ), plasma was separated and stored at $-20^{\circ} \mathrm{C}$ until the following analyses were performed: insulin, glucose, FFA and triacylglycerol (TAG). Insulin was measured by ELISA enzyme immunoassays (MG59011 and RE52061, Immuno-Biological Laboratories, Hamburg, Germany). Blood TAG and glucose were determined by enzymatic tests (BioMérieux 61236 and Roche Diagnostics AG 1447513) on a Cobas Mira centrifugal analyzer (Roche, Basel, Switzerland). Plasma FFA concentrations were quantified in duplicate by gas chromatography (Hewlett Packard 6890, Palo Alto, CA) after addition of an heptadecanoic acid (C17:0) internal standard to the samples. Lipids were extracted with chloroform:methanol, and FFAs were separated by thin-layer chromatography and converted to their methyl esters. The $\mathrm{GC}$ response was calibrated by using a series of GLC fatty acid methylester standards. 


\section{Determination of body fat free mass}

Adipose tissue was measured with a skin-fold caliper (GPM Siber Hegner, Zurich, Switzerland) at seven different locations of the body (chest, midaxillary, supra-iliac, abdomen, triceps, sub-scapular, and thigh above patella) before each $W_{\text {max }}$-test. The same person always performed the measurements with a subject, and the average of 3 determinations at each measuring site was taken as a valid result for the calculation of the fat free mass following a formula given by Sinning et al. (45).

\section{Calculations}

Protein oxidation during Ex2 was estimated from urinary nitrogen excretion without correction for changes in the body urea pool. Energy expenditure, CHO oxidation and fat oxidation were calculated from each 10 -min respiratory exchange data (25). The contribution of IMCL and muscle glycogen to substrate oxidation during Ex2 was estimated on the assumption of $10 \mathrm{~kg}$ of active muscle mass per $70 \mathrm{~kg} \mathrm{bw}$. IMCL decrement was converted from mole to weight using a mean molecular weight of 858 daltons for $\mathrm{TAG}$, and to energy with the factor of $38.9 \mathrm{~kJ} \cdot \mathrm{g}^{-1}$ TAG (4). Muscle glycogen decrement was converted from mole to weight using the molecular weight of 162 daltons per glycosyl unit, and to energy with the factor of $17.6 \mathrm{~kJ} \cdot \mathrm{g}^{\natural}$ glycogen.

\section{Statistical analysis}

Single parameters in the two diet groups $H F$ and $L F$ were compared by a paired, two-tailed $t$ test and, if significantly different, indicated with an asterisk $\left(^{*}\right)$. Differences over time between the two groups ( $H F$ and $L F$, respectively) were analyzed by multiple analysis of variance (MANOVA) and, if significant, indicated with an asterisk (*). Linear regression analyses were performed with standard procedures using Excel 2000 (Microsoft) and StatView 2002. Statistical significance was set at $\mathrm{p}<0.05$. Values are presented as mean $\pm \mathrm{SE}$.

\section{RESULTS}

\section{Preliminary testing $\left(W_{\text {max } \text {-test })}\right.$}

The maximum power $\left(W_{\max }\right)$ produced for at least 1 min during the $W_{\text {max }}$-test was $365 \pm 9 \mathrm{~W}$. Maximal oxygen uptake $\left(\mathrm{VO}_{2 \text { peak }}\right)$ was $4.68 \pm 0.13 \mathrm{~L} \cdot \mathrm{min}^{-1}$ $\left(63 \pm 2 \mathrm{~mL} \cdot \mathrm{min}^{-1} \cdot \mathrm{kg}^{-1}\right.$ bw or $68 \pm 2 \mathrm{~mL} \cdot \mathrm{min}^{-1} \cdot \mathrm{kg}^{-1}$ lean bw). During the $W_{\max }$-test heart rate rose to a maximal value of $186 \pm 3$ beats $\cdot \min ^{-1}$. 


\section{Dietary intake}

There was no difference in the daily average intake of CHO (HF: $5.7 \pm 0.6, L F$ : $5.4 \pm 0.6)$, fat $(H F: 1.1 \pm 0.2 ; L F: 1.2 \pm 0.2)$, proten $(H F: 1.2 \pm 0.1, L F$ : $1.2 \pm 0.1)\left(\mathrm{g} \cdot \mathrm{kg}^{-1} \mathrm{bw}\right)$ and energy $(H F: 166 \pm 15 ; L F: 158 \pm 15)\left(\mathrm{kJ} \cdot \mathrm{kg}^{-1} \mathrm{bw}\right)$ during the "run-in period" before Exll. During the diet treatment period between Ex1 and Ex2, all subjects complied with the instructions and ate the food provided in either diet $H F$ or $L F$.

\section{Endurance exercises}

Ex1 and Ex2 were performed at an identical power output (183 \pm 4 W) corresponding to $50 \% \mathrm{Wmax}$ or $51 \pm 1 \% \mathrm{VO}_{2 p \text { ealk. }}$. There was no difference in average heart rates neither during $\mathrm{Ex} 1$, before dietary treatment $(H F: 131 \pm 4$; $L F: 129 \pm 3$ ), nor during Ex2, after dietary treatment ( $H F: 131 \pm 4 ; L F: 130 \pm 3$ ) (beats $\cdot \min ^{-1}$ ). These values corresponded to an average of $70 \%$ of maximal heart rate. During all 3 h-exercises, subjects called their perceived exertion between $\mathbb{1 1}$ (fairly light) after $30 \mathrm{~min}$ and 14 ( $>$ somewhat hard) after $180 \mathrm{~min}$ and there was no difference in any of the given numbers comparing the different exercises. Weight loss was the same during Exl on both diets (mean $1.3 \pm 0.2$ $\mathrm{kg} ; \mathrm{p}<0.001$ ), but it was negligible during Ex2 (mean $0.01 \pm 0.03 \mathrm{~kg}$ ) as a result of water intake $(1.9 \pm 0.2 \mathrm{~L})$ and saline infusion $(1.0 \pm 0.2 \mathrm{~L})$.

\section{IMCL and muscle glycogen}

Table 2 displays muscle substrate concentrations and their change during the investigation time.

Table 2. Intramyocellular lipids (IMCL) and glycogen concentrations and their change during dietary treatments and exercise Ex2

\begin{tabular}{llll}
\hline & & $H F$ diet & LF diet \\
\hline IMCL & before diet & $4.5 \pm 0.5$ & $4.6 \pm 0.5$ \\
& diet effect & $+3.2 \pm 0.5 * *$ & $+0.2 \pm 0.3$ \\
glycogen & Ex2 effect & $-3.2 \pm 0.5 * *$ & $-1.1 \pm 0.5$ \\
& before diet & $33 \pm 4$ & $41 \pm 4$ \\
& diet effect & $+41 \pm 6$ & $+37 \pm 4$ \\
& Ex2 effect & $-40 \pm 2$ & $-41 \pm 4$ \\
\hline
\end{tabular}

Values are means $\pm \mathrm{SE}$ in $\mathrm{mmol} \cdot \mathrm{kg}^{-1}$ wei weights ${ }^{*}=\mathrm{p}<0.001$ for difference between $H F$ and $L F$

$I M C L$ Figure 2 shows the IMCL concentrations at the different time points in the two diet intervention groups. There was no significant difference in post-exercise concentrations of IMCL, after either Ex1 or Ex2 comparing the two groups. In contrast, IMCL concentration increased $(\mathrm{p}<0.001)$ during $H F$ diet intervention 
whereas it remained stable during $L F$. The resynthesis rate of IMCL over the 3 days after $H F$ was about $1.27 \mathrm{mmol} \cdot \mathrm{kg}^{-1}$ wi " $24 \mathrm{~h}^{-1}$. The reduction of IMCL during Ex2 was significant after both diet interventions (HF: $<<0.001 ; L F$ : $\mathrm{p}<0.05$ ) but after $H F$ subjects depleted significantly more in absolute $(\mathrm{p}<0.001)$ as well as in relative $(H F:-41 \pm 4, L F ;-21 \pm 8 \%, \mathrm{p}<0.01)$ terms.

Figure 2. Intramyocellular lipids (IMCL) concentration before and after diet intervention and after $\mathrm{E} \times 2$ in $H F$ and $L F$ diet groups

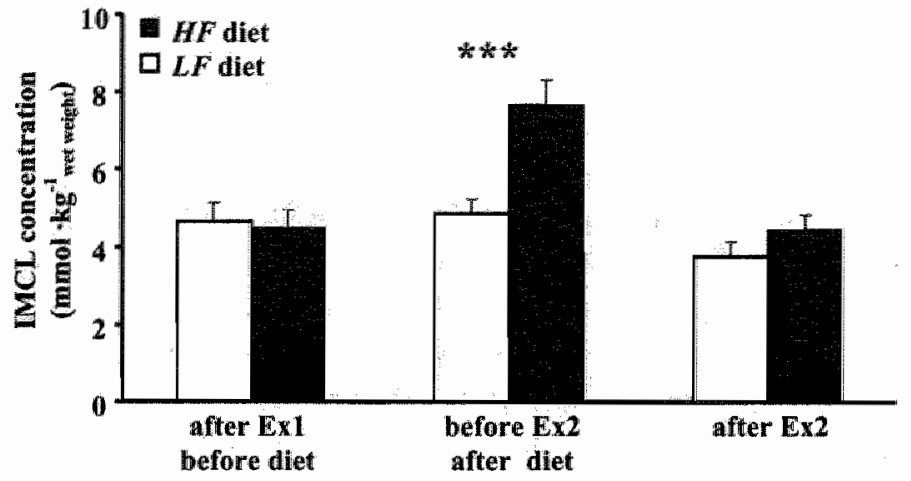

Values are means $\pm \mathrm{SE}$, IMCL concentration was significantly higher $(* * *=p<0.001)$ after $H F$ compared to $L F$ diet

Figure 3 shows a strong correlation $(\mathrm{p}<0.001)$ between IMCL levels prior to the main trial and their reduction during the subsequent 3 -h exercise.

Figure 3n Significant correlation of intramyocellular lipids (IMCL) concentration before Ex2 and its reduction during Ex 2 after $K F F$ and $L F$ diet

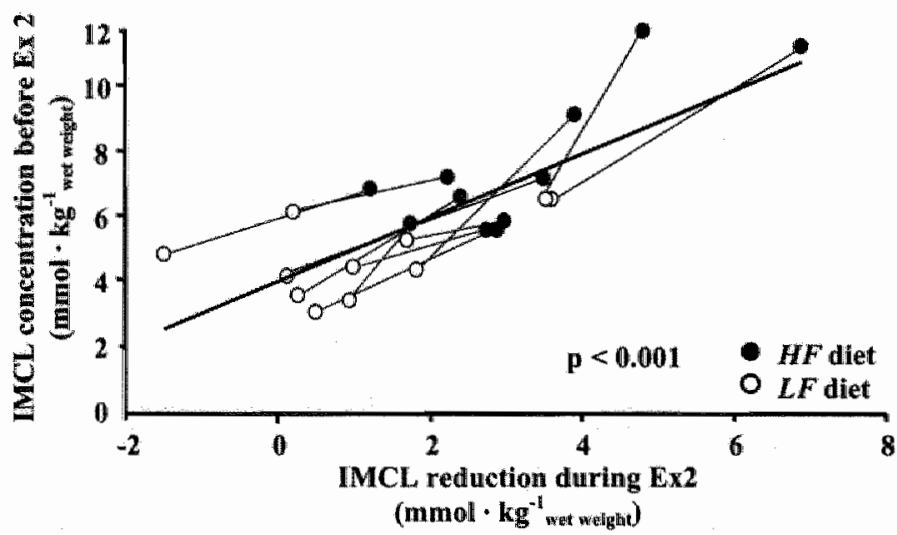

The connecting line within a subject between $H F$ and $L F$ diet shows that every single subject used more IMCL after $H F$ compared to $L F$ diet, $(y=0.988 \mathrm{x}+4.11 .5, \mathrm{r}=0.81)$ 
Correlations were found between aerobic capacity and IMCL responsiveness to diet (storage) and exercise (use): there was a correlation between $\mathrm{VO}_{2 \text { peak }}$ and IMCL concentration before exercise after $H F(\mathrm{r}=0.76, \mathrm{p}<0.01)$ and a trend after $L F(\mathrm{r}=0.59, \mathrm{p}=0.06) ; \mathrm{VO}_{2 \text { peak }}$ also correlated with the amount of IMCL depleted during exercise $\operatorname{Ex} 2(H F: \mathrm{r}=0.68, \mathrm{p}<0.05 ; L F: \mathrm{r}=0.82, \mathrm{p}<0.01)$.

During Ex2, there was a positive correlation between IMCL (mmol $\cdot \mathrm{kg}^{-1} \mathrm{ww}$ ) reduction and whole body fat oxidation $\left(\mathrm{g} \cdot \mathrm{min}^{-1}\right)$ after $H F(\mathrm{p}<0.01)$ and $L F$ $(p<0.01)$ diets (Figure 4). There were no correlations between IMCL and muscle glycogen, either in the extent of storage during dietary intervention or in the degree of reduction during exercise. The subjects who had the highest IMCL after $L F$ had also the highest IMCL after $H F(\mathrm{r}=0.72, \mathrm{p}=0.01)$.

Figure 4. Significant correlation between whole body fat oxidation and intramyocellular lipids (IMCL) reduction during Ex2 after $H F$ and $L F$ diets, $(y=0.047 x+0.417, \pi=0.76$ )

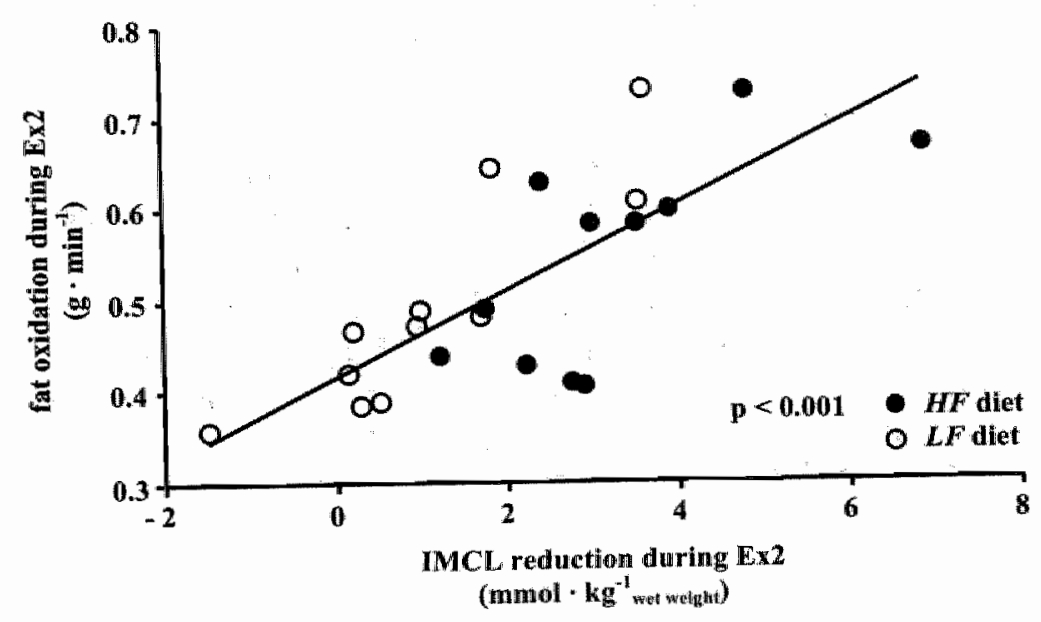

Glycogen Figure 5 shows muscle glycogen concentrations at the different time points in the two diet intervention groups. There was no significant treatment difference in post-exercise concentrations of glycogen after either Exil or Ex2. Furthermore, glycogen concentration increased significantly $(p<0.001)$ during both diet interventions. Glycogen reduction during Ex2 was significant after both diets $(p<0.001)$ but there was no difference neither in absolute nor in relative ( $H F:-56 \pm 4 ; L F:-52 \pm 4 \%$ ) terms. There was a correlation between glycogen levels prior to Ex2 and their reduction during Ex2 after $L F(\mathrm{r}=0.66, \mathrm{p}<0.05)$ but not after $H F(\mathrm{r}=0.16, \mathrm{p}=0.64)$. There was also a significant inverse 
correlation between IMCL concentration prior to Ex 2 and glycogen reduction after $H F(\mathrm{r}=0.74, \mathrm{p}=0.009)$ and a trend after $L F(\mathrm{r}=0.59, \mathrm{p}=0.06)$.

Figure 5. Muscle glycogen concentration ( $₫$ SE) before and after diet intervention and after Ex2 in $H F$ and $L F$ diet groups

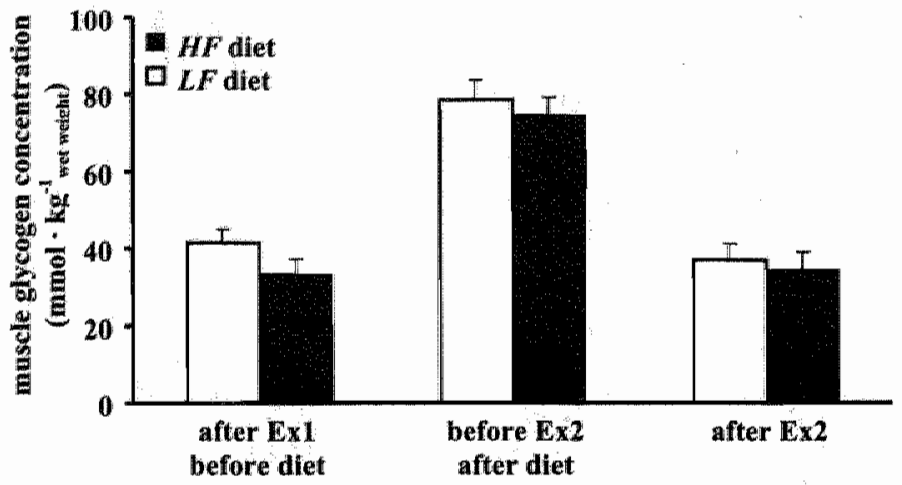

\section{Energy metabolism}

Figure 6 shows the time course of fat and CHO oxidation during Ex2. Total energy expenditure after $H F\left(48.6 \pm 1.0 \mathrm{~kJ} \cdot \mathrm{min}^{-1}\right)$ and after $L F(48.5 \pm 1.3$ $\mathrm{kJ} \cdot \mathrm{min}^{-1}$ ) as well as mean non-protein RER (respiratory exchange ratio) (HF $0.86 \pm 0.01 ; L F 0.88 \pm 0.01$ ) and mean protein oxidation $\left(H F 0.06 \pm 0.0 \mathrm{~g} \cdot \mathrm{min}^{-1}\right.$; LF $0.05 \pm 0.0 \mathrm{~g} \cdot \mathrm{min}^{-1}$ ) were the same during $\mathrm{Ex} 2$ after both treatments. There was a trend for a lower average RER and a higher percentage contribution of fat to total energy during Ex2 after $H F$ compared with $L F(\mathrm{p}<0.07)$.

Figure 6. Fat and carbohydrate (CHO) oxidation during Ex2 after $H F$ and $L F$ diets

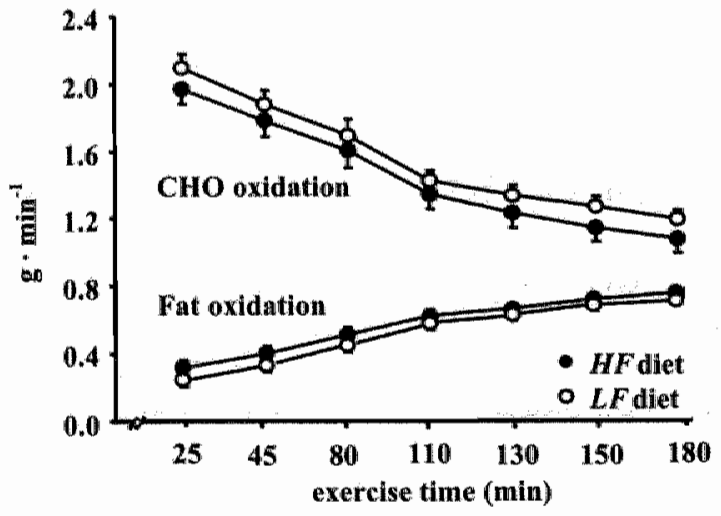

Values are means t $S E$, there was a trend $(\mathrm{p}<0.09)$ of a higher fat oxidation during the first hour of exercise after $H F$ compared to $L F$ diet 
Figure 7 shows a histogram of the relative contribution of the each single energy substrate to total energy expenditure according to diet: With the assumption of a $10-\mathrm{kg}$ active muscle mass per $70 \mathrm{~kg}$ of bw, subjects oxidized nore $\mathbb{M C L}$ duning exercise Ex2 after the $H F$ diet $\left(0.15 \pm 0.02 \mathrm{~g} \cdot \mathrm{min}^{-1}\right)$ than after the LF diet $\left(0.05 \pm 0.02 \mathrm{~g}\right.$ " $\left.\min ^{-1}, \mathrm{p}<0.001\right)$. In contrast, they utilized the same amount of glycogen ( $\left.H F \quad 0.39 \pm 0.02 \mathrm{~g} \cdot \mathrm{min}^{-1} ; L F \quad 0.40 \pm 0.04 \mathrm{~g} \cdot \mathrm{min}^{-1}\right)$. The estimated oxidation of plasma glucose during exercise was the same after both diet interventions ( $H F \quad 1.11 \pm 0.09 \mathrm{~g} \cdot \mathrm{min}^{-1} ; L F \quad 1.20 \pm 0.06 \mathrm{~g} \cdot \mathrm{min}^{21}$ ), as was the oxidation of plasma FFA and other fat sources except IMCL (HF $0.39 \pm 0.02 \mathrm{~g} \cdot \mathrm{min}^{-1}, L F 0.44 \pm 0.02 \mathrm{~g} \cdot \mathrm{min}^{-1}, \mathrm{p}=0.16$ ). Due to the discrepant use of IMCL during Ex2 after the two diets, total muscle energy contribution (from both IMCL and glycogen) was larger after HF $(24.6 \pm 1.9)$ than after $L F$ $(16.8 \pm 1.8 \%$ energy, $p=0.006)$.

Figure 7. Estimates of the relative contribution of muscle and blood-borne substrates to energy production during Ex2 after $H F$ and $L F$ diets

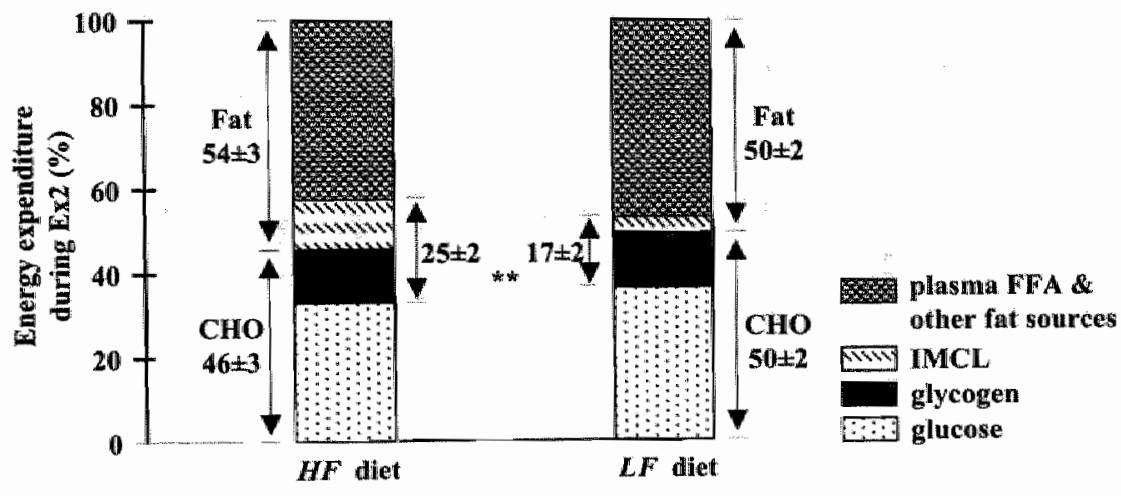

Values are means $\pm \mathrm{SE}$ in percent non-protein energy, FFA $=$ free fatty acids, IMLC $=$ intramyocellular lipids; $*=0<0.01$

\section{Plasma parameters}

In each group there were significant changes $(p<0.001)$ of all measured plasma parameters (TAG, FFA, glucose, and insulin) over time (Figure 8). TAG concentrations steadily and significantly increased during exercise after $H F$ (preexercise: $0.62 \pm 0.04$ vs. end of exercise: $1.06 \pm 0.05 \mathrm{mmol} \cdot \mathrm{L}^{-1} ;+71 \%$, $\mathrm{p}<0.003)$ and after $L F\left(0.82 \pm 0.09\right.$ vs. $1.27 \pm 0.08 \mathrm{mmol}^{-1} \mathrm{~L}^{-1} ;+55 \%$, $\mathrm{p}<0.0001$ ) diet. Over the whole exercise TAG concentrations were lower after $H F$ compared to $L F$ by an average of $0.23 \mathrm{mmol} \cdot \mathrm{L}^{-1}(\mathrm{p}<0.02)$. 
Fugure 8. Plasma concentrations of triacylglycerol (TAG), free fatty acids (FFA), glucose and insulin during $\mathrm{E} \times 2$ after $H F$ and $L F$ diet
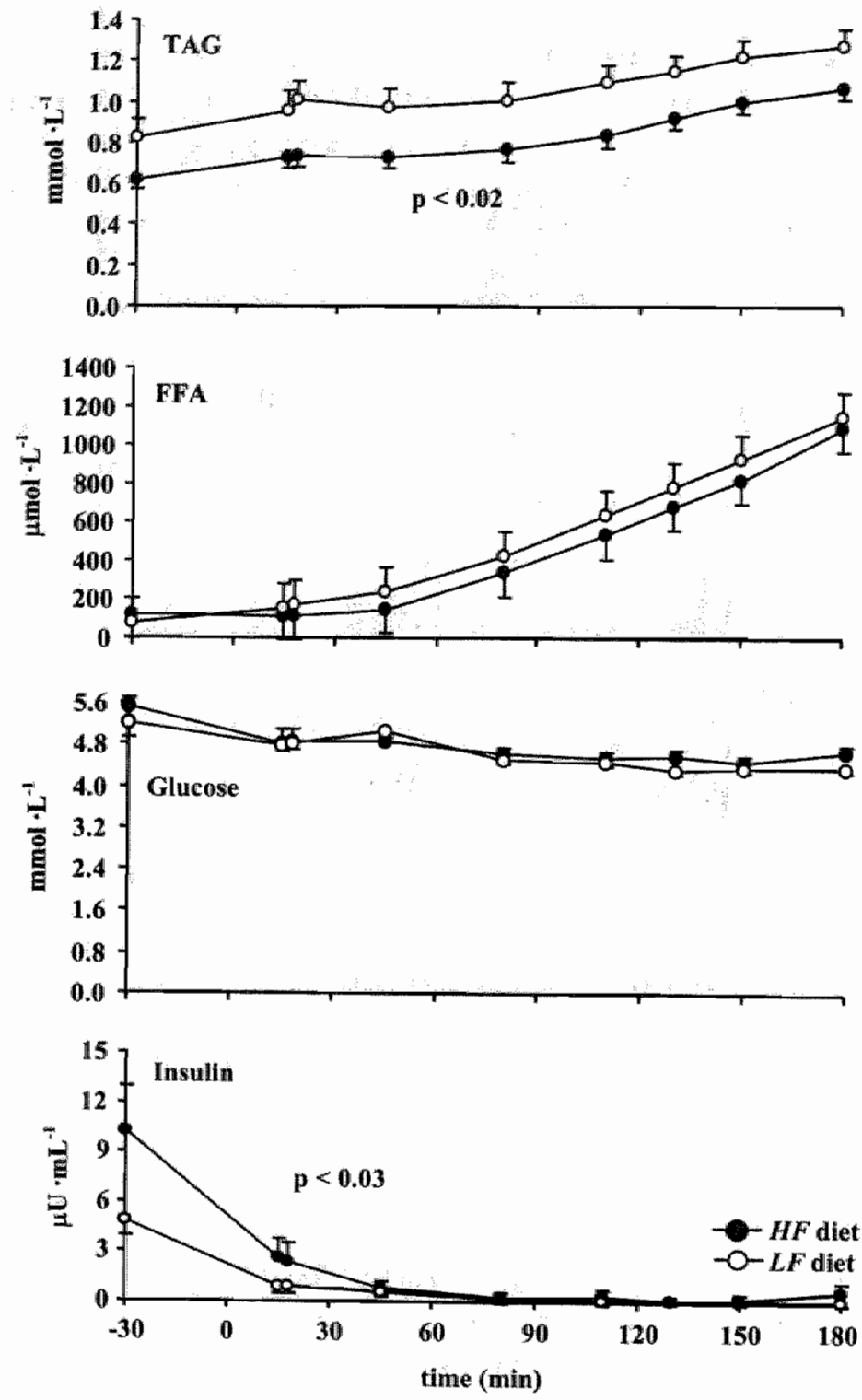

Vatues are means $\pm S E$, diet had a significant influence on $T A G(p<0.02)$ and insulin $(\mathrm{p}<0.03)$ curves 
Exercise resulted in a large increase in FFA concentrations after HF (preexercise: $121 \pm 42$ vs. end of exercise: $1086 \pm 97 \mu \mathrm{mol} \cdot \mathrm{L}^{-1} ; \mathrm{p}<0.0001$ ) and $L F$ (pre-exercise: $78 \pm 14$ vs. end of exercise: $1147 \pm 72 \mu \mathrm{mol} \cdot \mathrm{L}^{-1}, \mathrm{p}<0.0001$ ) diet. FFA concentrations started to rise after 45 minutes of exercise. During exercise there was no significant difference in FFA concentrations between $H F$ and $L F$ diets $(p=0.18)$. Glucose concentrations significantly decreased during exercise after HF (pre-exercise: $5.5 \pm 0.2$ vs. end of exercise: $4.7 \pm 0.1 \mathrm{mmol} \cdot \mathrm{L}^{-1}$, $\mathrm{p}<0.003$ ) and $L F$ (pre-exercise: $5.2 \pm 0.3$ vs. end of exercise: $4.4 \pm 0.1$ $\left.\mathrm{mmol} \cdot \mathrm{L}^{-1}, \mathrm{p}<0.0001\right)$ diet. Diet had no influence and, in both groups, the lowest values $H F 4.5 \pm 0.1 ; L F 4.3 \pm 0.1$, which were within the normal range (i.e. $>3.9 \mathrm{mmol} \cdot \mathrm{L}^{-1}$ ) were observed during the last hour of exercise. Insulin levels significantly decreased during exercise after $H F$ (pre-exercise: $10.3 \pm 2.7$ vs. end of exercise: $0.7 \pm 0.5 \mu \mathrm{U} \cdot \mathrm{mL}^{-1}, \mathrm{p}<0.0001$ ) and $L F$ (pre-exercise: $4.9 \pm 0.9$ vs. end of exercise: $0.2 \pm 0.0 \mu \mathrm{U} \cdot \mathrm{mL}^{-1}, \mathrm{p}<0.0001$ ) diet. Diet influenced insulin concentrations significantly. The curve was significantly elevated $(\mathrm{p}<0.03)$ after $H F$ compared to $L F$ during exercise, although this was clearly apparent only during the first $45 \mathrm{~min}$. Before Ex 2 there was a correlation between resting insulin concentration and IMCL levels in $H F(\mathrm{r}=0.62, \mathrm{p}<0.05)$ but not in $L F(\mathrm{r}=0.05, \mathrm{p}=0.90)$. There was also a correlation between the IMCL increase on the $H F$ diet and resting insulin concentration before $\operatorname{Ex} 2(\mathrm{r}=0.73$, $\mathrm{p}<0.01$ ).

\section{0-km cycling time trial}

Table 3 shows the parameters measured by the SRM-system during the TT. According to asthmatic problems one subject was excluded. After $H F$ subjects were $34 \pm 31 \mathrm{~s}$ faster than after $L F$. The weight of the subjects before the TT was the same after $H F(74.6 \pm 2.5)$ and $L F(74.3 \pm 2.5)$ and both times they ingested $0.5 \pm 0.1 \mathrm{~L}$ of plain water during the TT. Figure 9 shows the average velocities during the TT, splited in $5 \mathrm{~km}$ distances, after $H F$ and $L F$ diet.

Figure 9. Change in 20 -km cycling time trial performance after $H F$ and $L F$ diets, $(N=10)$

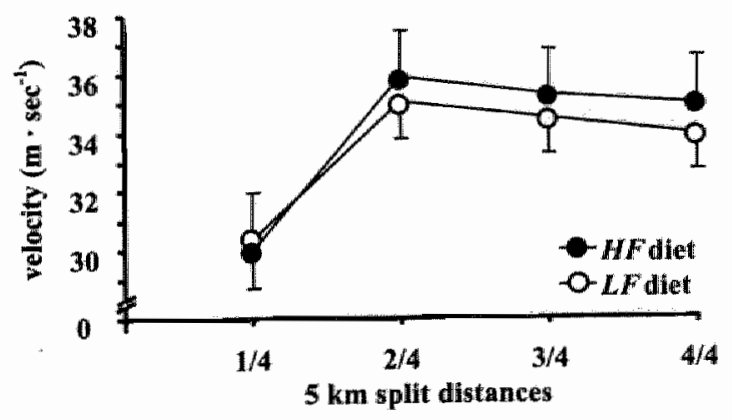


Additionally, the correlation between individual velocities, determined by the average of the two trials for each subject, and the improvement with $H F$ diet was significant $(p<0.04)$. In other words, the faster a subject was, the higher was the improvement after $H F$ diet Figure 10 shows the negative correlation $(\mathrm{p}<0.01)$ between the reduction of $\mathrm{MCL}$ during Ex2 and the required time for the $20 \mathrm{~km}$ TT for all subjects after both diets. No correlation was found after any diet intervention between TT performance time and glycogen concentration after Ex 2 or glycogen reduction during $\mathrm{Ex} 2$.

Table 3. Performance achieved during the 20-km time trial after $H F$ and $L F$ diets

\begin{tabular}{llll}
\hline & & HF diet & LF diet \\
\hline Distance & $\mathrm{km}$ & 20.00 & 20.00 \\
Heart rate & $\min ^{\mathrm{n}}$ & $175 \pm 3$ & $173 \pm 3$ \\
Time & $\min \cdot \mathrm{sec}$ & $34: 28 \pm 1: 32$ & $35: 02 \pm 1: 15$ \\
Speed & $\mathrm{km} \cdot \mathrm{h}^{-1}$ & $35.4 \pm 1.6$ & $34.5 \pm 1.2$ \\
Power & Watt & $232 \pm 10$ & $231 \pm 12$ \\
Work & $\mathrm{kJ}$ & $444 \pm 13$ & $457 \pm 5$ \\
Revolution & $\mathrm{rpm}$ & $91 \pm 2$ & $93 \pm 2$ \\
\hline
\end{tabular}

The time trial took place $1.5 \mathrm{~h}$ subsequently to Ex2, the 34 sec average improvement in performance time after the $H F$ diet was not significant, values are means $\pm \mathrm{SE}_{*}(\mathrm{~N}=10)$

Figure 10. Correlation between intramyocellular lipids (IMCL) reduction during Ex2 and time used for the subsequent $20-\mathrm{km}$ time trial (TT) after $H F$ and $L F$ diets, $(y=-0.004 \mathrm{x}+11.084$, $\mathrm{r}=0.58, \mathrm{~N}=10$ )

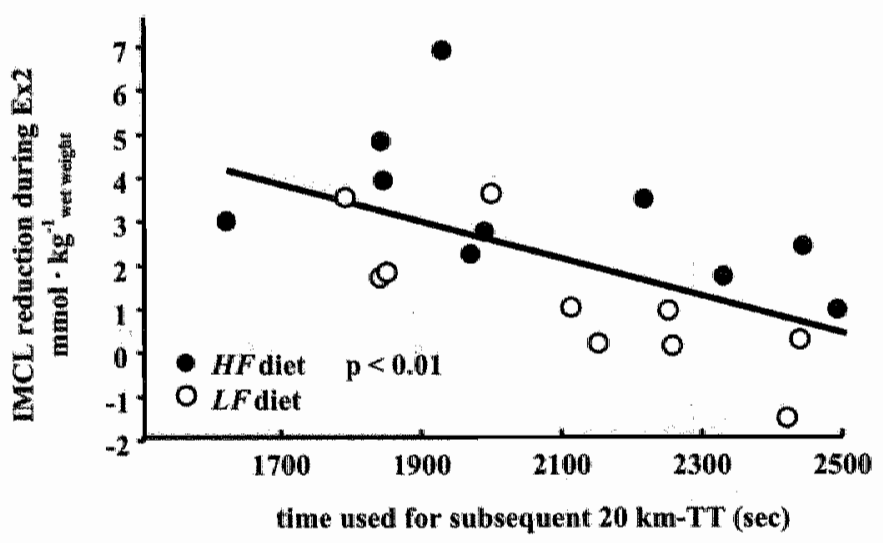




\section{DISCUSSION}

The main findings of this study are that (a) glycogen replenishment is not hindered by a high fat diet and, conversely, IMCL replenishment is not prevented by a relatively high $\mathrm{CHO}$ intake, and (b) at similar initial glycogen status, IMCL utilization during prolonged exercise is directly proportional to the IMCL stores; with no significant shift in whole body fat oxidation and no influence on glycogen breakdown.

The present study shows that within 2.5 days it is possible to replenish $\mathrm{CHO}$ and IMCL stores without delaying each other. When controlling for CHO intake, Johnson and coworkers (26) observed a smaller IMCL storage after $48 \mathrm{~h}$ on a high-CHO diet than on a low-CHO diet. They suggested that $\mathrm{CHO}$ intake rather than fat intake dictates the post-exercise replenishment of $\mathrm{MMCL}$ and that a high intake of CHO may inhibit IMCL storage. However, fat intake in their study was not controlled and the low-CHO diet actually supplied more than twice as much lipids as the high-CHO diet. The suggestion of Johnson et al. (26) may have been prompted by their earlier observation that IMCL accumulates during 3 days of total carbohydrate deprivation (47), in fact a period of total fasting during which dietary lipids were also absent. This shows that in situations of dramatic adipose tissue lipolysis (that are foreign to any feeding paradigm) with accumulation of potentially noxious FFA derivatives, dietary lipids are not indispensable to IMCL accumulation. More practically however, there are now several studies reporting that short term (1-2 days) feeding with a high-fat diet increases IMLC concentration in comparison with lower fat diets $(4,11,12,28,57)$. The present results demonstrate that a relatively high $\mathrm{CHO}$ intake does not prevent IMCL replenishment, provided that enough dietary lipids are fed as well. It has been estimated that a lipid intake of $\sim 2 \mathrm{~g} \cdot \mathrm{kg}^{-1}$ bw will achieve replenishment of the IMCL used during prior exercise in only one day of rest (13).

So far, studies have not attempted or have not been successful in manipulating IMCL concentrations without also affecting muscle glycogen concentrations. Most of the studies that change dietary macronutrients during the investigation time provide the subjects either with a high-fat low-CHO diet, or with a low-fat high-CHO diet $(7,8,10,15)$. Therefore, high-fat diets supply a suboptimal share of $\mathrm{CHO}$ that limit the rate of glycogen storage. The incomplete glycogen replenishment in the study of Coyle and coworkers (10) after a high-fat diet in spite of a relatively high $\mathrm{CHO}$ supply $\left(8 \mathrm{~g} \mathrm{~kg}^{-1}\right.$ bw $\left.\cdot \mathrm{d}^{-1}\right)$, may be explained by continued physical activity during the dietary treatment period $\left(2 \mathrm{~h} \cdot \mathrm{d}^{-1}\right)$ except on pre-test day. In contrast, the approach of this study to supplement a high-CHO $\operatorname{diet}\left(7 \mathrm{~g} \cdot \mathrm{kg}^{-1}\right.$ bw $\cdot \mathrm{d}^{-1}$ only, but subjects remained inactive) with additional lipids for a limited time, instead of exchanging one fuel for the other over a longer 
time, was as effective as the non-supplemented diet for replenishing muscle glycogen. The reliability of our data is supported by the reproducibility of initial muscle energy stores: glycogen and IMCL concentrations after the first $3-\mathrm{h}$ exercise were exactly the same before the wo different diet interventions. Then, subjects followed strictly either the $H F$ or the $L F$ diet. The order of the treatments could have been unmasked without error from looking at the IMCL values measured after the 2.5 days on the diet. Therefore as postulated, glycogen concentration increased identically after both diets, whereas IMCL increased only after $H F$.

The amount of $\mathrm{MMCL}$ stored and used was determined primarily by diet. However, IMCL use during exercise was strongly correlated to the absolute content prior to exercise (Figure 3). Previous transversal studies reported that higher IMCL concentrations lead to a greater degree of IMCL breakdown during exercise, e. in insulin dependent diabetic vs. healthy men (46) or in women vs men (49). Dietary intervention studies reached a similar conclusion from either indirect (10) or direct (26) inference. The present results support the prevailing view and bring the new information that pre-exercise IMCL concentration triggers IMCL breakdown during work independently of glycogen stores.

In addition to diet, there was a clear role for individual factors in IMCL storage and use. Subjects who had the highest IMCL concentration after $H F$ also had the highest IMCL concentration after $L F$. The inter-individual variation in IMCL accumulation was large (range 15-109\% increase) and has also been reported by others in apparently homogenous groups of subjects after controlled diets $(2,26)$. The correlation found between aerobic capacity and the magnitude of IMCL replenishement corroborates observations of larger IMCL stores in trained vs untrained subjects $(23,30)$, but contrasts with the lack of training effect on the rate of early post-exercise IMCL accumulation (12) and on mRNA concentration of diacylglycerol acyltransferase, the enzyme involved in storing FAA in IMCL (42). These differences support the notion of a predominant role for changes in muscle fiber ultrastructure rather than biochemical processes to explain the enhanced trainining-induced capacity for storing lipids.

There was also quite a large inter-individual variation in the ability to utilize (range 17-61\% decrease) IMCL as a substrate after the HF diet. Large interindividual variations in whole body fat oxidation at relative exercise intensities close to that used in this study are commonly observed $(16,52)$. It has been speculated that some individuals have the potential to up-regulate IMCL for reasons as yet unclear (34). The correlation between $\mathrm{IMCL}$ breakdown and whole body fat oxidation in the present work (Figure 4) suggests that IMCL 
breakdown during exercise may explain more than $50 \%$ of the variation in fat metabolism during exercise.

One may speculate on reasons for the variability in IMCL breakdown and total fat oxidation in endurance-trained subjects of comparable cycling aerobic capacity. Fat oxidation is more closely related to the aerobic-anaerobic transition than to $\mathrm{VO}_{2 \max }$ or $\mathrm{W}_{\max }$ (14). However, the intensity of exercise in this study was adjusted relative to $\mathrm{W}_{\max }$, not to the aerobic-anaerobic transition. In addition, as duathletes or triathletes, the subjects practiced running and cycling endurance activities in varying proportions and their training specificity and the distribution of fiber types in leg muscles may have been distinctly different dependent on training focus (9). Differences in adlaptive effects of habitual running and cycling schedules on aerobic and fat metabolism $(1,43)$ in relation to difference in $\mathrm{MCL}$ content of different fiber types may have contributed to difference in IMCL use.

A majority of studies investigating exercise metabolism after a high-fat diet have observed up to $50 \%$ increase in fat oxidation (e.g. $(6,8,15,20)$, however the subjects had usually been CHO-deprived for several days or weeks. In the present study it has been shown that when CHO status is conserved and in the absence of a prolonged fat adaptation period, fat oxidation during submaximal exercise is not significantly altered despite a large difference in IMCL content: Furthermore, glycogen breakdown, plasma glucose concentration and whole body CHO oxidation were similar after both $H F$ and $L F$ diet. This is in line with the primary role for $\mathrm{CHO}$ availability in determining the rate of fat oxidation (44). However, it is somewhat of a paradox that $\mathrm{MMCL}$ concentration seems to determine IMCL breakdown (Figure 3), which itself is positively correlated with whole body fat oxidation (Figure 4), but fails to reflect in a significant difference in whole body substrate oxidation between $H F$ and $L F$ at group level.

A first line of explanation, there was a trend $(p<0.07)$ for a higher fat oxidation after $H F$ during the first hour. This could be connected with the findings of Watt and coworkers (55) who reported a significant utilization of IMCL during the first $2 \mathrm{~h}$ of moderate exercise, but not during hours 2-4, and with indications on IMCL use derived from examining the course of FFA and total fat oxidation during prolonged exercise (41). Therefore, IMCL breakdown may have occurred early and its global impact was overwhelmed by the large total lipid budget of the $3-\mathrm{h}$ exercise. This is consistent with the model proposing that substrate availability is primarily determined by the intramuscular stores (36) before adipose tissue lipolysis has been fully activated. On the other hand, most studies have applied exercise trials exceeding 1 to $2 \mathrm{~h}$, and observations of a noticeable degree of $\mathrm{IMCL}$ breakdown during shorter exercise bouts are still rare (56).

Secondly, an increase in IMCL oxidation may have been opposed by a decline in peripheral lipid oxidation, resulting in comparable whole body fuel partition. In 
support, plasma TAG concentration was $\sim 30 \%$ higher after $L F$ throughout exercise, suggesting the possibility of contribution to muscle energy by circulating TAG (20). This warrants further examination, because in long-term feeding studies, a pronounced increase in muscle uptake of plasma TAG occurred after the high-fat, not the low fat diet (20). Although plasma FFA were not significantly different between groups, the FFA concentration curve after $L F$ was consistently above that after $H F$, also suggesting the possibility of a greater plasma FF availability when IMCL were low.

The phenomenon of higher plasma TAG after high $\mathrm{CHO}$ compared to low CHO diets has been described in various studies (see in (35)) and is related to both $\mathrm{TAG}$ hepatic overproduction and inadequate clearance. Interestingly in the present study, a dietary lipid load appears to blunt plasma TAG concentrations when no change is made to $\mathrm{CHO}$ intake, which, to our knowledge is a new observation.

Further to similar rates of total fat oxidation, $\mathrm{CHO}$ oxidation and glycogen breakdown were unchanged during exereise after $H F$ in spite of enhanced IMCL use. Energy expenditure being equal in both conditions, these data indicate an increase in systemic energy supply when IMCL are low, whereas the energy flux from adipose tissue and liver appears to be less important when IMCL are high (with a higher percentage of energy being derived directly from muscle).

The faster a subject was, the better was the improvement after $H F$ diet. It is intriguing, because the hypothesis of an improved performance with high IMCL stores implied a slower rate of muscle glycogen breakdown during submaximal exercise, such that glycogen stores at the onset of the subsequent time trial would be higher. However, as glycogen as well as IMCL stores were identical in both groups before the TT, the hypothesis could not be tested and there was no difference in performance at group level. Nevertheless, it is of interest to note the negative correlation observed between IMCL concentration prior to Ex2 and glycogen reduction during $\mathrm{Ex} 2($ HF: $\mathrm{p}<0.01 ;$ LF: $\mathrm{p}=0.06)$ and between $\mathrm{MCL}$ reduction during the 3 -h exercise and the required time for the TT $(p<0.01$, Figure 10 ). The latter can be an observation connected to training status. These data suggest that subjects with a higher aerobic capacity are able at the same time to store and use IMCL more efficiently than others, independently of the fat content of the diet, and they are better performers.

\section{CONCLUSION}

In conclusion, the present study demonstrates a successful short-term dietary strategy to maximize muscle energy stores prior to exercise, increasing $I M C L$ 
concentration without jeopardizing glycogen loading. The dietary-induced increase in IMCL leads, when CHO availability is safeguarded, to a larger IMCL contribution during submaximal exereise with no bearing on whole body lipid oxidation. Aerobic capacity, in other words the ability to burn more fat, appears to be a secondary factor favoring $I M C L$ storage and use. Hence the better an athlete is trained, the better his ability to mobilize MMCL and subsequently to perform at high intensity aerobic exercise.

\section{ACKNOWLEDGEMENT}

We thank the subjects of this study for their time and effort, Bemard Decarli as the diet advisor, Jean-Marc Schneider for diet transportation, Irina Monnard for the quantification of FFA and Anny Blondel for the determination of insulin and glucose.

For the evaluation of the glycogen spectra, the MRUI software package was kindly provided by the participants of the EU Network programmes: Human Capital and Mobility, CHRX-CT94-0432 and Training and Mobility of Researchers, ERB-FMRX-CT970160. We acknowledge Karin Zwygart for data acquisition. 


\section{REFERENCES}

1. ACHTEN I, VENABLES MC, JEUKENDRUP AE. Fat oxidation rates are higher during running compared with cycling over a wide range of intensities. Metabolism 52: 747-752, 2003.

2. BACHMANN OP, DAHL DB, BRECHTEL $K$, MACHANN $J$, HAAP M, MAIER T, LOVISCACH M, STUMVOLL M, CLAUSSEN CD, SCHLK F, HARING HU, JACOB $\mathrm{S}$. Effects of intravenous and dietary lipid challenge on intramyocellular lipid content and the relation with insulin sensitivity in humans. Diabetes 50: 2579-2584, 2001 .

3. BODEN O, LEBED B, SCHATZ M, HOMKO C, LEMIEUX S. Effects of acute changes of plasma free fatty acids on intramyocellular fat content and insulin resistance in healthy subjects. Diabetes 50: 1612-1617, 2001.

4. BOESCH C, DECOMBAZ J, SLOTBOOM J, KREIS R. Observation of intramyocellular lipids by means of $1 \mathrm{H}$ magnetic resonance spectroscopy. Proc Nutr Soc 58: 841-850, 1999.

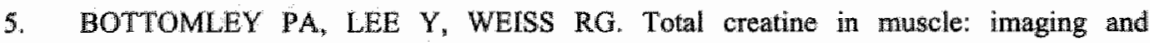
quantification with proton MR spectroscopy. Radiology 204: 403-410, 1997.

6. BURKE LM, ANGUS DJ, COX GR, CUMMINGS NK, FEBBRAIO MA, GAWTHORN $K$, HAWLEY JA, MINEHAN M. MARTIN DT, HARGREAVES $M$. Effect of fat adaptation and carbohydrate restoration on metabolism and performance during prolonged cycling. J Appl Physiol 89: 2413-2421, 2000.

7. BURKE LM, and HAWLEY JA. Effects of short-term fat adaptation on metabolism and performance of prolonged exercise. Med Sci Sports Exerc 34: 1492-1498, 2002.

8. CAREY AL, STAUDACHER HM, CUMMINGS NK, STEPTO NK, NIKOLOPOULOS V, BURKE LM, HAWLEY JA. Effects of fat adaptation and carbohydrate restoration on prolonged endurance exercise. $J$ Appl Physiol 91 : 115-122, 2001.

9. CLARKSON PM, KROLL W, MCBRIDE TC. Maximal isometric strength and fiber type composition in power and endurance athletes. Eur J Appl Physiol Occup Physiol 44: 35 $42,1980$.

10. COYLE EF, JEUKENDRUP AE, OSETO MC, HODGKINSON BJ, ZDERIC TW. LOWfat diet alters intramuscular substrates and reduces lipolysis and fat oxidation during exercise. Am J Physiol Endocrinol Metab 280: E391-E398, 2001.

11. DECOMBAZ J, FLEITH M, HOPPELER H, KREIS R, BOESCH C. Effect of diet on the replenishment of intramyocellular lipids after exercise. Eur IJ Nutr 39:244-247, 2000.

12. DECOMBAZ J, SCHMITT B, ITH M, DECARLI B, DIEM P, KREIS R, HOPPELER H, BOESCH C. Post-exercise fat intake repletes intramyocellular lipids, but no faster in trained than in sedentary subjects. Am J Physiol 281: R760-R769, 2001.

13. DECOMBAZ J. Nutrition and recovery of muscle energy stores after exercise. Schweiz Ztschr Sportmed Sportroum 51: 31-38, 2003.

14. FOX EL, and MATHEWS DK Bases physiologiques de lactivité physique. WB Saunders, Philadelphia, 1981, p. 210.

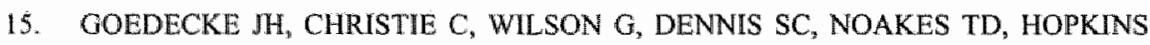
WG, LAMBERT EV. Metabolic adaptations to a high-fat diet in endurance cyclists. Metabolism 48: 1509-1517, 1999.

16. GOEDECKE JH, ST CLAIR GA, GROBLER L, COLLINS M, NOAKES TD, LAMBERT EV. Determinants of the variability in respiratory exchange ratio at rest and during exercise in trained athletes. Am J Physiol Endocrinol Metab 279: E1325-E1334, 2000 . 
17. HARGREAVES M, HAWLEY IA, JEUKENDRUP A. Pre-exercise carbohydrate and fat ingestion: effects on metabolism and performance, J Sports Sci 22:31-38, 2004.

18. HAWLEY JA, BURKE LM, ANGUS DJ, FALLON KE, MARTIN DT, FEBBRAIO MA. Effect of altering substrate availability on netabolism and performance during intense exercise. BrJ Nutr 84: 829-838, 2000.

19. HELGE JW, RICHTER EA, KIENS B. Interaction of training and diet on metabolism and endurance during exercise in man. J Physiol 492: 293-306, 1996.

20. HELGE JW, WATT PW, RICHTER EA, RENNIE MJ, KIENS B. Fat utilization during exercise: adaptation to a fat-rich diet increases utilization of plasma fatty acids and very low density lipoprotein-triacylglycerol in humans. I Physiol 537: 1009-1020, 2001.

21. HELGE JW, WATT PW, RICHTER EA, RENNIE MJ, KIENS B. Partial restoration of dietary fat induced metabolic adaptations to training by 7 days of carbohydrate diet. $J$ Appl Physiol 93: 1797-1805, 2002.

22. HELGE JW, WULFF B, KUENS B. Impact of a fat-rich diet on endurance in man: role of the dietary period. Med Soi Sports Exerc 30: 456-461, 1998.

23. HOPPELER H, HOWALD $H$, CONLEY K, LINDSTEDT SL, CLAASSEN H, VOCK $P$, WEIBEL ER. Endurance training in humans: aerobic capacity and structure of skeletal muscle. I Appl Phsiol 59: 320-327, 1985.

24. IVY IL. Dietary strategies to promote glycogen synthesis after exercise. Can $J A p p l$ Physiol 26 Suppl: S236-S245, 2001.

25. JEQUIER $E$, ACHESON $K$, SCHUTZ Y. Assessment of energy expenditure and fuel utilization in man. Annu Rev Nutr 7. 187-208, 1987.

26. JOHNSON NA, STANNARD SR, MEHALSKI $\mathrm{K}$, TRENELL MI, SACHINWALLA T, THOMPSON CH, THOMPSON MW. Intramyocellular triacylglycerol in prolonged cycling with high- and low-carbolydrate availability. $J$ Appl Physiol 94: 1365-1372, 2003.

27. LAMBERT EV, SPEECHLY DP, DENNIS SC, NOAKES TD. Enhanced endurance in trained cyclists during moderate intensity exercise following 2 weeks adaptation to a high fat diet. Eur J Appl Physiol Occup Physiol 69: 287-293, 1994.

28. LARSON-MEYER DE, NEWCOMER BR, HUNTER GR. Influence of endurance running and recovery diet on intramyocellular lipid content in women: a $1 \mathrm{HL}$ NMR study. Am J Physial Endocrinol Metab 282: E95-E106, 2002.

29. LITHELL H, ORLANDER J, SCHELE R, SJODIN B, KARLSSON J. Changes in lipoprotein-lipase activity and lipid stores in human skeletal muscle with prolonged heavy exercise. Acta Physiol Scand 107: 257-261, 1979.

30. MORGAN TE, SHORT FA, COBB LA. Effect of long-term exercise on skeletal muscle lipid composition. Am J Physiol 216: 82-86, 1969.

31. MUOIO DM, LEDDY JJ HORVATH PJ, AWAD AB, PENDERGAST DR. Effect of dietary fat on metabolic adjustments to maximal VO2 and endurance in runners. Med Sol Sports Exerc 26: 81-88, 1994.

32. NARESSI A, COUTURIER C, DEVOS JM, JANSSEN M, MANGEAT C, DE BEER R, GRAVERON-DEMILLY D. Java-based graphical user interface for the MRUI quantitation package. MAGMA 12: 141-152, 2001.

33. NOBLE B. J. Clinical applications of perceived exertion. Med Sci Sports Exerc 14: 406411,1982 .

34. ONEILL M, WATT MJ, HEIGENHAUSER GJ, SPRIET LL. Effects of reduced free fatty acid availibility on hormone sensitive lipase activity in human skeletal muscle during aerobic exercise. J Appl Physiol in Press 2004. 
35. PARKS EI, and HELLERSTEIN MK. Carbohydrate-induced hypertriacylglycerolemia: historical perspective and review of biological mechanisms. Am J Clin Nutr 71: 412-433, 2000 .

36. PENDERGAST DR, HORVATH PJ, LEDDY JJ, VENKATRAMAN JT. The role of dietary fat on performance, metabolism, and health. Am J Sponts Med 24; S53-S58, 1996.

37. PERONINET $\mathbf{F}$, and MASSICOTTE D. Table of nonprotein respiratory quotient: an update. Can J Sport Sci 16: 23-29, 1991.

38. PHLLIPS SM, GREEN HJ, TARNOPOLSKY MA, HEIGENHAUSER GF, HILL RE, GRANT SM. Effects of training duration on substrate turnover and oxidation during exercise. JAppl Physiol 81: 2182-2191, 1996.

39. PHINNEY SD, BISTRIAN BR, EVANS WJ, GERVINO E, BLACKBURN GL. The human metabolic response to chronic ketosis without caloric restriction: preservation of submaximal exercise capability with reduced carbohydrate oxidation. Metabolism 32: $769-776,1983$.

40. PIJNAPPEL WWF, VAN DEN BOOGAART A, DE BEER $R$, VAN ORMONDT D. SVD-based quantification of magnetic resonance signals. $J$ Magn Reson 97: 122-134, 1992.

41. ROMIN JA, COYLE EF, SIDOSSIS LS, GASTALDELLI A, HOROWITZ JF, ENDERT E, WOLFE RR. Regulation of endogenous fat and carbohydrate metabolism in relation to exercise intensity and duration. Am J Physiol 265: E380-E391, 1993.

42. SCFIMITT B, FLUCK M, DECOMBAZ J, KREIS R, BOESCH C, WITTWER M, GRABER F, VOGT M, HOWALD H, HOPPELER $H$. Transcriptional adaptations of lipid metabolism in tibialis anterior muscle of endurance-trained athletes. Physiol Genomics 15: 148- $157,2003$.

43. SCHNEIDER DA, LACROIX KA, ATKINSON GR, TROPED PJ, POLLACK $\%$ Ventillatory threshold and maximal oxygen uptake during cycling and running in triathletes. Med Sci Sports Exerc 22: 257-264, 1990.

44. SIDOSSIS LS, and WOLFE RR. Gluciose and insulin-induced inhibition of fatty acid oxidation: the glucose-fatty acid cycle reversed. Am J Physiol 270: E733-E738, 1996.

45. SINNING WE, DOLNY DG, LITTLE KD, CUNNINGHAM LN, RACANIELLO A, SICONOLFI SF, SHOLES JL. Validity of "generalized" equations for body composition analysis in male athletes. Med Sci Sports Exerc 17: 124-130, 1985.

46. STANDL E, LOTZ N, DEXEL T, JANKA HU, KOLB HJ. Muscle triglycerides in diabetic subjects. Effect of insulin deficiency and exercise. Diabetologia 18: $463-469$, 1980.

47. STANNARD SR, THOMPSON MW, FAIRBAIRN K, HUARD B THOMPSON CH. Fasting for $72 \mathrm{~h}$ increases intramyocellular lipid content in nondiabetic " physically fit men. Am J Physiol Endocrinol Metab 283: E1185-E1191, 2002.

48. STARLING RD, TRAPPE TA, PARCELL AC, KERR CG, FINK WJ, COSTILL DL. Effects of diet on muscle triglyceride and endurance performance. $J$ Appl Physiol 82: $1185-1189,1997$.

49. STEFENASEN CH, ROEPSTORFF C, MADSEN M, KIENS B. Myocellular triacylglycerol breakdown in females but not in males during exercise. Am $J$ Physiol Endocrinol Metab 282: E634-E642, 2002.

50. VAN LOON LJ, KOOPMAN R, STEGEN JH, WAGENMAKERS AJ, KEIZER HA, SARIS WH. Intramyocellular lipids form an important substrate source during moderate intensity exercise in endurance-trained males in a fasted state. I Physiol 553: 611-625, 2003. 
51. VANHAMME L, VAN DEN BOOGAART A, VAN HUFFEL S. Improved Method for Accurate and Efficient Quantification of MRS Data with Use of Prior Knowledge $J$ Magn Reson 129: 35-43, 1997.

52. VENABLES MC, ACHTEN J, JEUKENDRUP AE. Determinants of fat oxidation during exercise in healthy men and women: A cross-sectional study. $J$ Appl Phosiol In press 2004.

53. VERMATHEN P, KREIS R, BOESCH C. Intra-myocellular Lipids (IMCL) in thigh muscles - determination of distribution and measurement of reproducibility by MRSI. 21 st ESMRMB Annual Meeting, S17. 2004.

54. VIHKOV, SALMINEN A, RANTAMAKI J. Exhaustive exercise, endurance training, and acid hydrolase activity in skeletal muscle. $J$ Appl Physiol $47: 43-50,1979$.

55. WATT MJ, HEIGENHAUSER GJ, DYCK DJ, SPRIET LL. Intramuscular triacylglycerol, glycogen and acetyl group metabolism during $4 \mathrm{~h}$ of moderate exercise in man. J Physiol 541: 969-978, 2002.

56. WHITE LJ, ROBERGS RA, SIBBITT WL Ir, FERGUSON MA, MOCOY S, BROOKS WM. Effects of intermittent cycle exercise on intramyocellular lipid use and recovery. Lipids 38: 9-13, 2003.

57. ZDERIC TW, DAVIDSON CJ, SCHENK S, BYERLEY LO, COYLE EF. High fat diet elevates resting intramuscular triglyceride concentration and whole body lipolysis during exercise. Am J Physiol Endocrinol Metab 286: E217-E225, 2004. 



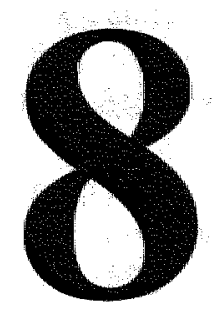

General Discussion 


\section{GENERAL DISCUSSION}

MRS is a relatively new technique to study muscle metabolism during exercise and recovery. It has several advantages over conventional techniques such as muscle biopsies or stable isotopic tracer techniques, although there are also several limitations to the technique. Some of the main advantages are that the technique is non-invasive and that good time resolution of measurements can be obtained. The general aim of this thesis was to answer several pertinent questions in muscle metabolism using MRS. More specifically MRS was used to (a) determine the degradation rate of the major intramuscular energy supplies as the different energy phosphates, glycogen and lipids during exercise, (b) monitor the effectiveness of dietary manipulations as such as carbohydrate (CHO) and fat loading protocols, and (c) study metabolic recovery, with or without special diet, from exercise sessions in connection with readiness to participate in a following event.

Soccer is probably the most popular sport worldwide. However, most research has focussed on endurance activities like cycling and running. This may be partly because soccer performance is in large part determined by technical and tactical skills and only secondarily by physical skills. Nevertheless, physical skills and aerobic capacity have often been mentioned as important factors in overall soccer performance.

It has been demonstrated that elite soccer players cover between $8-12 \mathrm{~km}$ during a 90 min match $(6,52,61)$. The sport is characterized by intermittent bursts of high intensity exercise followed by a period of relatively rest. The average intensity of a football match has been estimated to be between 70 and $80 \%$ $\mathrm{VO}_{2 \max }$ with $5-9 \%$ more distance covered in the first half compared to the second half (6).

Especially the high intensity exercise bouts are fuelled by relatively high rates of muscle glycogenolysis. These high breakdown rates of muscle glycogen can result in depletion of muscle glycogen stores within $45-90 \mathrm{~min}$ of match play, which has been confirmed by muscle biopsy measurements in a number of studies $(18,26,36,53)$. The extent of muscle glycogen depletion might be governed by the duration and intensity of the exercise (e.g. 47). Glycogen depletion has been linked to impaired running performance and this could affect overall soccer performance and could at least partly be responsible for the reduced distance covered during the second half compared with the first half. Also work volume and rate are influenced by level of muscle glycogen (e.g. 4, 5, 43). 
Although original studies in soceer players illustrated a possible role for muscle glycogen concentration in soccer performance $(18,30,36,48,53)$, since then, no systematic controlled study has been performed to show the relationship between muscle glycogen concentration or its utilization and influence on exhaustion during soccer-specific ruming performance. The purpose of Chapter 2 was therefore to determine resting muscle glycogen and energy phosphates of soccer players after consuming their habitual diet using MRS and to compare the measured values with values reported in the literature obtained by biochemical analysis of muscle biopsies. In Chapter 3 the ralationship between muscle glycogen and soccer specific running performance was further investigated. The detection of the onset of fatigue for a player during a real soccer match is a rather complicated task and almost impossible to determine. Various tests have been developed to test the endurance capacity of soccer players $(7,19)$ but the duration of the tests are often too short and do not represent the exercise intensity and duration of a real match (i.e. $90 \mathrm{~min}$ ). In Chapter 3, a soccer-specific test lasting 90 min was used to investigate soccer specific running performance in relation to muscie glycogen concentrations measured by MRS. The test consisted of an adapted shuttle nunning test involving running at three different velocities, representative of the actual running velocities during a soccer match.

The most important finding in Chapter 2 was that the muscle glycogen obtained by MRS were comparable to those obtained from biochemical analysis of muscle biopsies in other studies (e.g. 25, 58, 59). The advantage of the MRS methods is that the sample site is larger and the measurement can be made non-invasively without disrupting the muscle. MRS also makes it possible to have a higher time resolution than with muscle biopsies.

There are also advantages of the muscle biopsy technique over MRS: with the biopsy technique it is possible to make a distinction between muscle fiber types whereas MRS obtains values for a mixed muscle. Some studies distinguished between fast twitch and slow twitch fibers (e.g. 24, 40) and reported higher glycogen levels in fast twitch compared with slow twitch fibers but there were also others who showed no differences in glycogen content of fiber types (e.g. 20,21 ).

The adenosine triphosphate (ATP) and phosphocreatine (PCr) concentrations found in the Chapter 2 are comparable to values reported in the literature using biochemical methods. The majority of human studies show higher ATP and PCr values in fast twitch compared to slow twitch fibers (e.g. 49,54). Altogether it was concluded that MRS can be used to determine muscle energy phosphates and 
muscle glycogen in physical activities like soccer and that this gives comparable results to muscle biopsy data.

In Chapter 3 , a soccer-specific test was used, which consisted of an adapted shuttle runing test that involved running at three different velocities, representative of the actual running velocities during soccer match play, and permitting the detection of individual times to fatigue in elite soccer players. The results of the test were compared to muscle glycogen ( $m$. gastrocnemius) and its utilization during the test measured by ${ }^{13} \mathrm{C}$-MRS. The results showed a high positive correlation between muscle glycogen utilization and resting muscle glycogen concentration and a moderate correlation between the net muscle glycogen utilized and time to exhaustion during the test, thereby suggesting a role for muscle glycogen availability on the onset of fatigue in soccer.

E.g. in the studies of Leatt et all: (36), Balsom et al. (4) or Nicholas and coworkers (39) subjects ingested either a $\mathrm{CHO}$ solution or a placebo before and/or during a soccer match or intermittent high intensity exercise. Pre-game muscle glycogen concentrations were significantly higher following the CHO diet and were related to maintenance of a higher exercise intensity during the game (4). Additionally, reduced glycogen utilization was observed when $\mathrm{CHO}$ was ingested during the game compared to placebo $(36,39)$. Low muscle glycogen concentrations towards the end of a soccer match are often reflected in a decreased work rate $(42,61)$.

Although these results indicate that soccer specific running performance may be influenced by muscle glycogen concentration, the effects on actual soccer performance are unclear. Future studies should therefore attempt to investigate the role of muscle glycogen during actual match play or in soccer simulation protocols in which other skills are also measured. However these type of studies can also now performed with the use of MRS technology. In particular in elite soccer players this can be an advantage since these subjects are normally less willing to undergo muscle biopsy fearing negative impact on their professional career.

Since glycogen can become depleted and because there may be little time until the next match or training it is important to replenish glycogen stores. This was the focus of Chapter 4 . In this chapter the resynthesis of muscle glycogen after an intense glycogen depleting exercise was studied. Soccer is an endurance sport of varying intensities and it has been shown that on average about $50 \mathrm{mmol}$ glycogen . $\mathrm{kg}^{-1}$ wet weight is used during a soccer match $(18,53)$. In Chapter 4, CHO intake during the $24 \mathrm{~h}$ following the glycogen depleting exercise was $50 \%$ of the energy intake or about $5 \mathrm{~g}$. $\mathrm{kg}$ body weight ${ }^{-1}$ (bw), which is below the 
recommendation for optimal glycogen resynthesis (10). Even though, glycogen stores were not significantly lower $24 \mathrm{~h}$ after the depleting exercise than before the exercise, but a deficit of $10 \%$ has been measured, which may provoke decrements of performance after a few days.

In this study, a correlation was observed between glycogen utilization and glycogen resynthesized. Subjects ingested about $105 \mathrm{~g} \mathrm{CHO}$ in the first two hours after exercise. Analyzing the results of a larger number of studies, it was concluded that the intake rate of CHO following exercise that resulted in maximal resynthesis rates was about $1.2 \mathrm{~g} \mathrm{~kg}^{-1} \cdot \mathrm{h}^{-1} \cdot(32)$.

Not only the amount but also the timing and type of $\mathrm{CHO}$ are important for a fast and complete restoration of the glycogen stores. Often a fast phase and a slow phase of glycogen resynthesis are distinguished (32). The fast phase is insulinindependent and lasts up to about one to two hours post exercise, whereas the slow phase is insulin dependent and will take many hours until muscle glycogen concentrations are restored to their original levels. Ivy et al. (29) demonstrated that it is important to provide CHO immediately after cessation of exercise. It has been suggested that the rapid phase only occurs when post exercise muscle glycogen concentrations are very low and $\mathrm{CHO}$ is provided.

The addition of a mixture of protein hydrolysate and amino acids to a CHO containing drink (at an intake of $0.8 \mathrm{~g} \mathrm{CHO} \cdot \mathrm{kg}^{-1} \mathrm{bw} \cdot \mathrm{h}^{-1}$ ) can also accelerate muscle glycogen resynthesis. Nevertheless, an increased $\mathrm{CHO}$ intake $(1.2 \mathrm{~g}$ $\mathrm{CHO} \cdot \mathrm{kg}^{-1} \mathrm{bw} \cdot \mathrm{h}^{-1}$ ) provided at $30 \mathrm{~min}$ intervals after exercise reaches even slightly higher glycogen resynthesis rates (63).

A number of studies have compared the effect of CHO meals, which differed in the glycemic index (GD). It has been shown that the glycogen resynthesis rate was lower after low GI food compared to high Gl food $(8,14,62)$.

Glycogen synthesis is also influenced by the extent of muscle damage. It has been reported from muscle biopsies that the rate of muscle glycogen resynthesis is reduced after eccentric compared to concentric exercise (e,g. 2, 22). Muscle damage and delayed onset muscle soreness (DOMS) are caused by exercise of unaccustomed vigour or intensity, especially by exercise involving eccentric contractions. Manifestations of DOMS are muscle damage including inflammation, loss in muscle strength and range of motion, swelling, release of muscle proteins in the blood, and decrement in motor control (13). In Chapter $\mathbf{5}$ we studied the early and late glycogen resynthesis rate after eccentric exercise. In previous studies subjects were fed relatively small amounts of $\mathrm{CHO}$ in the hours after exercise and therefore it was not clear if muscle glycogen resynthesis was 
impaired because of the disturbed muscle metabolism after eccentric exercise or because of the perhaps too low CHO availability. The results in Chapter $\mathbf{5}$ indicate that even with a high rate of $\mathrm{CHO}$ ingestion $\left(>\mathbb{1 . 5} \mathrm{g}^{\prime} \mathrm{kg}^{-1} \mathrm{bw} \cdot \mathrm{h}^{-1}\right)$ muscle glycogen concentration in the ecentric exercise group was lower $2 \mathrm{~h}$ after the exercise than immedrately after exercise. Even $24 \mathrm{~h}$ later, after ingesting $>10 \mathrm{~g} \mathrm{CHO}$. $\mathrm{kg}^{-1}$ bw muscle glycogen was still significantly lower after eccentric versus concentric exercise. The reasons for this delay in glycogen restoration are still not completely clear. Possibilities are the enhanced utilization of glucose by the inflammatory cells, which are formed in the damaged muscle cells, short-term insulin resistance as found after eccentric exercise (e.g. 3) or a decreased GLUT-4 concentration (2), which is responsible for the glucose transportation into muscle cells. Future studies should investigate the mechanism behind the reduced glycogen synthesis with muscle damage.

In Chapter 5 the reduced glycogen resynthesis after eccentric exercise was accompanied by increased concentrations of $\mathrm{Pi}$ and enhanced $\mathrm{Pi} / \mathrm{PCr}$ ratios; which have been suggested as indicators of cell damage (e.g. 38). At the moment it remains to be determined if there is a possibility to prevent the delayed muscle glycogen resynthesis after eccentric exercise either with special procedures before or after the exercise. It is possible that a combination of the antioxidants vitamin $\mathrm{C}$ and/or $\mathrm{E}$, either alone or in combination with a $\mathrm{CHO}$-protein beverage could reduce muscle damage or enhance muscle cell recovery and enhance glycogen storage after eccentric exercise, but discussions in the literature are controversiall $(16,31,50,69)$.

During exercise the main substrates delivering energy are muscle glycogen, plasma derived glucose and fatty acids but intramuscular lipids have also been suggested to play an important role. There is still considerable debate about how much intramyocellular lipids (IMCL) contribute to the total fat oxidation and total energy consumption during endurance exercise. Although already in earlier studies evidence is accumulating that IMCL are utilized as a substrate during endurance exercise (e.g. 21,37,45), some studies using the muscle biopsy technique have reported no change in IMCL before and after exercise (e.g 34). These controversial results may be, in part, due to the methodology used. While muscle biopsies and indirect stable isotopic tracer methods have been used for many years, ${ }^{1} \mathrm{H}-\mathrm{MRS}$ has been introduced not too long ago $(9,51)$. It has been shown that biochemical analysis of IMCL in repeated biopsy samples is difficult and variable, with a coefficient of variation of 20-26\% (67). Morphometrical analysis on the other hand is observer dependent and time consuming (28): When using stable isotopes assumptions have to be made that may not always hold true. For example, the contribution from circulating plasma triglycerides and 
intermuscular lipids is neglected. This will most likely result in an overestimation of the IMCL oxidation.

Localized ${ }^{1} \mathrm{H}$-MRS was introduced in 1993 to measure two lipid compartments in muscle tissue, later named as IMCL and extramyocellular lipids (EMCL), noninvasively and safely (51). Based on the observation that two methylene resonances from different fat compartments can be distinguished in skeletal muscle, the signals from IMCL and EMCL have been characterized (9). In contrast to indirect methods, 'H-MRS of muscle tissue yield a resonance signal that is directly proportional to the concentration of $\mathrm{MMCL}$, thus allowing a determination of absolute IMCL concentrations based on the signal from muscle water. Repeated ${ }^{1}$ H-MRS measurements allow for a follow up of depletion and replenishment of a major intramuscular component. Since repeated MR spectra can be obtained from exactly the same location in a muscle this method is less susceptible to regional variations of IMCL than repeated biopsies.

It has been shown by several groups that IMCL concentrations can be manipulated by short term diet or exercise (e.g. 17, 33, 35, 55, 64, 66). However, it is not yet clear if IMCL storage and the contribution of IMCL varies in males and females. One study found decreased IMCL levels in females after exercise, while in males IMCL levels were unaffected by exercise (56).

In addition it has been shown by most (e.g. 12, 27, 57) but not all studies (e.g. 44, 46) that females have higher rates of fat oxidation compared to males at the same relative exercise intensity. In order to investigate these discrepancies in the literature, we studied the effects of moderate intensity exercise (for $3 \mathrm{~h}$ on a cycle ergometer) on IMCL in the m. vastus intermedius in both males and females. Additionally we were interested to see if gender differences existed in resting IMCL concentrations and IMCL utilizations during exercise at the same relative intensity in a group of males and females matched for training background.

In Chapter 6 we observed that total fat oxidation measured during $3 \mathrm{~h}$ of exercise was not different in males and females. It was found, however, that males had higher IMCL resting concentrations and a larger reduction in IMCL during exercise. These results are in contrast to other studies, which reported higher resting IMCL and increased IMCL utilization during exercise in females compared to males. The reason for this discrepancy is not obvious, but might be explained by the different methods used, the recruitment of a different type of subject (sedentary instead of well trained athletes), or in the measurement of different muscle groups $(41,56)$. Another study also used 'H-MRS to determine IMCL before and after exercise in females and males (68). If they calibrated 
IMCL by the water signal as it is done in our study, resting IMCL was $20 \%$ and its utilization $30 \%$ higher in males compared to females. The lack of significance in these results is probably due to the large between subject variability of IMCL decrements in both gender. In both studies subjects were in a fasted state and they exercised at a similar intensity $\left(65 \% \mathrm{VO}_{2 \max }\right.$, in our study F. $65 \pm 5 ; \mathrm{M}: 62 \pm 7 \mathrm{VO}_{2 \text { peak }}$ ). Using indirect calorimetry, no difference in total lipid oxidation ( $\mathrm{kcal} \cdot \mathrm{kg}^{-1}$ lean bw $\cdot \mathrm{min}^{-1}$ ) during $1 \mathrm{~h}$ of exercise between males and females was measured (68). Calculating lipid oxidation ( $\mathrm{g} \cdot \mathrm{kg}^{-1}$ lean bw $\min ^{-1}$ ) we did not observe a gender difference during the $3 \mathrm{~h}$ of exercise. Not only White and co-workers (68) but also Larson-Meyer et al. (35) noted that there was a large variability of $\mathrm{MMCL}$ decrements. They found IMCL changes between 0 $40 \%$. Additionally, a study by Thamer et al. (60) found higher IMCL levels in males compared to females in the soleus but not in the tibialis muscle. The large variability, the different applied methods to measure IMCL, and the differences in study designs (especially duration of exercise, different muscles) make it difficult to compare one study with another. Nevertheless it cannot be excluded in our study that the male subjects were somewhat better endurance trained than the female subjects and this would have contributed to the higher IMCL utilization during exercise $\left(\mathrm{VO}_{2 \text { peak }} \cdot \mathrm{kg}^{-1}\right.$ lean bw was $20 \%$ higher in males compared to females).

In fact at the same relative intensity during the endurance exercise, $\%$ max heart rate was the same, and females had a slightly lower RER than males. For the higher resting IMCL concentration in males compared to females it has to be taken into consideration that the higher fat intake (on average $1.2 \mathrm{~g} \cdot \mathrm{kg}^{-1}$ lean bw during 2 days prior to exercise) in males might be at least partly responsible for this difference. Although no correlation was observed between fat intake during the 2 days prior to the exercise and the resting IMCL concentration. In addition, Decombaz and co-workers (17) found no difference in the replenishment of IMCL when they fed the subjects 40 or $70 \%$ fat of total energy. It also has to be mentioned that one male subject in our study had $113 \%$ more resting IMCL than the average of all the other male subjects. If we exclude him from the data list the difference in resting IMCL concentration between males and females barely persists $(p=0.048)$.

The role of IMCL has received considerable attention in the last few years and often the role of IMCL is compared to that of muscle glycogen. However, so far studies have not been successful in manipulating IMCL concentrations without also affecting muscle glycogen concentrations (15) or without inducing possible metabolic adaptations to a diet (11). 
Therefore, the aim of Chapter 7 was to increase $\mathrm{MMCL}$ concentrations without affecting muscle glycogen concentrations and to study whether a high compared to a low content of IMCL at the start of a submaximal endurance performance would spare musele glycogen. The dietary manipulation involved the feeding of a high-fat high-CHO $(H F)$ or a low-fat high-CHO $(L F)$ diet during 2.5 days and this resulted in equal muscle glycogen concentrations but varying IMCL concentrations.

Indeed it was found that after $H F$ subjects who stored most IMCL utilized least glycogen during submaximal exercise and subjects utilized significantly more IMCL than after $L F$.

Interestingly, we observed only a trend of a higher fat oxidation over the 3-h exercise with the largest difference between the two groups in the first hour. This could support the results from Watt and co-workers (66) who found the highest IMCL degradation during the first two hours of cycling during a $4 \mathrm{~h}$ cycling exercise.

However, in our study performance during a $20-\mathrm{km}$ time trial (TT) after the $3-\mathrm{h}$ submaximal exercise was unaffected by the diet. But, it is interesting to note that subjects who used more IMCL during the submaximal exercise were faster in the subsequent $\mathrm{TT}$ and that the faster a subject was during the TT the higher was the improvement after $H F$.

Although all subjects were highly trained $\left(\mathrm{VO}_{2 \text { peak }}=68 \pm 6 \mathrm{~mL} \cdot \mathrm{kg}^{-1}\right.$ lean bw $)$ there seems to be quite a large inter-individual variation within this group of athletes in the ability to utilize IMCL as a substrate. This is in line with the large inter-individual variation in total fat oxidation that is often found in subjects. For example, Venables et al. (65) observed a large variation in RER (0.82-0.95) during exercise and in maximal fat oxidation $\left(0.18-1.01 \mathrm{~g} \cdot \mathrm{min}^{-1}\right)$. This is in line with earlier studies that also displayed large variability in fat oxidation in both trained and untrained (e.g. 1). Goedecke et al. (23) found RER to vary between 0.72 and 0.93 at rest and that the degree of variation persisted at all exercise intensities. The variation in fat oxidation and possibly IMCL oxidation can be ascribed to the exercise intensity, training status, gender and diet. However, in the study by Venables et al (65) maximal fat oxidation when corrected for lean body mass was predicted by physical activity, $\mathrm{VO}_{2 \max }$ and gender but not by fat mass. However, physical activity, $\mathrm{VO}_{2 \max }$ and gender explained only $12 \%$ of the inter-individual variation in maximal fat oxidation during exercise and it was concluded that the inter-individual variation in fat oxidation remains largely unexplained. 
Future studies should aim at investigating the mechanisms underlying the interindividual differences in fat oxidation and IMCL oxidation specifically.

With respect to the findings in Chapter 7 it would be interesting to develop a protocol, which depletes glycogen stores even further than during the submaximal endurance exercise protocol employed (muscle glycogen was reduced by about $50 \%$ ). Such a protocol could enhance the effects of the dietary manipulation.

The studies presented in this thesis have applied MRS to measure energy phosphates, muscle glycogen and IMCL in a variety of conditions. The technique provides a valid, reliable, sensitive and non-invasive way to study muscle metabolism during and after exercise in more detail. MRS is undoubtedly one of the most promising techniques to study muscle metabolism in the future. 


\section{REFERENCES}

1. ACHTEN J, and JEUKENDRUP AE. Maximal fat oxidation during exercise in trained men. Int J Sports Med 24: 603-608, 2003.

2. ASP S, DAUGAARD JR, RICHTER EA. Focentric exercise decreases glucose transporter GLUT4 protein in human skeletal muscle. J Plysiol (Lond) 482: 705-712, 1995.

3. ASP S, DAUGAARD JR, KRISTIANSEN S, KIENS B, RICHTER EA. Eccentric exercise decreases maximal insulin action in humans - muscle and systenic effects. $J$ Physiol (Lond) 494: 891-898, 1996.

4. BALSOM PD, WOOD K, OLSSON P, EKBLOM B. Carbohydrate intake and multiple sprint sports: with special reference to football (soccer). Int $J$ Sports Med 20: 48-52, $1999 \mathrm{a}$.

5. BALSOM PD, GAITANOS GC, SODERLUND K, EKBLOM B. High-intensity exercise and muscle glycogen availability in humans. Acia Physiol Scand 165: 337-345, $1999 \mathrm{~b}$.

6. BANGSBO J, NORREGAARD L, THORSO F. Activity profile of competition socer. Can J Sport Sci 16: 110-116, 1991.

7. BANGSBO J, and LINDQUIST $\mathbb{F}$. Comparison of various exercise tests with endurance performance during soccer in professional players. Im J Sports Med 13: 125-132, 1992.

8. BLOM PC, HOSTMARK AT, VAAGE O, KARDEL KR, MAEHLUM S. Effect of different post-exercise sugar diets on the tate of muscle glycogen synthesis. Med Sci Sports Exerc 19: 491-496, 1987.

9. BOESCH C, SLOTBOOM $J$, HOPPELER H, KREIS R. In vivo determination of intramyocellular lipids in human muscle by means of localized IH-MR-spectroscopy. Magn Reson Med 37: 484-493, 1997.

10. BURKE LM, COX GR, CULMMINGS NK, DESBROW B. Guidelines for daily carbohydrate intake: do athletes achieve them? Sports Med 31: 267-299, 2001.

11. BURKE LM, and HAWLEY JA. Effects of short-term fat adaptation on metabolism and performance of prolonged exercise. Med Sci Sports Exerc 34: 1492 1498, 2002.

12. CARTER SL, RENNIE C, TARNOPOLSKY MA. Substrate utilization during endurance exercise in men and women after endurance training. Am J Physiol Endocrinol Metab 280: E898-E907, 2001.

13. CLARKSON PM. Eccentric exerctse and muscle damage. Int is Sports Med 18: \$314S317, 1997.

14. CONLEE RK, LAWLER RM, ROSS PE. Effects of ghucose or fructose feeding on glycogen repletion in muscle and liver after exercise or fasting. Ann Nutr Metab 31: 126$132,1987$.

15. COYLE EF, JEUKENDRUP AE, OSETO MC, HODGKINSON BJ, ZDERIC TW. LOWfat diet alters intramuscular substrates and reduces lipolysis and fat oxidation during exercise. Am J Physiol Endocrinol Metab 280: E391-E398, 2001.

16. DAWSON B, HENRY GJ, GOODMAN C, GILLAM I, BEILBY JR, CHING $s$, FABIAN V, DASIG D, MORLING P, KAKULUS BA. Effect of Vitamin $C$ and $E$ supplementation on biochemical and ultrastructural indices of muscle damage after a 21 $\mathrm{km}$ run. Int J Sports Med 23:10-15,2002.

17. DECOMBAZ J, FLEITH M, HOPPELER H, KREIS R., BOESCH C. Effect of diet on the replenishment of intramyocellular lipids after exercise. Eur J Nutr 39: 244-247, 2000.

18. EKBLOM B. Applied physiology of saccer. Sports Med 3: 50-60, 1986. 
19. EKBLOM B. Aield test for soccer players. Sci Football 1: 13-15, 1989.

20. ESSEN $\mathrm{B}_{x}$ and HENRIKSSON J. Glycogen content of individual muscle fibres in man. Acta Physiol Scand 90: 645-647, 1974.

21. ESSEN B. Intramuscular substrate utilization during prolonged exercise. Ann NY Acad Set $301: 30-44,1977$.

22. EVANS WJ. Muscle damage: nutritional considerations. In $J$ Sport Nutr I: 214-224, 1991.

23. GOEDECKE JH, ST CLAIR GIBSON A, GROBLER L, COLLINS M, NOAKES TD, LAMBERT EW. Determinants of the variability in respiratory exchange ratio at rest and during exercise in trained athletes. Am J Physiol Endocrinol Metab 279: E1325-1334, 2000 .

24. OREENHAFF PL, SODERLUND K, REN JM, HULTMAN E. Energy metabolism in single human muscle fibres during intermittent contraction with occluded circulation. $J$ Physial (Lond) 460: 443-453, 1993.

25. HARRIS RC, HULTMAN E, NORDESIÖ LO. Glycogen, glycolytic intermediates and high-energy phosphates determined in biopsy samples of musculus quadriceps femoris of man at rest. Methods and variance of walues. Scand J Clin Lab Invest 33: 109-120, 1974.

26. HAWLEY JA, DENNIS SC, NOAKES TD. Carbohydrate, fluid, and electrolyte requirements of the soccer player: a review. Int J Sport Nutr 4: 221-236, 1994.

27. HORTON Ty, PAGLIASSOTTI MI, HOBBS K, HILL JO. Fuel metabolism in men and women during and after long-duration exercise. $J$ Appl Physiol 85: 1823-1832, 1998.

28. HOWALD $H$, BOESCH $C$, KREIS $R$, MATTER $S$, BILLETER $R$, ESSENGUSTAVSSON B, HOPPELER H. Content of intramyocellular lipids derived by electron microscopy, biochemical assays, and (1)H-MR spectroscopy. I Appl Physiol 92: 2264-2272, 2002.

29. IVY JL, KATZ AL, CUTLER CL, SHERMAN WM, COYLE EF. Muscle glycogen synthesis after exercise: effect of time of carbohydrate ingestion. $J$ Appl Physiol 64: 1480-1485, 1988.

30. JACOBS I, WESTLIN N, KARLSSON J, RASMUSSON M, HOUGHTON B. Muscle glycogen and diet in elite soccer players. Eur J Appl Physiol 48: 297-320, 1982.

31. JAKEMAN $P$, AND MAXWELL S. Effect of antioxidant vitamin supplementation on muscle function after eccentric exercise. Eur J Appl Physiol 67: 426-430, 1993.

32. NENTIENS R, and JEUKENDRUP A. Determinants of post-exercise glycogen synthesis during short-tierm recowery, Sports Med 33: 117-144, 2003.

33. JOHNSON NA, STANNARD SR, MEHALSKI K, TRENELL MI, SACHINWALLA T, THOMPSON CH, THOMPSON MW. Intramyocellular triacylglycerol in prolonged cycling with high- and low-carbohydrate availability. I Appl Physiol 94: 1365-1372, 2003.

34. KIENS B, ESSEN-GUSTAVSSON B, CHRISTENSEN NJ, SALTIN B. Skeletal muscle substrate utilization duting submaximal exercise in man: effect of endurance training. $J$ Physiol (Lond) 469: 459-478, 1993.

35. LARSON-MEYER DE, NEWCOMER BR., HUNTER GR. Influence of endurance running and recovery diet on intramyocellujar lipid content in women: a LH NMR study. Aw J Physiol Endocrinal Metab 282: E95-E106, 2002.

36. LEATT PB, AND JACOBS I. Effeets of glucose polymer ingestion on muscle glycogen utilization during a soccer match. Can J Sport Sci 14: 112-116, 1989. 
37. LITHELL H, ORLANDER $\int$, SCHELE R, SIODIN B, KARLSSON I: Changes in lipoprotein-lipase activity and lipid stores in human skeletal musele with prolonged heavy exercise. Acta Physiol Scand 107: 257-261, 1979.

38. MOCULLY KK, ARGOY Z, BODEN BP, BROWN RL, BANK WJ, CHANCE B. Detection of muscle injury in humans with 31-P magnetic resonance spectroscopy. Muscle Nerve 11: 212-216, 1988 .

39. NICHOLAS CW, TSNTZAS K, BOOBIS L, WILLIAMS C. Carbohydrate-electrolyte ingestion during intermittent high-intensity ruming. Med Sci Sports Exerc 31: 1280$1286,1999$.

40. PASCOE DD, COSTILL DL, ROBERGS RA, DAVIS JA, FINK WJ, PEARSON DR. Effects of exercise mode on muscle glycogen restorage during repeated days of exercise. Med Sci Sports Exerc 22: 593-598, 1990.

41. PERSEGHIN G, SCIFO P, PAGLIATO E, BATTEZZATI A, BENEDINI S, SOLDINI L, TESTOLIN G, DEL MASCHIO A, LUZI L. Gender factors affect fatty aoids-induced insulin resistance in nonobese humans: effects of oral steroidal contraception. $J \mathrm{Clin}$ Endocrinol Metab 86: 3188-3196, 2001.

42. RELLY T. Energetics of high-intensity exercise (soccer) with particular reference to fatigue. I Sports Sci 15: 257-263, 1997.

43. RICO-SANZ I, ZEHNDER M, BUCHLI R, DAMBACH M, BOUTELLIER U. MUSCle glycogen degradation during simulation of a fatiguing soccer match in elite soccer players examined noninvasively by 13C-MRS. Med Sici Sports Exerc 31: 1587-1593, 1999.

44. ROEPSTORFF C, STEFFENSEN CH, MADSEN M, STALLKNECHT B, KANSTRUP IL, RICHTER EA, KIENS B. Gender differences in substrate utilization during submaximal exercise in endurance-trained subjects. Am $/$ Physiol Endocrinol Metab 282: E435-E447, 2002.

45. ROMIJN JA, COYLE EF, SIDOSSIS LS, GASTALDELLI A, HOROWITZ JF, ENDERT E, WOLFE RR. Regulation of endogenous fat and carbohydrate metabolism in relation to exercise intensity and duration. Am I Physiol Endocrinol Metab 265: E380E391, 1993.

46. ROMIJN JA, COYLE EF, SIDOSSIS LS, ROSENBLATT J WOLFE RR. Substrate metabolism during different exercise intensities in endurance-trained women. $J A p p l$ Physiol 88: 1707-1714, 2000.

47. SALTIN B, and KARLSON J. Muscle glycogen atilization during work of different intensities. In: Muscle nuetabolism during exercise, Pernow and Saltin (eds), Plenum Press, New York, 1971, pp. 289-299.

48. SALTIN B. Metabolic fundamentals in exercise. Med Scf Sports 5: 137-146, 1973.

49. SANT ANA PEREIRA JA, SARGEANT AJ, RADEMAKER AC, DE HAAN A, VAN MECHELEN W. Myosin heavy chain isoform expression and high energy phosphate content in human muscle fibres at rest and post-exercise. I Physiol (Lond) 496:583-588, 1996.

50. SAUNDERS MJ, KANE MD, TODD MK. Effects of a carbohydrate-protein beverage on cycling endurance and muscle damage. Med Sci Sports Exere 36: 1233-1238, 2004.

51. SCHICK F, EISMANN B, JUNG WI, BONGERS H, BUNSE M, LUTZ O. Comparison of localized proton NMR signals of skeletal muscle and fat lissue in vivo: two lipid compartments in muscle tissue. Magn Reson Med 29: 158-167, 1993.

52. SHEPHARD RJ. Biology and medicine of soccer: an update. I Sports Sei 17: 757-786, 1999. 
53. SMAROS O. Energy usage during football match. In: Proceedings Ist International Congres on Sports Medicine Applied to Football. L Vecchiet (ed), D Guanillo, Rome, 1980, pp. $795-801$.

54. \$ODERLUND $K_{\text {, GREENHAFF PL }}$ HULTMAN E. Energy metabolism in type I and type II human muscle fibres during short term electrical stimulation at different frequencies: Acta Physiol Scand 144: 15-22, 1992.

55. STARLING IRD, TRAPPE TA, PARCELL AC KERR CG, FINIK WJ, COSTLL DL. Effects of diet on muscle triglyceride and endurance performance. $J$ Appl Physiol 82: 1185-1189, 1997.

56. STEFFENSEN CH, ROEPSTORFF C, MADSEN M, KIENS B. Myocellular triacylglycerol breakdown in females but not in males during exercise. Am $J$ Physiol Endocrinol Metab 282: E634-E642, 2002.

57. TARNOPOLSKY LI, MACDOUGALL JD, ATKINSON SA, TARNOPOLSKY MA, SUTTON JR. Genden differences in substrate for endurance exercise. $J$ Appl Physiol 68: $302-308,1990$.

58. TAYLOR R, PRICE TB, ROTHMAN DL, SHULMAN RG, SHULMAN GI. Validation of ${ }^{13} \mathrm{C}$ NMR measurement of human skeletal muscle glycogen by direct biochemical assay of needle biopsy samples. Magn Reson Med 27: 13-20, 1992.

59. TAYLOR R, PRICE TB, KATZ LD, SHULMAN RG, SHULMAN GI. Direct measurement of change in muscle glycogen concentration after a mixed meal in normal subjects. Am J Physial Endocrinol Metab 265: E224-E229, 1993.

60. THAMER C, MACHANN J, BACHMANN O, HAAP M, DAHL D, WIETEK $B$, TSCHRITTER O, NIESS A, BRECHTEL $K$, FRITSCHE A, CLAUSSEN C, JACOB $S$, SCHICK F, HARING HU, STUMVOLL M. Intramyocellular lipids: anthropometric determinants and relationships with maximal aerobic capacity and insulin sensitivity. $J$ Clin Endocrimal Metab 88: 1785-1791, 2003.

61. TUMILTY D. Physiological characteristics of elite soccer players. Sports Med 16:80-96, 1993.

62. VAN DEN BERGH AJ, HOUTMAN S, HEERSCHAP A, REHRER NJ, VAN DEN BOOGERT HJ, OESEBURG B, HOPMAN MT. Muscle glycogen recovery after exercise during glucose and fructose intake monitored by 13C-NMR. J Appl Physiol 81: 1495$1500,1996$.

63. VAN LOON IJ, SARIS WH, KRUIJSHOOP M, WAGENMAKERS AJ. Maximizing postexercise muscle glycogen synthesis: carbohydrate supplementation and the application of amino acid or protein hydrolysate mixtures. Am J Clin Nurr 72: 106-111, 2000 .

64. VAN LOON LJ, KOOPMAN R, STEGEN JH, WAGENMAKERS AJ, KEIZER HA, SARIS WH. Intramyocellular lipids form an important substrate source during moderate intensity exercise in endurance-trained males in a fasted state. J Physiol (Lond) 553: 611$625,2003$.

65. VENABLES MC, ACHTEN J, JEUKENDRUP AE. Determinants of fat oxidation during exercise in healthy men and women. A cross-sectional study. J Appl Physiol In press 2004.

66. WATT MJ, HEIGENHAUSER GJ, DYCK DJ, SPRIET LL. Intramuscular triacylglycerol, glycogen and acetyl group metabolism during $4 \mathrm{~h}$ of moderate exercise in man.

I Physiol (Lond) 541: 969-978, 2002. 
67. WENDLING PS, PETERS SJ, HEIGENHAUSER GIF, SPRIET LL. Variability of triacylglycerol content in human skeletal muscle biopsy samples. I Appl Phwiol 81: $1150-1155,1996$.

68. WHITE LJ, FERGUSON MA, MCCOY SC, KIM H. Intramyocellular lipid changes in men and women during aerobic exercise: a (1)H-magnetic resonance spectroscopy study. $J$ Clin Endocrinol Metab 88: 5638-5643, 2003.

69. WOJCIK JR, WALBER-RANKIN J, SMITH LL; GWAZDAUSKAS FC. Comparison of carbohydrate and milk-based beverages on muscle damage and glycogen following exercise. Int J Sport Nutr Exerc Metab 11: 406-419, 2001. 
Summary 


\section{SUMMARY}

Energy for all processes in our body, including muscle contraction, is derived from the hydrolysis of adenosine triphosphate (ATP). During exercise, the main sources which deliver energy, are glycogen from muscle tissue, and glucose as well as fatty acids derived from liver or gut and adipose tissue, respectively. Recently it also has been suggested that intramuscular lipids (IMCL) have to play an important role as an energy substrate. Some groups have shown that shortterm diet changes or exercise can influence IMCL concentrations. However, there are some studies which used the muscle biopsy technique, which have reported no change in IMCL before and after exercise.

Magnetic resonance spectroscopy (MRS) is a relatively new technique for studying muscle metabolism with the main advantage of being non-invasive compared to conventional techniques such as muscle biopsies or stable isotope tracer techniques.

For this thesis, MRS was used to measure the major intramuscular energy supplies such as the different phosphates, glycogen and IMCL before and after exercise.

Soccer is probably the most popular sport worldwide and aerobic capacity has often been mentioned as one of the important factors in overall soccer performance. However, most research on muscle metabolism has focused on endurance activities like cycling and running and not on intermittent activities like soccer. Therefore in Chapter 2-4 we studied phosphate and glycogen metabolism in the calf muscle during and after high intensity intermittent exercise to mimic soccer activity.

In Chapter 2 we demonstrated that the measurements of resting muscle glycogen and phosphate concentrations (phosphocreatine, ATP and inorganic phosphates) in the calf muscle obtained by using MRS are reliable and comparable with muscle biopsy data. Additionally, in making several follow up measurements we demonstrated that the use of NMR as non-invasive method is very suitable for this type of exercise study.

In Chapter 3 a soccer-specific test was used to investigate intermittent running performance in relation to muscle glycogen degradation. The results show a high positive correlation between muscle glycogen utilization and resting muscle glycogen concentration and a modest positive correlation between muscle glycogen utilized and time to exhaustion during the running test. These results 
indicate that soceer specific running performance may be influenced by muscle glycogen concentration, which is in line with other studies.

We also investigated glycogen resynthesis after a highly intense, intermittent exercise, as described in Chapter 4: During the $24 \mathrm{~h}$ following the glycogen depleting exercise the individual carbohydrate (CHO) intake of the soccer players was $50 \%$ of their total energy intake. With this diet, a decrease of $10 \%$ of resting muscle glycogen was measured $24 \mathrm{~h}$ after the depleting exarcise. On the one hand, this was not significantly different from the resting value. On the other hand, it may provoke decrements of performance after a few days.

The effects of eccentric exercise on glycogen resynthesis were studied in Chapter 5. The results of the study indicate that even with a high rate of $\mathrm{CHO}$ intake $\left(>1.5 \mathrm{~g} \cdot \mathrm{kg}^{-1}\right.$ body weight $\left.(\mathrm{bw}) \cdot \mathrm{h}^{-1}\right)$ during the first $2 \mathrm{~h}$ after cessation of a glycogen depleting or a glycogen depleting and an eccentric exercise, muscle glycogen concentration continued to decrease after eccentric exercise, and the resynthesis rate was significantly lower than after concentric exercise. $24 \mathrm{~h}$ later, after ingesting $>10 \mathrm{~g} \mathrm{CHO} \cdot \mathrm{kg}^{-i}$ bw the difference between the two groups was still observed. This study confirms earlier suggestions from muscle biopsy studies that the rate of muscle glycogen resynthesis after eccentric exercise is reduced compared to after concentric exercise. The reasons for this delay in glycogen restoration are not yet completely clear. They may be due to muscle damage including inflammation, loss in muscle strength and range of motion, swelling, release of muscle proteins in the blood, and decrease in muscle coordination during delayed onset of muscle soreness, which follows eccentric exercise.

During exercise the main substrates delivering energy are muscle glycogen, plasma deriwed glucose and fatty acids. Next to these, it has also been suggested that IMCL play an important role. There is still considerable debate about how much IMCL contribute to total fat oxidation and total energy consumption during endurance exercise, and it is not yet clear if IMCL storage and the contribution of IMCL varies in males and femalles.

In Chapter 6 we measured total fat oxidation and IMCL resting concentration and breakdown in trained females and males during a 3 -h sub-maximal exercise performance on a cycle ergometer. Total fat oxidation measured during exercise was not different in males and females, but it was found that males had higher IMCL concentrations at rest and a larger reduction during exercise. Our results are in contrast to several other studies, which report higher resting $\mathrm{MCL}$ and increased IMCL utilization during exercise in females compared to males. The 
reasons for this discrepancy are not obvious. They might be explained by the different methods used, the recruitment of a different type of subject, in the measurement of different muscle groups, or in the large between subject variability of IMCL decrements, which are reported by various investigators. Nevertheless, it must be mentioned that in our study the male subjects were somewhat better trained for endurance than the female subjects, which would have contributed to the higher IMCL utilization during exercise. Male subjects had a higher $\mathrm{VO}_{2 \text { peak }} \mathrm{kg}^{-1}$ lean bw than the females.

In Chapter 7 we measured IMCL and glycogen concentrations in endurance athletes who followed special dietary treatments. We were interested to know whether a high compared to a low content of IMC $\mathrm{L}$ at the start of a submaximal endurance performance would spare muscle glycogen, which would then be avallable in larger quantities for a final high performance exercise. The dietary manipulation involved eating a high-fat high-carbohydrate (HF) or a low-fat high carbohydrate $(L F)$ diet during 2.5 days. It was found that after $H F$ subjects who stored most IMCL utilized least glycogen during sub-maximal exercise and subjects utilized significantly more IMCL than after $L F$. Interestingly, after $H F$ compared to $L F$ we observed only a trend for a higher fat oxidation over the 3-h exercise with the largest difference between the two groups in the first hour. During the final $20-\mathrm{km}$ time trial (TT), after the $3-\mathrm{h}$ sub-maximal exercise, performance was unaffected by the diet. Nevertheless, it is interesting to note that subjects who used more IMCL during the sub-maximal exercise were faster in the subsequent TT, and that the faster a subject was during the TT the higher was the improvement after $H F$. It seems that even among similarly trained endurance athletes there are differences in IMCL utilization during a sub-maximal exercise and one could speculate that some athletes are able to take more advantage of an increased fat concentration in the diet than others. Further studies are needed to confirm this observation as well as to study the factors which cause these different responses. 


\section{Zusammenfassung}




\section{ZUSAMMENFASSUNG}

Alle Energie, die wir in unserem Körper brauchen, inklusive diejenige für Muskelkontraktionen, stammt aus der Spaltung von Adenosin Triphosphat (ATP). Während einer körperlichen Belastung wird ATP vor allem aus Muskelglykogen, Plasmaglükose und aus freien Fettsäuren zur Energiegewinnung freigesetzt. Auch den intramuskulären Fetten (TMCL) wird eine wichtige Rolle als Energielieferant zugeschrieben. Mehrere Studien haben gezeigt, dass IMCL sowohl durch eine Diät, als auch durch eine körperliche Betätigung beeinflusst werden können. Ebenfalls gibt es Biopsie-Studien, die keine Veränderung der IMCL Speicher während einer körperlichen Belastung messen konnten.

Magnet Resonanz Spektroskopie (MRS) ist eine relativ neue Technik, um den Muskelstoffwechsel zu messen. Der Hauptvorteil dieser Technik gegenüber konventionellen Methoden, wie Muskel Biopsien oder "Tracer" Techniken mit Infusion stabiler Isotope, liegt in ihrer nicht-invasiven Art.

In dieser Dissertation wurde MRS zur Messung muskulärer Energielieferanten wie Phosphate, Glykogen und Fette (IMCL), vor und nach körperlicher Belastung, angewandt.

Fussball ist wahrscheinlich der populärste Sport weltweit. Es handelt sich dabei um eine Sportart, die durch intensive, intermittierende Belastungen charakterisiert ist, und bei der die aerobe Kapazität ein wichtiger physiologischer Faktor ist. Trotzdem hat sich die Forschung im Bereiche des Muskelstoffwechsels bis anhin hauptsâchlich mit Ausdauersportarten wie Radfahren und Laufen und nicht mit intermittierenden Aktivitaten wie Fussball befasst. Deshalb untersuchten wir in den Kapiteln 2-4 den Phosphat- und Glykogen-Stoffwechsel in der Wadenmuskulatur während und nach einer hoch intensiven, intermittierenden, einen Fussballmatch nachahmenden, Belastung.

In Kapitel 2 konnten wir zeigen, dass im Ruhezustand MRS-Messungen von Glykogen und Phosphaten (Kreatinphosphat (PCr), ATP und anorganisches Phosphat (Pi)) in der Wade verlässlich, und mit den Daten (Konzentrationen) von Muskel Biopsien zu vergleichen sind. Wir machten in dieser und in den weiteren Studien dieser Dissertation Gebrauch von der Nicht-Invasivität der MRSMethode indem mehrere, aufeinander folgende Messungen am exakt gleichen Ort in einem Muskel durchgeführt wurden und demonstrierten damit, dass NMR für diese Art von Studien sehr geeignet ist. 
In Kapitel 3 wurde ein fussballspezifischer Belastungstest angewandt, um den Einfluss einer intermittierenden Laufbelastung auf den Muskelglykogen-Abbau zu untersuchen. Die Resultate zeigen eine hohe positive Korrelation zwischen dem Muskelglykogen-Verbrauch und der Ruheglykogen-Konzentration, und eine schwache positive Korrelation zwischen dem Verbrauch an Muskelglykogen und der Zeit bis zur Erschöpfung während des Belastungstests. Diese und andere Studienresultate zeigen, dass eine fussballspezifische Laufbelastung durch die Muskelglykogen-Konzentration beeinflusst wird.

In Kapitel 4 wurde die Muskelglykogen-Resynthese nach einer hoch intensiven, intermittierenden Belastung untersucht. Nach einer Muskelglykogen entleerenden Belastung nahmen die Fussballspieler während den nächsten $24 \mathrm{~h}$ ihre individuelle Diät ein. Von der insgesamt aufgenommenen Energie machten die Kohlenhydrate (KHO) nur $50 \%$ aus, was zur Folge hatte, dass die Glykogenspeicher nach $24 \mathrm{~h}$ nur $90 \%$ der Konzentration vor der Belastung erreichten. Dieser Unterschied war zwar nicht signifikant, ein ungenugendes Wiederauffillen der Glykogenspeicher kann aber während intensiven Trainingseinheiten zu Leistungseinbussen nach ein paar Tagen führen.

Die Effekte, die eine exzentrische Belastung auf die Glykogenresynthese ausüben, wurden im Kapitel 5 studiert. Die Resultate zeigen, dass trotz einer hohen Aufnahmerate an $\mathrm{KHO}\left(>1.5 \mathrm{~g} \cdot \mathrm{kg}^{-1} \mathrm{Körpergewicht}(\mathrm{KG}) \cdot \mathrm{h}^{-1}\right)$ während den ersten $2 \mathrm{~h}$ nach einer Glykogen entleerenden plus exzentrischen Belastung, die Glykogenkonzentration in der Wadenmuskulatur weiter abnahm, und die Resyntheserate signifikant tiefer (sogar negativ) war als nach einer konzentrischen Belastung. Auch nach $24 \mathrm{~h}$, nachdem über $>10 \mathrm{~g} \mathrm{KHO} \cdot \mathrm{kg}^{-1} \mathrm{KG}$ aufgenommen wurden, zeigte sich immer noch ein signifikanter Unterschied zwischen den beiden Gruppen. Diese Studie bestatigt frühere Resultate von Biopsiestudien, bei denen eine verminderte Glykogenresyntheserate nach exzentrischer gegenüber konzentrischer Belastung gemessen wurde. Die Gründe fur diese Verzögerung in der Wiederauffüllung der Glykogenspeicher sind noch nicht vollumfänglich geklärt. Am wahrscheinlichsten sind Muskelrisse im Zusammenhang mit Entzündungen, Verlust an Muskelkraft und Bewegungsfreiheit, Schwellungen, Freisetzung von Muskelproteinen ins Blut und Abnahme der Muskelkoordination während des verzögert auftretenden Muskelkaters, der auf die exzentrische Belastung folgt.

Die Hauptenergielieferanten während einer körperlichen Belastung sind Muskelglykogen, P]asmaglukose und freie Fettsâuren. Des Weiteren spielèn sehr walhrscheinlich auch IMCL eine wichtige Rolle. Es wird immer noch uber das Ausmass des IMCL Beitrages zur totalen Fettoxidation und zum Gesamtenergie- 
verbrauch während einer körperlichen Leistung (speziell Ausdauerbelastung) debattiert. Ausserdem ist noch nicht ganz klar, ob geschlechtsspezifische Unterschiede in der Speicherung und im Verbrauch von IMLC bestehen.

In Kapitel 6 wurde sowohl die Gesamtfettoxidation, als auch die IMCL Konzentration und deren Verbrauch während einer 3-stündigen Ausdauerbelastung auf einem Fahrradergometer bei trainierten Männern und Frauen gemessen. Die totale Fettoxidation wâhrend der Belastung unterschied sich nicht zwischen den beiden Geschlechtern. Die Männer hatten jedoch eine höhere IMCL Konzentration in Ruhe und wiesen einen höheren Verbrauch während der Belastung auf. Unsere Resultate sind gegensätzlich zu einigen anderen Studien, bei welchen höhere Ruhe-IMCL-Speicher und auch ein erhöhter Verbrauch unter körperlicher Belastung bei Frauen gegenüber Männern gemessen wurden. Die Gründe für diese Unterschiede sind nicht ganz offensichtlich. Sie könnten mit unterschiedlich angewandten Messmethoden, der Rekrutierung von verschiedenen Próbandentypen, der Messung anderer Muskelgruppen, oder in der hohen Variabilităt des IMCL Verbrauchs zwischen verschiedenen Probanden, begründet werden. Auch können wir in unserer Studie nicht ganz ausschliessen, dass die männlichen Probanden besser trainiert waren als die weiblichen, was zum höheren IMCL Verbrauch beigetragen hätte. Auf einen besseren Trainingszustand der Männer gegenüber den Frauen deutet die höhere maximale Sauerstoffaufnahme $\left(\mathrm{VO}_{2 \text { peak }}\right) \cdot \mathrm{kg}^{-1}$ fettfreies $\mathrm{KG}$ hin.

In Kapitel 7 wurden die IMCL und Glykogen Konzentrationen bei Ausdauerathleten, welchen eine spezielle Diät verordnet wurde, gemessen. Es interessierte uns, ob hoher gegenüber tiefem IMCL Gehalt zu Beginn einer submaximalen Ausdauerleistung Muskelglykogen sparen könnte, welches dann in grösseren Mengen für eine abschliessende Maximalbelastung zur Verfügung stehen würde. Die diatetische Intervention bestand darin, dass den Probanden während 2.5 Tagen entweder eine "hoch-Fett, hocln-KHO" $(H F)$ oder eine "tief-Fett, hoch$\mathrm{KHO}^{\prime \prime}$ ( $L F$ ) Ernährung verabreicht wurde. Die Resultate zeigen, dass nach $H F$ die Probanden, welche am meisten IMCL zu speichern vermochten, am wenigsten Glykogen während der submaximalen Leistung verbrauchten und auch signifikant mehr IMCL als nach $L F$ verbrannten. Interessanterweise wurde nach $H F$ gegenüber $L F$ nur ein Trend für eine höhere Fettoxidation während der 3stündigen Belastung beobachtet, wobei der grösste Unterschied zwischen den beiden Gruppen in der ersten Stunde gemessen wurde. Die Leistung während des abschliessenden $20 \mathrm{~km}$ langen "time trials" (TT) nach der 3-stündigen Belastung wurde durch die Diăt nicht signifikant beeinflusst, obwohl die Athleten nach $H F$ 34 Sekunden schneller waren als nach $L F$. Nicht desto trotz ist es interessant, dass die Probanden, welche während der Ausdauerbelastung am meisten IMCL 
verbrauchten auch am schnellsten waren während des TT, und je schneller ein Athlet während des TT war, umso grösser war seine Verbesserung der Leistung unter der HF Diät. Es scheint, dass sogar bei ähnlich trainierten Ausdauerathleten Unterschiede in der Nutzung von IMCL während einer submaximalen Belastung bestehen, was darauf hinweist, dass gewisse Athleten mehr Vorteile aus einer erhöhten Fettkonzentration in der Ernährung ziehen können als andere. Um diese Beobachtungen als auch die Faktoren, welche diese Unterschiede hervorrufen, zu bestätigen beziehungsweise zu studieren, müssen weitere Studien durchgeführt werden. 


\section{Publications}




\section{ORIGINAL PAPERS/PUBLISHED ABSTRACTS}

J. Rico-Sanz, M. Zehnder, R. Buchli, G. Kühne, and U. Boutellier: Noninvasive measurement of muscle high energy phosphates and glycogen concentrations in elite soccer players by ${ }^{31} \mathrm{P}$ - and ${ }^{13} \mathrm{C}$-MRS. Med Sci Sports Exerc 11: $1580-1586$, 1999.

J. Rico-Sanz, M. Zehnder, R. Buchli, M. Dambach, and U. Boutellier: Muscle glycogen degradation during simulation of a fatiguing soccer match in elite soccer players examined noninvasively by ${ }^{13}$ C-MRS. Med Sci Sports Exerc 11 : $1587-1593,1999$.

M. Zehnder, J. Rico-Sanz, G. Kinhne, and U. Boutellier: Resynthesis of muscle glycogen after soccer specific performance examined by ${ }^{13} \mathrm{C}-\mathrm{MRS}$ in elite players. Eur J Appl Physiol. 84: 443 - 447, 2001.

J. Rico-Sanz, M. Zehnder, R. Buchli, G. Kühne, and U. Boutellier: Creatine loading does not enhance myocellular glycogen concentration nor glycogenolysis during exercise in humans as assessed in vivo by ${ }^{13}$ C-MRS. (submitted)

M. Zehnder, M. Mülli, R. Buchli, and U. Boutellier: Further glycogen decrease during early recovery after eccentric exercise despite a high carbohydrate intake. Eur J Nutr 43: 148-159, 2004.

M. Zehnder, M. Ith, R. Kreis, W. Saris, U. Boutellier, and C. Boesch: Genderspecfic usage of intramyocellular lipids and glycogen during exercise. (submitted)

Monica Zehnder, Emanuel R. Christ, Michael Ith, Kevin Acheson, Etienne Pouteau, Roland Kreis, Roman Trepp, Peter Diem, Chris Boesch, and Jacques Décombaz: Higher intramyocellular lipid (IMCL) concentrations lead to an increased contribution from $\mathrm{IMCL}$ and total muscle energy stores during exercise. (submitted)

Emanuel R. Christ, Monica Zehnder, Chris Boesch, Roman Trepp, Primus E. Mullis, Peter Diem, Jacques Decombaz: The impact of increased lipid intake on hormonal responses during aerobic exercise in endurance trained males. (submitted) 
P. Colombani, M. Zehnder, and C. Wenk: Ammonia expiration during endurance exercise. Med Sci Sports Exerc 28 (Suppl.), p 62, 1996.

M. Zehnder, G. Kühne, R. Buchli, U. Mäder, and U. Boutellier: Correlation between the mechanical work and glycogen decrease: A quantitative in-vivo ${ }^{13} \mathrm{C}$ MRS study on human musele physiology. Proe Int Soc Magnet Res Med 2: 1343, 1997.

J. Rico-Sanz, M. Zehnder, M. Dambach, R. Buchli, G. Kühne, and U. Boutellier: In vivo measurements of muscle high energy phosphates and glycogen concentrations in elite soccer players by ${ }^{31} \mathrm{P}$ - and ${ }^{13} \mathrm{C}$-MRS. Med Sci Sports Exerc 30 (Suppl.): \$33, 1998.

M. Zehnder, J. Rico-Sanz, G. Kühne, M. Dambach, R. Buchli, and U. Boutellier: Muscle phosphocreatine and glycogen concentrations in humans after creatine and glucose polymer supplementation measured noninvasively by ${ }^{31} \mathrm{P}-$ and ${ }^{13} \mathrm{C}$ MRS. Med Sci Sports Exerc 30 (Suppl.); S264, 1998.

Th.A. Scherer, D. Owassapian, M. Zehnder, E. Imhof, and U. Boutellier: Effect of a ventilatory endurance training on respiratory muscle and physical performance, quality of life, and dyspnea. Am. I Respir Crit Care Med 159: A589, 1999.

M. Zehnder, M. Mülli, R. Buchli, and U. Boutellier: The influence of delayed onset muscle soreness on muscle metabolism measured by magnetic resonance spectroscopy. Med Sei Sports Exerc 5 (Suppl.): S76, 1999.

J. Rico-Sanz, M. Zehnder, M. Dambach, M.Mülli, and U. Boutellier: Effects of creatine and carbohydrate loading on muscle energy storage, muscle metabolism during alternating velocity ruming, and sprint velocity. Med Sci Sports Exerc 5 (Suppl.): S102, 1999.

M. Zehnder, M. Mülli, R. Buchli, and U. Boutellier: Magnetic resonance spectroscopy - a useful tool to investigate the effects of delayed onset muscle soreness on muscle metabolism. Proceedings of the Nutrition Society 4: 163 A, 1999.

M. Zehnder, M. Ith, Ch. Boesch, W. Saris, and U. Boutellier: Intramyocellular lipids and muscle glycogen before and after endurance exercise measured by magnetic resonance spectroscopy. The Physiologist 4: 7.15, 332, 2000. 
M. Zehnder, M. Ith, Ch. Boesch, W. Saris, and U. Boutellier: Gender differences in the consumption of intramyocellular lipids during endurance exercise measured by ' $\mathrm{H}$ magnetic resonance spectroscopy. Canadian Journal of Applied Physiology 26: $\$ 269 ; 2001$.

P.C. Colombani, B. Walter, T. Wirth, M. Zehnder: Muscle glycogen resynthesis by magnetic resonance spectroscopy (MRS) after an intense run: Influence of carbohydrate \& protein drink supplementation. Canadian Joumal of Applied Physiology 26: \$251,2001.

M.Zehnder, M.Ith, B.Jung, R.Kreis, W.Saris, U.Boutellier, and C.Boesch: 1HMRS of intramyocellular lipids (IMCL) and 13C-MRS of glycogen before and after endurance exercise: Observation of Gender differences. Magnetic Resonance Materials in Physics, Biology and Medicine 15 (Suppl): S55, 2002.

M. Zehnder, M. Ith, B. Jung, R. Kreis, W. Saris, U. Boutellier, and C. Boesch: ${ }^{\mathrm{l}} \mathrm{H}$-magnetic resonance spectroscopy to evaluate gender differences of intramyocellular lipids (IMCL). Med Sci Sports Exerc 35 (Suppl.): S93, 2003.

Monica Zehnder, Emanuel R. Christ, Michael Ith, Roland Kreis, Chris Boesch, and Jacques Décombaz: Effect of two different intramyocellular lipid contents on substrate utilization during endurance exercise and performance. Med Sci Sports Exerc 36 (Suppl.): S218, 2004.

Emanuel R. Christ, Monica G. Zehnder, Roman Trepp, Primus E. Mullis, C. Boesch, Peter Diem, and Jacques Décombaz: Influence of diet on the response of GH-IGF-I axis and Ghrelin secretion during endurance exercise in trained. athletes. Med Sci Sports Exerc 36 (Suppl.): S218-219, 2004.

Monica Zehnder und Urs Boutellier: Fatburner oder Fettverbrennung durch Sport - Mythos und Wahrheit. FORUM, Magazin für mehr Lebensqualität 1: 26-36, 2002. 
Curriculum vitae

177 


\section{CURRICULUM VITAE}

Monica Gita Zehnder was born on July 20, 1968 in Kathmandu, Nepal. She completed her basic education in Wettingen, Switzerland in 1988 and started to study physical education at the Swiss Federal Institute of Technology (ETH) in Zurich. She graduated in 1992, and in the following two years she taught sports and swimming and gave lectures on didactics for physical education students at the ETH. During this period she also attended the final year of food science and technology studies and started post-graduate human nutrition studies at the ETH, which she completed in 1995. In the following year she had an opportunity to start working as a research assistant in exercise physiology at the Institute for Human Movement Sciences at the ETH. There she also started to work on her Ph.D. in October 1997. At the same time she was lecturing on applied laboratory techniques and on sport nutrition for physical education- and pharmacy students and supervising various graduate theses of physical education, food science and technology and medical students. In 2002 she was offered a job as the local study leader of a project initiated by the Nestlé Research Center in Lausanne and started working in the Department of Clinical Research at the University of Berne. Since February 2005 she has been working part time as a research assistant in the obesity program at the Psychiatric Polyclinic of the Inselspital in Berne. In addition she will be doing research in a field study investigating the incidence of acute mountain sickness in children.

In her leisure time she enjoys endurance sport, mountaineering, rock climbing, traveling in foreign countries, especially Australia - her second home, listening to music and reading professional literature. 
Acknowledgement/Verdankungen

179 


\section{ACKNOWLEDGEMENT/VERDANKUNGEN}

An dieser Stelle möchte ich mich bei all jenen bedanken, die mich über die nicht einfachen "Dissertations-Jahre" auf irgendeine Art und Weise unterstïtzt und begleitet haben. Ohne sie ware diese Arbeit nicht zu Stande gekommen.

A special thank to:

Prof. Dr. Wim Saris, Promoter of this thesis and scientific director of the Department of Human Biology at the University of Maastricht, who supported me from the distance, never gave up on me and made it possible that I could write my thesis in his department,

Prof. Dr. Urs Boutellier, der mir ermöglichte, bei ihm am Institut für Bewegungs- und Sportwissenschaften der ETH Zürich als Assistentin und später als Doktorandin zu arbeiten, mir sein Vertrauen schenkte und das Amt des „zweiten" Promoters ubernahm,

Prof. Dr. Chris Boesch, in dessen Gruppe (Departement klinische Forschung, Abteilung für Magnetresonanz-Spektroskopie und -Methodologie) ich die letzten beiden Studien dieser Dissertation durchführen konnte, und der mir seine fachliche wie auch persönliche Unterstützung entgegenbrachte,

und „last but not least" möchte ich in diesem Zusammenhang Dr. Fred Brouns hervorheben. Vor Jahren lernte ich ihn bei einem seiner Vorträge über Sporternährung kennen und er war derjenige, der mich motivierte, diese Dissertation zu schreiben, mich vor allem in der Anfangsphase unterstützte, und für mich immer wieder Ansprechperson für wissenschaftliche aber auch Lebensfragen war. Er war auch für die ersten Kontakte zwischen der ETH Zürich und der Universität Maastricht verantwortlich.

Besonders möchte ich auch Guido Kühne und Dr. Reto Buchli danken, welche mich in die MR-Methodik einführten, fur ein ausserordentlich gutes Arbeitsklima an Paul Scherrer Institut, wo ich meine ersten MR-Messungen und Versuche durchführte, gesorgt haben, und zu denen ich eine wertvolle Beziehung aufbauen konnte.

Herzlich danken möchte ich Claudia Knöpfli, einer Freundin und über lange Zeit Büronachbarin. Sie war immer eine der Ersten, welche über Freuden und Leiden dieser Arbeit erfuhr, Dr. Hubert Wey, Verantwortlicher für Informatik in der Gruppe von Prof. Boutellier, und nicht selten „Daten-Retter in der Not", und den beiden Medizinern Dr. Mirjam Mülli und Dr. Micha Dambach, welche mich bei meinen Projekten unterstützten. 
I express my particular gratitude to Dr. Asker Jeukendrup and Prof. Dr. John Hawley who have both become good friends. They supported ne scientifically and gave me the opportunity to stay and work at their place.

Interessante Zusammenarbeit ergab sich mit Dr. Jesus Rico-Sanz, Initiant der ersten Studien, Prof. Dr. Caspar Wenk und Dr. Paolo Colombani, mit denen ich bereichernde Gespräche über ernährungswissenschaftliche Fragen führen konnte und mit ihnen zusammen Diplomarbeiten betreute, und Dr. Emanuel Christ und Jacques Décombaz, die meine Hauptansprech- and Diskussionspartner in der letzten Studie waren aber auch ein offenes Ohr für persönliche Gespräche hatten.

Mein Dank gilt auch allen Versuchspersonen, ohne deren unermüdlichen Einsatz all die Studien gar nicht durchfuihrbar gewesen wầren, dem Labor des INW der ETH Zürich (besonders Myrtha Arnold und Thony Moses), dem Nestlé Research Center und dem Inselspitals für die vielen Blutanalysen, und der Schweizerischen Gesellschaft für Ernährungsforschung und dem Nationalfonds für ihre teilweise finanzielle Unterstittzung einzelner Projekte.

Ein grosser Dank gilt natürlich all meinen Freunden (Aad, Barbara, Bettina, Dani, Inge, Karen, Markus, Max, Michael, Stephie, Susanne, Thom, Ursle, Vera u. andere), die mich während dieser Zeit auf verschiedenste Art und Weise unterstützten, den nötigen Rückhalt gaben und trotz einigen Entbehrungen die Beziehung zu mir aufrecht erhielten. Danken möchte ich auch der „Frauenrunde“" (Alex, Bea, Yole und Yvonne) in deren Gesellschaft ich mich immer wieder von der kopflastigen Arbeit lösen konnte.

Meinen Brüdern (Daniel, Lukas und Dominik) mit Familie/Partnerin, besonders Heike, welche sich Zeit nahm, das Titelblatt zu gestalten, und Verwandten gilt ebenfalls ein herzliches Dankeschön - ihre Türen standen stets offen für mich. Danken möchte ich auch meinen Patenkindern, mit denen ich jeweils fur kurze Zeit in eine andere Welt entschwinden konnte und Balali, der mich stets und treu an alle Kongresse begleitete.

I also dedicate my special thanks to Helen and Rene with family and to Chris and Sue who gave me a second home.

Besonders erwähnen und herzlichst danken möchte ich zum Schluss meinem Partner Marc, der mich tatkräftig unterstützte, mich immer wieder motivierte und stets an mich glaubte. 